\title{
Organizational Stressors and Police Performance
}

\author{
By Jon M. Shane \\ A dissertation submitted to the \\ Graduate School-Newark \\ Rutgers, The State University of New Jersey \\ in partial fulfillment of requirements \\ for the degree of \\ Doctor of Philosophy \\ Graduate Program in Criminal Justice \\ Written under the direction of \\ Professor George L. Kelling \\ and approved by
}

Dr. George L. Kelling, Chair

Dr. Ronald V. Clarke

Dr. Marcus Felson

Dr. Karen L. Amendola, Outside Reader

Newark, New Jersey

October, 2008 
(C)2008

Jon M. Shane

ALL RIGHTS RESERVED 


\author{
ABSTRACT \\ Organizational Stressors and Police Performance \\ By Jon M. Shane \\ Dissertation Director: Professor George L. Kelling
}

The evidence on police stress is mixed as to whether or not the nature of police work is inherently stressful. A growing body of research suggests police officers are no more stressed than other groups and police work is not especially stressful. Instead, organizational stressors may be the greatest source of stress in police officers. Various structural arrangements, policies and practices imply police agencies can be inhospitable workplaces, where officers must withstand a variety of daily hassles generated internally by the organization.

The purpose of this study is to answer the question: What is the relationship between perceived organizational stressors and police performance? This cross-sectional study pools secondary data collected by the Police Foundation, Washington, D.C. from the Detroit (MI) Police Department $(N=113)$ and primary data collected from the Paterson (NJ) Police Department $(N=348)$ to quantify the level of stress urban police officers may be under. This study uses a non-probability sample of incumbent sworn police officers assigned to the patrol division. Two instruments, the Police Stress Questionnaire (McCreary and Thompson, 2006) and the Daily Hassles and Uplifts Scale (Hart, Wearing and Heady, 1993) are used to measure stress via a composite index (Explanatory variables) extracted from a principle components factor analysis. Internal 
police data collected from agency records measures performance (Criterion variable) also via a composite index.

Controlling for several demographic variables, organizational stressors made a statistically significant contribution to predicting police performance ( $F=22.316$; $p<.001$ ). This finding suggests, as the perceived level of stress increases performance decreases. The policy implications include developing a multidimensional performance framework, developing a discipline sentencing matrix, improving management practices and organizational restructuring.

Future research should include: 1) Predicting police performance in smaller and mid-size police agencies as well as suburban and rural agencies compared to urban agencies; 2) examining organizational stressors over a longer time period and over the course of different police administrations to provide better insight into how management practices correlate with stress and performance; and 3) widening the participant pool to include superior officers and civilian personnel to estimate the effects of organizational stress on performance for other police employees. 


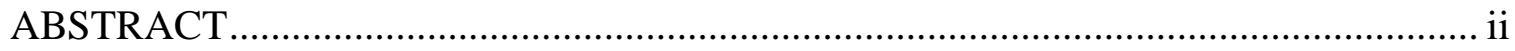

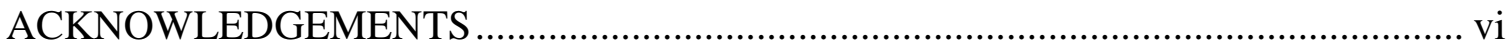

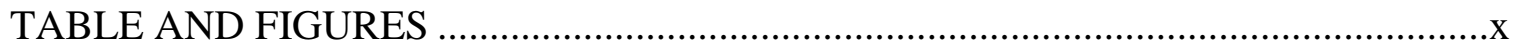

\section{CHAPTER}

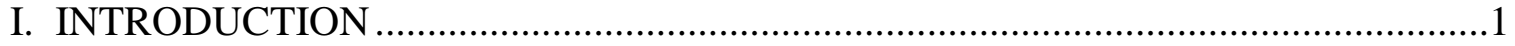

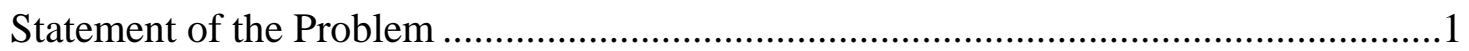

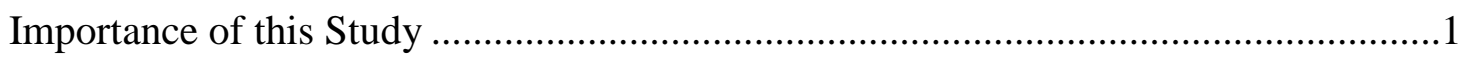

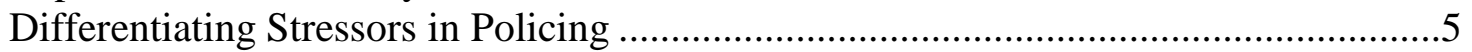

General Findings of Previous Research ....................................................................

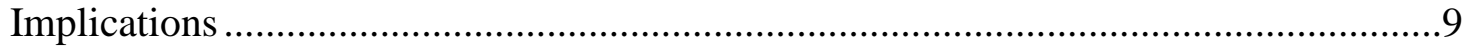

Framework for the Study ..................................................................................11

II. THEORETICAL FRAMEWORK AND REVIEW OF THE LITERATURE................14

Theoretical Conception for Organizational Stress ………............................................14

Organizational Antecedents to Stress...............................................................19

Stressors in Organizational Life ......................................................................42

Perception and Cognition: The Appraisal Process ................................................85

Properties of the Person as Stress Mediators........................................................89

Properties of the Situation as Stress Mediators ...................................................95

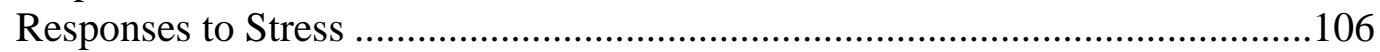

Consequences of Stress ................................................................................111

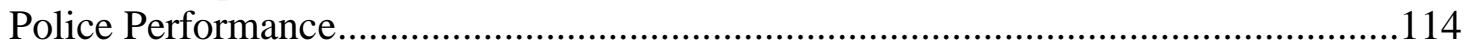

III. METHODOLOGY AND RESEARCH DESIGN ................................................123

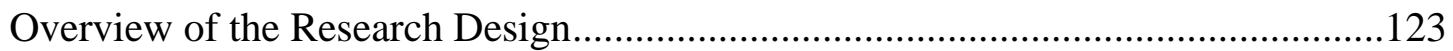

Original Police Foundation Study............................................................................123

Research Question and Null Hypotheses ..................................................................126

Participants, Informed Consent and Confidentiality Notice .......................................127

Data Sources, Instruments and Validation.............................................................130

Unit of Analysis ...........................................................................................132

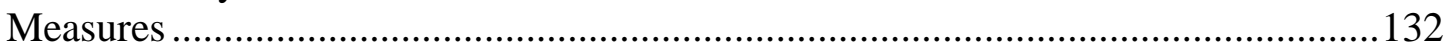

Site Description and Selection...............................................................................141 


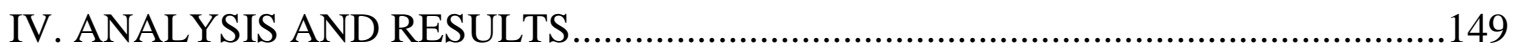

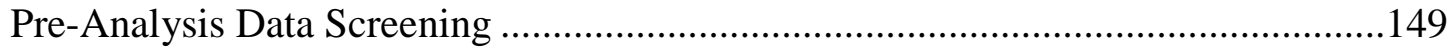

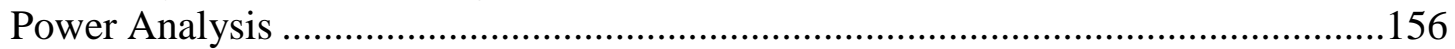

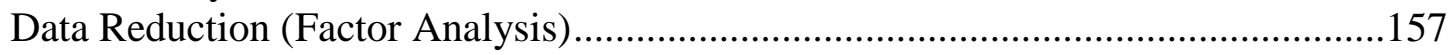

Transforming the Variables (Computing the $z$-scale) ............................................161

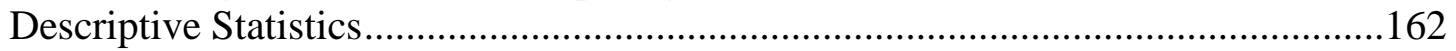

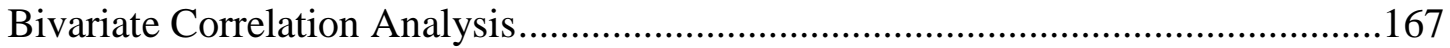

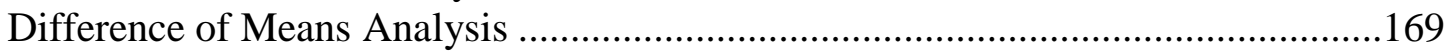

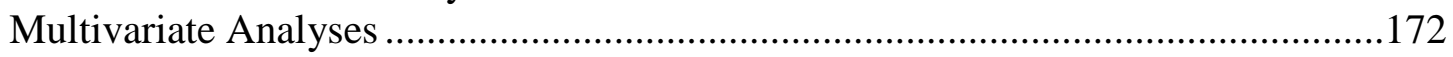

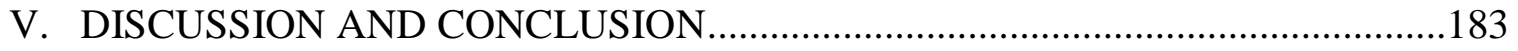

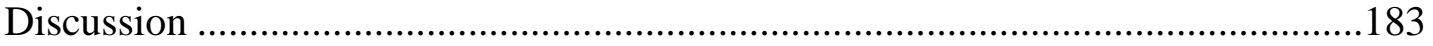

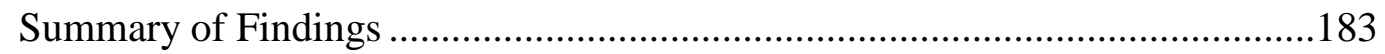

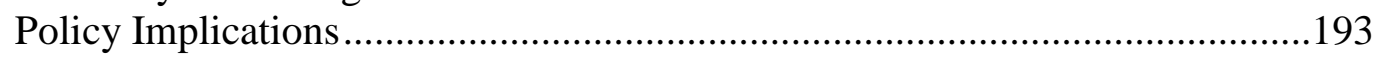

Strengths, Limitations and Threats to Validity of the Current Study.................203

Directions for Future Research.................................................................214

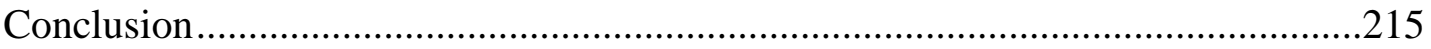

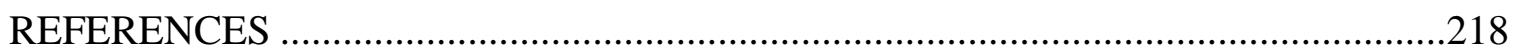

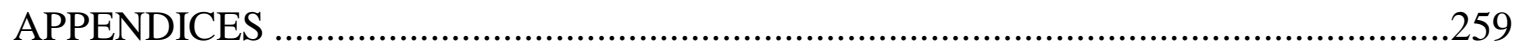

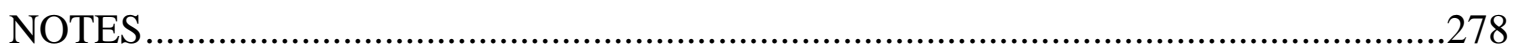

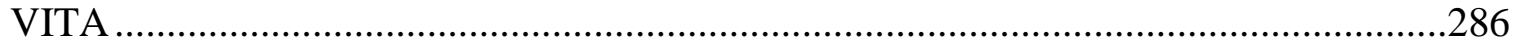

KEYWORDS: Police organizations; job stress; police performance; work pressure;

hierarchical multiple regression analysis; factor analysis 


\section{ACKNOWLEDGEMENTS}

This dissertation reflects my experience in policing and marks the end of one chapter in my life and the beginning of another. Being a police officer was an outstanding life experience that formed a natural segue to becoming a police researcher. I wish to thank my exceptionally talented, supportive and loving wife Vincenza, who inspired me to pursue this degree and to "do something you want to do." She knows me well and has always supported my interests. Her inexhaustible patience and good humor helped make this arduous sojourn tolerable.

Few dissertations ever written have been done under the direction of as many industry giants as this one. I am eternally gratefully to my committee and wish to acknowledge them individually. Dr. George Kelling, my chair, began influencing my thoughts and perspective on the police in my formative years in the Newark police department. Of course, he did not know that at the time because I did not know him then. In 1993, I used an article entitled Broken Windows as the foundation for various police programs that just may have changed the way the Newark police approach their protracted crime problem. Dr. Kelling supported me and my topic from the outset and provided me with outstanding advice that helped propel me into my next career. Dr. Marcus Felson has been a friend and mentor for many years and graciously stepped in to fill an unanticipated vacancy on my committee. His research has always interested me because of its straightforward explanation and the obvious implications for police policy and practice. I learned a great deal about crime and criminology from reading his research and listening to him make logical connections between theory and practice. 
Dr. Ronald Clarke is the reason why I chose to pursue doctoral studies. Dr. Clarke has been a friend and mentor for nearly fifteen years. After some course work in the masters program and a few discussions about the doctoral program, he convinced me of the rewards that would follow. I heeded that advice and he has yet to fail me. I owe him a debt of gratitude larger than a single person could repay in one lifetime. His patience with me and his and pursuit of excellence are characteristics I refined during my time at Rutgers. I will use these skills to build on the rich tradition of criminology and hold Dr. Clarke’s name in the highest esteem as I go forward in my second career.

Dr. Karen Amendola has been a close friend and mentor for over twelve years. I first met Dr. Amendola when I participated in the Police Fellows program at the Police Foundation Washington, D.C. in 1996. It was then that I truly appreciated why education is an exercise in liberation. We have remained friends and colleagues throughout the years and I anticipate many more! Karen, thank you for all your advice, which has culminated in this treatise. I wish to thank Hubert Williams, President of the Police Foundation for extending the original fellowship opportunity in 1996 and for keeping me involved with the Foundation for the last decade, which served as the basis for this research. Hubert has been a good friend and advisor especially during my years in the Newark Police Department. Thank you, Hubert.

I also wish to thank professors and staff at Rutgers who made the doctoral program an enriching experience: Dr. James O. Finkenauer, whom I have known since 1994 and had some of the most intellectual and thought-provoking discussions about criminal justice policy and program evaluation; Dr. Wayne Fisher, a devout professional 
whose advice and candor is second to none! I wish had met Dr. Fisher earlier in my police career so I could have capitalized on his talent to a larger degree; Dr. Edem Avakame for never denying me his time to discuss even the most fundamental topic. Of course, this journey could not have happened without the leadership of the Dean; thank you Dr. Graycar for allowing me to bend your ear and perhaps provide a little fodder toward shaping your legacy at Rutgers. If an article is written and no one reads it, does it exist? Felson asks a similar question. I ask Phyllis Schultze, librarian extraordinaire, who has the unique ability to find that obscure article (Or document, book, periodical) tucked into a journal somewhere in the world. If it exists, then Phyllis will find it! It is just not possible to complete the Ph.D. without Phyllis. Thank you Phyllis for your patience and remember all the delicious pastries!

Along any road to a doctoral degree, you are bound to make a few friends and share experiences. In particular, I wish acknowledge Dr. Zeck Lee, Chris Andreychak, Jennifer Kimble, Christine Barrow and Elaine Chernin all of whom follow closely in pursuit of their Ph.D. Before I met Chris did not know how much we had in common in terms of intellectual pursuits and career aspirations. Some day Chris will leave the New Jersey State Police and that day will leave an irreplaceable void in the command staff.

Field research like this is always made easier and more enjoyable when it is supported by a willing and gracious host agency. I wish to thank Paterson Police Director Michael Walker and Chief James Wittig for granting me access to their police department. As well, I thank Chief Ella Bully-Cummings, Detroit Police Department for supporting the original Police Foundation project, which sparked my interest in this 
research. And, of course, the superb men and women from the Paterson and Detroit police departments who agreed to participate in this study and provide a view from the field about what bothers them so much in their workplace.

They say, always save the best for last. So, I have done just that and reserved this space for my beloved son Michael Donovan. Some days when you feel like throwing in the towel, his innocence, precociousness and inquisitiveness remind me how important this venture is to his future as well as mine. Watching him discover the world I already know is pure magic, and that ignites my inspirational fire. Although looking forward seems like an eternity before he graduates from university, looking back on the first four years of his life went by like a strike of lightning. He has used that time wisely to fill it with some of the most memorable moments life has to offer, particularly when asked “Dad, what is a disseration?” I love you Michael, I hope you benefit from this journey as much as I will. 


\section{TABLES AND FIGURES}

PAGE

FIGURES

Figure 1 Theoretical Framework for Organizational Stress

Figure 2 through 14 Normal Probability Plots (Q-Q)....

$.153-156$

\section{TABLES}

Table 1 Comparison of Military, Police and Fire Department Organizational

Environments.

Table 2 State and Local Law Enforcement Agencies, by Size of Agency United

States

Table 3 Sherman's Defiance Theory and its Application to an Administrative Setting.

Table 4 Six Alternative Approaches to Evaluating Police Performance and their

Terminology

Table 5 The Seven Primary Corporate Stakeholders and their Analogous Police

Stakeholders

Table 6 Eleven Police Performance Indicators, within Four Performance

Categories.

Table 7 Six Previous Studies That Sought to Measure Police Performance

Table 8 Description of the Measures for the Criterion Variable, Their Source, Their Convention and Explanation.

Table 9 Survey Questions for Operational and Organizational Stressors’ Subscales

Table 10 Description of Control Variables

Table 11 z-score Values on Criterion and Explanatory Variables’ Test for Outliers. .152

Table 12 Power Analysis 157

Table 13 KMO and Bartlett's Test of Assumptions with Determinant Value .158 
Table 14 Factor Loadings for the Varimax Rotated Factors....................................159

Table 15 Indexed Factors and Stress Constructs .....................................................160

Table 16 Descriptive Statistics for the Variables in the Analysis............................165

Table 17 Bivariate Correlation Matrix among Dependent and Explanatory

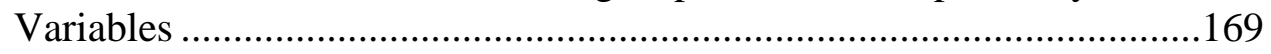

Table 18 Paired Samples $t$ Test for Organizational and Operational Stressors Between Cities ........................................................................................170

Table 19 Independent Sample $t$ Test for Stressors by City......................................171

Table 20 Multiple Regression Analysis Summary Predicting the Change in Police Performance

Table 21 Summary of Hierarchical Regression Analysis for Variables Predicting Police Performance .............................................................................181

Table 22 Summary of Statistical Results................................................................184

Table 23 Sample Progressive Discipline Sentencing Matrix...................................198 


\section{CHAPTER I. INTRODUCTION}

\section{Statement of the Problem}

Occupational stress research has an impressive history with more than three decades of sound studies that show clear correlations between certain organizational factors and stress. However, as best as can be determined, there are no quantitative studies that measure the impact those stressors may have on police performance. Part of the problem may be that defining performance has been a conundrum for many years and there is no consensus among scholars how to operationalize the concept. Compounding the problem is the definition of stress and the instruments used to measure it in police

work. This has led researchers to move away from generic stress scales and into domainspecific scales that measure the unique characteristics of policing.

This study represents a focused interest in stress research in that it seeks to isolate specific self-reported organizational stressors that may negatively impact police performance, as well as predict the extent of the impact those stressors have on performance. If performance is an element of police professionalism, then determining which organizational stressors are related to lower performance may improve organizational effectiveness.

\section{Importance of this Study}

The literature review suggests police organizations may be a significant source of police stress, which consequently reduces performance. Because performance is an aspect of professionalism, the implication is that reducing stress may raise professionalism including the image and reputation of the agency. Although there is a wealth of research that describes and categorizes the origin and extent of stressors in 
policing, such as those from personal experience (Eisenberg, 1975; Sandy and Devine, 1978), from non-representative samples (Kroes and Gould, 1979), from interviews (Kroes, et. al., 1974) and from stress-control programs (Baxter, 1978; Potter, 1978), there are no studies that quantify the impact organizational stressors have on police performance. "More importantly, the failure to link occupational stress to organizational performance has tended to marginalize the issue of occupational stress in the broader management and organizational behavior literature. It may also explain why managers in many police organizations still view occupational stress as an occupational health and safety issue, rather than an issue that is central to the leadership and management practices of the organization” (Hart and Cotton, 2002:107, citing Hart and Cooper, 2001; see also Wright and Cropanzano, 2000).

The organization's management philosophy, policies and structure translate into operational practices at the line level. My impression is the more onerous these policies, the more likely stress is to develop and negatively influence performance. The message received by the public from a police officer as he or she carries out his or her duty leaves a lasting impression about the organization. Police-citizen encounters that produce conflict and negative emotion are long-lasting and vastly remembered over those interactions that produce collaboration (Dean, 1980; Rosenbaum, et al, 2005; Weitzer and Tuch, 2005). If police officers are laboring under stress and treat citizens in a differential manner, then a negative image of the organization may be imprinted, where trust and legitimacy are vitiated; trust and legitimacy once lost are not easily regained. In this context, stress creates irritability, which lowers the quality of officers' decisions and leaves them prone to aggression and anger (Park, 1987; Thayer, 1989:110-136). If left in 
a state of perpetual irritability, officers may respond aggressively to even the slightest provocations by misinterpreting the magnitude or seriousness of the event as potentially harmful. Moreover, officers who resort to using alcohol and/or drugs to compensate for stress may increase personal risk and liability due to diminished cognition and sleep deprivation. This means they may not listen carefully to important information broadcasted over the police radio, their reaction time may be slowed and they may take unnecessary risks because their attention is divided (Cottam and Marenin, 1981; Dwyer, 1991; Laub and Kayten, 1988).

Although trust and legitimacy are significant threats to organizational effectiveness, other performance dimensions are also threatened. When police officers labor under stress, on-duty motor vehicle accidents and duty-related injuries may rise (Dwyer, 1991). Motor vehicle accidents pose a serious risk to officers nearly as much as assaults; the ratio of motor vehicle accidents to felonious assaults resulting in death is .77:1. This suggests that police officers are nearly as likely to die from accidents as they are from being assaulted (Bureau of Justice Statistics, 2006: Table 3.154).

In addition to performance problems, there are also empirical problems that must be addressed. Measurement scales that fail to consider the organizational context leaves interventions to focus on the employee instead of the organization as a source of stress, which typically addresses only the "symptoms" and not the causes of occupational stress (Hart and Cotton, 2002:107). Scales such as ASSET-A Shortened Stress Evaluation Tool (Cartwright and Cooper, 2002), the Occupational Stress Indicator (Cooper, Sloan and Williams, 1988), the Life Events Theory (Holmes and Rahe, 1967), and the Job Stress Survey (Speilberger and Reheiser, 1995; Turnage and Speilberger, 1991) are generic and 
may not capture the stressors unique to policing. Findings that rely on these types of measurement scales may attribute blame to the employee for their stress instead of analyzing the organization and its attributes more systematically.

For example, the Holmes and Rahe (1967) Social Readjustment Rating Scale assigns an absolute value to various life events termed life change units (LCU) (e.g., death of a spouse $=100 \mathrm{LCU}$; divorce $=73 \mathrm{LCU}$; marital separation $=65 \mathrm{LCU})$. The life events theory suggests over the course of one year, individuals accumulate points for the events in their life that require adjustment. The more significant the event, the more coping that is required; the more coping that is required the greater the investment in personal energy. As an individual expends personal energy trying to cope with these negative events, they eventually reach a state of mental fatigue where they are unable to cope with additional LCU's. The response may be emotional collapse from burnout, social withdrawal in the form of alcohol or substance abuse and eventually lower performance.

There are some limitations with this rating scale and with the theory itself. First, the scale assumes individuals are equally affected by life events and does not account for personality or coping skills since people perceive and respond to events differently. Second, there is no empirical validation for the scale (Hart, Wearing and Heady, 1993:556). Third, while it is possible that police officers may incur a significant life event, research suggests that most police officers will not encounter a job-related lifethreatening situation in their entire career (Kirkham and Wollan, 1980). Lastly, daily hassles rather than singular events may be more troublesome to police officers because they represent enduring features of the workplace that are inescapable. 
Measuring stress from an "absolute value" fails to account for individual differences in perceived levels of stress (An internal standard) for various events. It is entirely possible that not all life events affect each person equally, since people may perceive the same event differently_some people may welcome a divorce. This may be why past research has found that police stress may not be as significant as once believed. Indeed, officers may be mentally prepared to deal with events such as abuse and death, and therefore may not perceive these events as particularly stressful (Hageman, 1978; Hughes, 1945; Rand and Manuele, 1987; Ward, 1979). This research relies on two domain-specific instruments that are unique to police organizations. Therefore, the scales are more likely to measure the true nature of stress in policing.

\section{Differentiating Stressors in Policing}

There are two generally accepted sources of stress in policing, those arising from "job content” and those arising from "job context." Job content, or operational stressors, are the aspects of police work inherent in the occupation: Operational overtime, ${ }^{1}$ court overtime (Boorstin, 1986; Crank et al., 1993; Davis, 1983; Duggan, 1993; Harriston, 1993; Kroes, 1985; Savery et al., 1993), outside employment ${ }^{2}$ (Arcuri et al., 1987; Bayley, 1994:67; Reiss, 1988; Vila, 2000) and job-related violence (Amaranto, Steinberg, Castellano and Mitchell, 2003; Glasser, 1999). While research on operational stressors has dominated the literature, there is also an impressive body of research that suggests organizational stressors may be a significant source of stress for police officers. This literature is limited in its relationship to police performance.

Organizational or "job context” stressors may be a greater source of stress for police officers because officers may perceive them as oppressive, unnecessary and 
inescapable. ${ }^{3}$ Job-context stressors include characteristics of the organization and behaviors of the people in them that may produce stress. It is interesting to note that although Amaranto and colleagues (2003:52) investigated the need for stress interventions due to job-related violence ${ }^{4}$ —a "job-content" stressor—-the research participants (Rank and file police officers) from the Newark (NJ) police department specifically identified several "job-context" stressors as a direct source of stress:

1. Being "second-guessed" in field work (Possibly due to unsupportive supervisors and managers);

2. Punishment for "minor" infractions (Nitpicking de minimis infractions from autocratic managers and zealous internal affairs investigators);

3. Lack of reward for a job well done (Unsupportive management);

4. Fear of being "degunned"-having their department issued firearm and personal firearms administratively confiscated by the department for personal or stressrelated problems (Lack of support); and

5. Low morale - a result of the aforementioned conditions (Possibly due to unsupportive management and favoritism).

Job-context stressors that are likely to create stress and tension in the police milieu include organizational structure (i.e., bureaucracy, capacity, and work schedules) (Monk, 1988; O’Neill and Cushing, 1991; Peacock, et al., 1983; Pierce and Dunham, 1992; Pilcher and Huffcutt, 1996; Rosa et al., 1989; Scott, 1990) and various aspects of organizational life (i.e., facilities and equipment, role ambiguity, and role conflict) (Alexander et al., 1993; Brown and Campbell, 1990; Brown et al., 1999; Cooper et al., 1982; Gershon, 2000; Glowinkowski and Cooper, 1985; Gudjonsson and Adlam, 1985; Manolias, 1983; Robinson, 1981; Vila, 1996; Vila and Kenney, 2002). These features seem to hold over cross-cultural comparisons between U.S. and foreign police agencies. Various stress studies in the South African Police Service (SAPS) revealed similar findings including lack of supervisory and management support (Gulle, Tredoux, and 
Foster 1998; Koortzen, 1996), indifference of command staff officers, limited opportunities for promotion, working conditions and poor support systems (Roosendaal, 2002). These conditions may combine with various personal or situational mediators (i.e., personality, self-esteem, locus of control and supervisory support) to mediate performance.

\section{General Findings of Previous Research}

Employees in the human-service professions-those occupations where employees have an obligation for other people’s health, safety or well-being-such as care providers (i.e., nurses, physicians, radiation assistants and general practitioners) (Griffiths, et al., 2003; LeBlanc and Schaufeli, 2003, Winefield, 2003), correction officers (Cullen, et al, 1985), teachers (Greenglass and Burke, 2003), the clergy (Cotton, et al., 2003) and police officers (Hart and Cotton, 2002), are particularly vulnerable to stress (Cherniss, 1980). In these professions, stress results primarily from the structural arrangement of the organization and because the agents exercise very little control over their clientele (Cherniss, 1980), the intended outcomes of their service are subject to annoying and objectionable interactions with their clientele (Albrecht, 1979) and they often experience a disjunction between career goals and actual achievement (e.g., the route to promotion) (Edelwich, 1980; Pearlin, 1989).

Police work is a human-service profession that bears some of these features since the work is regarded as physically and emotionally demanding. The evidence, however, is mixed regarding the nature of police work as inherently stressful. Researchers, police practitioners, health-care professionals, psychologists, as well as the lay community contend that police work is inherently stressful (Brown and Campbell, 1994; Burke, 
1994; Cacioppe and Mock, 1985; Fell, Richard and Wallace, 1980; Kroes, 1985:32-36; Seigler and Wilson, 1988; Stratton, 1978; Tang and Hommontree, 1992; Violanti and Aron, 1993; Violanti et al., 1986, Yarmey, 1990). This belief is intuitively appealing, especially when stereotypical Hollywood images, noteworthy media coverage and fictional portrayals enhance the image that police officers are exposed to the seamier side of life that is filled with unsavory or dangerous individuals, critical or traumatic incidents, ${ }^{5}$ unpredictability and boredom punctuated by moments of sudden adrenaline surges. Perhaps this is true to a limited extent. However, these conditions are infrequent for many officers who work in a field setting, especially for officers working in suburban and rural agencies compared to their urban counterparts, and even less so for those assigned to administrative functions.

Yet, it may not be the nature of police work that generates the greatest amount of stress in police officers. There is a growing body of research that suggests police officers are no more stressed than other groups (Hart et al., 1995; Kirkcaldy et al., 1998), including a number of researchers who argue there is little or no empirical evidence to support the conventional belief that police work itself is especially stressful (e.g., Anson and Bloom, 1988; Brown and Campbell, 1990; Hart et al., 1994b, 1995; Lawrence, 1984, Malloy and Mays, 1984; Terry, 1981). The empirical research does not support the image that police officers suffer from stress and frustration that is as extreme as many believe (French, 1975:60, 63; Kroes et al., 1974) nor is police work itself beyond the officers’ emotional capabilities (Blackmore, 1978:47; Resier, 1973:6). There is some research that suggests individual coping mechanisms become embedded in a police officer's personality, which enables them to deal with death and hysteria and accept these 
facts in their lot as police officers much the same way morticians routinely deal with dead bodies (Hageman, 1978; Hughes, 1945; Rand and Manuele, 1987; Ward, 1979).

Admittedly, “job-content” stressors may affect an officer’s well being or performance (Coman and Evans, 1991). However, as some researchers argue (Cattell, 1967), police officers are an emotionally stable group that have a temperament amenable to dealing with people. More importantly, “job-content” stressors are not necessarily part of the daily hassles related to the organizational structure, which many officers must endure throughout their career.

\section{Implications}

Police officers can neither escape from nor control the daily job-context stressors. The more officers perceive the organization (i.e., police management) has failed them by creating unnecessary stress, the more the officers will unite around an anti-managerial theme that arises from a “...fundamental distrust of superior officers and bureaucratic administration” (Pollock-Byrne, 1989:78; see also Brown, 1981:82). The notion that the organization for which an individual is employed is the cause of their stress is counterintuitive, yet studies show officers frequently cite organizational stressors as more onerous than operational stressors, primarily because they cannot control them (Alexander, et al., 1991; Crank and Caldero, 1991; Davey et al., 2001; Kroes et al., 1974). The working environment for many police officers is not often regarded as a source of “job enrichment” or enjoyment. Instead, it is seen as an objectionable, stifling atmosphere that must be endured and often leaves casualties of burnout, cynicism and low performance in its wake (Zhao, Thurman and He, 1999). 
The implication is that police agencies can be inhospitable workplaces, where officers must withstand a variety of daily hassles generated internally by the organization. Kelling and Pate (1975:117) noted over three decades ago, while there seems to be public “...[concern] over how the police behave, there is little concern as to how the police feel as a result of their assigned role, and as to how these feelings correlate with behavior and with emotional and physical well being.” The emotional well-being and performance of police officers may be linked to various features of the organization including its structure, capacity (i.e., staffing) and various stressors in organizational life. When resources are apportioned in an inequitable manner or officers are treated "unfairly" due to favoritism (e.g., being skipped for a promotion; being denied a coveted position; receiving disparate treatment during an internal affairs investigation or during a disciplinary hearing), they may view the agency as unnecessarily harsh, capricious and punitive emanating from incompetent and illegitimate authorities (Weber, 1971).

Correcting these issues necessarily requires police administrators to embrace nontraditional policing models such as community-policing (Hart and Cotton, 2002; National Research Council, 2004), to flatten the organizational structure, to acknowledge managerial shortcomings and modify the working environment before any permanent change can be made. Identifying the nexus between organizational stressors and performance represents an opportunity for police management to shape organizational philosophy, operational policy and the style of policing that is practiced (Hart and Cotton, 2003; Terrill, 1997) in a way that embraces employees to reduce stress and improve performance. 
Framework for the Study

The purpose of this research is to examine the relationship between organizational stressors and police performance. As an element of professionalism, police performance represents the service-related activities of a government entity that are essential for community stability. How that service is delivered is almost entirely dependent upon the employees who are responsible for its execution. When those employees are laboring under stress, the likelihood that performance will be diminished is heightened. The present study aims to extend the scholarly knowledge of what we know about stress in law enforcement into a new area by answering the question: What is the relationship between perceived organizational stressors and police performance?

To lay the groundwork that will answer this question, Chapter II begins with organizational stress theory and the related literature, which highlights some of the shortcomings of previous studies. Following a model of organizational stress developed by Kahn and Byosiere (1992), there are seven components that will be examined: 1) Organizational antecedents, 2) stressors in organizational life, 3) perception and cognition, 4) properties of the situation as stress mediators, 5) properties of the person as stress mediators, 6) responses to stress and 7) consequences of stress.

The limitations of previous research establish the framework for Chapter III, methodology and research design. The methodology section provides an extensive explanation of the methodological process including the research question, null hypotheses, participants, data sources, data collection procedure, unit of analysis, measures (Criterion, explanatory and control variables), site description and site selection. 
Since this study also attempts to improve upon the measurement scales used in prior research, there is a discussion about the surveys used in this research that are specific to policing. Previous measures, while valid, may not necessarily capture the stressors unique to policing and police organizations. A review of the literature suggests that a great deal of previous organizational stress research in policing relied heavily on a qualitative approach using focus groups, semi-structured interviews, observational and anecdotal evidence to capture the stressors that negatively impact police officers (Band and Manuelle, 1987; Kroes et al., 1974; Wexler and Logan, 1983). Although a qualitative approach is useful for detecting the presence of stressors and “...gives researchers an excellent snapshot into the lives of officers, it cannot be used to quantify how much stress officers are under or the degree to which those stressors are associated with outcome variables such as job satisfaction” (McCreary and Thompson, 2006:496). To detect how much particular stressors contribute to decrements in performance, a quantitative method must be employed.

This same line of previous research also relies on stressors that are generic to many different occupations or life events. Researchers specifically assert that generic scales are useful for measuring a wide range of generic occupational stressors, but underrepresent the nature of stress unique to policing, therefore they necessarily underreport true and unique stress levels in police work. This is a limitation of the previous research insofar as the broad focus does not account for the important “job context” stressors in policing believed to influence organizational performance (Hart and Cooper, 2001). Moreover, previous studies only sought to identify or describe stressors in policing. That 
line of research falls short of specifying the extent to which organizational stressors may affect police performance.

Chapter IV presents the analysis and the results. The analytic plan begins with pre-analysis data screening techniques, a critical process to ensure the data are suitable for bivariate and multivariate analyses and to ensure the study has sufficient power. Because there are over one hundred explanatory variables, the data was reduced, via factor analysis, to determine which latent constructs explain the greatest amount of variance. Following data reduction, univariate, bivariate and multivariate analyses describe the relationship and extent certain organizational stressors have on police performance.

Chapter V, the discussion and conclusion, begins with a summary of the findings and the relationship between the research question and the hypotheses. There is a detailed interpretation of the findings and their implications for policy, recommendations to deal with the consequences of stress and directions for future research. Additionally, there is a discussion of the strengths, limitations and threats to validity of the present study. 


\section{CHAPTER II. THEORETICAL FRAMEWORK AND REVIEW OF THE LITERATURE}

This chapter describes the stress development process and its relationship to performance. The relevant literature is organized into two sections with various subsections. The first section is the theoretical conception for organizational stress. This section examines the theory of stress development and the components of the organizational stress, including : 1) organizational antecedents to stress; 2) stressors in organizational life; 3) perception and recognition; 4) properties of the person as stress mediators; 5) properties of the situation as stress mediators; 6) responses to stress; and 7) consequences of stress. The second section reviews police performance. Some conclusions can be drawn from the literature, specifically that quantitative research showing the relationship between organizational stressors and police performance has not been well established. Therefore, this chapter prepares for a methodology that analyzes that relationship more thoroughly.

\section{TheORETICAL CONCEPTION FOR ORganizational STRESS}

Conceptualizing occupational stress has been a conundrum for many years. Hart and Cooper (2001:94-95) noted “...the scientific community still has not reached an agreed position on the meaning and definition of occupational stress.” Despite the work from many renowned researchers, lack of a clear definition of stress has complicated uniform research efforts and theoretical construction. The debate among scholars about whether stress should be defined from the human (Individual) perspective, the environmental (Macro) perspective or both (Interactive) (Brown and Campbell, 1994:1415; Goldberger and Breznitz, 1982; Hart and Cooper, 2001:94; Lazarus and Folkman, 1984), causes fragmentation in the literature (Cooper, 1998; Cotton, 1995; Quick, 
Murphy and Hurrell, 1992) and is a threat to construct validity (Shadish, Cook and Campbell, 2002). Selye’s (1956, 1974) pioneering work in biological stress conceptualized the term to mean the human body's non-normal reaction to any demands placed upon it. The demands Selye referenced can be thought of as a collection of aversive stimuli that accumulates over time and leads to emotional states and cognitive adaptations that accompany the stress. Identifying the source of aversive stimuli and the extent of their relationship to performance provides a theoretical framework for how humans interact with and respond to their environment.

In the organizational setting, aversive stimuli may arise from the structural characteristics of, or adverse experiences in the workplace that upset the normal operating environment a person is accustomed to, which leads to negative behavioral, physiological and psychological responses. Inside a police department, aversive stimuli may emanate from the organization’s design (Bureaucratic and hierarchical), as well as life within this structure. The interaction between the person and their environmentinteractive theory — has its roots in the physical sciences, specifically physics. In the physical sciences, stress is defined as “...the distortion produced by an external force placing strain on an object. The amount of damage that results will depend on both the strength of the force and the ability of the object to withstand it” (Stinchcomb, 2004:261). The interactive approach offers a well-substantiated explanation of the stressors confronting police officers that emanate from the organizational environment. In this context, the distortion that results is reflected in the variance in police performance. Beehr and Newman (1978:669-670) offer a definition of occupational stress that captures the integrated fit between person and environment: 
"Job stress refers to a situation wherein job-related factors interact with a worker to change (i.e., disrupt or enhance) his or her psychological or physiological condition such that the person (i.e., mind-body) is forced to deviate from normal functioning."

The interactive approach is embedded in Folkman et al.'s (1986:572) derivative theory known as the transactional model of stress and coping, which establishes the individual and their environment are entwined in a "dynamic, mutually reciprocal, bidirectional relationship.” They caution that this model is not necessarily linear, but should be viewed as cyclical, which accounts for the nuances and intricacies of human behavior. Within this conceptual framework, stress results when the person-environment relationship is appraised by an individual as exceeding or taxing that individual's personal resources and endangering one’s well-being (Folkman et al., 1986). The translation from the physical sciences to the social sciences is that stress results from the many intricate, complicated and interrelated environmental forces that are exerted upon a person and give rise to abnormal or unhealthy physical, psychological, psychosocial conditions (Cooper and Marshall, 1977; Cox, 1978). The interactive theory also posits that when environmental demands (e.g., those conditions brought about by the organization) exceed personal resources (e.g., individual coping capabilities), stress will result (Cherniss, 1980:22).

Stinchcomb (1980, 2006:261) elaborated on this position and suggested that when the forces exerted upon a person exceed the person's capabilities, and the person does not have the ability to “... avoid, alter or control the demands,” stress will result. This implies that stress emanates from the conditions that are imposed on police officers under circumstances beyond their control. The job of police officer may be characterized as 
high demand and low control because of the authoritarian, quasi-military structure and bureaucratic nature, which fails to recognize the autonomy and decision latitude of individual officers (Bittner, 1980; Brown, 1996; Cowper, 2000; Fogelson, 1977; Goldstein, 1979; Harrison, 1975; Harrison and Pelletier, 1987; Potts, 1982 Villa, 1999). Karasek (1979) argues that high-demand jobs produce normal physiological changes that enable the body to meet the particular challenge (e.g., increased heart rate, increased adrenaline level, increased breathing level). However, when environmental constraints reduce the amount of control a person has over the situation, the state of arousal cannot be managed effectively. Police departments, for example, are bureaucracies with rigid hierarchical power (Control) structures, where the greatest degree of control resides at the top of the organization. Therefore, it seems to me that employees at the lowest level of the organization who have the highest demands and the least amount of control may suffer from the highest levels stress.

The interactive theory has strong empirical support in the workplace (Amick et al. 1998; Bosma et al., 1997; Schnall et al., 1994; Standsfell et al., 1999; Theorell, 1998) and fits well with Kahn and Byosiere’s (1992) process of stress development in organizations (Figure 1). Kahn and Byosiere conceptualize a series of successive precursors, responses and consequences of stress that lead to health and illness-related problems for the employee, personal problems for the employee in other life roles (i.e., interpersonal relationships) and decrements in organizational performance. The developmental process is outlined in figure 1, where the authors put forth a hypothesized causal sequence. Muchinsky (1997:306) commented that this model “...reflects one of the primary research findings about stress — there are complex associations between the antecedents 
of stress, individual differences in how people respond to stress, and the consequences of stress.”

If we apply this model to the police department, then the theoretical causal sequence suggested would begin with "organizational antecedents," the broad internal characteristics of the workplace that includes the functional interface between police officers and their operating environment. These preexisting workplace features envelope police officers as they contend with “stressors in organizational life.” Various jobrelated stimuli generate negative consequences for those exposed to them and typically include physical (e.g., buildings, facilities and equipment) and psychosocial (e.g., role conflict, role ambiguity and role overload) aspects of the workplace.

Although police officers are exposed to these potentially aversive stimuli, before they "feel" stressed they must recognize the stimuli as negative and appraise the harm the situation is likely to cause. This is the "perception and cognition” (Appraisal) process. Once the appraisal process begins, stress may be mediated by "properties of the situation" and "properties of the person.” Properties of the situation include relations with and support from co-workers and supervisors, whereas properties of the person focus on individual coping mechanisms such as personality and self-esteem, all of which buffer the effects of stress. These structures may help reconcile the conflict with a viable solution to limit an adverse "response to stress." If the conflict is not resolved, then physiological, psychological and behavioral responses may occur. Prolonged exposure to physical and psychological stressors may lead to "consequences” that eventually affect the officers' health and performance both at work and in other life roles. The causal sequence for organizational stress is explained in detail on the following pages. 


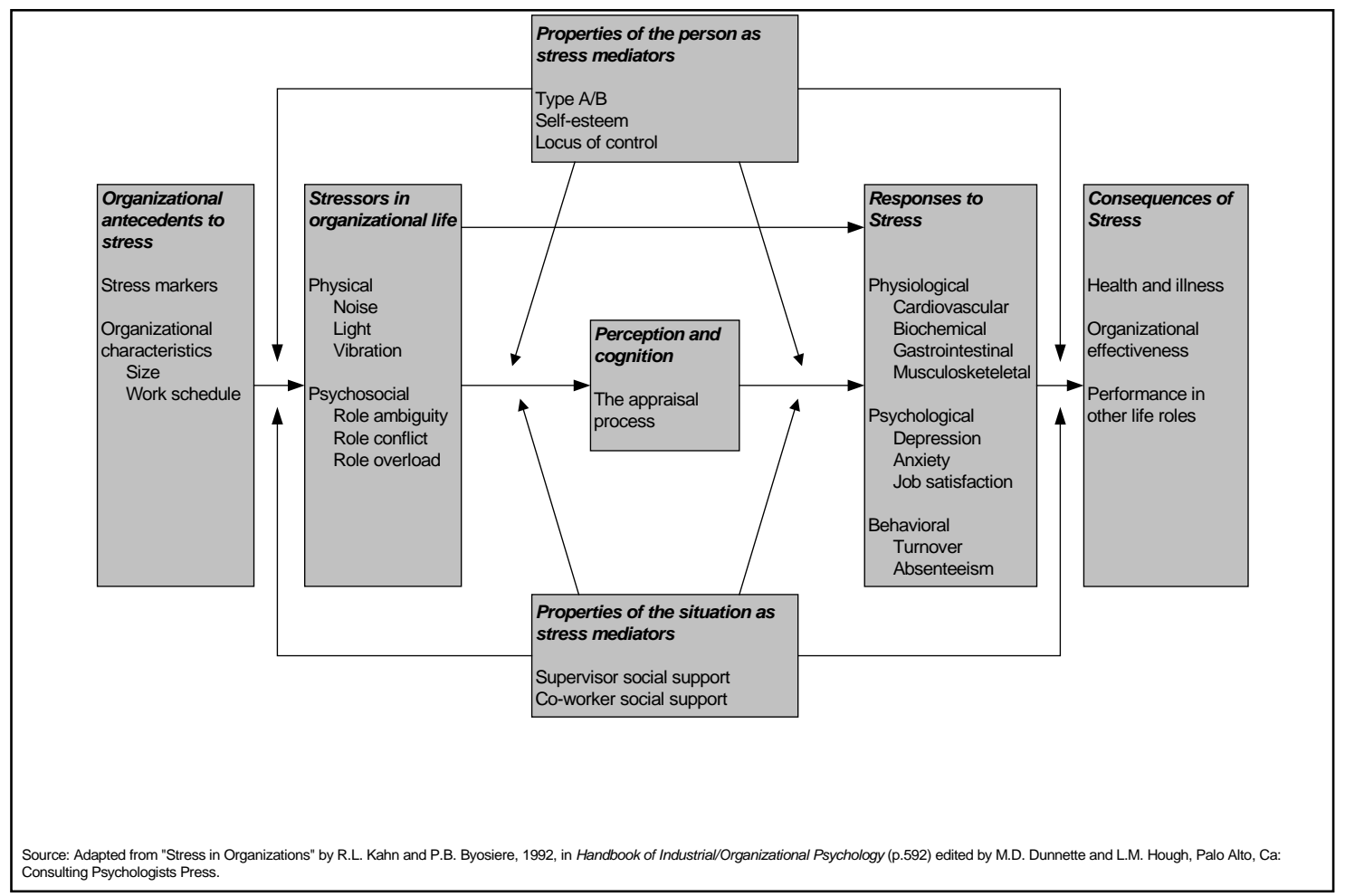

Figure 1 Theoretical Framework for Organizational Stress

\section{Organizational Antecedents to Stress}

Organizational antecedents are precursors of the occupational environment, those pervasive and enduring features of the workplace that may adversely affect the working psychology of police officers (Crank et al., 1995; Hays, Regoli and Hewitt, 2007). Organizational antecedents reside in the characteristics of police departments insofar as police departments are structured in ways that inhibit autonomy, flexibility and participation in decisions that affect the employees. The broad phenomena, which subsumes the organizational characteristics that may form the basis for stress and poor performance include bureaucracy, organizational capacity and work schedules. 


\section{Bureaucracy}

Bureaucracy, characterized by the excessive formality and routine required before official action can be taken or decisions rendered, has been recognized as an impediment to organizational effectiveness (Harrison, 1975; Harrison and Pelletier, 1987).

Bureaucracies exist because they are generally efficient, but not entirely. Their positive contribution in business and government is they enable a great deal of work to be carried out in a specialized manner by spreading the work across several segments or "bureaus" of the organization (Hence, "bureaucracy”). However, bureaucracy is also an obstacle to professionalization. Gross and Grambusch (1974, quoted in Reiss, 1992:90) note that “...there are certain inherent contradictions between ideology that emphasizes autonomy of professional practitioners with minimal bureaucratic control and an ideology of bureaucracy in which the professional is subject to hierarchal authority that infringes on autonomy.” Gerth and Mills (1946:196-204) described the attributes of Max Weber's ideal bureaucratic model, the similarities to policing appear evident:

1. "Distribution of organizational tasks among various positions as official duties [This is reflected in the various bureaus and divisions of modern police departments, such as narcotics, homicide, robbery, burglary];

2. Organization of positions into hierarchical structure based on authority [This is reflected in the quasi-military rank structure in virtually every police department, demarcated by clear lines of authority: Sergeant, lieutenant, captain, deputy chief, chief, etc.];

3. A formal system of rules and regulations governing official actions [This is reflected in the voluminous rules, regulations and policy manuals that govern, in minute detail, the behaviors of police officers];

4. Impartiality in terms of dealing with clients and other officials [This is reflected, primarily, in the "professional" movement of police agencies, where there is an emphasis on legal/statutory authority for decisions];

5. Career-oriented employment, based on technical competence, as demonstrated by examination and certification of educational attainment" [This is reflected in the closed occupational system so eminently characteristic of police departments, which prohibit lateral movement for promotion and places tenure ahead of merit (i.e., performance) for personnel decisions]. 
The quintessential police bureaucracy was described by Kuykendall and Roberg (1982:243), which comports nicely with Weber's bureaucratic model:

1. "Specialization

2. Hierarchical

3. Authority

4. Rule-oriented and

5. Position-oriented"

Other researchers (e.g., Katsampes, 1974:60-61 quoted in Stinchcombe, 1980:51) have likened the police department to Frederick Taylor's Principles of Scientific Management, with “detailed allocation of responsibilities, distribution of workload, lines of authority and administrative principles around which the police task is organized." ${ }^{\text {6 }}$ It is apparent from these models there is a dysjunction between professional autonomy, individual skill and control over career goals. The bureaucratic model has a tendency to sap an employee's motivation and initiative by relegating them to a position within the hierarchy, stratified by level of authority, where their professional advancement (i.e., promotion) is predicated on an official exam that may not be linked to performance.

Most, if not all police departments, but especially larger ones, tend to be designed along bureaucratic lines (Bittner, 1970, 1990; Fogelson, 1977; Kroes, 1986; Manning, 1977). Because of the tall structure, characterized by a high degree of specialization (e.g., divisions for narcotics, homicide, gang enforcement, robbery, vice, sexual assault, juvenile) and the hierarchical rank structure, ${ }^{7}$ the design increases the social distance between ranks (Banton, 1964; Mastrofski, 1981; Mastrofski et. al., 1987; Violanti and Aron, 1995). This creates a highly impersonal atmosphere, where police officers at the lowest level rarely, if ever, communicate or interact with superior officers beyond their 
immediate supervisor. As the literature suggests, this distance may impede internal communication that is critical for feedback and decision-making, as well as breeding leadership/management styles that do not appreciate the contribution individual employees may make to the goals of the agency.

Criticism of the classic bureaucracy can be found throughout the policing literature (Argyris, 1957:1-24; Bennis, 1966; Bennis and Slater, 1964). Angell (1971:187-188) identified four common criticisms of classic bureaucracies that are as relevant to policing as they are for other forms of bureaucracy:

1. "Classic theory and concepts are culture bound.

2. Classic theory and concepts mandate that attitudes toward employees and clients be inconsistent with the humanistic democratic values of the United States.

3. Classic structured organizations demand and support employees who demonstrate immature personality traits.

4. Classic organizations are unable to cope with environmental changes; therefore, they eventually become obsolete and dysfunctional.”

Several police scholars (Band and Manuelle, 1987; DeGeneste and Sullivan, 1997;

Perrow, 1986; Wilson, 1989) have remarked about the problems associated with bureaucracy specific to policing. Recently Walker (2008:98) and Alexander et al.

(1991:50) identified several problems relating specifically to police bureaucracy that may generate stress and impair performance:

1. "Too rigid, inflexible and not easily adaptable to external or community change;

2. Communication often fails to reach its intended destination resulting in poor decisions or pursuit of conflicting goals;

3. Institutionalization and isolation are cultivated, which promotes a self-serving disposition instead of focusing on community concerns;

4. Failing to take a talent inventory of personnel and employing their skills for the betterment of the organization, and in some cases stifling creativity altogether; (Walker)

5. Repetitious and redundant work, such as preparing unnecessary administrative forms;

6. Supervisory feedback about performance” (Alexander et al.). 
Three of the leading features of classic police bureaucracy-hierarchal design, internal communication and leadership/management style-are outlined more extensively in the following subsections.

Hierarchical Design. American policing has a well-establish English heritage, which was founded on quasi- or paramilitary military principles, steeped in command and control doctrine ${ }^{8}$ (Bittner, 1980, 1990). Bittner (1980) noted that the quasi-military design is so prevalent among police agencies that it is virtually a given by those who practice or study the police. The quasi-military model for police agencies imposes constraints on personnel, and dictates organizational expectations about how things are to be accomplished (Vila and Morris, 1999). The command and control doctrine regulates, in minute detail, the mundane behavior of those under its control. Yet, the system fails miserably when personnel must make split-second and complex decisions (e.g., when to use deadly force) and does little to recognize individual discretion at the operating level, which is the lynchpin of policing (Bayley, 1994:64-66, in Chemerinsky, 2000-2001:565566; Bordua and Reiss, Jr., 1966; Van Maanen, 1978). The military model stands in stark contrast to civilian policing in several respects and more closely resembles the structure of fire departments than police departments (Table 1$){ }^{9}$ 


\begin{tabular}{|c|c|c|c|}
\hline & Military & Police & Fire \\
\hline Structure & - Centralized & - Decentralized & - Centralized \\
\hline Environment & $\begin{array}{l}\text { - Sequestered on } \\
\text { military installations }\end{array}$ & $\begin{array}{l}\text { - Dispersed throughout } \\
\text { the community }\end{array}$ & $\begin{array}{l}\text { - Sequestered in fire } \\
\text { stations }\end{array}$ \\
\hline $\begin{array}{l}\text { Decisions on } \\
\text { Engagement }\end{array}$ & $\begin{array}{l}\text { - Move as a unit } \\
\text { - No independent action } \\
\text { - Await instructions } \\
\text { from leaders }\end{array}$ & $\begin{array}{l}\text { - Move as individuals } \\
\text { - Autonomous } \\
\text { independent action } \\
\text { - Discretionary }\end{array}$ & $\begin{array}{l}\text { - Move as a unit } \\
\text { - No independent action } \\
\text { - Await instructions } \\
\text { from leaders }\end{array}$ \\
\hline Supervision & - Embedded & - Dispersed & - Embedded \\
\hline Membership & $\begin{array}{l}\text { - Accepts members "of } \\
\text { rank" }\end{array}$ & $\begin{array}{l}\text { - Accepts entry-level } \\
\text { only }\end{array}$ & $\begin{array}{l}\text { - Accepts entry-level } \\
\text { only }\end{array}$ \\
\hline Training & - As a unit or team & - As an individual & - As a unit or team \\
\hline Tactics & $\begin{array}{l}\text { - Unit-centered/mission } \\
\text { driven }\end{array}$ & - Individualistic & $\begin{array}{l}\text { - Unit-centered/mission } \\
\text { driven }\end{array}$ \\
\hline
\end{tabular}

The implication is that through a stratified rank structure, a concentration of power at the top of the organization and a rigid body of rules and regulations coupled with rudimentary police academy training, police officers are equipped to handle all of the potential encounters in the absence of police leaders.

The rule-bound nature of police departments became institutionalized as part of the "professional" or "reform" movement that swept across American police departments between the 1920’s and the 1970’s (Kelling and Moore, 1988). The intent of the professional movement was to reduce the political interference in policing. As Wilson (1968:282) noted this movement sought to "reduce corruption by reducing the amount of discretion the officer has to sell," hence imposing tighter controls over behavior. The intent was to divorce the police from widespread political interference that was so prevalent at the turn of the $20^{\text {th }}$ century by creating a well-disciplined and highly 
structured workforce. Although there are some similarities between the military and American law enforcement agencies (e.g., they both wear uniforms and carry weapons), several scholars criticize the quasi-military structure for its use in civilian policing (Brown, 1996; Cowper, 2000; Potts, 1982), particularly community policing (Bittner, 1980; Goldstein, 1979).

Prominent among the criticisms is the authoritarian command style (Smith and Ward, 1983), where power is concentrated at the top of the agency in the hands of the agency's leader. This autocracy limits employee participation and decision-making and results in low morale and job dissatisfaction (Walker, 2008:93). One early study on police stress (Margolis et al., 1974) found that among a national sample of 1,400 workers, lack of participation was consistently correlated with job-related stress, including low motivation and self-esteem, a depressed mood state and job dissatisfaction, all of which negatively influence performance.

The resulting frustration may lead police officers to exact their frustration on unsuspecting citizens as a response to the limitations imposed on them by the organization (Dollard et al., 1939). Through a process of behavior modeling-a form a social learning theory-persistent subjugation to the authoritarian command system and the indifference that arises from that system may contribute to performance problems when police officers interact with citizens. Since the dominant operating style is one of deference to rank and authority, the officer does not get a chance to participate in decisions that affect them or practice negotiation, compromise and diplomacy consistent with the values and obligations of a democratic police (Rhoades, 1991:13; see also Angell, 1971:187-188). Instead, officers rely on taking control, issuing imperatives and 
perhaps using force to gain compliance (Neiderhoffer, 1967:150-151, 182), in the same manner they have been exposed to in their dealings with police supervisors and management. Police officers learn how to exert their authority when dealing with citizens; they learn the motives, drives, rationalizations, and attitudes necessary to gain compliance from (Potentially) uncooperative citizens as well as explain away their actions when necessary. Inspiration for this behavior lies in the processes of cultural/intergenerational transmission of values, roles and attitudes passed along in the language of the vocation.

It appears to me that decentralized decision-making is not something widely embraced or valued in police departments, except for police agencies who are attempting to move toward community policing, where it is encouraged, although, the traditional model is still pervasive. Franz and Jones (1987:155) conceptualized the "pathologies” of the military model used in civilian policing, which describes how department performance is ultimately impaired; the hypothesized causal sequence is: Military model $\rightarrow$ Impaired communication $\rightarrow$ Relatively greater distrust of upper levels of the police hierarchy $\rightarrow$ Relatively low levels of morale $\rightarrow$ Impaired departmental performance.

The tall organizational structure may also inhibit clear and effective communications (Brown and Campbell, 1990), promote “authoritarianism,”"10 erode trust in management and degrade officer morale, which ultimately impedes individual performance. With respect to morale, Angell (1971:191) noted "The classic organization model appears to support a perpetual state of low morale among employees of bureaucracies.” The impersonal nature of the organization may create an aloof atmosphere and perceptions of unresponsiveness and a general sense of a lack of 
communication from the upper strata of the organization (Gaines et. al., 1991). The highly centralized structure of police organizations and the associated complexity is denoted by a clear division of labor controlled by managers residing at the top of the organizational plan. The resulting complexity and structure of police bureaucracy, compounded by the personal temperament and proclivities of individuals inside the organization become barriers to effective internal communication. The resulting problems may be embedded in another military concept known as “chain of command,"11 a slow and cumbersome internal communication process that must be adhered to. Internal communication problems may also emanate from the departmental status system (Rank structure) and from rumor or filtered information.

Internal Communication. Internal communication is the primary conduit for management and labor to express their goals, achievements and problems to each other. It is also the primary mechanism to deliver basic information about the agency or the workforce, to assess the operating climate and to facilitate decision-making. Decisions are, perhaps, the most important aspect of organization, which ensures the agency's goals are achieved (Pfiffner, 1951). Decisions are made and work is accomplished in a police department by transmitting information via the "chain of command.” This concept borrows from the military and implies there is a clear delineation of authority and responsibility along which orders and internal communiqué are passed, through a process of delegating and re-delegating to successively lower levels within the agency; the same delegation process applies to information passing upward in the agency.

The chain of command typically follows the formal lines of organizational authority as depicted in the agency’s organizational plan. ${ }^{12}$ Observing the chain of 
command means communicating only with one's immediate supervisor (The military principle of "unity of command" ${ }^{13}$ ). The chain of command is tightly controlled and violating it is often viewed as a personal affront to a supervisor's rank and authority, which may subject the offender to negative disciplinary action (Schroeder, Lombardo and Strollo, 1995).

Because information typically "rolls downhill," the prerogatives of rank may induce stress among subordinate junior staff who must endure the same exasperation their superiors once endured while occupying lower ranks. Speaking of senior management's responsibility to reduce bureaucracy and create simplified systems that may improve communication, Alexander et al. (1991:51) noted "This view tends to run counter to the traditional police insistence that it is the task of junior officers to do what they are bid on pain of disciplinary action, and that senior officers have earned the right to impose whatever tasks they feel to be necessary.” Since police officers are taught not to question their superior officers, there is an apprehension that arises based on the status system. This may create a barrier to communication by inhibiting personnel from lower ranks from communicating with personnel of higher ranks, particularly when they need advice or direction.

Because the chain of command is inherently cumbersome, poor communication may arise from slow or no feedback from supervisors, from rumors and from filtered information that circulates throughout the organization. In particular, supervisory feedback about performance is essential for individual job satisfaction, morale and as a display of organizational support (Hutchinson and Garstka, 1996). Clear communication between employees and supervisors ensures management is informed about problems in a 
timely manner so they can be addressed (Thibault et al., 1985). Research shows there is a direct positive relationship between job satisfaction and an employee's satisfaction with their supervisor and the information they receive from their supervisor (Zhao, Thurman and He, 1999).

Rumors and filtered information throughout the communication chain represent another threat to performance. A rumor, for example, that an officer will be transferred from their current assignment or from their current geographic area, or a layoff is impending, or the officer is the subject of a pending citizen complaint is particularly distressing because the rumor is an unconfirmed bit of seemingly true information. The longer the rumor lingers without a disposition or feedback, the higher the experienced stress level. Rumors are particularly distressing to the psyche because of the intrinsic quality of unpredictability and uncertainty. The police literature on the relationship between unpredictability and performance is limited; however, studies in behavioral psychology suggest support for this relationship. Glass and Singer (1972:462) found support for the relationship between performance and predictable and unpredictable noise levels. Study participants who were exposed to unpredictable noise made more errors during the test and had a lower tolerance for frustration. Researchers concluded “...unpredictable noise produced adverse after-effects because it is more aversive than predictable noise, its greater aversiveness being a function of the same helplessness induced in an individual who is unable to control and/or predict its onset or offset.”

Officers do not know when rumors will surface, the accuracy of their content or their source. The unpredictable nature creates the sense of a lack of control over the situation, which consequently raises anxiety levels. When anxiety is high, performance is 
degraded. By their very nature, rumors tend to have an air of authenticity because they are typically passed along in conversation from peers, friends or other trusted colleagues, even though the source remains unverified. As the information travels along in conversation between officers, there is a tendency for the information to become distorted and consequently inaccurate since a small piece of its authenticity is lost each time it passes from the preceding person to the succeeding person in the communication chain. The distortion results from cumulative errors either from mishearing or from misinterpreting the information and filling in what one believes they heard from the last person in a process of filtering (Day, 2004; Iannone, 1987:111).

Filtering occurs when one party to the communication passes along only that portion of the information that was important to them but leaves out the other elements of the message. When filtered information is passed along in a police department from top (i.e., superior officers) to bottom (i.e., subordinate officers), it creates an adverse effect on the workforce by eroding confidence in management and leadership, consequently harming morale; the process of performance degradation is: Low morale $\rightarrow$ poor job satisfaction $\rightarrow$ decreased motivation $\rightarrow$ decreased productivity (Herzberg, 1968).

Filtered information keeps people suspended in a state of tension and anxiety until the information is confirmed or dispelled. Anxiety and tension are heightened when there is only a small piece of information available and a great deal of curiosity surrounding the information. Fears and suspicion arise in the void for this coveted information. The effect is especially acute when rumor and filtered information are used in a deliberately deceitful manner as bureaucratic propaganda from top police administrators to influence sentiment, emotion or motives toward the police as an institution or to further self- 
interested goals of the top administrator. This may occur as part of management's rhetoric to counter political semantics in an effort to force concessions from the workforce, to frustrate policy decisions that may upset the status quo, or to set opposing parties or interests against one another to advance the chief executive's own goals.

Police administrators may adopt different persona depending on the target audience to bolster support for their image or to advance a personal agenda. Velez (2006:145) noted some police executives may behave in a recklessly irresponsible or deceitful manner with rhetoric to portray themselves to elected officials as a "strong leader" determined to "overcome an incompetent staff” protected by civil service regulations. Then, when communicating with their own staff, the executive suggests to them that he or she is protecting them from city hall's bureaucrats and "an inept city staff." Once more, the executive uses the same rhetoric to ensure residents he or she is attempting to improve the community's quality of life, but is "hindered by a bureaucracy and police personnel he inherited from a prior chief,” all the while setting opposing parties or interests against one another to advance a personal agenda, a tactic of questionable ethical propriety.

When subordinate personnel are exposed to mixed messages such as those described by Velez, they may attempt to satisfy their curiosity for the truth by chasing after outside sources such as politicians or the media, instead of turning inward to the administration. This may lead to a sense among the workforce that the agency is deliberately withholding valuable information and trying to harm them—a significant leadership failure. Allowing subordinate officers to communicate directly with the chief executive, or those who speak with his or her delegated authority to "air their 
grievances, " provides a medium for officers to release their tension and vent their frustrations to the person vested with decision-making authority. However, in the quasimilitary environment of most police departments, this is virtually non-existent.

When communications in a police department break down, an atmosphere of uncertainty arises. This leaves employees in a state of suspense waiting for direction; as the waiting time increases, anxiety builds, which subsequently degrades performance. If employees do not receive the direction they are seeking, they may take action based on the limited information within their ken, or they may do nothing, which may be worse than taking action. The consequences of communication breakdown in other government operations have proved disastrous, far worse than just morale. ${ }^{14}$

Leadership and Management Style. The style of leadership and management and the emphasis on certain functions in a police department is also a function of the quasi-military bureaucracy. The leadership and management style often adopted in larger agencies tends to be autocratic, a style dominated by oppressive orders and dictatorial methods. An autocratic leader is characterized as:

“...highly authoritative. He makes decisions without allowing subordinates to participate. They often are made to feel they are not part of the team because they are not allowed a voice in the decision-making process...He directs, commands and controls his subordinates in such a manner that no one ever forgets who is the boss. He rules through fear, intimidation and threat” (Iannone, 1987:36-37).

Autocratic leadership may be found in agencies that employ a "legalistic" style of service (Wilson, 1968). The legalistic model places an emphasis on effecting arrests and enforcing the law and deemphasizes service delivery. Since service delivery is a primary function of the police, smaller agencies tend to emphasize the patrol function (Ostrom, Parks and Whitaker, 1977), whereas larger agencies use more specialized divisions to 
apportion the work. The interpersonal relationships that exist in larger police agencies tend to be more formal than smaller agencies, which may be a result of the management style adopted by the agency. Brooks and Piquero (1998) conducted survey research of ten police departments and found that, generally, police officers from larger departments experienced higher levels of stress resulting from administrative bureaucracy than those in smaller departments.

With rising egalitarianism, there is increased sentiment for more democratic forms of organization, particularly how management exercises control over the workforce and the terms of employment. One effort to counter autocratic management may be, as Terry (1981) and Stinchcomb (2004) suggest, for police agencies to adopt a democratic management style, which is a form of shared or representative management that may lead to greater job satisfaction (Witte, Travis and Langworthy, 1990). A democratic leader is characterized as someone:

“...seeking ideas and suggestions from [their] subordinates and allowing them to participate in decision-making that affects them...He uses little authority because he encourages his employees to participate with him in getting the job done. He treats them as associates in a joint venture and thereby increases their feelings of responsibility, their sense of achievement, recognition and personal growth; but most important, he increases their commitment to the goals of the organization" (Iannone,1987:37).

Allowing subordinates a voice in decisions that affect them demonstrates to the subordinate they matter as an employee and their suggestions make a meaningful contribution to the agency's goals.

Organizational Capacity (Staffing)

At the turn of the century, changes in demographic trends, urban sprawl including suburbanization and annexation began to spread police resources thinner and change the 
way services were delivered (Monkkonen, 1992). Police patrol was primarily conducted on foot when organized policing was introduced to the United States in the mid $19^{\text {th }}$ century. As cities grew by incorporating smaller surrounding suburbs into metropolitan areas, foot patrol gave way to motorized patrol (Lane, 1977; Reiss, 1992). Consequently, many police departments, even the largest ones such as Los Angeles, Chicago, New York City and Boston, found it difficult to keep pace with the growth and increasing social demands of the new populace. Police departments began a gradual shift from a decentralized intimate environment cultivated by foot patrol, to a centralized, distant and impersonal environment cultivated by motorized patrol and other technological innovations. The result was more territory, more work, but not necessarily more personnel.

There is often a misconception that larger police organizations have the capacity to handle the volume of work. Reiss (1992:57-58), speaking about the number of police officers required to adequately staff modern police departments noted that, per capita, the bureaucratic models used today require "twice as many police officers" than the foot-beat systems of years past. He attributes the need for more officers to the rise and diversification of "specialized squads and bureaus," which serve a support role for patrol operations and consequently require more administrative personnel. As the agency grows more heterogeneous due to the division of labor, economies of scale are lost due to coordination and communication problems (Blau, 1974; Scott, 1975). The more diversified (i.e., complex) the organization the fewer personnel there are to handle the majority of the work (i.e., reactive workload demands) and fill personnel shortages due to vacations, days off and unplanned absences (i.e., sick days, emergency excusals). This 
creates a situation where officers may be denied discretionary excusals (e.g., request for a personal day off) since they are needed to fill shortages created by the expanding bureaucracy.

As the division of labor expands, so too does the administrative overhead that is necessary for support. Administrative overhead are the resources necessary to support the line function, such as supervision and support services (e.g., dispatching, recordkeeping, evidence storage), but which do not directly produce organizational output (Langworthy, 1985:21). This too leaves fewer personnel to handle the bulk of the work. Since the largest drawing pool for administrative and support personnel is the patrol force, patrol is rapidly depleted and left with the bare minimum number of personnel to handle ever-increasing service demands.

Service demands and expectations from the public have grown dramatically since the beginning of policing's "professional era” movement between 1920 and 1970, primarily through technological advancements. The rise in residential telecommunications and the advent of the 9-1-1 system, inculcated a habit among the public that they should "call the police" whenever they feel the need (Walker, 1998). The result was a steady upward trend in workload. The advent of the patrol car, the telephone and the two-way police radio transformed how police services were delivered. The decentralized intimate environment gave way to a centralized, remote environment, where there was less emphasis on community interaction (Kelling and Moore, 1988). The result was that citizens could summon police service more quickly and efficiently. While these innovations seemed to herald a new era in policing, it also began to stretch resources to their upper limit, an unwelcome and unanticipated cost (Reiss, 1992). 
As society grew more complex, calls for service in police departments became backlogged, an idea that is counter to efficiency in bureaucracies (Klinger, 1997; see also Weber, 1946). The resulting increase in workload requires calls to sit in a queue until an officer is available. In this work environment patrol officers, barely keeping pace with the volume of calls, often resort to cutting corners, providing facile answers to complex problems all the while relying on informalities and discretion “...to manage their work in a timely fashion” (Klinger, 1997:292). Two long-term consequences of being overworked are physical exhaustion, which may result in substance abuse to reenergize the body and psychological exhaustion known as burnout, a condition resulting from persistent exposure to troubled people (Maslach, 1976, 1982; Schaufeli and Enzman, 1988). Both conditions may lead to decrements in performance.

\section{Work Schedules}

Research suggests that work schedules tend to play a role in stress due to the physical and psychological demands they place on the officers (Cooper et al, 1982; Doctor et al, 1994). The demands of a 24-hour, 365-day per year organization necessitate scheduling policies that provide sufficient personnel during non-traditional business hours, weekends and holidays. Stress may result from not having enough sleep and disrupting the body's circadian rhythm (Aschoff, 1978). ${ }^{15}$ The human body is not designed to constantly stay awake during nighttime hours. Consequently, adjusting to abnormal work hours interrupts the cycle of sleeping, eating and working. The problems become more pronounced when police officers are required to rotate across shifts instead of being assigned to fixed shifts. Steady shift assignments enable officers to adjust to given work hours even if they are outside standard business hours (Barton, 1994), which 
may improve job satisfaction (White-Sydney, 1981). Shiftwork has been implicated in a variety of risks for police personnel including issues that affect health, performance and safety.

A substantial body of evidence suggests there are physiological disruptions associated with shiftwork and non-standard schedules that manifest in a variety of performance issues for the agency and the individual. Previous studies suggest that rotating shift workers suffer greater sickness and absenteeism than workers assigned to steady shifts, especially when the hours are long (Holbrook et al., 1994). Research has also found negative associations between rotating schedules and employee productivity, safety and accident-proneness (Johnson et. al, 1981; Regestein and Monk, 1991), reduced total sleep and poorer sleep quality (Torsvall, et. al., 1989). Moreover, rotating shifts are especially difficult on people over aged 50 and those who need more the 9 hours of sleep (Monk and Folkard, 1985). Snyder (1995) monetized the economic impact from shiftwork-related problems (i.e., absenteeism, lost productivity, medical bills, and accidents) in United States-based companies and found that approximately $\$ 70$ billion a year was lost.

A related but different problem associated with work schedules in policing is the operational imperative for mandatory minimum deployment strength (i.e., staffing coverage). A study of 37 Ohio police executives found that $78 \%$ of represented agencies were understaffed (Vila, 2000), a problem that directly contributes to organizational capacity. Police work necessitates minimum staffing levels and scheduling decisions to ensure vacancies are covered around the clock (Bopp, 1974). For example, police officers may be scheduled to work from 3:00 PM to 11:00 PM and then be required to 
return to work at 7:00 AM to fill a scheduling vacancy. This process of "quick changeovers" tends to increase absenteeism on shift-change days (Harrington, 1978). A study by Czeisler, et al. (1982) found that industrial plant workers on rotating shift schedules who had a longer rotation period (21 days) compared to those who had a shorter rotation period (weekly rotation) showed increases in job satisfaction, productivity and improvements in health.

One aspect of police work that may aggravate the effects of shift work and may accelerate physical and emotional problems is overtime. Overtime is a common occurrence in most police departments for a variety of reasons including mandatory court appearances after just having work through the night; working a double shift (two consecutive shifts); and covering for officers who call out sick. There is also the economic reality that it is more cost effective to pay overtime than to hire and train more officers to fill vacancies (Claiborne, 1994; Serrano, 1994; Suro, 1991), thus mandating officers work a second shift is common.

Overtime is a necessary, often mandatory part of police work that may result in fatigue. Fatigue describes a range of afflictions such as feeling tired, physically exhausted and lethargic, which tends to impair a person's ability to continue functioning at the level of one’s normal ability (Gandevia, 1992; Hagber, 1981; Hawley and Reilly, 1997). Vila (1996) found that off-duty court overtime was a primary source of fatigue (See also Boorstin, 1986; Duggan, 1993; Harriston, 1993; Kroes, 1985), and is often compounded by sleep deprivation. Pilcher and Huffcutt (1996) and Vila (2000) found that police officers had an average of 6.2 hours of sleep when working 8-hour shifts and 6.5 hours when working 12-hour shifts. In a similar study of shift length, Peacock et al. 
(1983) found 53\% of police officers reported an average of 6.5 hours of sleep or less. The short sleep cycle may result in impaired performance.

Operational overtime is often viewed by police officers as a means to earn extra income. However, many police officers also work second jobs to earn extra income, something known as secondary employment or “moonlighting” (O’Neil and Cushing, 1991; Vila, 1996). Vila (2000) found that nearly $50 \%$ of the 45 agencies that participated in a 1999 study reported half or more of their officers held secondary employment, and some agencies reported their police officers average 100 hours of moonlighting per week. Police departments often regulate secondary employment to a limited number of hours per week that officers may work to reduce fatigue-related issues. ${ }^{16}$ Fatigue and sleeprelated problems have also been implicated in other industries as a source of accidents, particularly tanker spills in the maritime industry (Stevenson, 1996).

One of the problems resulting from fatigue is sleep difficulties and its attendant circumstances. Research suggests that police officers experience difficulties not only during individual sleep periods, but also during individual situations such as nodding off at a stop light while driving (Maas et al., 1998), eating or attending social gatherings (Vila, 2000; Vila and Kenney, 2002). Other research shows fatigue increases the possibility officers will become involved in official misconduct (Burke, 1994), are more likely to be involved in accidents or become injured (Vila, 2000; Vila and Kenney, 2002) and are more prone to errors in judgment (Mitler et al., 1994), which may result in costly litigation for the employer (Barrineau, 1987; Christopher Commission, 1991; Kolts, 1992; Swanke, 1989). 


\section{Summary}

The police bureaucracy creates a series of problems for personnel. In particular, the command and hierarchical design in policing limits autonomy and fails to recognize individual discretion, which is not only prevalent in police work but an operational necessity. The command and control doctrine that is embedded in the hierarchical design is well suited for ensuring compliance with the mundane minutia of daily police work, but is wholly ineffective for reconciling the complexities of policing that take place in a decentralized, unsupervised environment where individual officer discretion is the final arbiter of many moral dilemmas.

When a police officer finds himself or herself in a moral dilemma, there are few others to turn to beyond the officer's immediate supervisor. The tall organizational structure and the concept of "chain of command" prevent a bewildered police officer from requesting assistance from the top of the organization, where most control resides and where a suitable decision is likely to emanate. The tall police bureaucracy also inhibits personal growth and autonomy by stifling creativity and initiative. In many instances, officers are precluded from advancing without taking a competitive examination, which leaves meritorious service out the promotional equation. The result is a state of malaise and a lack of initiative, compounded by excessive paperwork and rote operating procedures, where police officers do just enough to satisfy peering supervisors but do little extra to achieve organizational goals, particularly since there are few avenues to participate. These conditions often affect the organization's capacity to handle the workload. 
Some police agencies have rather large bureaucracies, which lends the impression that the agency is well resourced and capable of handling the volume of work. Many modern police agencies, even the largest ones, have seen a concurrent rise in service demands as society grew more complex and territorial boundaries expanded. However, as policing moved from a decentralized, intimate environment, to a centralized, remote environment, coupled with the advent of new technology, the policing industry did not anticipate the strain on its resources. Consequently, many police agencies lack the resources to handle service demands expeditiously and police officers are often overworked. Compounding the problem are work schedules that necessitate personnel coverage 24 hours per day, 365 days per year. The pace of quick-change work hours and working overnight hours exacts physical and psychological stress.

Continuous personnel coverage and working overnight creates physiological complications that may lead to stress. The literature is replete with examples of performance effects and accidents that emanate from odd work schedules in policing as well as other industries (i.e., maritime). In addition to performance, the physiological effects may impair sleeping, eating and attentiveness, problems that may lead to increased absenteeism and lower job satisfaction.

The principles of classic bureaucracy are at odds with the individual-level discretion inherent in civilian policing and the democratic ideal of public participation in setting police priorities. As Stinchcombe (1980:59) commented, the military model is appropriate if we want police officers to assume automaton qualities and "do everything 'by the book.'” However, if we want to capitalize on individual police officers' creativity, ingenuity and resourcefulness, then we must abandon the military model in 
favor of flattened organizational structures that considerably reduce bureaucracy and are employee centric.

\section{Stressors in Organizational Life}

The conditions that precede stress envelope the workforce and are coupled with conditions that are characteristic of life inside the organization. Negative physiological and psychological consequences often accompany such stressors for a significant portion of the people exposed to them. Kahn and Byosiere (1992) categorized stressors in organizational life into two groups termed task content and role properties. Task content stressors are the physical aspects of organizational life that characterize the task at hand including its complexity, simplicity, or monotony and the physical conditions under which it must be carried out, such as extreme temperatures, equipment inadequacies or excessive noise. Role properties are the psychosocial aspects of organizational life, which characterize the social nature of the job including role ambiguity, role conflict, role overload and interpersonal relations between superior officers and subordinate personnel. Task-content Stressors (Physical Aspects)

That police officers must work under adverse physical conditions is virtually a given. Excessive heat in summer months, brutal cold in winter months, rainy or windy weather when officers are assigned to foot patrol, a traffic-control post, or must ride a motorcycle creates adverse work experiences that may lead to stress. This may be compounded by substandard equipment and facilities, which may create potentially harmful situations and a general sense of inconvenience and uncaring from the administration, which reduces a police officer's performance. I witnessed this in Detroit and Paterson, and the implications for morale-which are theoretically linked to 
performance (See Herzberg, 1968)—may be greater than some are willing to admit.

Facilities provide a good example. When a police department outgrows the facility it occupies or fails to maintain the existing facility, risks of all types may increase. Cluttered hallways and stairwells become congested from a lack of storage, increasing the risk of slip and fall accidents. To alleviate the clutter, boxes are moved into areas not intended for storage, but now must double as such (e.g., a cafeteria area that houses lockers; a training room that doubles as an interrogation room). Exposed electrical wiring becomes a fire hazard. Bathrooms are unsanitary and may have broken fixtures that only deliver cold water or toilets that do not flush. Items of evidentiary value are stored in a closet, comingled with broken equipment awaiting repair instead of being housed in a secure area; this presents a severe corruption hazard as well as a judicial hazard. Police cars with bald tires, no heat or air conditioning and retrograde emissions in the cabin present both a health hazard and a safety risk.

The potential for assault during arrest processing also increases because police officers may not have a separate entry area and must parade their unprotected prisoner in front of the prisoner's family and friends who are congregating at the station as the officer arrives. Prisoners eventually detained at the station often face substandard conditions in holding cells including overcrowding, which increases the risk of fights between prisoners necessitating police intervention and other conditions that amount to violations of the prisoners’ federal civil rights (Narvaez, 1984).

The physical stature and aesthetics of police facilities sends an important symbolic message to the officers who work there as well as the people who visit. The facility is a visible manifestation of government authority and the image projected by the 
facility signals the quality of policing and justice the city dispenses. Dutton and Dukerich (1991:548) note:

“An organization's image matters greatly to its members because it represents members' best guesses at what characteristics others are likely to ascribe to them because of their organizational affiliation. An organization's image is directly related to the level of collective self-esteem derivable from organizational membership; individuals' self-concepts and personal identities are formed and modified in part by how they believe others view the organization for which they work."

Facilities and equipment are symbols of professionalism that promote feelings of morale ${ }^{17}$ and esprit de corps. Esprit de corps, from the French "spirit of the body,” is defined as “A common spirit of comradeship, enthusiasm, and devotion to a cause among the members of a group” (American Heritage Dictionary, 1996:627). This is the collective sense of belonging and identity police officers interpret from the top of the police organization and the government structure, which makes them feel they are different from and better than other people and that the organization is more important than the individual (Houston, 2000:56).

These symbols create a professional appearance and a professional atmosphere that builds a sense of camaraderie, unity and solidarity among officers. Police officers are associated in a common organization with a common direction and ascribe to certain values they are willing to fight for such as preserving the good name of the profession and the image, reputation and identity of the agency. Top police administrators and elected leaders drive the communal purpose of the police and they use labels and symbols to express pride in what the agency does and what it stands for. Those labels and symbols (i.e., facilities and equipment) create and perpetuate what the members think of themselves and what outsiders think about them and their organization. 
In addition to the physical conditions, the simplicity of police work is drastically overstated. Policing a democratic society is exceedingly complex (Goldstein, 1977) and the opportunity for contradiction is always present (Kinnane, 1979). Police-citizen encounters occur within a defined set of laws, rules and regulations that is ever increasing and vague, where decisions are not dichotomized into right and wrong, yes or no. The decision environment is often ambiguous and less than ideal, which may not produce the ideal outcome or satisfy all of the interested parties. ${ }^{18}$ This leaves the door open for citizens to complain or vent their frustration at a police officer who may have selected the lesser of two evils given the particular circumstances.

As for the monotony of policing, tedium, especially during the overnight shift, is virtually inevitable. Boredom is punctuated by brief periods of excitement that raise and lower physiological responses to the stimuli creating fatigue (Coman and Evans, 1991; Dwyer, 1991), which may impair judgment, slow reaction time and increase the risk that a police officer will respond in an inappropriate manner (Lauber and Kayten, 1988). The more pronounced these features, the more likely performance is to suffer.

Role Properties (Psychosocial Aspects)

Psychosocial aspects of police work refer to the interaction between a police officer’s psychological state and their social environment. Psychosocial properties are used to describe the unique internal cognitive processes that occur inside the individual that may be shaped by their environment. Role properties are aspects of the work environment that involve relations with coworkers, supervisors and top administrators and interpretation of the police role, which is acquired through individual and social processes. These interactions and associated interpretations may result in role conflict, 
role ambiguity and role overload for the officers, stressors that seem to hold across occupational settings and are not unique to police work (Weiss, 1983). They may also result in a complicated daily existence, inasmuch as the officer's ability to shape their role and their future inside the police department is constrained by several factors that impinge on the officers' career including the promotional process, internal affairs investigations and performance ratings.

Role Conflict. Role conflict is the "perceptual differences regarding the content of the role or the relative importance of its elements” (Muchinsky, 1997:308). These differences may occur between a police officer and others in the workplace (e.g., supervisors, top administrators and peers), who do not necessarily hold the same role expectations as the officer (Caplan and Jones, 1975; Kahn, Wolfe, Quinn and Snoek, 1964). When an individual enters the law enforcement profession, they bring with them preconceived expectations about what the job entails, which may be fostered by their upbringing or exposure from different sources (e.g., family, friends, and media). These individual-level experiences are married with social experiences that are acquired when the individual enters the police academy (Harris, 1973:45-78). A resocialization and acculturation process begins during recruit training, where the professional cues, norms and traditions of the job are imparted by formal authority figures (Academy instructors and supervisors) and informal figures (Incumbent police officers) eventually reshaping the officer’s “working personality” (Skolnick, 1966:42-62).

New police officers process the information and attempt to reconcile it with their previously held beliefs about what the job is supposed to be. Both the formal and informal cultures of the police milieu compete for the officer's attention and allegiance 
by exerting pressure to conform. When confronted with these different pressures, police officers may experience conflicting internal and externals demands in a continuously changing environment, where both the formal and informal systems punish the officers for failing to conform (Gross, 1973:54-110). The formal organization subjects the officers to rigid bureaucratic operating strictures set forth in rules and policies enforced via the rank structure. This limits the officers' ability to adopt other roles that may help resolve a problem (Kirschman, 1983). The chief requirement of the formal organizational culture is obedience. When an officer violates formal agency norms, they may be subjected to disciplinary charges. Police departments are well-known for punishing the disobedient while honoring the obedient (Rubenstein, 1973)

Likewise, the informal subculture subjects the officer to its own operating code laden with discretion, secrecy and solidarity in an attempt to insulate the officer from an uncaring and generally unsupportive management structure, as well as a hostile public (Burbeck and Furman, 1985; Neiderhoffer, 1967; Van Maanen, 1978). The chief requirement of the subculture is loyalty, which is police argot for supporting fellow officers by ignoring or otherwise keeping silent in the face rule violations or law breaking. In other words, being a real "stand up guy," one who can be trusted not to reveal anything during questioning by superior officers, a seemingly irreconcilable demand betweenth4 formal and informal cultures (Brown, 1981). John Kleinig reported on what loyalty meant to officers in the New York City Police Department: "When an organization wants you to do right, it asks for your integrity; when it wants you to do wrong, it asks for your loyalty” (Quoted in Souryal and McKay, 1996:46). 
Because police officers spend nearly all their time working with each other, very little time interacting with supervisors and almost no time interacting with top administrators, the subculture's influence over the officer typically reigns supreme, which may create severe role conflict (Hunt, 1976). When an officer violates the norms of the informal subculture, they may be subject to harassment, sarcasm, a lack of support and ultimately group rejection for what the group characterizes as untrustworthiness and disloyalty.

When an air of uncertainty about a police officer's role exists and there is no clarification from management about that role or feedback about individual performance, research suggests that, ultimately, assimilation with the informal police subculture will shape the standards of behavior and performance (Hillgren and Bond, 1981). Moreover, the informal standards may or may not conform to the official standards (Stoddard, 1968). Research in the United States (Christopher Commission, 1991; Mollen Commission, 1994; Rampart Independent Review Panel, 2000) and Israel (Herzog, 2000; State Comptroller, 1986) suggests that informal messages contrary to the organization’s formal messages may be the source of excessive physical force-a clear performance problem. Herzog (2000:420) found that double-edged messages passed along in the informal (Subcultural) communication chain, particularly by middle managers, were interpreted by front-line police officers as “... an effective way of achieving success in the war against crime; therefore, police officers who resorted to violence should be shielded from disciplinary or judicial action against them.”

Another type of role conflict facing police officers is the requirement they simultaneously enforce the law and protect civil liberties (Collier, 2001; Eisenberg, 1975; 
Skolnick, 1968), a mandate that may produce irreconcilable conflict. Controlling crime in a Constitutional democracy is a complex endeavor, one that Packer (1968) eloquently describes in The Limits of the Criminal Sanction. The dichotomy between Packer's “due process model” of criminal justice, that emphasizes individual rights, and the "crime control model” that emphasizes regulating criminal conduct, describes the delicate balance police must strike in a democracy (Skolnick, 1994). There is pervasive conflict between these models, where the police are expected to deal aggressively with criminal and antisocial behavior, yet do so in accordance with Constitutional provisions that guarantee the right of citizens to be free from unreasonable governmental intrusion. ${ }^{19}$ Although police officers are expected to do both, proactive crime control and order maintenance are often prioritized over due process. This may result in police officers working beyond the limits of the law (Galliher, 1971; Gould and Mastrofski, 2004; Bayley, 2002) or at least push the limits of the Fourth Amendment to its fringes (Kelling, 1999). This result is most apparent when the circumstances of the situation or the procedures the courts have defined are ambiguous (Eterno, 2003), which may lead to citizen or administrative complaints. The contrast between what the police are expected to do and what the police actually do is great. The police function suffers from numerous conflicts, contradictions and ambiguities that are not easily resolved. Goldstein (1977:910) noted that there are a number of perpetual inconsistencies and compromises that shape the police role:

“As one delves more deeply into the various factors that shape police functioning, one finds that laws, public expectations and the realities of the tasks in which the police are engaged require all kinds of compromises and often place the police in a no-win situation... The need for compromise-with the law, with administrative directions, with public expectations and even with one's personal ethics - has become an important, albeit unarticulated, requirement of the police job... The 
situation makes for some rather unusual working conditions. Specifically, police officers are often required to ignore their oath of office; to ignore much of what is taught in formal training; to bluff or lie, not necessarily out of malevolence, but often out of a desire to be helpful in the face of irreconcilable demands upon them; to subject themselves to disciplinary actions and civil suits for ignoring the law while following the instructions of their superiors; and to work under a style of supervision that is often more concerned with protecting the organization and supervisory personnel against allegations of wrong doing than with providing positive guidance to prevent improper behavior in the first place.

Resolving the ambivalence Goldstein identifies may lie in documenting performance standards to reduce role conflict and clarify expectations. For example, Jones, Flynn and Kelloway (1995) found that low role conflict and ambiguity are positively related to perceived organizational support; Wilson (1968:53) found that creating reasonable performance standards may give employees "a better sense of what is expected of them...The objectives are much clearer and less ambiguous;” Skolnick (1968:180) found that the employee "always tried to perform according to his most concrete and specific understanding of the control system;” and Kuykendall (1975) noted that “...the essential elements for any control system include the development of standards for performance, observations for deviations from these standards, determination of the causes of deviation and implementation of corrective action" (in Meagher, 1986:69).

Yet another source of role conflict may be the paradox between police training and the realities of police work. Restated, those occupying the role of police officer have a conception of what is expected of them, which may be drawn from mythical portrayals of the role. One strong myth of the police officer is the image of a crime fighter, born of Hollywood and media renderings. The entertainment media reinforce the value that the police exist to "fight crime." The police adopt this portrayal and perpetuate the myth, 
which gives them a sense of professional and technical competence for controlling crime, something others do not (Or cannot) possess (Feuille and Juris, 1976), which enhances the power and prestige of the vocation (Goode, 1969).

The reality however, as noted by several scholars, is that crime fighting is a very narrow part of the service delivered by police, in fact, the police mandate is more social service than crime fighting (American Bar Association, 1973; Bayley, 1994; Bittner, 1980; Manning, 1971; Reiss, Jr., 1971; Skolnick, 1966). Their daily routine consists of a variety of tasks that have nothing to do with “crime fighting," which, for some individuals such as Type A personalities, upsets their perceived role. Keller (1978:24) noted that “although 90 percent of the police officer's time is devoted to providing interpersonal services, as much as 90 percent of his training has traditionally been devoted to crime control and law enforcement.”

The socialization process, the conflicting demands facing police officers in a democratic society and the disjunction between training and actual police work may be aggravated by those who have authority over police officers. Superior officers such as immediate supervisors and upper-level managers may also place unreasonable demands on the officers resulting in role overload.

Role Overload. Role overload is a variant of role conflict, where the conflict arises from a "necessity to compromise either quantity, time schedule or quality" to meet managerial demands (Muchinsky, 1997:308) (See also French and Caplan, 1970; Margolis, Kroes and Quinn, 1974). Supervisors, for example, may be pressured by upper management to set unrealistic deadlines for a work product and place qualifiers on it such as "I need that report for the chief tomorrow by 10:00 AM and I need it done to his 
satisfaction.” The conflict arises between the time pressure created by the unrealistic deadline and the demand for a high quality work product, set inside an environment of competing demands, where time is precious. To this extent the face of contemporary policing mirrors the face of private industry in that there is an "intensification of work," where employees are expected to “...work harder and faster, and meet new management objectives and performance criteria” (Maureen, quoted in Ford, 2004:1).

Today’s police officers are being told to step-up the operational tempo (Bousfield, 1999), in the face of an increasing workload (Townley, 2000), that is set within longer shifts (Heiler, 1998; Winefield et. al, 2002). Changing demands in policing, specifically a renewed emphasis on accountability and efficiency, in an environment where resources are dwindling may contribute to the problem. When a police chief demands effectiveness and efficiency without providing the necessary resources, the result is increased pressure and strain between the chief and subordinate personnel because neither can meet the other’s expectations (Potts, 1982).

Some research differentiates the concept of role overload as too much work (Quantitative) and work that is too difficult (Qualitative) (Cooper and Marshall, 1976). Work that is perceived as too difficult may be the product of poor training or lack of experience, where police officers are confronted with a situation that is outside their frame of reference. By contrast, too much work may be a product of organizational capacity, where volume exceeds the number of available personnel to handle it. Alexander et al. (1991:52) found the pressure for “qualitative and quantitative” results among male and female officers was experienced at all ranks, “...particularly when young officers feel the need to get their careers launched.” 
This fast-paced managerial mindset may come from the short-lived tenure of chief executives, which is historically between three and five years, more commonly only two or three years, where the chief has but a small window of opportunity to make an indelible impression on their agency and leave a legacy. ${ }^{20}$ Turnover at the chief's position has had a negative influence on agency performance including leadership, efficiency and service delivery practices since at least 1931, when studies on impact of turnover were first undertaken (Waite, 1931); the problem persists today in spite of calls for tenure reform (Mahtesian, 1997; Rainguet and Dodge, 2001; Smith, 1940; Weinblatt, 1999).

Other research suggests that being overworked may result in various health problems. One study suggests there is a relationship between coronary heart disease for those who work over 48 hours per week compared to those who work 40 hours per week (Breslow and Buell, 1960). Other studies show a relationship between being overworked and psychosomatic illness, lower self-esteem, elevated cholesterol levels, increased smoking, excessive use of alcohol and absenteeism (French and Caplan, 1973; House, 1974; Margolis et al., 1974; Quinn et al., 1971). Although research on being overworked has dominated the literature, being underworked has also been identified as a stressor in policing; however, the research is somewhat weak. Some scholars posit that tedium, monotony and routine activities are common in policing, which operate similarly to role overload (Alexander et al., 1991; Kroes, 1976; Rubenstein, 1973).

Police work is often boring and unpredictable (Underload) yet punctuated by periods of overload that interact and combine as a unique stressor instead of one or the either acting as the primary stressor (Eisenberg, 1975). Muchinsky (1997:308) made an interesting observation about the vicissitudes of stress in the fire service noting how it is 
not necessarily the actual call that produces stress in firefighters. Rather, it is the anticipation and waiting (Underload) for something to occur before firefighters can ply their skills that is stressful. The effect of anticipation as a stressor has been documented in other settings as well, most notably public speaking (Droppleman and McNair 1971; McNair et al., 1982).

Role Ambiguity. Role ambiguity is derived from the symbolism and rhetoric proffered by police departments to legitimize aspects of its behavior. Because many dimensions of police work are undefined, police departments fail to provide officers with adequate information concerning expectations, authority or responsibility to perform their role, which may leave them confused (Kahn, Wolfe, Quinn and Snoek, 1964). Top police administrators often resort to symbolic measures and rhetoric to preserve the status quo and to create favorable public impressions (Lorinskas et al., 1985). Symbolic statements or perfunctory policies serve a variety of functions, many of which police executives use to shape the workforce and community sentiment for the agency and its policies instead of making any substantive change:

1. Creating buffers that protect the organization from external influences;

2. Enhancing the popularity of the chief executive among the workforce or community;

3. Providing police personnel with a sense of camaraderie, synergy and organizational solidarity, where every officer is encouraged to ply their skills for the benefit of the community.

4. Reassuring the public, through the agency's chief executive, that something can be done to solve the crime problem quickly and easily;

5. Shrouding the complexity of police problems as they relate to the limited resources available to the organization;

6. Educating the public about particular police problems and possible solutions (Edelman, 1964; Lorinskas et al., 1985; Marion, 1997). 
Indeed, criminal justice agencies in general often resist any substantive change, particularly when the potential exists to disrupt the operational status quo. In response to perceived external pressure for change, many criminal justice agencies use symbolic means to improve appearances, which creates false favorable impressions. This behavior is referred to as "applied symbolism" and it is intended to shroud the status quo among a series of measures that do not actually provide a better level of service, nor are the services intended to endure beyond the immediacy of the complainant's wishes (Lorinskas et al., 1985:43-44, quoted in Edelman, 1964:5; Edelman, 1964:5).

Pressure for substantive change in police departments often comes from external (Community or political) sources in response to a particular issue, such as a plea for change due to a crime problem, in response to an integrity/corruption probe, disparate treatment/differential enforcement or excessive use of force. However, police departments are not typically confronted by well-resourced groups that apply sustained pressure (Lorinskas, 1985). To the contrary, there is a tendency for top administrators to listen intently as community members or political figures vent their frustration over a particular issue, knowing they will ignore the requests and will not make any substantive change that is likely to disrupt the organization's basic structure or its inner workings (e.g., passive resistance). Public promises of change may be buttressed with ambiguous statements of commitment that the police department will "do what it takes" to make the streets safe, a leadership maxim designed to allay community fears and engender support from the community as well as from the workforce. The private face of those public promises may be filled with brusque language and vague orders to police officers, tinged 
with double meanings, from autocratic administrators who are equally exasperated by a seemingly intractable crime problem.

This atmosphere of duplicity and hypocrisy is a reaction to the frustration emanating from the social responsibility bestowed on the police as the moral agents who must do something about the evils of crime, now (Bittner, 1980)! In an organizational environment where the police department places a premium on crime fighting, the message is that the "troops" must be "mustered" to a state of high alert to repel the advancing enemy. Kelling (1999:9) noted that "Increasingly, police are under renewed and constant pressure from neighborhood groups and city halls across the country-not to mention State legislatures and Congress— ' to do something now' about eliminating the excesses of the drug market, getting guns off the street and regaining control over public places.” What may develop in this dubious pressure-filled environment, where crimecontrol is a top priority, is a set of practices, that, at best, can be described as over-the-top and at worst, illegal.

The relentless pressure for productivity often translates into management turning a blind eye toward questionable practices (O’Hara, 2005). This over-the-top attitude may be a consequence of cultural deviation that takes hold and propagates when supervision and leadership are overlooked (Haar, 1997). When the fallout from these over-the-top practices becomes front-page news, supervisors and executives may back away from their original proposition that officers "have their backing” resulting in a lack of support from the command structure that embraced their practices all along. Goldstein (1977:163) commented, “Police officers are frequently accused of having acted improperly despite the fact that their actions were in accord with their instructions from their supervisors, in 
harmony with the actions of fellow officers, and in conformity with long-standing practice...Ideally a police administrator should be in a position to mean what he says. But, the great inconsistencies between articulated policies and actual practices often require a police administrator to play a hypocritical role.”

When complaints are generated from police-citizen encounters, the rules of engagement suddenly change. Police officers are eventually judged by the bureaucratic standards enunciated in formal policies, although the officers' actions almost certainly were consistent with the accepted subculture and the informal operating code of discretion endorsed by management. The dilemma is that police officers are expected to operate illegally, or least unethically, in certain situations, and for their effort, they expect management will rationalize their conduct and support them. However, what typically occurs is that their conduct is evaluated against the formal agency policy and not by the informal operating code that is sanctioned on a daily basis (Goldstein, 1977). Police officers are now caught in a contradiction between the department's informal operating code and the formal policies. Management did not literally mean we will "do what it takes” to make the streets safe, although that is the very message that was received and acted upon. The text of the message is “you are free to do whatever you are doing” and the subtext is "because what you are doing is good” (O’Hara, 2005:125), tacit approval of the informal operating procedures from police management.

The result is police officers find themselves caught between competing philosophies, an inconsistency that arises from the competing ideologies of practical policing and the principles of democracy: Police officers have a legal obligation to enforce the law justly and abide by the philosophy that is the "rule of law," the other is 
the “...very direct pressure to engage in differential enforcement of the law based on political considerations” (Sigler and Wilson, 1988:151; see also Bayley, 2002; Ellison and Genz, 1983), such as those enunciated by management in the aforementioned symbolic statements (Terry, 1981).

Regardless of how it results, my experience has been that it will only take a few ambiguous messages from their superiors for police officers to become enmeshed in contradictions before they feel the effects of this leadership paradox, a paradox where officers no longer take seriously what they are told. Thus begins the gradual downward spiral into a cynical world. Neiderhoffer (1967:52) eloquently described the cynicism that evolves from these contradictions. He noted the new officer begins his or her career believing in the system. The officer embraces the agency's operating policies and management philosophy, which have been inculcated throughout the police academy and the field training experience. Soon, the inconsistencies between articulated official policy and the complexities of human nature intersect and place the officer in a conflicted position. The "book" seems wholly ignorant and unable to resolve the seemingly endless configurations of disputes, fights and social strife the officer is summoned to resolve. The officer may be ridiculed by his or her peers for trying to follow the book. Gradually, the officer realizes the official agency dictum is a sham, which cannot be adhered to by any stretch of the imagination. The officer begins relying on intuition, past experiences and colleagues for assistance instead of agency policy. Eventually, the officer casts the book aside as a symbol of failed criminal justice and department policy. The result: Substandard performance. 
Promotion Process. The belief that promotions should come from within the police department is consistent with Max Weber’s idea of “career-oriented employment” (In Gerth and Mills, 1946:196-204) and is supported by some literature that espouses the virtues of the bureaucratic career ladder (Bopp, 1974; Germann, 1962; Kelly, 1975; Potter and Blackmore, 1980) and the ideology of internal recruitment (Wall, 1994). To accept this model is to acknowledge that promotions inevitably come to those who are patient, obedient, loyal and demonstrate performance above their colleagues. The expectation that exceptional—or at least above average—performance will result in promotion is an outgrowth of an employment movement that occurred during the Industrial Revolution (Marsh, 1961; Rodgers, 1974). During this movement, the Protestant Work Ethic arose, which espoused the notion that good work should be rewarded through advancement and enriching work experiences (Rodgers, 1974). This notion is the dominant theme of the modern success ideology.

However, incumbent police officers often recognize that promotions do not necessarily come to those who tow the company line. For example, how "good work" will be measured is an issue. Beehr and Taber (1993:580) note that "good work" may be the product of "reliable effort (How hard one tries, regardless of the outcome), exceptional accomplishment (Results obtained, regardless of how hard one tries) or personal credentials (Personal traits, abilities and skills)." Consequently, subjective interpretations about good work and how it will be measured may create stress, which concurrently lowers performance. Limited opportunity, managerial prerogative (i.e., discretion) and a closed occupational system that prohibits lateral movement for upward 
mobility may make for an environment where personal development is stifled, creativity is slowed and corruption is ignored.

Limited opportunity for career advancement in a police department often arises from the size of the agency. Smaller and mid-size agencies, where the workforce pyramid narrows considerably and where a surplus of talent far exceeds the number of potential positions, establishes that most police officers will never be promoted. The majority (51.8\%) of U.S. state and local law enforcement agencies employ fewer than ten sworn officers; seventy-five percent employ fewer than twenty-five officers and ninetyfour percent employ fewer than 100 officers (Table 2) (U.S. Department of Justice, Bureau of Justice Statistics (2002:3, Table 2). It may be the perception of promotion and the belief that opportunities exist for more career-enriching assignments that keeps police officers motivated to perform (Scholl, 1983). The reality is that since most police officers spend their entire careers in a single agency, the rank structure closes and competition for the infrequent vacancy is intense.

\begin{tabular}{|c|c|c|c|}
\hline \multirow[b]{3}{*}{ Agency Size } & w Enforcement Agenci & y Size of A & y United States, \\
\hline & \multicolumn{3}{|c|}{ Agencies } \\
\hline & Number of Officers & Percent & Cumulative \% \\
\hline 1,000 or more & 77 & $0.4 \%$ & $100.0 \%$ \\
\hline $500-599$ & 83 & $0.5 \%$ & $99.6 \%$ \\
\hline $250-499$ & 203 & $1.1 \%$ & $99.1 \%$ \\
\hline $100-249$ & 669 & $3.8 \%$ & $98.0 \%$ \\
\hline $50-99$ & 1,177 & $6.6 \%$ & $94.2 \%$ \\
\hline $25-49$ & 2,237 & $12.6 \%$ & $87.6 \%$ \\
\hline $10-24$ & 4,124 & $23.2 \%$ & $75.0 \%$ \\
\hline $5-9$ & 3,623 & $20.4 \%$ & $51.8 \%$ \\
\hline $2-4$ & 3,453 & $19.4 \%$ & $31.4 \%$ \\
\hline 1 & 1,907 & $10.7 \%$ & $12.0 \%$ \\
\hline 0 & 231 & $1.3 \%$ & $1.3 \%$ \\
\hline Total & 17,784 & $100 \%$ & \\
\hline
\end{tabular}


Because there is infrequent movement between ranks, the promotion process tends to be slow, which may discourage aspiring leaders and sap their energy and enthusiasm for the position. As they sit and wait, sometimes years, for a single vacancy that is eventually granted to someone else, police officers resign themselves to the fact they will probably spend their entire career at the entry level performing the same monotonous role, a potential source of exasperation and lower performance (Web and Smith, 1980).

The promotional process varies among police agencies (Kohlan, 1973; Watts, 1982) and at least one form may contribute to diminished performance. Promotional processes include competitive written exams administered according to civil service regulations, to assessment centers that place candidates in simulated management and supervisory situations (Quarles, 1985) to discretionary systems that may rely on a combination of accumulated experience, training, and education or nothing at all. When promotions involve selecting personnel based on managerial prerogative (i.e., discretionary), the process is often contentious because it is not merit (Performance) based. Historically, these types of promotions have been based on nepotism or personal affiliation with the chief, a politician or another high-ranking police official or elected leader. Some regarded this process of cultivating a "hook" ${ }^{21}$ to receive a promotion as socially and ethically objectionable because it is rarely, if ever, based on competence or merit, it is not equitable and is often indefensible from even the most rudimentary standards. $^{22}$

My experience with the promotion process has been that discretionary appointments based on friendships or associations not governed by an external monitor 
(e.g., civil service commission), may also place a promotee in an ethically compromising position. The promotee must rely on continued good relations with their sponsor (i.e., the chief of police or political figure) for their current or future position and the sponsor may use the promotion as a means to control the officer. For example, the chief may use the newly promoted officer as a personal valet. Or, through intimation or subtle persuasion, may attempt to steer certain aspects of an investigation that may not comport with accepted police practices or may violate substantive or procedural law.

In an effort to maintain camaraderie and a harmonious workplace, the officer may acquiesce to the steady diet of contrived necessities. If the officer acquiesces, then the chief and the officer's supervisors continuously hold those compromises over the officer's head. As time wears on the need for compromise may arise again, instructions on how the officer should proceed are suffixed with a "wink" and "nod" as the officer's supervisor trivializes the importance or the quality of the compromises the officer must make by attributing them to a noble cause. The dilemma facing the officer is to comply, or abstain and potentially risk demotion or hit the glass ceiling. Since the officer cannot leave the agency in search of a new job at the same rank because the profession does not permit lateral movement, they generally concede.

Moving to another police agency—a process known as lateral transfer or lateral movement- to advance one’s career is virtually non-existent in U.S. police departments. The President's Commission on Law Enforcement and Administration of Justice (1967:142) noted this shortcoming more the forty years ago:

"Under existing police structures, nearly all local law enforcement agencies restrict advanced appointments to personnel within the department. The only exception to this restriction is that some departments exempt the position of chief administrator from Civil Service, and it is possible for persons who are not in the 
department to compete for this position. A consequence is that America's police personnel are virtually frozen into the departments in which they started."

The civil service system shoulders a great deal of the responsibility for police reform failures in this area, because the laws frequently impose restrictions on local authorities from enacting policies that permit lateral movement for promotion (Buerger, 2000). In general, the policing industry is a closed, self-contained occupational system compared to the private sector. Where employees in the private sector cultivate their knowledge, skills and abilities with the hope and opportunity of seeking a promotion at another firm, this option is not available to police officers. Although they possess certain skills that are not easily obtained, those skills are not transportable like a physician, lawyer, accountant or professor, which officers can freely market in an effort to advance their careers.

Police officers are partly captive to their profession because they are agents of the state and the authority vested in them is not like that which is granted to the aforementioned professionals. While this indicates individual police officers cannot ply their trade outside the rubric of an established government corporation (e.g., municipality), it does not mean they should be severed from offering their skills to another agency willing to promote them.

Career mobility between one city or state in an effort to upgrade one's career is typically closed for police officers, except if they wish to undergo the entire application and training process and enter the new agency only at the lowest rank. This leaves the overwhelmingly majority of police officers with no exit strategy; as salary and benefits increase over the years because of tenure, the option of leaving one agency for another becomes a choke point for an officer who may be willing to leave for the entry-level 
position at a different agency. Life inside the closed promotional system creates a narrowly circumscribed workforce with a very provincial outlook. Although many inside the agency resent the notion anyone from outside the agency would dare "take a job away" from an incumbent, regardless of experience or qualifications, they also desire supervisors that are more qualified. While some progressive cities and states are experimenting with lateral entry at various ranks in an effort to enhance professionalism, ${ }^{23}$ general prohibitions against the practice are widespread, especially for officers seeking lateral entry at the supervisory level.

The closed promotional system also stifles initiative and creativity among incumbent supervisors. Knowing they have to "live with these people” for a career's worth of time, many supervisors refrain from offering new proposals to improve performance, lest they be labeled a sycophant by their peers or their subordinates. This way they do just enough to get by without raising their supervisor's ire or irking their subordinates, which usually means satisfying only that work which is given to them, not by self-generating any work. "Don't rock the boat” or “don't make waves” becomes the unifying and dominant attitude as incumbent personnel assume a comfortable albeit stagnant career, where “no one gets hurt." The notion that "no one gets hurt” means not drawing any unwanted attention from supervisors or top administrators thus preserving the status quo. It is also police argot for keeping quite in the face of corruption.

If corruption is a performance issue, then one of the enduring and destructive qualities of the closed promotional system is silencing police officers who witness it. Since police officers must spend their entire careers in a single agency and cannot market their competence elsewhere, the only hope for promotion or advancement is from within 
the agency. It is seems self-evident that rewards like promotional opportunities narrow even further and career aspirations may be halted if an officer reports corrupt activities, particularly if it involves those who are responsible for his or her promotion. Police officers may request a transfer from one assignment or from one geographic location to another with the hope of avoiding the instant problem, but they cannot escape the reach of their peers. This atmosphere provides little if any incentive to report their peers' performance since the officer's future rests entirely in the hands of the people above him or her, who may not care to hear about the problem. Hence, more personal compromises in the interest of self-preservation.

Consequently, not able to leave for "greener pastures" because the industry does not permit such movement and not willing to risk losing their livelihood or their personal safety, officers adopt a sense of “willful blindness” (Mollen Commission, 1994:80), purposely ignoring peer behavior they know is wrong instead of reporting it. This display of comradeship and peer loyalty (Wren, 1985) suggests that some officers place “loyalty over integrity” (O’Malley, 1997:21) and will not expose wrongdoing even if there is hope of bringing it to an end. Indeed, many officers, even those tasked with investigating corruption, believe their reputation, careers and personal safety are jeopardized by the closed system because they cannot seek a better situation in a different police agency. Police officers who do report corruption may be ostracized, threatened, harassed or may become the targets of theft or vandalism to the point where their careers are ended, something few are willing to risk (Christopher Commission, 1991: Goldsmith, 2001-2002; Mollen Commission, 1994). Indeed, whistleblowers may suffer some rather 
severe unintended consequences including questions surrounding their motives and ad hominem attacks directed at their personal identity (Nichols, 1991; Vaughn, 1993). ${ }^{24}$

Opposition to promotion via lateral entry also comes vociferously from within the agency from police administrators and unions, although civil service regulations do prohibit personnel from entering a police agency at the supervisory level. Conservative by nature and skeptical of outsiders, police administrators often suggest loyalty to the organization is at issue insofar as allowing supervisors lateral entry would weaken that particular supervisor's commitment to the agency; those from within the agency have already demonstrated their loyalty and integrity to the agency (Half, 1985). Police administrators prefer to think of their employees as loyal to the organization instead of loyal to their careers. By creating loyalty to the organization, the chief is able to reduce autonomy, so employees think of themselves as members of the organization rather than as skilled professionals whose expertise could be placed on the open market and made available to other interested police departments, should a promotional opportunity arise (Donohue, 1992; Price, 1976).

My experience has been that independence and autonomy threaten top administrators since it weakens their control over the employee, especially if outside promotional opportunities exist (Price, 1976). Top police administrators do not cherish these qualities, notwithstanding their rhetoric claiming they wish they had more of it. They pay great lip service to on-lookers but there is no sense of urgency to cultivate these qualities since they know that independent officers are not dependent on the agency for their livelihood, which necessarily undercuts their ability to control them. 
The process of reducing an officer's independence begins the day the officer enters the police academy. New recruits are stripped of their identity by having to shave the hair off their heads; to stand at attention, silent and answer only when their assigned "number" is called; to clean the toilets; to "keep your mouth shut and listen" (Van Maanen, 1972:278) and to assume a "uniform personality molded by the department” (Goldstein, 1977:260). This hazing ritual establishes their new identity and as part of it, their unquestioned compliance is demanded. In the interest of discipline, their independent thoughts, opinions and meaningful participation in department affairs are pushed aside in deference to conformity with department policies and established authority. This carries over from the police academy into the daily work routine, where conformity with rules and regulations is rewarded and independent action is at least frowned upon or outright punished.

Loyalty to the organization, as the chief suggests, is a ruse for personal loyalty to superior officers in the department, such as the chief or a prominent political figure. The “organization” is a nameless faceless entity, reified by the people in it. Therefore, creating loyalty to the organization, as the chief describes it, essentially means arranging personal loyalties with one or more superior officers, a maxim that is “culturally embedded” in policing (Souryal and McKay, 1996:46). Personal loyalty engenders indebtedness, where public service and commitment to the ideals and values of the profession may be subordinated to the incestuous superior-subordinate relationship. In this relationship, subordinates are often expected to affiliate themselves with a particular political party, where they may "lose faith in their bureaucratic values and adopt political ones” (Hummel, 1994:234). They subordinate themselves with the hope of receiving a 
promotion. This arrangement may force aspiring police leaders to compromise their personal virtues and perhaps their integrity to satisfy the motives of those who wield control over their careers.

Another source of opposition to promotion via lateral movement is from police unions who perceive a loss of power, lost opportunities and lower morale that might result. Union officials are elected to their post through the union's membership. If the membership were able to leave the organization at any given time, the union's collective power would diminish in direct proportion to the percentage of members leaving. This is a fallacious argument put forth by union officials who are frequently seen as obstacles to professionalizing the police (Donohue, 1992; Sherman, 1975).

One notable exception to the practice of career advancement via lateral entry promotion is the top administrator's position (i.e., the chief of police; police commissioner). Frequently, the chief of police is an outsider who applies for a vacant position. While chiefs and civil service commissions typically will not allow lateral entry because they insist that promotions must come from within the agency, the chief executive, who controls the entire agency, can be someone from outside. The very logic incumbent chiefs use to bar police officers and supervisors from moving between agencies for a promotion (i.e., loyalty; integrity; dedication to the agency) suddenly no longer applies to the top position. Indeed, lateral entry for the chief of police is characterized as an important step toward improving police management (Angell and Endell, 1981; Potts, 1980).

The prohibitions against lateral movement complicate the promotional process for the officer and the agency, a problem that has existed for decades. The policing industry 
as a whole has done little to address these barriers and upgrade interagency promotional practices. This relegates both the agency and the officer to a position of inferiority, each unable to capitalize on the other: The agency cannot recruit a qualified person to fill an existing vacancy and an employee cannot leave one agency for another to accept a vacant position. This marginalizes the employee and upward mobility in their chosen career is stunted. They must compete for a limited number of positions in an environment that may be dominated by discretion, where favoritism, personal loyalties, political affiliations and other meaningless obligations pervert the process so someone with a "hook" may be promoted ahead of someone without a hook, even when the other person is more qualified. A direct consequence may be a ritualistic existence where little initiative to improve performance exists.

Internal Affairs Function. The internal affairs function is embedded in the principle of the First Amendment to the U.S. Constitution that grants citizens the right to redress government. Operationally, that right translates into the internal affairs unit of a police department. U.S. courts and have come to regard the internal affairs function as an important means of safeguarding the constitutional rights and civil liberties of citizens as well as an element of police reform (Livingston, 1994) and accountability. The Commission on Accreditation for Law Enforcement Agencies (CALEA) — a voluntary national law enforcement credentialing authority—also recognizes internal affairs as a mandatory standard for police departments pursuing national accreditation status. ${ }^{25}$

In the broadest sense, accountability is an obligation or willingness to accept responsibility and to proffer a statement or explanation of reasons, causes, or motives to account for one's actions (Walker and Katz, 2008). As public employees, police officers 
are obligated to present themselves and answer for their conduct. While it seems straightforward that police departments will investigate claims of wrongdoing among their members to ensure they are held accountable for their actions, the internal affairs function bears a stigma that may be responsible for creating stress in police officers. However, some of the stigma may be misdirected. For example, internal affairs may be a proxy for police officers' true hostility, which is the agency's (i.e., the chief's) operating style. Police officers project their vitriolic comments at internal affairs when being investigated as an expression of disdain for oppressive policies, an arbitrary disciplinary process, and autocratic top management.

I will explore three areas of internal affairs that may negatively influence individual performance: 1) the subculture of police work, 2) the level of support officers receive during an internal investigation and 3) the broad rules and policies upon which internal affairs investigators rely to exact accountability. These three aspects converge to create an accusatorial environment, where police officers may view internal affairs as an extension of an autocratic uncaring management structure that is not designed to ensure accountability. Rather, the intent is to nitpick at the most de minimis infractions that are largely meaningless and which does little to cultivate an atmosphere of overall discipline. ${ }^{26}$

Subculture of Policing. The thought that "all police officers stick together" may not be as factual as widely believed (Paoline, 2004:209). It is my experience that police officers not only assume a defensive posture to resist yielding to external pressure from citizens, they also resist internal demands from police management by adopting the same Us (Police officers) against Them (Management) mentality. Line-level police officers 
throw up the Us against Them corporate veil as a defense mechanism to a perceived uncaring management structure that is willing to sacrifice them for the sake of “politics." 27

Reuss-Ianni (1984) described this notion of a culture within a culture (i.e., management cops vs. street cops), where supervisors are not necessarily aligned in thought or deed with patrol officers. She contends that “...incongruent value systems and variable job expectations are major factors in the alienation of line officers at the patrol level. The absence of a unifying, organization-wide culture may result in organizational stress and exacerbate control and role pressures” (in Meagher, 1986:69). This reflects the dichotomy of management and labor in terms of expectations, values and operating principles. The distinction between police officers who are assigned to an administrative element of the agency (i.e., internal affairs) and a line element (i.e., patrol) is important because there may be a culture clash between "management cops” and "street cops," where street cops allege "their bosses have forgotten about being cops and are more professional managers” (Reuss-Ianni, 1984:3). The sentiment that some bosses “forgot where they came from” may arise from two structural arrangements: Distance and operating principles.

Internal affairs investigators are an element of administration (i.e., management), as such, they manage officer behavior from a distance. They rarely have direct contact with line personnel and the higher an officer ascends through the hierarchy of the organization, the greater the distance between offices (i.e., line and staff). This leaves internal affairs investigators removed from the danger of the job and the intricacies of decision making that occur daily in routine patrol work. The gradual ascension in rank 
requires police officers to replace the skills once honed for patrol work with new ones necessary for management; as responsibilities change due to rank or assignment, the officer must adapt in direct relation to the scope of their new office. Changes in procedural and substantive law, department policy and administrative law continue to rapidly evolve, yet with promotion, these changes mean less to a manager who imposes them than they do to an officer who is bound by them. As management piles on the mandates, some of which may conflict, the patrol officers feel management is not concerned about their welfare or about making their job easier (Alexander et al., 1991:51). This may be aggravated by the differences in normative operating principles held by managers and patrol officers.

As police officers ascend in rank and grow closer to the chief (i.e., the administrative level) and further from their comrades (i.e., operating level), they tend to embrace the “company line,” which favors a more formal (i.e., "by-the-book”) operating principle and shrug off the informal operating principles embraced by patrol officers. When something goes wrong, managers evaluate the officer's behavior according to official department policy instead of the informal operating principles that get police work done on a daily basis. This causes line-level police officers to castigate internal affairs investigators who they see as sitting in an ivory tower, insulated from the rigors of patrol work and a hostile public, who cast judgment upon the "grunts" in the trenches who are fighting crime. This is why police officers believe their superior officers are out of touch with the realities of police work. That the investigator suddenly "forgot" what it was like to use short cuts or "bend the rules" as a way to satisfy demands for performance and efficiency suggests an air of hypocrisy since both the officer and the 
investigator have been in field performing daily police work. It also seems that police officers who suggest their boss "forgot" where they came from is an insinuation the officer under investigation is biased; they are biased in favor of their immediate personal situation because they want the investigator to "have a heart," to show some compassion for tough job and overlook the infraction.

Line-level police officers may regard internal affairs personnel as an extension of top management, particularly as an instrument of the chief, who may have autocratic leadership tendencies. Because the chief typically sets the tone for the agency (Armacost, 2004), he or she may use internal affairs to exact retribution or satisfy a personal vendetta against certain officers without ever getting his or her hands dirty. Thus, the subculture, in general, casts internal affairs as a group of unscrupulous and ruthless “company men" whose first loyalty is to the department (i.e., the chief) rather than to fellow workers and who are motivated by personal gain (e.g., hope of a promotion) (Enter, 1986), not agency integrity.

Compounding this issue is that by virtue of their assignment, internal affairs investigators must breech the solidarity that binds the subculture. Breeching solidarity means breaking the "code of silence” and potentially revealing operating secrets, forcing police officers to testify against fellow police officers and perhaps having the internal affairs investigator testify against fellow officers in a criminal trial or administrative hearing. The irony is that most police officers will claim they do not wish to work alongside unethical or corrupt police officers. Yet, when internal affairs investigators set out to uncover misconduct and ask patrol officers’ for assistance, they are met with claims of ignorance about the incident (“I didn't see anything”). 
The paradox facing internal affairs investigators is that all of the investigations they undertake are ostensibly important, however, those under investigation rarely, if ever, would characterize their policy violation as one damaging to the department's image or reputation. In their zeal to ferret out misconduct and hold police officers accountable, patrol officers perceive internal affairs investigators as "enjoying” their work, thus intensifying the animosity between them. Although this image may not be accurate, it is, nonetheless embedded in the subculture (Ruess-Ianni, 1984).

Lack of Administrative Support. Defining "support” and how much to grant an officer under internal investigation varies based on who is making the determination (e.g., the police chief, the mayor, a community leader, fellow police officers, union leaders). Supporting an officer is not necessarily "blind loyalty;" however, not doing so may be perceived by line officers as managerial abandonment since "cops expect their agencies to stand by them and support them against hostile outsiders” (Kirschman, 1998:129). Granting employees the benefit of the doubt and keeping lines of communication open during an internal investigation may be seen as a testament to the reciprocal employer-employee relationship that officers expect will envelope the workforce. Alexander et al. (1993:162) noted that "meticulous feedback" about the progress of internal investigations is important toward minimizing stress, since "Unfair or inconsiderate treatment of those being investigated may make matters worse by convincing officers of the punitive attitude of the service and the inadvisability of admitting discipline offenses.” Support for the organization may fade if police officers believe the administration has acted unfairly during an internal investigation or when dispensing punishment. Police officers may feel the department will not give them a fair 
chance to prevail against the complaint. This may be rooted in the structural differences between investigating criminal conduct and investigating an internal complaint; criminal conduct is investigated as part of the adversarial system, whereas internal (Administrative) investigations are part of the inquisitorial system (Wechter, 2004).

The agency’s administrators (i.e., upper management, mid-level management and supervisors) and to some degree the parent government's elected leaders (i.e., mayor, city manager, council representatives) serve a paternalistic role, part of which includes counseling or reassuring officers in the face of negative influences or traumatic events. ${ }^{28}$ When officers run afoul during a citizen encounter, they expect to be able to turn inward for support. Officers attach considerable importance to the knowledge and wisdom of their superior officers. This may derive from the element of co-dependence inherent in police work, where officers rely heavily on each other for safety and to pass along the cues, customs and traditions of their vocation. When officers are confronted with an internal investigation, they look to their superior officers for guidance, emotional and moral support. When officers perceive that support to be less than desired, a sense of betrayal and desertion may arise, perpetuating the "Us" (Line officers) against "Them" (Management) dichotomy.

Broad Rules and the Accountability Structure. Police departments are oriented toward control, both externally and internally. As a fundamental tenet of their social and political mandate, the public expects the police will control human behavior that threatens others’ physical safety or disrupts neighborhood tranquility (External mandate). The internal control orientation is aimed primarily at officer discretion (Chemerinsky, 2000-2001:565). Agency policies and rules typically emanate as a reaction to some 
unanticipated officer conduct or some previous bad decision. As such, what tends to happen is instead of articulating what level of performance is expected, the agency promulgates broad general orders for what is not expected. Stated differently, policies and rules tend to be framed in the negative (Auten, 1988:3; Wilson, 1968) thus making them difficult to measure in terms of performance (Cordner, 1989:19).

Whether an officer's conduct was malicious, accidental or seen as an imaginative way resolve a complex social problem, various courts have held individual police officers, police agencies or their parent government accountable for the actions of their employees (Canton v. Harris, 1989; Davis v. Mason County, 1981; Hafer v. Melo, 1991; Monell v. New York City Department of Social Services, 1978). Since police departments are oriented toward operational control, they promulgate rules, policies and regulations to govern minute details of a police officer's every-day behavior. However, in the quest for control and uniformity in operations, the tendency to over-regulate officer conduct has crept into the increasingly complex world of policing.

Excessive regulation has encroached on officer discretion, which is necessary for efficient policing (Adams, 1990). Agency control and individual discretion are fundamentally at odds_-as control increases, discretion decreases. While written directives are essential to channel discretion, police policies have become redundant and oppressive to the degree that they often limit creative solutions to complex situations and may insulate incompetence. Much of the language in policies is permissive, thus leaving decisions to the best judgment of the officer. The friction results when an officer exercises their discretion and no performance standard has been enunciated, then the 
officer is held accountable, post hoc, for something internal affairs suddenly deems inappropriate.

A separate but related aggravating factor of the broad rules and policies that complicates the internal affairs function is the aspect of strict liability that encompasses department rules. Violating a department rule or policy is a strict liability offense that does not account for an officer's state of mind when they acted. ${ }^{29}$ The agency's rules and policies are akin to society's regulatory laws that do not require the prosecution to prove intent. Unlike most provisions of the criminal law, which necessitate a guilty mind (Mens rea) before culpability may attach, internal affairs need only prove by a preponderance of the evidence that the officer acted in a manner proscribed by the rule. This lower standard of proof reduces the burden on the department to substantiate an officer’s guilt. This may be why administrative investigations are often perceived as more onerous and intrusive than criminal investigations because they are not subject to the same constitutional guarantees and rules of evidence as a criminal trial. Therefore, the outcome of disciplinary proceedings (e.g., reprimand, suspension or termination) is easier to reach since the officer has fewer protections.

Whether the officer acted intentionally, recklessly, or negligently is not at issue. The doctrine of strict liability essentially removes a police officer's defense of ignorance $^{30}$ (e.g., the officer was unaware the rule was promulgated) or mistake of fact (e.g., the officer was not trained in the tenets of the rule). This leaves the officer vulnerable to a wide variety of infractions, some of which may occur incident to executing their duty (e.g., damaging a police car during a motor vehicle pursuit; engaging 
in a foot pursuit after an armed felon without their uniform hat; directing profane language at a suspect to drop their gun during an encounter).

My experience is there are hidden dangers in this amalgam of policies, procedures and rules, some of which are vague, others specific, some that grant authority, others that restrict it. There seems to be a "rule for everything" that constrains behavior in such a way the officers defy them in an attempt to relieve some of the pressure from an overbearing administration (Cordner, 1989:17). The internal affairs function is inextricably linked to the department's body of policies, rules and procedures since they are the mechanism for investigators to exact accountability. The outmoded and unreasonable nature of some rules and policies may be a source of stress and lower performance since they fail to articulate employee expectations and encroach on personal autonomy. As such, many officers view the policy manual as a Draconian instrument of autocratic managers who keep it within reach merely for the day when they need to punish an officer (Manning, 1977) and not as an accepted guide for performance.

Constant stern imposition of agency rules via internal affairs connotes control, conformity and obedience. In police organizations, obedience is characterized by submission to authority without question; questioning an order is tantamount to disobedience, an infraction subject to disciplinary action. As the demand for, and enforcement of, compliance rises, creativity and initiative (i.e., performance) decrease, so much so that police officers adopt an "I do nothing until I am told" attitude, and even then, they do only as much as necessary to get by without raising their supervisor's ire. Therefore, the less the officer does, the less negative attention they attract. Excessive compliance does little to ignite the employee's desire for the challenge of higher 
achievement, to empower them with the autonomy to act, or to engender feelings of affiliation and esteem for their efforts, all essential aspects of Maslow's (1943) "hierarchy of needs” theory. Excessive compliance also creates hostility by setting managers and supervisors against each other and against the line officers for even the most trivial and inconsequential matters. Working under these conditions can sap the energy, enthusiasm and initiative that are critical to performance in a police department. By the time daily operating conditions reach this point, the agency is stagnant and is no longer considered healthy (Cordner, 1989; Kaufman, 1973).

When an internal affairs investigator critiques an officer's action and notices that the behavior does not fit within an established rule or policy, they may resort to a “catchall” rule that could potentially cover any conduct that someone else simply "felt" was not appropriate. Some catchall rules govern obligations to duty such as "Neglect of Duty," and “Bound by Duty," others govern various aspects of behavior such as “Conduct," "Conduct Unbecoming an Officer," and “Conduct in Public or Private."31 The investigator then determines the officer did not exercise "good judgment," sustains the allegation and recommends discipline. Internal affairs plays this game of "gotcha" to signal they have caught or defeated the officer in a perverse and trifling game of accountability that reinforces the authoritarian quasi-military structure of the agency.

In the end, the agency sanctions the officer and the officer never fully appreciates what they did wrong, how to correct their behavior or how to proceed in the future, for no one can explain to them how to do so. The officer treads ever so slightly during their next citizen encounter for fear of being disciplined (Unnecessarily) again. Officers who witness their friends and colleagues subjected to the same slipshod process gradually 
grow detached socially and emotionally from their involvement with the agency. They may resort to handling complex problems in a mechanical manner that lacks interest or concern for the wishes or feelings of the complainant or victim, the sort of aloof and distant police-community relationship that served as the undercurrent for the 1992 Los Angeles riots (Webster and Williams, 1992:29-34).

Ultimately, the officer may avoid situations where decisions are required — to arrest, to stop, to mediate, to intervene_-or perhaps avoid responding to the next call altogether. As a result, internal affairs may contribute to the problem of stress and poor performance by subjecting police officers to “Victorian”-era infractions (Giannetti, 2003:48) codified in volumes of regulations that are incongruent with the social complexities of contemporary society and the modern structure of police accountability.

Performance Rating System. The history of evaluating employee performance dates to at least third-century China (Patten, 1977). Performance rating systems for individual police officers or police agencies have been used in the United States since at least 1933 (Unites States Conference of Mayors, 1933) and began gaining acceptance in the 1960s. Since their inception, they have been subject to various criticisms because of their shortcomings to measure actual performance (Best, 1957; Dallas Police Department, 1972; Whisler, 1955). As their use became more widespread, a number of court challenges to their validity emerged resulting in a body of labor relations case law (Basnight and Wolkinson, 1977; Field and Holly, 1982) recommending police agencies use behaviorally anchored systems (Landy, 1977), thus making them more reliable and valid. 
Rating employee performance is an especially important aspect of police administration since legitimacy and organizational effectiveness are tied to it directly. One approach to measuring organizational effectiveness is to measure the individual performance of members of the agency (Cummings and Schwab, 1973), the sum of which is an indication of collective effectiveness (Kanter and Brinkerhoff, 1981:339). One major concern of this approach is that personnel ratings are "inherently subjective" (Iannone, 1987:254), technical in detail and prone to personal interpretation instead of being grounded in objective criteria. The subjective nature of performance ratings may engender distrust among employees in a meritocracy because the basis for judgment may be grounded in irrelevant factors such as personal characteristics (Race, ethnic heritage or sex), nepotism, or political affiliation.

The highly idiosyncratic nature of performance ratings is what causes stress and frustration among officers because there is seldom agreement about what performance standards they should meet, how the standards were derived, and how the standards should be measured (Mastrofski and Wadman, 1991). One study (Walsh, 1990:101) found that $87 \%$ of sergeants responsible for conducting performance ratings did not find any value in the ratings. The sergeants' recurring complaints were:

1. "The performance criteria are all subjective.

2. The system lacks management control. This creates rater inconsistency and favoritism.

3. Supervisors have very little input into the process but are its major users

4. In those department that have quotas, most officers meet the required amount and do little more.

5. The forms are filed and mean nothing.

6. Management is not concerned about performance, just making sure that things run smoothly.

7. Supervisor's performance assessments are changed by administrators who have not observed the officer perform on a daily basis." 
Moreover, police departments rarely use performance ratings as the basis for promotions or pay grade determinations (For an exception see Holden, 1986) and if they do, the ratings are criticized for being biased from the outset because the rating categories are ill conceived or because the rater allowed his or her personal biases to influence the process. Even when supervisors are properly trained in their application, there may be a tendency for error to creep into the rating process.

There are several types of rating errors including leniency, personal bias, central tendency, halo effect, related or associated traits, overweighting and subjectivity (Iannone, 1987; Kellog, 1975; Thorndyke, 1920). The error of "leniency" is perhaps the most common in performance ratings (Schroeder, Lombardo and Strollo, 1995:161). This error results from a supervisor’s tendency to "overrate" his or her subordinates, which has a negative effect on morale particularly for competent, diligent officers. When a supervisor rates an underperforming officer just as well as a truly high-performing officer, the high-performing officer may question the supervisor's veracity and motives. Then, the high-performing officer may begin to ponder whether his or her hard work is meaningful and appreciated if all that happens is they are rated equally with their malingering peers. This perception is rooted in equity theory (Adams, 1965), which states that when employees perceive their investment in the agency (e.g., hard work, low absenteeism, conformance with rules and goals) as disproportional to the rewards they receive (e.g., a fair and accurate performance rating, career decisions based on performance), morale may decline, which concurrently lowers performance.

The source of rating problems may be rooted in friendships, personal appeal and popularity between supervisors and subordinates. Supervisors want to be liked by their 
subordinates and maintain amicable relations (Iannone, 1987). They often "go along to get along” instead of leading by example, providing fair and equitable ratings and instilling values that promote accountability. When supervisors shirk their responsibility for truthful and factual performance ratings, they are concurrently abdicating their obligation to identify problem/corruption-prone personnel and they are avoiding unpleasant, but essential, face-to-face confrontations about performance (Kellog, 1975:14).

When the agency itself does not take seriously the performance rating system because the ratings are not linked to performance-based decisions (i.e., transfer to a preferred assignment; promotion; pay increase), neither do the personnel responsible for conducting the ratings nor the personnel being rated. The workforce sees the ratings as perfunctory, replete with boilerplate language that does little to promote performance or integrity. The rater sees them as "one more thing” heaped upon an already full plate, the only goal of which is to comply with an agency directive that the rating be completed by a certain date. Indeed, in this environment even the most corrupt officers may receive a “meets standards” rating, given the supervisor’s proclivity for leniency and disinclination to correct poor performance (Mollen Commission, 1994:81). And, to compound matters, when a supervisor does act to enforce policy and identifies training deficiencies via performance ratings, they may not receive support from management because they said or did something to upset someone, especially if they took initiative and became involved in something that is outside their realm of authority. This makes the error of leniency in ratings the path of least resistance for supervisors. Managerial neglect that derives from the error of leniency such as that described by the Mollen Commission (1994) may form 
the basis for negligence lawsuits in training, supervision and employee retention (Callahan, 1989; Spell v. McDaniel, 1981), which may lend credibility to the officers' assertion that performance ratings are perfunctory, haphazard and largely meaningless. Summary

Organizational life for police officers is fraught stressors that compete for priority and may collide. When new police officers discover the occupation they have chosen differs drastically from their conception of that role, conflict arises thereby causing stress. Most officers manage to muddle through their daily work albeit with less enthusiasm because they are unsure of what is required and clarification from an administrator is not easy to come by. The discrepancies are often set inside a fast-paced work environment where time is precious and productivity is at a premium. What tends to develop is role overload, whether it be too much work or work that is too difficult, in an environment that is typically filled with uncertainty and mixed messages about what to do and how to do it. These frustrations are compounded by limited opportunity for career advancement in a promotional system that is often fraught with bias, favoritism and unfettered discretion juxtaposed with a perfunctory performance rating system.

Reaching decisions during internal affairs investigations is subjective and fraught with interpretation problems because specific aspects of rules and policies are undefined and there may be disagreement about the goals of discipline. When the agency cannot find a specific rule that was violated, it uses catchall rules to sanction what it determines (On this particular occasion) to be inappropriate behavior. When the rules are vague and the goals are undefined, inevitably there will be inconsistency in outcomes, which is why previous research recommends disciplinary procedures be precisely articulated (Carter, 
1994; Iannone, 1994). Meanwhile, the agency has done little to explain what conduct is permissible, and the ends of discipline have not been achieved.

\section{Perception and Cognition: The Appraisal Process}

Although police employees are exposed to the antecedents of stress and stressors in organizational life on a daily basis, before an individual can "feel" stressed, they must recognize the event as a threat or a burden and appraise the potential consequences (Chan, 1977; Heinrich and Speilberger, 1982; Laux and Vossel, 1982). Stated differently, before stress can affect someone he or she must first get a sense of what is occurring. Appraisal, therefore, refers to the act of estimating or judging the nature or value of something as perceived by the individual. A person undergoes this cognitive process by examining their environment and gaining an understanding of the potential consequences, positive or negative. The appraisal process is inherently subjective and seeks to understand why two people can encounter the same situation yet react differently, even to seemingly objective circumstances (Smith and Lazarus, 1990). Holroyd and Lazarus (1982:22) noted:

"Even in extreme circumstances the consequences of stress cannot be understood merely in terms of the stressful event...Stressful circumstances do not take their toll from a passive individual, as is implicitly assumed by the stimulus definitions of stress, but from an individual who is imbuing stressful circumstances with personal meaning and struggling to control and master those circumstances.”

This suggests that an individual's interpretation of the situation and not the situation itself is what may cause particular emotions to occur (Roseman, 1984). This process is especially important because interpretation is the mechanism that permits a person to adapt to their circumstances and shape the eventual disposition, which ultimately has implications for performance and well-being (Lazarus and Folkman, 1984; 
Roskies and Lazarus, 1980). For example, when a person enters a situation they appraise it as good, bad or indifferent ("How much trouble does this present for me"?) and how likely the consequences are to impact their state of well-being (Either negatively or positively). The interpretation takes place within the officer's realm of training, education and general life experience, set within the boundaries of agency operating policy. How well someone copes with the situation represents the dynamic interaction between the person and their environment, which is iterative and subject to change as the situation changes; as new information becomes available, reassessment occurs and different strategies are applied to meet the new demand (Folkman and Lazarus, 1980, 1985).

Coping style may take different forms, however two common strategies are problem-focused and emotion-focused coping. In problem-focused strategies, the person actively deals with the situation they are confronting (e.g., solve the problem or seek assistance), whereas in emotion-focused strategies, the person deals with the emotional aftermath the situation produces (e.g., withdrawal). Various coping instruments suggest people with resilient personalities are better able to directly confront stressful situations. Carver, Scheier, and Weintraub (1989) developed the Coping Orientation to Problems Experienced (COPE) scale, which shows hat strategies involving active coping and planning are positively related to optimism, self-esteem, hardiness (Resilience) ${ }^{32}$ and Type A personality.

When an individual confronts a stressful situation, they undergo a two-stage risk assessment. During the first part, they assess the extent of the risk in the primary appraisal stage. During primary appraisal, individuals make a determination about what 
they can do to mediate the situation by discerning whether: 1) the situation affects their well-being and to what extent, such as how harmful the consequences may be, 2) the situation is consistent with their goals, 3) someone is responsible for causing the situation, 4) they can influence the outcome of the situation, 5) they can handle, that is cope, with the situation emotionally; and 6) they can psychologically shape the situation to be more consistent with their future goals (i.e., what degree of control can they exercise over the situation).

Once the individual makes a determination, they select a viable alternative that minimizes the risk, this is termed secondary appraisal. At least to some degree, research suggests that an individual's social position as well as personality traits may influence whether they appraise a situation as harmful or something with which they can cope. Pearlin (1989:249) notes “...the threat that people experience from the circumstances they face depends to some degree on the values they hold - that is, what they define as important, desired or to be cherished,” such as status enhancement or upward mobility. My experience has been that one police officer may interpret the orders from his or her superior as risky, vague or unconstitutional, thus, if they proceed, they do so with great caution because the consequences may be severe. A different officer interprets the same order as an interesting challenge to their own resourcefulness and sees a potentially career-enriching opportunity, thus, they charge headlong into the situation with enthusiasm and vigor, shrugging off the potential consequences as the cost of doing business. The latter reaction seems indicative of a healthy personality, where the individual perceives a challenge, interprets the challenge positively, then confronts the challenge directly. These individuals typically have higher coping scores on 
conscientiousness hardiness, internal locus of control and self-esteem and may be less likely to experience stress. By contrast, individuals who react in the former manner may have higher scores on anxiety and neuroticism and may hesitate or view the challenge as illusory and unattainable or blame themselves for not getting the job done. These individuals are more likely to score low on conscientiousness and deliver poor performance (Rothman, Meiring, Van der Walt, and Barrick, 2002; Scheier, Carver and Bridges, 1994; Williams, Wiebe and Smith, 1992).

Since police organizations are complex bureaucracies that are generally inflexible, a police officer's choice of available alternatives (Secondary appraisal) is limited when resolving a problem or completing delegated tasks. Rather, most decisions must be carried out in accordance with policy, rule or regulation. Moreover, if an order is issued by a supervisor to a police officer, then it must be carried out without question usually within some narrow parameters, lest the officer risk insubordination or other disciplinary action. There is no room for debate or discussion regarding direct orders, so secondary appraisal is minimized leaving the officer with little choice but to forge ahead, perhaps against their will, and with fewer options to resolve the situation. When an officer enters a situation with little or no experience, guidance or training, they are left to appraise the situation within a limited frame of reference and few outlets for advice. This restricted ability in the face of an unfamiliar situation may leave police officers prone to stress.

\section{Summary}

Perhaps the most important facet of perception and recognition is the fact that it is inherently subjective. Before someone succumbs to the effects of stress, they must interpret the situation along with environmental cues as a problem that poses 
consequences they may not be able to resolve in their favor. This process is different for each person and is predicated on knowledge, skills and abilities (KSA's) that are forged through life experience and formal training. Helping to shape one's perception and recognition are properties that reside within the person and properties of the situation itself that can mediate the effects stress. Properties of the person are primarily aspects of personality, such as type of personality, self-esteem and locus of control that can shape the eventual outcome. Properties of the situation include relations with and support from co-workers and supervisors.

\section{Properties of the Person as Stress Mediators}

\section{Type A and B Personalities}

Researchers have long recognized how individual attributes such as personality, self-esteem and locus of control may act as stress mediators. How people perceive and respond to stress is individualistic; two people can be exposed to the same event and have different appraisals and reactions (Smith and Lazarus, 1990). Researchers attribute this partly to the individual's personality, particularly extraversion and conscientiousness (Vollrath, Torgersen, and Alnaes, 1995).

Type A personalities have dispositions that intensify the effects of organizational stressors due to their insatiable desire for achievement and competitiveness (e.g., hardcharging attitude, competitive, time-sensitive and hostile-irritable). These people rarely "sit still.” They are characterized as overly ambitious to the degree that they are constantly setting new and higher personal goals; when they cannot compete against someone else, they compete against themselves for higher goal attainment. Part of goal attainment is the speed with which success comes. Early success in childhood coupled 
with quickly accomplishing new tasks later in adulthood is a function of personal performance expectations, which motivates them and may improve self-esteem. Part of the performance rubric is multitasking. Instead of concentrating on a single task, they delve superficially into many tasks—-the principle of intensiveness versus extensiveness. The thoughts, emotions and behaviors of Type A personalities are associated with increased hormone production, specifically norepinephrine, epinephrine, cortisol, testosterone and prolactin (Treichel, 1982:279). Coursing throughout the bloodstream, these chemicals keep the body in a constant state of heightened alert, ready to meet new challenges.

Intuitively, it seems to make sense that Type A personalities may be well suited for police since the work environment can be challenging, at times. However, the research is mixed on whether people with Type A personalitiesy are universally better performers compared to Type B personalities. Type B personalities concern themselves less with "finishing first," or time pressures. Instead, they enjoy the course of life and are more affable and relaxed (Stephens, 1994). Wright (1988:13) concluded that Type A personalities will suffer the effects of stress (e.g., coronary heart disease) more so than Type B personalities and "What is needed are ways of training ourselves and others to maintain diligence with pacing — that is, to run the race of life like a marathon and not a series of 100-yard dashes.” In an industrial setting of 325 Canadian managers and linelevel employees, Jamal (1985) found Type B personalities outperformed Type A in measures of quality but not quantity. Matteson, Ivancevich and Smith (1984) found no statistically significant differences between Type A and Type B personalities in the quantity of sales performance. Similarly, Lee and Gillen (1986) did not find any 
statistically significant differences between quantity or quality in sales performance. Other research suggests the degree of task difficulty may be the determinant for performance, where Type A personalities outperformed Type B's on difficult tasks but not on less complex tasks (Gastorf, Suls and Sanders, 1980).

Self-esteem

As an element of personality, self-esteem has been described as one of the most important and influential aspects of the self-concept (Rosenberg, 1976, 1979). Cast and Burke (2002:1042) define self-esteem as “... an individual’s overall positive evaluation of the self” (Citing Gecas, 1982; Rosenberg, 1990). They note that it is primarily composed of two dimensions, competence and worth, where competence is defined as the "degree to which people see themselves as capable and efficacious" and worth is defined as the “degree to which individuals feel they are persons of value.” Research suggests the predominant belief in how self-esteem is formed is from direct social exposure to interpersonal processes (Rosenberg, 1990). Other research suggests that individuals form conclusions about themselves by examining their personal performance and attainments, compared to others who are similarly situated (Rosenberg, 1990). Self-esteem is typically thought of as an enduring personality trait, which can be increased or decreased based on group identify verification.

Identity verification is a self-assessment process individuals undergo by examining the meanings of situations, then matching those meanings with self-identities. “An identity is a set of meanings that represent the understandings, feelings and expectations that are supplied to the self as an occupant of a social position” (Cast and Burke, 2002:1043, citing Burke and Tulley, 1977 and Stets and Burke, 2000). Self- 
esteem is believed to increase when the meanings between the situation and self-identities are congruent because there is affirmation of the self. Conversely, when identity is not verified, the individual may be left feeling unaccepted by the group, consequently leaving them alienated (Cast and Burke, 2002). When an individual forms their role identity (i.e., as a police officer) the result is to match meanings of the situation to their conception and expectations of the role. The meanings are derived from specific actions that mirror what the person occupying the role believes the role to be. For example, a police officer who believes that in his or her role as a "crime fighter" they should dedicate $90 \%$ of their activities to law enforcement, then they will engage in behaviors that reflect that role (e.g., effecting arrests; stopping pedestrians; stopping motor vehicles; issuing traffic summonses; conducting searches). By behaving in ways that support their beliefs, they create organizational arrangements that leave other police officers responsible for the remainder of the work that needs to be done, which they believe does not constitute law enforcement (e.g., attending community meetings; conducting service-related activities; engaging in community policing activities; conducting directed citizen contacts). When identity is relevant to the role, in relation to others in a group, then the roles are complimentary. When they diverge, the roles are incompatible and may result in psychosocial distress (i.e., anger, depression or anxiety) (Cast and Burke, 2002).

In a police organization, an officer's self-esteem may be increased or decreased according to the feedback they receive from their supervisors, which is closely associated with self-perception theory (Bem, 1967). Self-perception theory suggests that, to the extent internal cues may be weak or ambiguous, people infer beliefs or feeling about themselves according their behavior in the context in which they occur. A police officer, 
who, as part of his or her identity, considers him or herself a responsible and hard working employee who prides him or herself on a low absenteeism, will strive to miss as little work as possible. If the officer receives feedback from a supervisor that is positive, then they will perceive their behavior as valued by the organization, thus increasing their self-esteem. If, on the other hand, the supervisor concludes the officer's attendance record is substandard and the officer is unreliable, and the supervisor makes it known to the officer, then the officer may feel dejected and unappreciated, consequently reducing his or her self-esteem.

This implies that self-esteem may be linked to decrements in performance, insofar as performance is reflected in the police officer's initiative. If a police officer's selfesteem is lowered because of perceived stigma associated with police work, the public or the administration does not support them, or that the work they do is not appreciated by society, then individual performance may suffer. This may be exacerbated by the style of policing adopted by the agency_legalistic, watchman or service-(Wilson, 1968), particularly if the police officer has one conception of his or her role and the organization dictates something different. The style of policing adopted by the agency will dictate, to a degree, the frequency and type of activities the officer will pursue (i.e., heavy emphasis on arrests and traffic citations; heavy emphasis on service-related tasks).

\section{Locus of Control}

Another element of personality that may act as a stress mediator is locus of control. Research suggests when people feel their behavior is constrained creating unpredictability or a lack of control over circumstances, there may be a tendency for stress to increase (Coman and Evans, 1991; Duckworth, 1987). Stinchcombe (2004:262) 
noted this is precisely why many people are afraid of flying despite the fact that flying is a safer mode of transportation than driving: They have no control. The locus of control theory differentiates between individuals who attribute situational outcomes to things within their control or outside their control. Lack of control produces adverse work experiences from which negative physiological and psychological consequences result (e.g., strain), a link that is well established in the occupational stress literature (Beeher, 1995; Beehr and Newman, 1978; Cooper, 1998; French, Caplan and Harrison, 1982; Hart and Cooper, 2001). Adverse experiences include events or situations in organizational life that bring unpleasant stimuli to the person being exposed and are believed to contribute to a decline in performance, such as increased absenteeism through sickness, stress-related disability claims, early retirement, citizen complaints, and accidents (Baratta, 1998; Bostrom, 2003; Cascio, 1977; Daley, 1978; Heyer, 1998; Wolfskill, 1989).

Whether someone appraises a situation within or outside their control may drive their level of stress and performance. Those who attribute situations to being within their control are known as internals. Internals have a proclivity to meet challenges with a great deal of energy and enthusiasm and will adjust their approach to the circumstances to ensure a favorable outcome. When they achieve success, they will raise their personal expectations for the next challenge and only become anxious when they feel they have no control over their situation. Conversely, individuals who feel they lack control over their situation and that everything is preordained are known as externals. Externals have a deterministic view and attribute situational outcomes to circumstances beyond their control. They typically will not strive to alter the course of events when circumstances 
become challenging, for they believe the effort is futile: What will happen has already been determined (Predestination). In this sense, externals simply endure what they are facing rather than act. Because externals locate control outside themselves, they feel no sense of control over their fate and may become more cynical (Neiderhoffer, 1967), thus they may be more prone to stress, depression and job dissatisfaction (Lester et al., 1982). Summary

Individual personality traits may act to mediate stress. Whether a person has a competitive, hard-charging attitude, or a relaxed affable attitude may predispose them to the effects of stress, which consequently reduces performance. An enduring personality trait that affects personal identity, which in turn mediates stress, is self-esteem. A person's self-esteem can increase or decrease based on the relationship with and feedback from the organization. If the organization communicates to the employee that they are a valued asset, then the likelihood that performance will increase is higher. However, if the employee receives negative feedback that affects how their role in the organization is perceived, then performance may decrease. Personality and self-esteem often combine with how much control over a situation an individual can exercise. When an individual feels they are able to direct or alter the outcome of a situation, then they are less likely to experience a decrease in performance due to stress. While properties of the person can influence performance, so too can properties of the situation faced by an individual.

\section{Properties of the Situation as Stress Mediators}

Beyond individual characteristics that can mediate the effects of stressors, the situation itself facing a police officer has properties that can act as a buffer for organizationally created stress. The primary variable thought to act as a buffer is social 
support from supervisors and co-workers. Social support may reduce certain indices of emotional and physical well-being, such as anxiety, depression and irritability, but does not alleviate "boredom or job satisfaction” (Muchinsky, 1997:311). In a test of the “social support model” of stress, Cullen et al. (1985) found a significant inverse relationship between the impact of work stressors and supervisory support. Previous research suggests the police have historically been suspicious of the extent of administrative support given to them by upper-level management: Corbett (1979:451) found that “...police perceive themselves as a minority within an unsupportive environment;" Skolnick (1966) found that, as an occupational group, the police as generally suspicious; and Tift (1974) found that police officers are distrustful of police bureaucracy. Whether actual or perceived, feelings of antagonism, estrangement and alienation between supervisors and police officers may carry serious substantive implications including adversarial feelings in police unions (Juris and Feuille, 1973), officer conduct (Hahn, 1974) and police-community cooperation (Cromwell and Keefer, 1973; Fink, 1974), all of which have implications for performance.

\section{Supervisor Social Support (Administration and Supervision)}

Some experts believe that first-line supervision is the primary determinant for a police department's success or failure, more so than any other level of supervision or management in the department (Schroeder, Lombardo and Strollo, 1995). This places first-line police supervisors in an unenviable and conflicted position: They are expected to represent management's interests to the line officers (e.g., conformance with and execution of policy) and to represent the line officer's interests to management (e.g., equitability and compliance with the labor agreement, if one exists) (Iannone, 1987; 
Trojanowicz, 1980). Failures of first-line supervisors may be viewed as the source of larger systemic organizational problems. Supervisors act as delegates of the organization who are responsible for controlling and directing subordinates' activities. Favorable or unfavorable impressions of supervisors by their subordinates reflect the organization's level of support (Eisenberger, Huntington, Hutchinson, and Sowa, 1986; Rhoades and Eisenberger, 2002). Research suggests that perceived organizational support (POS) influences performance when the agency's policies and decisions indicate concern for the employee as a valuable and productive member of the organization. Strong employeesupervisor relations have been positively related to POS (Wayne, Shore and Linden, 1997).

If we accept the organization as a credible source of stress, then the implications of supervisor social support take on added importance. In the traditional quasi-military organization, the chief tends to adopt a management style that is non-supportive and is likely to contribute to poor morale and job dissatisfaction (Pursley, 1974). Environmental-level variables may contribute to the perception of a lack of supervisory and administrative support. In particular, the agency's management style tends to exert influence over negative feelings; the more rigid the management style (e.g., autocratic), the more likely officers feel suspicious of supervisors and administrators (Talarico and Swanson, 1983). The suggested method for achieving harmony in this conflicted environment is to remain objective; objectivity is an essential ingredient for a harmonious and cooperative work environment, but is degraded when supervisors play favorites (Schroeder, Lombardo and Strollo, 1995). Police officers are particularly sensitive to objectivity, especially when they sense bias, favoritism or preferential treatment in 
decisions. As such, favoritism deserves further explanation of just how it affects individual officers and their performance.

Favoritism as a Lack of Supervisor Social Support. Favoritism has been cited by scholars as an organizational stressor (Klockars et al., 2006: Chapter 10; Kroes et al., 1974) and by investigative commissions as a corrosive management practice that leads to corruption (Mollen Commission, 1994; Philadelphia Police Study Task Force, 1987). Favoritism may arise from the personal relationships and alliances that gradually arise in organizational life between superior officers and subordinates because of the viewpoints they share; the literature suggests that like-minded individual tend to group together (Kanter, 1977; Senger, 1971:416). When an organization makes personnel decisions in this environment, they tend to evoke tension and criticism among the workforce particularly when the decisions involve extraneous factors such as age, race, gender or kinship. Although favoritism surfaces in many areas of police life (e.g., coveted training, requests for transfer, promotion, performance ratings), one aspect where it may have particularly damaging effects is during the disciplinary process (Hickman, Piquero and Greene, 2000), when supervisors render a sanction with bias based on circumstances other than the facts of the matter.

Two well-publicized investigative commissions, one following a corruption probe in the Los Angeles Police Department (LAPD) (Rampart Independent Review Panel, 2000) and one following a similar probe in the New York City Police Department (NYPD) (Mollen Commission, 1994) drew similar conclusions about favoritism in the disciplinary process and its corrosive effects. The Commissions' findings are consistent with an earlier study, which revealed numerous factors that might account for differential 
treatment during the disciplinary process, which cited “...special interests and politics... ${ }^{33}$ (Melnicoe and Menning, 1978:193) as extraneous factors, unrelated to the merits of the allegation that upset officers.

In Los Angeles, the Rampart IRP concluded the most contentious defect in the disciplinary system, from the employees' perspective, was the Department's failure to confine and structure discretion—an essential ingredient of favoritism—within a matrix of sentencing/punishment options for personnel whose allegations of wrongdoing are sustained. ${ }^{34}$ The Commission stated there is an “....absence of structured discretion. Some aspects of its disciplinary system leave the Department no ability to respond to varying circumstances; other aspects give the Department virtually unfettered flexibility. What the system consistently lacks, and what it critically needs, is room for the sensible exercise of discretion within limits imposed by formal guidelines” (Rampart IRP, 2000:9). Kraus (2007) observed this is a common problem across the policing industry and few departments are willing to self-impose sentencing standards that limit upper management's unfettered discretion, which would reduce, if not eliminate altogether, favoritism and disparity in punishment. ${ }^{35}$

Disparate treatment and favoritism in the LAPD resulted from a lack of formal written criteria for dispensing administrative sanctions when the department sustained disciplinary charges. As a result, personnel frequently complained that imposing discipline was arbitrary, inconsistent and applied unfairly, which led to a “...widely perceived double standard: Staff and command officers were almost universally thought to receive more lenient sanctions than rank and file” (RIRP, 2001:97). Top executives of the LAPD confirmed that when dispensing sanctions the Department would “...'come 
down hard' on an officer with little time in service, but officers who have been with the LAPD for many years would 'catch a break'” (RIRP, 2001:97).

Applying one disciplinary standard for junior officers and another for senior officers, or differentiating between rank and file police officers and command-rank officers as to who receives leniency, may set the tone for widespread cynicism and defiance toward department policy. This may result in a concurrent downturn in morale, where police officers may lose trust and confidence in their supervisors eventually leading to lower performance. This sort of differential treatment implies the merits of the case mean less than who the officer's "hook" might be.

Similar circumstances were uncovered in New York City in 1994, when the Mollen Commission investigated corruption inside the NYPD. The Mollen Commission (1994:63-64) found that favoritism at the upper ranks contributed to officers' cynicism, which helped corrupt officers rationalize their conduct while keeping honest officers silent about others’ behavior:

“...many police officers believe that for the favored 'boss,' the same rules of integrity do not apply. In their view, while the Department will quickly penalize street cops for minor infractions, it protects favored commanders from their own incompetence and indiscretions... Officers' cynicism toward the Department fuels the worst aspects of police culture. It further makes bonds of loyalty to fellow officers, honest and corrupt alike, greater than their loyalty to the Department, and often the law.”

When rewards and punishments are tinged with favoritism because of political patronage $^{36}$ or "hooks," a great deal of resentment may occur. That resentment from employees may translate into “organizationally motivated aggression (revenge, retaliation)...when workers perceive inequitable disbursement of rewards and other resources by the organization” (O’Leary-Kelly et al., 1996 in Dollard, Winefield and 
Winefield, 2003:4). Organizationally-motivated aggression may result from the frustration-aggression hypothesis (Dollard et al., 1939), which suggests aggression follows frustration. Frustration may generate aggressive inclinations particularly when there is an accumulation of aversive stimuli. In this environment, where a lack of supervisory and administrative support exists, the thought of blowing the whistle on a corrupt peer places a police officer in an awkward position: Face contempt from their peers for reporting misconduct, or face the scorn of unsupportive supervisors and administrators for reporting misconduct. Either outcome virtually ensures their silence.

As the Mollen Commission (1994) alludes to, some of the structural features of the organization and policing itself (e.g., politics, inconsistent performance ratings, inconsistent and arbitrary discipline) may elevate the bitterness officers hold toward management. In response, officers may use their silence, through pleas of ignorance or plausible deniability to quietly retaliate against reviled supervisors with the hope that external forces such as an investigative commission will shame the supervisors into changing their detestable habits. There may also be the hope that officers will watch the "favored boss" finally endure the unpleasant consequences of discipline for their actions by "hanging them out to dry" just as the favored boss may have done to them in the past by failing to support them.

My experience is that it is oddly understandable why police officers react the way they do in the face of persistent favoritism. In such a climate, even officers with different career aspirations or views about agency policy may become unlikely bedfellows to confront a common enemy: The administration. On-lookers view their colleagues who are facing disciplinary sanctions for ostensibly failing to comply with oppressive policies 
as an act of self-sacrifice, a show of pride and loyalty to the entire workforce who may one day be in the same position, thus galvanizing officers in their misery. Any punishment that is meted out by the department is seen as unwarranted or disproportionate exacted by unsupportive and hypocritical administrators. Perplexed by continued acts of deviance and defiance toward policy, exasperated administrators begin drafting additional policies to tighten control over officer behavior and levy stiffer penalties.

The officers and the administration become locked in a downward spiral of mutual disdain and the source of the problem is forever overlooked, never addressed and sadly perpetuated. The officers believe they are political pawns whose talents are forsaken for ulterior motives, such as preserving the image and reputation of the agency. The administration believes the officers are recalcitrant and ignorant to the time-honored practices of a quasi-military structure and the solution rests in their submission to authority. The end result is the same: Increasing levels of stress and decreasing levels of performance, which subsumes morale, personal integrity, and overall agency effectiveness.

Police officers' reactions to disciplinary sanctions, where favoritism pervades, may be rooted in Tyler’s (1990) theory of procedural fairness and Sherman’s (1993) theory of defiance, both of which comprise the compliance literature. Tyler suggests people obey the law because they feel obligated to do so based on their perceived level of trust and legitimacy in the organization (Or the individual). Sherman suggests crime may recur despite punitive sanctions by the criminal justice system because the sanctions are perceived as unfair by the offender. Applying Sherman’s (1993) theory to an 
administrative setting it is easy to see how police deviance can persist in an atmosphere dominated favoritism, despite facing administrative sanctions: 1) The officer perceives the discipline as arbitrary and unreasonable; 2) the officer is alienated from management; 3) the officer perceives management as hypocritical (i.e., illegitimate and untrustworthy), and 4) the officer refuses to accept the shame imposed by the punishment.

\begin{tabular}{|c|c|c|}
\hline $\begin{array}{c}\text { Theoretical } \\
\text { Principle }\end{array}$ & $\begin{array}{l}\text { Administrative } \\
\text { Equivalent }\end{array}$ & Interpretation \\
\hline $\begin{array}{l}\text { The offender } \\
\text { must define the } \\
\text { sanction as unfair }\end{array}$ & $\begin{array}{l}\text { The [officer] must define } \\
\text { the sanction as unfair }\end{array}$ & $\begin{array}{l}\text { Police officers frequently cite department } \\
\text { administered punishment as unreasonable, arbitrary } \\
\text { and capricious (Alex, 1976), as evidenced in the } \\
\text { LAPD (Christopher Commission, 1991; Rampart } \\
\text { IRP, 2000) and the NYPD (Mollen Commission, } \\
\text { 1994) commission investigations. }\end{array}$ \\
\hline $\begin{array}{l}\text { The offender is } \\
\text { poorly bonded to } \\
\text { or alienated from } \\
\text { the sanctioning } \\
\text { agent or the } \\
\text { community the } \\
\text { agent represents }\end{array}$ & $\begin{array}{l}\text { The [officer] is poorly } \\
\text { bonded to or alienated } \\
\text { from [their immediate } \\
\text { supervisor] or the } \\
\text { [agency's top } \\
\text { administrators] }\end{array}$ & $\begin{array}{l}\text { Police officers frequently perceive an "us vs. } \\
\text { them" environment, meaning the line officers (Us) } \\
\text { are pit against management (Them) creating or } \\
\text { perpetuating alienation (Bayley, 1994:64-66; } \\
\text { Chemerisnky, 2000-2001; Reuss-Ianni, 1984; } \\
\text { Zhao, Thurman and He, 1999:157). In this } \\
\text { environment, a struggle for supremacy takes place } \\
\text { between autonomy and control. When control } \\
\text { (Management) wins, the battle does not end it is } \\
\text { turned up a notch making it a contest of } \\
\text { ingenuity-"catch me if you can"-between line } \\
\text { officers and management, where line officers } \\
\text { snicker and try to outsmart supervisors in their } \\
\text { daily work as they try to recapture a small bit of } \\
\text { autonomy in their oppressive workplace. The cat } \\
\text { and mouse game of evasion and pursuit continues } \\
\text { as a way for non-favored officers to create simple } \\
\text { pleasures in daily work life that resemble what } \\
\text { favored (Or "hooked-up") officers reap. This } \\
\text { sends the message across the department grapevine } \\
\text { that "I may not have a hook, but I can still screw } \\
\text { the system" just as the system screws me. }\end{array}$ \\
\hline
\end{tabular}


The offender defines the sanction as stigmatizing and rejecting a person, not a law breaking act
The offender denies or refuses to acknowledge the shame the sanction has actually caused him to suffer
The [officer] defines the sanction as stigmatizing and rejecting a [superior officer or administrator], not a [rule or policy violation]
The [officer] denies or refuses to acknowledge the shame the sanction has actually caused him to suffer
Police officers who are found guilty at a department hearing often view the sanctioning agent (e.g., the chief of police) as a hypocrite and an illegitimate authority, who is out of touch with the realities of police work or who is pandering to political motives. Thus, the chief is not worthy of the officer's contrition as the officer neutralizes his or her own behavior ( "Condemnation of the condemners," see Sykes and Matza, 1957). The officers view their actions that brought them before the hearing as noble, necessary and in concert with fellow officers, except they were unlucky enough to be caught operating outside of policy bounds and must now be judged by an administrative code that is outdated and sporadically applied in a disciplinary system fraught with disingenuousness and incompetence where the ends are never served.

Police officers may deny shame through "impotence or indignation” (Quoting Karl Marx in Scheff and Retzinger, 1991:64) by resorting to maladaptive behaviors such as excessive absenteeism or using alcohol or drugs to retreat from the situation (Impotence) or through “organizationally motivated aggression (Revenge, retaliation)...” (O’Leary-Kelly et al., 1996, in Dollard, Winefield and Winefield, 2003:4) such as destroying department/city-owned property, or through passive-aggressive behavior ${ }^{37}$

(Indignation) that lowers performance.

It has been my experience that police officers quickly learn the culture of policing is one steeped in a tradition of hidden, duplicitous, politically driven dynamics, ulterior motives and personal agendas that control the outcomes of key discipline and other personnel decisions (i.e., preferred assignments), the effects of which may be long lasting and difficult to reverse. To compound the problem, police management is frequently spared criticism and accountability for the failings of its members. The undeniable reality is that the organization (i.e., the chief and the command staff) shapes the operating environment, the culture and the behavior of its employees. Jermeir and Berkes (1979:3) noted that “organizational influences” are so evident that several police scholars have 
suggested if a "working personality" like Skolnick (1966) defined truly does exist, it does so because it is a product of those influences.

When officers go awry on their watch, management should be held accountable for the performance problems they have created, instead of sidestepping their responsibility and claiming the problems are the product of individual moral failings (Armacost, 2004; Bayley, 1996; Chemerinsky, 2000-2001; Goldsmith, 2001-2002; Hall, 1991; Walker, 1993). The police organization often places police officers on the defensive in an effort to deflect blame, a tactic designed to protect the image and reputation of the organization (i.e., the chief) at the officer's expense (Kirschman, 1983). The reality of police organizations is a deep-seated institutional reluctance toward introspection. Since management censures the information they release and vets who they permit to examine the organization, it is far easier to point to the moral failings of individual officers and brand them "rotten apples" (Sherman, 1974) than it is to acknowledge that management may be systematically turning its officers into "behavior problems" by playing favorites.

\section{Summary}

As part of a police officer's perception and recognition process, there are properties of the person and there are properties of the situation that can mediate stress. The primary variable thought to act as a buffer is social support from supervisors and coworkers. Supervisors, in particular, have a great deal of influence over employees in that they must act as an intermediary between management and the employees. How a supervisor implements policy and the decisions they render can impair performance when the decision is believed to stem, at least in part, from bias or favoritism. When this 
occurs, inherently distrustful police officers may sabotage the work product in an effort to exact revenge on the agency they believe has harmed them. Worse, when officers become cynical due to perceived bias and a lack of supervisory support, misconduct may arise.

\section{Responses to Stress}

Researchers have identified three stress response categories: Physiological, psychological and behavioral (Muchinsky, 1997).

\section{Physiological Responses}

There is a well-developed physiological process that is triggered when responding to stress that includes deviation from normal homeostatic states all of which contribute to adverse health effects. The process has been described as adaptive, meaning individuals are able to summon energy reserves in the body to meet the challenge presented by the stressor. When exposure to the stressor is chronic, with no opportunity for relief, physical health problems may occur, presumably due to continued physiological arousal. Selye’s (1956) early explanation of the physiological responses to stress, was captured in his seminal work the General Adaptation Syndrome.

Selye identified three stages of response to stress: Alarm stage, resistance stage and exhaustion stage. The "alarm stage" occurs when a person is first exposed to stressors. Exposure to stressors produces physiological changes in the human body, such as increases in blood pressure and heart rate, elevated levels of cholesterol, cortisol and blood glucose, constriction of peripheral blood vessels and increased respiration. These protective mechanisms prepare the body for the classic "fight or fight” syndrome. This acute stress response was first described by Cannon (1915) as a reaction in animals to a perceived imminent threat with a general discharge of the sympathetic nervous system 
that prepares the animal for fighting or fleeing. In the literal sense, fight or flight is a primal reaction to threatening conditions, where fighting is manifested by aggressive physical confrontation and fleeing is running away from dangers or pursuers. As stress research evolved the fight or flight syndrome assumed a broader range of meanings. In the contemporary sense, the "fight” response includes angry, argumentative or recalcitrant behavior, and the "flight" response includes substance abuse, social and organizational withdrawal and passive-aggressive behavior (Friedman and Silver, 2006).

The fight or flight response is both vital and valuable, but sustained exposure can also be disruptive and damaging to the human body. Sustained exposure to stressors pushes the human body into stage two known as the "stage of resistance." In the stage of resistance, the body adapts to the environment in which it is thrust in order to withstand the stressors. Elevated levels of cortisol, neuroendocrines and other stress-generated hormones saturate the body to help maintain the prolonged and heightened state of arousal. Suspended in this stage for an extended period of time finally pushes the human body into stage three, known as the "stage of exhaustion.” In this final stage, health problems and even death may occur due to the unrelenting, inescapable presence of the stressor. Persistent elevated levels of these hormones, without respite or control, may suppress the immune system leaving the sufferer vulnerable to physical ailments such as viral infections and emotional disorders such as panic attacks and post-traumatic stress disorder (PTSD) (Crowley, 1997).

\section{Psychological Responses}

Psychological responses include assessments of the work environment as unfavorable and commonly manifest themselves as job dissatisfaction, boredom and 
fatigue. Other affective responses include irritability and anger (Thayer, 1989:110-136), which, if acted upon, could have serious negative consequences including community upheaval, disciplinary action, termination, criminal prosecution, civil liability, divorce and suicide.

\section{Behavioral Responses}

Behavioral responses are less understood than psychological responses by the research community but have been assembled into five categories: 1) "the work role (job performance, accidents), 2) oppressive behavior at work (theft, purposeful damage), 3) flight from the job (absenteeism, turnover) 4) degradation of other life roles (spouse and child abuse) and self-damaging behaviors (alcohol and drug abuse)” (Muchinsky, 1997:309-310). Behavioral responses that manifest against the agency, such as stealing, sabotaging the work product, damaging city-owned property, absenteeism, and neglect of duty are tantamount to occupational deviance that mars the image, reputation and goals of the agency. These stress-related behavioral responses are manifestations of job dissatisfaction or other stressors. When police officers become dissatisfied with their job they may undertake harmful activities that purposely undermine the goals of the agency to exact revenge or otherwise "get even” with the very agency they believe has wronged them (Haar, 1997:788; Punch, 1985; Sherman, 1974).

Other maladaptive behavioral responses such as alcohol and drug abuse, and alienation syndrome (Manderscheid et al., 1975) provide temporary relief from the effects of stress. Researchers have yet to disentangle the incidence of alcohol use among police officers as an effect of stress or other factors such as the “macho” image.

Alienation is often identified as a stress coping mechanism and consists of feelings of 
powerlessness and isolation (More, 1976) and self-estrangement (House, 1974). The implication is that those suffering the effects of stress retreat; they may withdraw socially and emotionally from the organization or from interpersonal relationships as way to keep from being "hurt" by the perceived stressors. In a study of 551 police officers on Staten Island, New York, researchers found the police officers felt more alienated from the agency than did higher ranks (Jirak, 1975). The findings were curvilinear, that is feelings of alienation gradually increased until around the fifteenth year of service, thereafter they began to decline.

The findings imply junior officers may come to the police department with preconceived ideas and expectations about the job. They may start out with great vigor and enthusiasm, endowed with visions for improving the community. Soon, they discover the departmental, community and criminal justice machinations are often at odds and do not necessarily operate as the "system" they believed it to be. Still, they persist and continue to find ways to overcome resistance-resistance to internal strife, political fiefdoms and perceived criminal justice inequities — to improve community quality of life. Then, around the fifteenth year, their alienation peaks and they stop trying, they become burned out (Maslach and Jackson, 1982). They adopt a ritualistic existence in the agency by accepting their lot and their indifference and disaffection toward the agency may evanesce, as they grow more accustomed to the daily operating routine. Since they stop trying, they do not search for the best alternatives to problems. They apply rote solutions that evidence little empathy and may not account for the unique circumstances affecting the victim. While the solution is within accepted practice, it does 
not "go the extra yard" to engender community support and satisfaction, a valuable performance dimension.

The common thread among physiological, psychological and behavioral work stressors is that they impose human, financial and organizational costs to the agency. They also create a spill-over effect into the officers’ personal lives, which affect relationships; an officer may find him or herself locked in a reciprocating situation, where the job creates stress, which is brought home and exacted on the family who responds negatively, which creates added stress that is brought back to work and exacted on citizens and so forth.

\section{Summary}

The research seems to suggest the life of a police officer is a tangled by a web of intricate and mutually degenerative stressors that place strain on work life and family life alike. The situation is such where the officer vents his or her frustrations of the job on their family, then returns to work and exacts similar behavior on the public, based on what happens inside the family. As the pressures of home life intersect with those of professional life, the community is left with a police officer who is short tempered and less resourceful, and the family is left with someone who lacks the empathy and emotional intelligence, in essence, someone unable to cope with multiple stressful situations (Territo and Vetter, 1981).

Research has demonstrated clear physiological, psychological and behavioral responses to stress that may impair performance. When a person experiences a stressful situation, there are biologically induced reactions that occur to help the person meet the challenge. This is a normal process. However, when exposure to stress is sustained, the 
human body begins to deteriorate from the elevated chemical and hormonal changes leading to a variety of health and performance consequences.

\section{Consequences of Stress}

The consequences of stress manifest gradually. Sustained exposure to organizational stressors accumulates progressively, eventually sapping a police officer's energy and enthusiasm for their chosen career. Conditions that were once perceived as insignificant or inconsequential are now seemingly intractable and intolerable. This gradual erosion can wear upon a police officer's patience and temperament, which may lead to organizational withdrawal, lapses in judgment and attitude problems.

\section{Health and Illness}

A well-developed body of research concludes that chronic exposure to workrelated stressors can have serious adverse health consequences including physical and psychological ramifications (Ganster and Schaubroeck, 1991). The physical effects may include: 1) high blood pressure; 2) heart attack; 3) immune deficiencies; 4) gastrointestinal problems (i.e., peptic ulcers) (Cox et al., 2000); 5) fatigue and sleep disruption (Rosekind et al., 1994). The psychological effects may include: 1) diminished concentration; 2) job dissatisfaction (Dollard et al., 2001); 3) anxiety, depression (Amick et al., 1998) and anger (Kendall et al., 2000); 4) headaches and dizziness (Caplan, et al., 1975; Perrewe and Anthony, 1990); 5) burnout (Veninga and Spradley, 1981) and; 6) suicide (Kendall et al., 2000; Violanti, 1996a).

A major psychological consequence of stress is burnout. Over the last twenty-five years, burnout theory has received a great deal of attention. "Burnout is thought to result from prolonged exposure to chronic interpersonal stressors on the job from working with 
troubled people” (Dollard, Winefield and Winefield, 2003:14). Burnout is a threedimensional psychological condition that is seen frequently among individuals who work in human-service professions, including policing (Silbert, 1982) and is characterized by: 1) depersonalization — a sense of being disconnected from and lack of concern for other people and withdrawing from others’ company; 2) reduced sense of personal accomplishment — fear of failure or few positive feelings about recent accomplishments; and 3) emotional exhaustion - feelings of being completely spent of fortitude, either by work demands, other people or a combination of both (Maslach, 1976, 1982; Schaufeli and Enzman, 1988).

Although an individual's personality is thought to contribute to the burnout syndrome, Maslach and Jackson (1982) suggest the condition has more to do with a bad environment than a bad individual. Their research indicates that the best explanation of the variability in job-related stress may come from the interaction between certain social and situational sources. The range of professions across which stress-related illnesses occur (i.e., clergy, corrections, nursing, teaching) seems to suggest it is not personal shortcomings that influence stress. Instead, it is the structural characteristics of the setting (i.e., the organization) where normal, healthy people are working that induces the problem. This suggests that the organizational context is more of an influence on burnout than the officer's ability to cope with the situation. When burnout becomes apparent, police officers may lose control of their emotions by being quick tempered and defensive, by shirking their responsibilities and by refusing to accept responsibility. Burnout may degrade into an apathetic “I don't care” attitude toward the public, a state of indifference 
that may be carried into an individual's personal life, where relationships suffer and depression or suicide may occur.

Organizational Effectiveness

The behavioral effects of stress that may impair organizational effectiveness include: 1) apathy; 2) cynicism; 3) passive-aggressive behavior that deliberately undermines performance (Kroes, et al., 1974; Robin and Anson, 1990; Terry, 1981; Violanti, 1996b); 4) increased or excessive use of alcohol, tobacco products and drugs; 5) increased levels of absenteeism or sick leave; 6) workplace accidents; 7) staff turnover (Caplan, et al., 1975; Perrewe and Anthony, 1990); and 8) marital problems and other social issues (Sauter et al., 1990). Officer performance and safety may also be compromised by policies on work schedules. The organization may suffer from police officers’ increased variability in vigilance, slowed reaction time, impaired judgment, inattentiveness, deteriorations in mood and the inability to articulate and interact socially, all of which may impair judgment and performance (Bonnet, 1985; Broughton and Ogilvie, 1992; Mitler et al., 1994).

\section{Summary}

Police departments are service-related organizations whose efficiency and effectiveness are directly attributable to the quality of personnel that comprise them. Like other human-service professions, the individual brings with him or her certain personality characteristics that lend themselves to altruistic behavior or to authoritarianism. These characteristics are cultivated in a rigid bureaucratic environment that stifles personal autonomy, is fraught with communication problems and reduces organizational capacity to address mission-related objectives. Inside this environment, a variety of priorities are 
set by top management. Organizational priorities may not be in accord with the expectations held by individual employees. When this occurs there is a disjunction between what the employee perceives as their function and what management expects of that function. The result is role conflict that may be aggravated by ambiguous or double messages and role overload from supervisors. As the pressures mount from these inescapable and persistent conflicts, stress may arise. Unresolved stress may accumulate and as it does, anxiety, depression, psychosomatic illness and cardiovascular disease may develop. Each of these issues may directly contribute to organizational withdrawal and operational lapses, which negatively affect performance.

\section{Police Performance}

The dimensions of police performance are complex and can take different forms partly because there is no consensus about what constitutes performance or how to measure it (Alpert and Dunham, 2001; Alpert, Flynn and Piquero, 2001; Horne, 1992; Langworthy, 1999; Maguire, 2004; Skogan and Hartnett, 1997:74). This may stem from differences in the social and political expectations and priorities about what the police should achieve and what they should be responsible for. Disagreement over performance comes from various constituent groups including elected officials, special interest groups, the community and the police themselves who each conceive of the police role differently, yet expect to have their demands satisfied. An ambiguous role and changing social demands leave police in a difficult position trying to reconcile the differences about what performance should look like.

Contributing to the performance problem are various myths associated with the police role and function. Popular misconceptions that the police are “crime fighters," or, 
they are ministerial agencies that have no discretion in shaping public safety priorities, or that "arrest" is the best option to resolve conflict, all forge expectations about how the police should perform. The reality is that public police tend more to social service matters than crime fighting (American Bar Association, 1973; Bayley, 1994; Bittner, 1980; Manning, 1971; Reiss, Jr., 1971; Skolnick, 1966), and given limited resources and ambiguous laws, they exercise wide discretion in selecting which laws to enforce, when they will arrest someone, when they will release someone and what strategies to employ that are least oppressive to the community (Banton, 1964; Goldstein, 1966:1125; Goldstein, 1960). Indeed, a wide body of research suggests crime and disorder conditions can be controlled from a preventative standpoint instead of from a reactive standpoint (i.e., arrest-based model) (e.g., Brantingham and Brantingham, 1995; Clarke, 1997; Eck and Spellman, 1987; Goldstein, 1990), which clearly shapes police priorities, operating strategy and management ideology. Therefore, measuring performance from a one-dimensional perspective such as crime control (i.e., the crime fighter perspective) is not appropriate.

\section{Developing Suitable Performance Measures}

Developing suitable measures of police performance has at its core monitoring and accountability. Monitoring helps agency executives assess various conditions in support of its mission, examine resource allocation and consider alternatives. Agency accountability is a fundamental tenet of democratic government that contributes to public oversight. That the agency holds itself out to public scrutiny is an expression of transparency to ensure resources and motives can be reviewed and contested as a matter of social and political redress. The task becomes engaging citizens in helping shape 
performance measures, expectations and outcomes that the police department will endeavor to meet. Police leaders, elected officials and the community must collaborate and decide on what they view as "intrinsically valuable” as part of the police department's operations (Moore and Braga, 2004:4). In this sense, the community is part of what Moore (2002:84) describes as the "authorizing environment,” which constitutes “...all those political actors or agents who have the formal power to review police department operations, or the informal power to influence those who do. In short, it is all the people who can, as a practical or legal matter, call the police to account.” Of these agents, perhaps the most important is the community whose voice is raised through elected officials, for without the community's sentiment about what they value, efforts to improve performance and public satisfaction are likely to fail (Collier, 2006:165).

The effort to describe performance and construct meaningful measures may lie less in policing and criminal justice and more in ethics. The challenge becomes conceptualizing an exhaustive list of categories that captures the principles the police should be held accountable for and developing a mutually exclusive list of performance indicators that measure those principles. This too suggests the "bottom line" of police performance ought not to be developed from a one-dimensional perspective such as crime control (Moore and Braga, 2003). Although controlling crime is nearly universally accepted as a measure of police performance and undoubtedly remains the "first priority of policing” (National Research Council, 2004:85), there are other elements of service delivery that concern constituent groups, such as timely response, courtesy, use of force, transparency, and competency (Bratton, 1998; Skolnick, 1999). Some of these soft (Qualitative) measures, for example courtesy and competency, may be expressed by 
ensuring officers provide "practical advice, counseling and referring callers to public and private agencies that are able to assist them further with their problems” (National Research Council, 2004:86).

From an ethical perspective, shaping the police department one eventually wants is a matter of examining the agency from various perspectives that guarantee the policewho have a monopoly on the use of force and coercive authority in civilian life-act fairly and legitimately. The approach is to conceive performance from a multidimensional perspective similar to the way responsible corporations define their identity. A multidimensional model means there is no single best way to express performance; rather, multiple dimensions better express what the agency does because they include things beyond just controlling crime, such as service delivery, financials, trust and legitimacy. The dimensions represent an exhaustive list of the things police do, meaning everything they do can be categorized under a single outcome. Once the outcomes are identified, performance indicators can be developed that measure the outcomes. By applying such a model, top police administrators have more flexibility to align activities and core processes with democratic principles, financials as well as crime control measures to establish a culture of accountability and appropriate monitoring practices (Hoover, 1995).

Adopting performance measures that reflect the multiple dimensions of policing are what Kaplan and Norton (1996) define as the "balanced scorecard.” Previous research reveals this type of model is not new to policing; several scholars have presented their interpretation of what police departments should be measuring. 


\begin{tabular}{|c|c|c|c|c|c|c|}
\hline & 1 & 2 & 3 & 4 & 5 & 6 \\
\hline Dimensions & $\begin{array}{l}\text { O'Neil et al., } \\
\text { (1980) }\end{array}$ & $\begin{array}{l}\text { Hatry et al., } \\
\quad(1992)\end{array}$ & $\begin{array}{c}\text { Alpert and } \\
\text { Moore (1994) }\end{array}$ & $\begin{array}{c}\text { Mastrofski } \\
\text { (1999) }\end{array}$ & $\begin{array}{l}\text { Moore et al., } \\
(2002)\end{array}$ & $\begin{array}{l}\text { Milligan and } \\
\text { Fridell } \\
\text { (2006) }\end{array}$ \\
\hline Prevention & $\begin{array}{l}\text { Crime } \\
\text { prevention }\end{array}$ & $\begin{array}{l}\text { Prevention of } \\
\text { crime }\end{array}$ & $\begin{array}{l}\text { Promoting } \\
\text { non-criminal } \\
\text { options }\end{array}$ & & & $\begin{array}{l}\text { Community } \\
\text { safety and } \\
\text { security }\end{array}$ \\
\hline Control & Crime control & $\begin{array}{l}\text { Apprehension of } \\
\text { offenders }\end{array}$ & $\begin{array}{l}\text { Promoting } \\
\text { secure } \\
\text { communities }\end{array}$ & & $\begin{array}{l}\text { Call offenders to } \\
\text { account; } \\
\text { Guarantee safety } \\
\text { in public spaces; } \\
\text { Use force and } \\
\text { authority fairly, } \\
\text { efficiently and } \\
\text { effectively }\end{array}$ & \\
\hline $\begin{array}{l}\text { Assisting } \\
\text { Victims }\end{array}$ & $\begin{array}{l}\text { Conflict } \\
\text { resolution }\end{array}$ & $\begin{array}{l}\text { Responsiveness } \\
\text { of police }\end{array}$ & $\begin{array}{l}\text { Restoring } \\
\text { crime victims }\end{array}$ & & $\begin{array}{l}\text { Reduce fear and } \\
\text { enhance } \\
\text { personal } \\
\text { security; } \\
\text { Reduce criminal } \\
\text { victimization }\end{array}$ & $\begin{array}{l}\text { Perceptions } \\
\text { of safety and } \\
\text { security }\end{array}$ \\
\hline Service & General service & $\begin{array}{l}\text { Feeling of } \\
\text { security }\end{array}$ & Doing justice & $\begin{array}{l}\text { Reliability; } \\
\text { Responsiveness; } \\
\text { Attentiveness; }\end{array}$ & $\begin{array}{l}\text { Satisfy customer } \\
\text { demands/achieve } \\
\text { legitimacy with } \\
\text { those policed }\end{array}$ & \\
\hline Organization & $\begin{array}{l}\text { Police } \\
\text { administration }\end{array}$ & $\begin{array}{l}\text { Fairness, } \\
\text { courtesy, } \\
\text { helpfulness/ } \\
\text { cooperativeness, } \\
\text { honesty }\end{array}$ & & $\begin{array}{l}\text { Fairness; } \\
\text { Manners; } \\
\text { Competence; }\end{array}$ & $\begin{array}{l}\text { Use financial } \\
\text { resources fairly, } \\
\text { efficiently and } \\
\text { effectively }\end{array}$ & $\begin{array}{l}\text { Confidence, } \\
\text { trust and } \\
\text { satisfaction } \\
\text { in law } \\
\text { enforcement }\end{array}$ \\
\hline
\end{tabular}

When conceptualizing the principles a police department should be measured against, it is inspiring to think about how the corporate world evaluates its performance. The corporate sector has always been revered for its ability to measure the "bottom line" and thus often serves as a model for public sector organizations to emulate. Corporate performance is evaluated on more than just financial profit. Corporations are assessed annually on seven dimensions for their responsibility and how well they serve various stakeholders, not only the stockholders; they are also rated on "consumer confidence, responsiveness to customers, and consumer satisfaction using the American Customer Satisfaction Index [ACSI]” (Maguire, 2003:9) (Table 5). 
Various constituent groups will likely assess the police department for how well they perform on the numerous services they deliver, not just crime. Therefore, police departments can borrow from the corporate model to identify dimensions that satisfy their stakeholders. This model comports nicely with Moore and Braga's (2004) normative framework for a performance measurement system that accounts for the various stakeholders affected by public policing.

\begin{tabular}{|c|c|}
\hline \multicolumn{2}{|c|}{$\begin{array}{l}\text { Table } 5 \\
\text { The Seven Primary Corporate Stakeholders and their Analogous Police Stakeholders }\end{array}$} \\
\hline $\begin{array}{c}\text { Seven Primary } \\
\text { Corporate Stakeholders }\end{array}$ & Analogous Police Stakeholders \\
\hline Stockholders & $\begin{array}{l}\text { Taxpayers: Those who have a financial interest in the organization } \\
\text { through property taxation }\end{array}$ \\
\hline Employees & $\begin{array}{l}\text { Employees: Those who have a human, often long-term, interest in the } \\
\text { organization through their employment }\end{array}$ \\
\hline The Community & $\begin{array}{l}\text { Constituent groups: Segments of society that may suffer harm in public } \\
\text { or quasi-public places (Victims; witnesses; bystanders; informants; } \\
\text { complainants; offenders; crowds; peaceful demonstrators) }\end{array}$ \\
\hline The Environment & $\begin{array}{l}\text { By-products of police operations: Harmful side effects and sometimes } \\
\text { unintended consequences of police action (Poor police-community } \\
\text { relations; abuse of authority; unlawful or oppressive tactics; excessive } \\
\text { force; corruption; differential treatment) }\end{array}$ \\
\hline Overseas Stakeholders & $\begin{array}{l}\text { Stakeholders: Individuals or groups who have a human or financial } \\
\text { interest in the organization and the organization's performance that may } \\
\text { be exploited (Collaborators, nonprofit groups; community groups; state, } \\
\text { county federal government; developers; investors) }\end{array}$ \\
\hline Minorities and Women & $\begin{array}{l}\text { Minorities, women and other traditionally underserved populations: } \\
\text { Segments of society that have historically received inequitable treatment } \\
\text { or who have been categorically excluded thus reducing their social } \\
\text { status or self-sufficiency (Elderly; disabled; juveniles; homeless; } \\
\text { mentally ill; domestic violence victims) }\end{array}$ \\
\hline Customers & $\begin{array}{l}\text { Residents, citizens and those who summon the police for assistance: The } \\
\text { primary source of work with whom the police must deal }\end{array}$ \\
\hline
\end{tabular}

The police-corporate comparison model can draw explanatory variables from the rational/technical theory of organizations (Maguire and Uchida, 2000). According to Maguire and Uchida, the rational/technical theory is often used by administrators and 
policy makers because they can change the performance indicators as public policy or public priorities changes, which are likely to influence how the organization operates (i.e., in response to substantive and procedural law; civil law suits; social movements; internal and external regulatory mandates). The theory implies that "organizations are rational entities that enact policies and procedures necessary to improve effectiveness and efficiency” (Archbold and Maguire, 2002:233). This theory suggests that police departments who measure their performance from one-dimensional perspective may not capture the true extent of their performance. It stands to reason, then, that police departments who examine their performance from only a crime-control perspective might improve their performance by making changes to the organization.

This line of inquiry needs to be explored further; however, this approach represents a new direction for improving police performance. The police-corporate comparison model helps law enforcement agencies focus their attention on a wider audience. Most police administrators do not consistently weigh corporate dimensions as important sources of legitimacy when they conceptualize performance (Indeed, they frequently rely on output measures instead of outcome measures developed with input from multiple stakeholders). Yet, they are imperative to understanding who law enforcement agencies serve and what these groups consider important to their communities.

Establishing who law enforcement agencies serve and what these groups consider important should be articulated in a mission statement. This is vital because it provides a doctrine for the members of the agency to follow. There is some debate about the utility and relevance of mission statements in policing (Mastrofski, 1999); however, others 
agree they serve a valuable function for police agencies (Schroeder, Lombardo and Strollo, 1995; Weiss, 1996; Weiss and Piderit, 1999; Wilson, 1989). DeLone (2007:221) noted, "You cannot adequately evaluate police performance if you do not first examine what it is police say they are doing.” Similarly, Wadman and DeLadurantey (1984:231) note a vital first step toward measuring productivity is to establish goals that are connected to a mission. The mission statement also provides a sense of identity for the organization (Denhardt, 1999:249) and defines its core purpose (e.g., the reason for its existence), which forms the basis upon which the organization builds its policies, programs and ultimately delivers its services. Once the mission is formally recognized, concrete goals can be operationalized.

Absent a unifying performance structure, the police are vulnerable to criticism about their operating practices as a whole and individual police officers are left without any direction from management about what to achieve and how to achieve it. Moreover, this leaves individual officers subject to criticism from management for exercising "poor judgment” in an atmosphere dominated by discretion. Performance measures are instrumental for creating a sensible even-handed internal environment (Jones, 1998:110). As a matter of principle, Moore et al., (2002:142) noted that the ethical implications for police administrators are weighty. When someone assumes command of a police department, they take the reins of a "collectively owned asset.” Although taxpayers can move out of the jurisdiction if they are displeased with services — the public sector equivalent of selling their shares of a private corporation-police managers should still they promulgate suitable measures to ensure the agency is creating the public value citizens expect. 


\section{Chapter III. Methodology and Research Design}

Overview of the Research Design

This research will test the direct effects of organizational stressors on police performance by pooling secondary data originally collected by the Police Foundation, Washington, D.C., as part of a larger study on the impact of shift work on police officers, and from primary data collected in the Paterson (NJ) police department. The survey instrument captures organization-based stressors, personal data and demographic characteristics. All of the variables are continuous.

The original Police Foundation study began in Detroit, Michigan in December 2006 with incumbent sworn police officers. The sample includes sworn police officers from the Detroit Police Department's patrol division $(n=113)$. The second sample was collected between May 2008 and June 2008 from the same population of personnel in the Paterson police department $(n=348)$; supervisors and civilian personnel were not included and officers assigned to duties other than patrol were not included.

This research is designed to examine the relationships between various predictors of stress and multiple outcome measures of police performance. Previous stress studies rely on survey instruments that are not specifically designed for police work and are therefore common to all types of work, not only policing. This study attempts to deal with that shortcoming.

Original Police Foundation Study

The purpose of the Police Foundation's original study is to examine the impact of various shift practices and related policies (e.g., overtime, off-duty employment, minimum staffing requirements, special events/ circumstances, etc.) on a variety of 
individual and organizational performance measures. ${ }^{38}$ The evaluation consists of an indepth examination of the Detroit Police Department's shift configurations to determine the relative benefits and risks of various shift practices. The original study sought participation from five U.S. cities to compare the outcomes of shift practices across cities. However, at the time the present study was undertaken only Detroit had agreed to participate.

The original research question is: What is the impact of shift length on police officer well-being and performance? The goal of the study is to determine whether variations in shift length have any meaningful impact on police officers' health, safety, performance, and/or quality of life; previous research suggests that shift configuration may negatively affect performance. The results are intended to provide a scientific basis for using a fatigue risk management approach to guide police administrators and policymakers in the use of the most beneficial and lowest risk scheduling policies and practices. The findings from this project may be used to manage the known risks associated with 24-hour operational demands and provide police officers and their communities with safer and better law enforcement services.

The study uses a non-probability sample (i.e., volunteers) of sworn police officers that are randomly assigned to one of three different shift-length configurations $(8,10$, or 12-hour shifts). Superior officers (i.e., supervisors or command-rank officers) and civilian personnel are not eligible for the study. As an incentive to participate, the officers were paid \$100 in two \$50 cash payments to complete the Law Enforcement Officer Survey (LEOS). Officers who completed the survey were also entered into random drawings for one of two $\$ 1,000$ cash prizes that were to be held at the end of the 
experimental period. The Police Foundation recruited volunteers in the following

manner:

1. Through a cooperative agreement with the local police union-DPOA;

2. Publishing an announcement in the department's newsletter;

3. Promulgating internal memoranda and distributing it to officers at roll call;

4. Placing posters in all district stations and other common locations across department; and;

5. Having Police Foundation staff attend roll call briefings during each shift in each district to announce the study and solicit volunteers.

Officers that agreed to participate were informed of the benefits and risks of participation and their rights as participants.

Once a sufficient pool of volunteers was generated, they were randomly assigned to an 8,10 , or 12 -hour shift. Those assigned to 8-hour shifts continued working the standard 5-day schedule. Those assigned to a 10-hour shift began working four 10-hour days for the 6-month period of the study. Lastly, those assigned to a 12-hour shift began working three 12-hour days during the first week and three 12-hour days plus one additional 8-hour day the second week for the 6-month study period.

The study is designed to capture performance, demographic and wellness data via several different measures. The instruments include:

1. Firearms proficiency via a computerized shooting simulator known as MILO; ${ }^{39}$

2. Driving performance via a computerized driving simulator known as STISM Drive; ${ }^{40}$

3. Interpersonal interaction and judgment simulation via prerecorded law enforcement-specific scenarios known as B-PAD; ${ }^{41}$

4. Psychomotor vigilance via the Walter Reed Palm-Held Psychomotor Vigilance Test (PVT) program (See Thorne et al., 2005);

5. Pupil alertness via an objective non-invasive pupillomter known as the FIT test; ${ }^{42}$

6. "On-site" survey concerning the officers' activities during the day of the simulated exercises; and

7. Law enforcement officer survey (LEOS), a 456-question survey that captures perceptions, wellness and demographic data. ${ }^{43}$ 
Measurements were taken at two points: 1) prior to the study and 2) six months after random assignment to a specific shift schedule. Performance data are drawn from agency records for the six-month period prior to random assignment and the six-month period during assignment. The simulated trials lasted about three hours and were conducted during the last three hours of the officers' shift.

Research Questions and Null Hypotheses

By using domain-specific instruments, given what previous studies suggest about the relationship between job-context stressors and officer performance, the primary research question is: What is the relationship between perceived organizational stressors and police performance? The null hypothesis is that there is no significant difference between the increase in perceived organizational stressors and decreased performance. The secondary research questions are:

1. To what extent do perceived organizational stressors correlate with police performance? The null hypothesis is there are no significant correlations between perceived organizational stressors and police performance.

2. Are perceived organizational stressors higher than perceived operational stressors? The null hypothesis is there is no difference between organizational stressors and operational stressors.

3. To what extent do perceived organizational and operational stressors differ between Detroit and Paterson? The null hypothesis is there is no difference between organizational stressors and operational stressors between each city.

4. Which of the regressed explanatory variables are influential in predicting police performance? The null hypothesis is none of the explanatory variables has a significant effect on decreased police performance.

5. To what extent do various demographic factors significantly influence the relationship between perceived organizational stressors and police performance? The null hypothesis is there is no significant difference between demographic factors and a decrease in police performance. 
Participants, Informed Consent and Confidentiality Notice

\section{Participants}

The data for this research were collected from a non-probability (i.e., convenience) sample of sworn incumbent police officers from the Detroit (MI) (n=113) and Paterson (NJ) police departments ( $\mathrm{n}=348)$, who were actively working in the patrol division. The sample consisted of various men and women from different age groups, racial groups, and ethnic backgrounds of varying demographic characteristics. The difference in sample size between both agencies necessitates clarification. The officers in Detroit were invited to participate as part of a larger study on the impact of shift work, conducted by the Police Foundation (Mentioned earlier) and sponsored by the National Institute of Justice, Washington, D.C. The Police Foundation did not have access to the entire Detroit police department to conduct the LEOS by itself. Before Police Foundation researchers could survey the officers, the officers had to agree to participate in the larger study on shift work. The final sample of officers participating in the Detroit shift work study was 113. In Paterson, the Police Director granted me full access to members of the patrol division. I was not constrained by the situation in Detroit, where the officers were first required to participate in a larger study before they could be surveyed; the sample in Detroit would undoubtedly have be larger if the entire patrol division was open to be surveyed as it was in Paterson.

As an incentive to participate, the officers in Detroit were paid \$100 in two \$50 cash payments to complete the LEOS. Officers who completed the survey were also entered into random drawings for one of two $\$ 1,000$ cash prizes that were to be held at the end of the experimental period. Recruiters visited officers during roll-call on each 
shift, between November 5 and December 17, 2006 and again between January 4 and January 12, 2007. Recruiters read from a prepared script that explained the nature of the study, the risks, benefits, protections and their rights as participants. If officers volunteered to participate in the study, then they were mailed a packet that included the LEOS. Officers prepared the survey and hand delivered it to Police Foundation personnel during a separate visit to the data collection site. In addition to roll-call visits, officers were recruited through advanced notice of the study through: 1) flyers posted in all police stations; 2) a police union (Detroit Police Officers Association) newsletter; and 3) email distribution to department accounts.

In Paterson, the officers were invited to participate in the LEOS during the annual in-service firearms requalification at the police academy between May 1, 2008 and June 30, 2008. I personally addressed the officers on each shift for the first two weeks (May 5 to May 19, 2008) and read from the informed consent form that explained the nature of the study, the risks, benefits, protections and their rights as participants. Thereafter, the range master and academy staff announced the study and invited officers to participate. No incentives were offered in Paterson.

\section{Informed Consent and Confidentiality}

Each officer that agreed to participate was given an informed consent form (Appendix 3) and the form was read and explained to him or her prior to completion. The Institutional Review Board of Rutgers University and an external review board used by the Police Foundation approved the form. The form indicated that: 1) the study involved a survey of perceptions of daily work experiences; 2) the participants were volunteers and not required to participate; 3) they were to complete a survey; 4) they authorized a review 
of relevant departmental performance data; and 5) if they decided to participate, they could refuse to answer any question, and they could withdraw from the study at any time without incurring any penalties, negative consequences or adverse employment action.

Two separate processes were used to maintain confidentiality. In Detroit, the questionnaires were handed to the individual officers who agreed to participate. The officers returned the competed surveys during subsequent prearranged site visits, where other data elements were captured. The Police Foundation maintained the data in its final form in a secure facility. In Paterson, the survey was administered during the annual inservice firearms requalification at the police academy. Although academy instructors were present, they were advised not walk around or otherwise interfere with or observe the participants' answers during or after completion. In addition, students returned the surveys, face down, to a secure area inside the academy, accessible only to instructors. The surveys were collected each day so they did not linger for a long time. At no time was any academy instructor or other member of the police department permitted to peruse a completed survey. Each day after the surveys were collected, the data was coded and the original surveys were shredded to ensure confidentiality. Furthermore, the resulting data are only stored in aggregate form so that no person can be individually identified. The only exception to confidentiality was if a specific officer made a direct threat or expressed intention to harm himself or herself or someone else. This did not occur. 
Data Sources, Instruments and Validation

\section{Data Sources}

The data were drawn from two sources: 1) agency records and 2) the law enforcement officer survey. Police performance data were collected via a data collection protocol developed by the Police Foundation. The performance data are stored by both police departments in various divisions according to the Departments’ established internal record-keeping system. Both Departments capture this data by two means: 1) hand-written records (e.g., hard-copy reports and log books) and 2) computerized files.

\section{Instruments}

Each of the surveys used in this research was previously validated. To narrow the focus from generic stressors applicable to many professional fields to those specific to policing, researchers McCreary and Thompson (2006) and Hart, Wearing and Heady (1993) each created scales that measure the characteristics unique to the police work environment and police organizations. The Police Stress Questionnaire (PSQ) and the Daily Hassles and Uplifts Scale (DHUS) contain subscales that measure operational and organizational stressors.

\section{Validation}

Police Stress Questionnaire (PSQ). The PSQ is a 40-item questionnaire consisting of two measures: One captures operational (Job content) stressors and the other captures organizational (Job context) stressors on a seven-point Likert-type scale, ranging from "no stress at all” (1) to "moderate stress” (4) to "a lot of stress” (7). The PSQ appears between questions 1 and 40 of the law enforcement officer survey. "The findings showed that both forms of the PSQ were shown to reliable and demonstrated 
construct validity (Correlations between perceived stressors and frequency), discriminant validity (Compared with general life stressors) and, and concurrent validity (compared with job satisfaction measures)” (McCreary and Thompson, 2006:494). A three-phase development procedure was used to create the PSQ, which included focus groups, pilot testing (Phase I) and reliability and validity testing (Phase II). During Phase I, the initial metrics revealed strong internal consistency (Cronbach’s alpha > .90) and corrected itemtotal correlations between .30 and .60, and the instruments were correlated with their respective frequency ratings $(r=.70)$. In Phase II the questionnaires were revised and demonstrated that both were highly reliable (alpha > .90; corrected item-total correlations between .40 and .60$)$ and both were positively correlated ( $r=.50$ or less) with the other general stress measures. ${ }^{44}$

Daily Hassles and Uplifts Scale (DHUS). The DHUS is an 86-item questionnaire consisting of a single measure of daily hassles and uplifts experienced by police officers that also includes two subscales, one for operational (Job-content) stressors and one for organizational (Job-context) stressors. The DHUS appears between questions 41 and 126 of the law enforcement officer survey. The original scale was subjected to factor analysis to identify cross-loadings, which retained 86 of the 112 original items. The purpose of developing the scale was to “...have available, valid measures that assess a police officer's daily work experience... [and to] allow the nature and extent of police stress to be investigated within a multivariate framework reflecting the important aspects of the person-environment process” (Hart, Wearing and Heady, 1993:558, 564).

The DHUS captures organizational (Job context) stressors on a five-point Likerttype scale, ranging from "strongly disagree” (1) to "neither agree nor disagree” (3) to 
"strongly agree” (5). The sample consisted of 330 police officers of the Victoria, Australia Police Department: 89 Constables, 144 Senior Constables, 55 Sergeants, 21 Senior Sergeants and 21 Commissioned Officers. The results indicated there were no significant difference between ranks $\left(\chi^{2}=6.65, d f_{4}, p>.10\right)$. The mean for Police Daily Hassles Scale was 141.9 with a standard deviation of 63.42 and high internal consistency (Cronbach’s alpha, > .91). The mean for Police Daily Hassles Scale was 132.8 with a standard deviation of 28.97 and high internal consistency (Cronbach’s alpha, > .77). Correlations between police hassles and the validity measures were in the expected direction.

Unit of Analysis

Kahn and Byosiere's (1992) model focuses on the interaction between the individual and their environment and the resulting impact to performance. Because the model is a micro-level theory, tests of hypotheses are conducted most appropriately at the individual or micro level. This study focuses on sworn police officers $(n=461)$. Measures

\section{Criterion Variable}

Kahn and Byosiere's (1992) model suggests that performance can be explained by the environmental factors arising inside the police organization, which may be mediated by situational or individual coping factors. In terms of police performance, both what constitutes performance and how to measure it have been a conundrum for many years. Restated, there has been considerable debate about what to measure in police departments particularly because there is little consensus about what constitutes "good performance" and because measuring it is complex and takes many forms (Alpert and Dunham, 2001; 
Alpert et al., 2001; Cascio, 1977:89; Langworthy, 1999; Maguire, 2004). Skogan and Hartnett (1997:74) commented that “developing performance indicators that reflect either the activities or the outcomes associated with community policing is a difficult task-one which few departments have successfully faced up to.”

Using a single dimension to measure police performance is not adequate, since the police deliver a broad array of services and are entrusted with a great deal of discretion and authority. For example, police officers do make an effort to control crime and disorder, but it is not reasonable to accept they should use any means necessary to do so. Therefore, while they endeavor to control crime and disorder by effecting arrests, issuing citations and initiating stops, they must also be accountable for how they deliver that service; a proxy measure for how that service is delivered may be citizen and administrative complaints. To avoid the problems associated with operationalizing performance from a single dimension, this research uses eleven measures that form a composite of officer performance. Operationalizing the criterion variable in terms of the multiple dimensions of police performance described in the literature (Table 4) can be conceived of this way: 


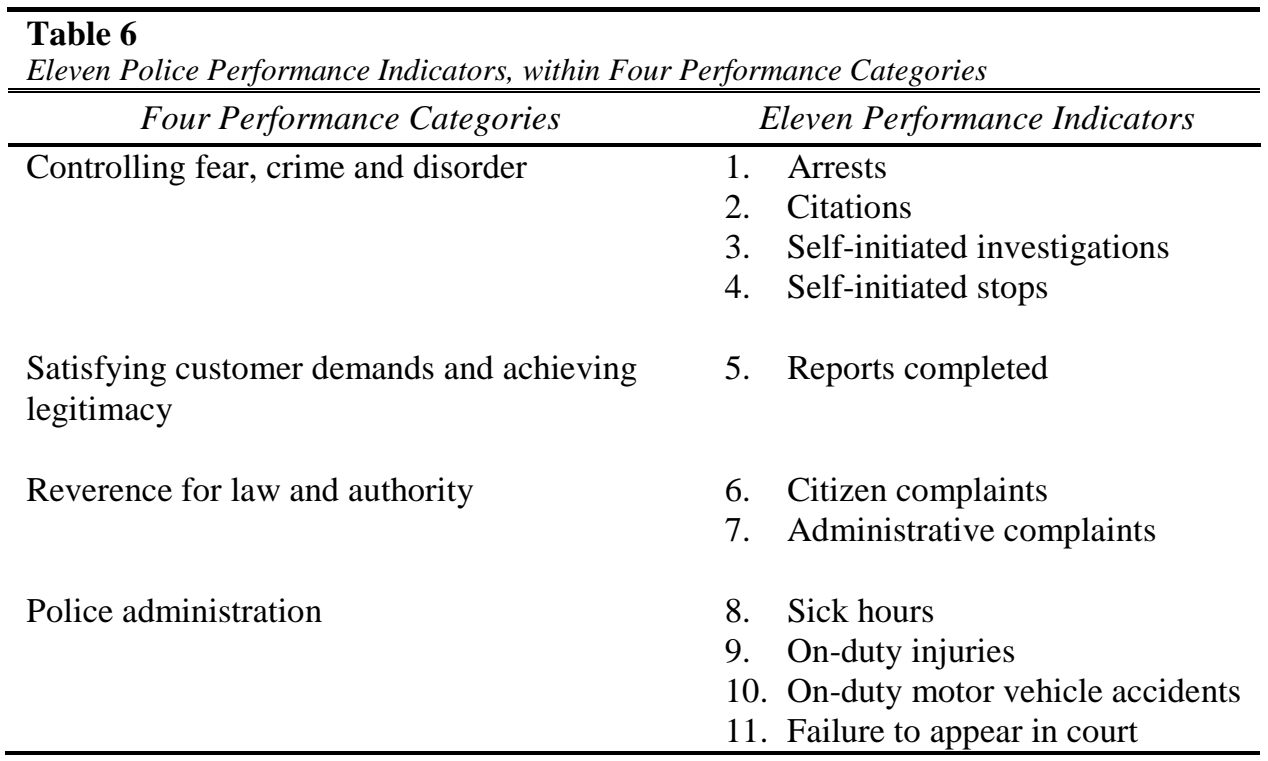

Performance indicators for the criterion variable are drawn from the literature on police performance and comport with at least six previous studies that operationalize similar variables (Table 7).

\begin{tabular}{|c|c|c|}
\hline Previous Study & Performance Variables Meas & \\
\hline Baratta, 1998 & $\begin{array}{l}\text { Use of force } \\
\text { Discipline problems }\end{array}$ & Absenteeism \\
\hline Bostrom, 2003 & $\begin{array}{l}\text { Department vehicle accidents } \\
\text { Discipline }\end{array}$ & Sick absenteeism \\
\hline Cascio, 1977 & $\begin{array}{l}\text { Injuries } \\
\text { Accidents } \\
\text { Use of force }\end{array}$ & $\begin{array}{l}\text { Disciplinary investigations } \\
\text { Complaints } \\
\text { Sick days }\end{array}$ \\
\hline Daley, 1978 & $\begin{array}{l}\text { Illness } \\
\text { Injuries }\end{array}$ & Disciplinary infractions \\
\hline Heyer, 1998 & $\begin{array}{l}\text { Citizen complaints } \\
\text { Sick days }\end{array}$ & Vehicle accidents \\
\hline Wolfskill, 1989 & $\begin{array}{l}\text { Disciplinary actions } \\
\text { Sick days }\end{array}$ & Duty-related injuries \\
\hline
\end{tabular}

Previous research conceptualizes officer performance in two ways: 1) as trait dimensions that are scored subjectively by the officer's immediate supervisor based on 
observed behaviors (e.g., a qualitative appraisal of communication skills, appearance, decisiveness, leadership, emotional stability, assertiveness, etc.), or 2) as activities arising from the tasks related to the police function that are scored objectively based on the number of instances per activity (e.g., a quantitative appraisal of activity such as arrests, citations, reports completed and self-initiated stops). In its final form, this study uses the latter concept primarily because it is objective and grounded in relevant observable behaviors. Therefore, performance is defined as quantifiable output resulting from police activity.

The initial exploration concerning the interrelationships among variables reveals some statistically significant correlations. However, the highest correlation is only moderate $(.662 ; p<.001)$ and does not exceed the conventional level of .7, where colinearity becomes an issue (Bachman and Paternoster, 2004). A factor analysis reveals that certain items do tend to group together, however, the KMO measure of sampling adequacy is weak (.562) and the determinant value (.017) is low indicating the data are not suitable for factor analysis. Therefore, a single composite measure of the combined average for the eleven performance variables was created instead of creating factors.

Although the individual measures that comprise the criterion variable seem objective, some may introduce measurement error so further explication of the objectivity and subjectivity of each measure is warranted. Moreover, a quantitative approach does not account for the intangible qualities of performance that are indispensible for good policing, which includes the trait dimensions mentioned earlier. Police officers assigned to higher crime areas may have more opportunities than those assigned to lower crime areas to bias performance, which may systematically inflate the dependent variable. 
Intuitively, higher crime areas may have a larger reactive and proactive workload that presents more opportunities for police-citizen interaction. Performance may also be biased by the type of offense the police encounter (e.g., felony or misdemeanor), the point at which an incident occurs during the officer's shift (e.g., near the end), or the officer's general disposition (e.g., tired or indifferent). However, deployment strength may minimize part of this differential opportunity since higher crime areas should have more assigned than lower crime areas, which may hold the performance criteria constant.

\begin{tabular}{|c|c|c|c|}
\hline \multicolumn{4}{|c|}{$\begin{array}{l}\text { Table } 8 \\
\text { Description of the Measures for the Criterion Variable, Their Source, Their Convention and } \\
\text { Explanation }\end{array}$} \\
\hline Measure & Source & Convention & Explanation \\
\hline $\begin{array}{l}\text { Number of } \\
\text { arrests }\end{array}$ & $\begin{array}{l}\text { Department forms that } \\
\text { catalogue the data for } \\
\text { each officer at the patrol } \\
\text { division }\end{array}$ & $\begin{array}{l}\text { Objective } \\
\text { standard measure }\end{array}$ & $\begin{array}{l}\text { Police officers who display } \\
\text { initiative tend make more arrests. }\end{array}$ \\
\hline $\begin{array}{l}\text { Number of } \\
\text { citations }\end{array}$ & $\begin{array}{l}\text { Department forms that } \\
\text { catalogue the data for } \\
\text { each officer at the patrol } \\
\text { division }\end{array}$ & $\begin{array}{l}\text { Objective } \\
\text { standard measure }\end{array}$ & $\begin{array}{l}\text { Police officers who display } \\
\text { initiative tend issue more } \\
\text { citations. }\end{array}$ \\
\hline $\begin{array}{l}\text { Number of } \\
\text { reports } \\
\text { completed }\end{array}$ & $\begin{array}{l}\text { Department incident } \\
\text { reports archived at the } \\
\text { records division }\end{array}$ & $\begin{array}{l}\text { Objective non- } \\
\text { standard measure }\end{array}$ & $\begin{array}{l}\text { Police officers who display } \\
\text { initiative tend write more reports. } \\
\text { This is a non-standard measure } \\
\text { that is not found in previous } \\
\text { research, but one that is suggested } \\
\text { in the literature (Bostrom, } \\
2003: 135) \text {. }\end{array}$ \\
\hline $\begin{array}{l}\text { Number of self- } \\
\text { initiated } \\
\text { investigations }\end{array}$ & $\begin{array}{l}\text { Department CAD } \\
\text { system }\end{array}$ & $\begin{array}{l}\text { Objective non- } \\
\text { standard measure }\end{array}$ & $\begin{array}{l}\text { Police officers who display } \\
\text { initiative tend undertake more } \\
\text { self-initiated investigations. This } \\
\text { is a non-standard measure that is } \\
\text { not found in previous research, but } \\
\text { one that is suggested in the } \\
\text { literature (Bostrom, 2003:135). }\end{array}$ \\
\hline $\begin{array}{l}\text { Number of self- } \\
\text { initiated stops }\end{array}$ & $\begin{array}{l}\text { Department CAD } \\
\text { system }\end{array}$ & $\begin{array}{l}\text { Objective non- } \\
\text { standard measure }\end{array}$ & $\begin{array}{l}\text { Police officers who display } \\
\text { initiative tend make more self- } \\
\text { initiated stops. }\end{array}$ \\
\hline
\end{tabular}




$\begin{array}{ll}\begin{array}{l}\text { Number of sick } \\ \text { hours }\end{array} & \begin{array}{l}\text { Department forms that } \\ \text { catalogue the data for } \\ \text { each officer at the patrol } \\ \text { division }\end{array} \\ \begin{array}{l}\text { Number of } \\ \text { citizen }\end{array} & \begin{array}{l}\text { Department forms that } \\ \text { catalogue the data for } \\ \text { each officer at the } \\ \text { internal affairs division }\end{array}\end{array}$

Number of administrative complaints
Department forms that catalogue the data for each officer at the internal affairs division
Objective standard measure

Subjective standard measure

Police officers who display initiative tend use fewer sick hours.

Police officers who are respectful and diligent tend to acquire fewer citizen complaints. This measure has merit; however, it is complicated by the human dynamic that exists in every police-citizen encounter. Some of the factors influencing whether a citizen logs a complaint about an officer is the type of situation the officer is resolving; whether an arrest was involved; whether a citation was issued; the officer's level of field activity/frequency of citizen contact (i.e., how aggressive/ proactive). A more objective measure of complaints would be the number of disciplinary actions (i.e., sustained complaints) adjudicated at a department hearing, however that data was not available.

Subjective standard measure

Police officers who are respectful and diligent tend to acquire fewer administrative complaints. Similar to citizen complaints, this measure has merit but is subject to the whims of zealous supervisors. A supervisor's leadership style may influence whether administrative complaints are filed against the officer (See Schroeder, Lombardo and Strollo, 1995:69-74 for examples).

Number of onduty injuries

Number of onduty motor vehicle accidents
Department forms that catalogue the data for each officer at the patrol division

Department forms that catalogue the data for each officer at the records division
Objective nonstandard measure

Objective standard measure
This measure is subject to some error particularly if the injury is minor, where it may not be reported.

This measure is subject to some error particularly if the accident is minor, where it may not be reported. 
Ratio of failure to appear in court (\# of times failed to appear/\# of times schedule to appear)
Department forms that catalogue the data for each officer at the patrol division
Objective nonstandard measure
Failure to appear in court may be the result of burnout, apathy or indifference, which are indicators of organizational withdrawal. Although police officers may effect arrests or issue citations, they may fail to appear in court and prosecute when duly subpoenaed, which negatively affects organizational effectiveness.

The performance data for Detroit is for the six-month period between July and December 2006; for Paterson, it is the six-month period between October 2007 and March 2008. The composite index draws from data that is aggregated to a monthly level to minimize the problems associated with random fluctuations.

\section{Explanatory Variables}

Kahn and Byosiere's (1992) model contends that the interaction between the individual and the organization spawns stress. Therefore, to test the dimensions of their model, it is necessary to measure the perceived degree of stress in individual officers that is associated with the organization. Stressors are defined here as organizational stimuli that evoke negative feelings, which may reduce performance. Because this research is testing aspects Kahn and Byosiere’s (1992) hypothesized model, stress is measured based on two validated self-report surveys, the Police Stress Questionnaire (McCreary and Thompson, 2006) and the Police Daily Hassles and Uplifts Scale (Hart, Wearing and Heady, 1993), which measure operational and organizational stressors (See appendix 6): 


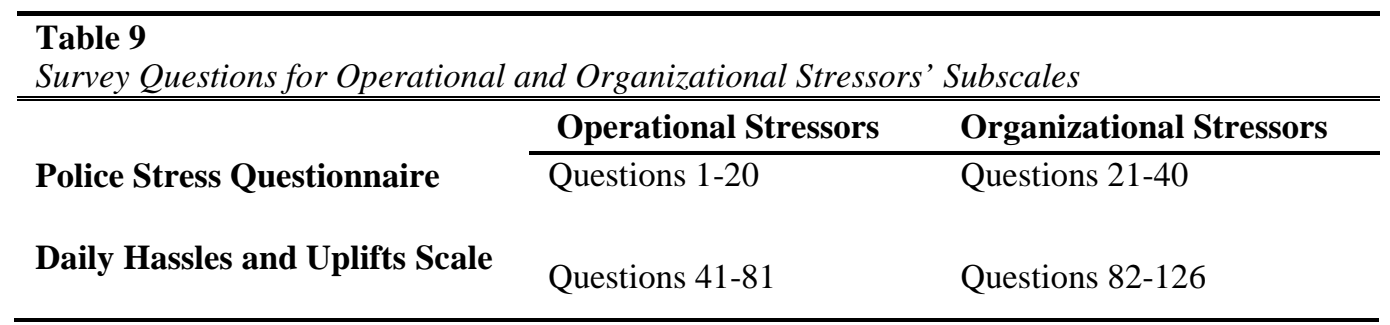

Stressors are operationalized via a Likert-type scale for each survey, where the respondent specifies their subjective level of agreement with the statements. The intent is for officers to self-identify how they feel about specific aspects of the police department. There are twelve explanatory variables grouped under four categories for this research The explanatory variables were derived from a factor analysis of both the PSQ and DHUS scales. The twelve factors accounted for nearly $75 \%$ of the total variance and all the items loaded at .60 or higher. This fact, coupled with strong findings from the KMO and Bartlett's Test of sampling adequacy reinforces confidence in creating a composite measure, which better reflects the overall degree of perceived stress by individual officers.

\section{Control Variables}

Aside from the primary theoretical variables, there are a variety potentially confounding factors that must be controlled, which increases confidence that the estimates on performance are not spurious. Following similar studies of stress (e.g., Bostrom, 2003:48), this study controls for several social and demographic variables. The control variables are: 


\begin{tabular}{|c|c|}
\hline \multicolumn{2}{|c|}{$\begin{array}{l}\text { Table } 10 \\
\text { Description of Control Variables }\end{array}$} \\
\hline Variables & Description \\
\hline Race & $\begin{array}{l}\text { American Indian or Alaskan Native } \\
\text { Asian } \\
\text { Black or African American } \\
\text { Native Hawaiian or other Pacific Islander } \\
\text { White and Other }\end{array}$ \\
\hline Age (Grouped) & $\begin{array}{l}18-24 \\
25-34 \\
35-44 \\
45-54 \\
55 \text { or more }\end{array}$ \\
\hline Sex & $\begin{array}{l}\text { Male } \\
\text { Female }\end{array}$ \\
\hline Education Level & $\begin{array}{l}\text { HS/GED } \\
\text { Some college } \\
\text { Associate's Degree } \\
\text { Bachelors Degree } \\
\text { Graduate Degree } \\
\text { Doctoral Degree } \\
\text { Professional Degree }\end{array}$ \\
\hline Marital Status & $\begin{array}{l}\text { Married } \\
\text { Separated } \\
\text { Divorced } \\
\text { Widowed } \\
\text { Never Married }\end{array}$ \\
\hline Number of Children & $\begin{array}{l}0 \\
1 \\
2 \\
3 \\
4 \text { or more }\end{array}$ \\
\hline Driving Distance to Work & $\begin{array}{l}15 \text { miles or less } \\
16-30 \\
31-60 \\
61-100 \\
101-150 \\
>150\end{array}$ \\
\hline Commuting Time to Work & $\begin{array}{l}<15 \text { minutes } \\
15-29 \\
30-44 \\
45-60 \\
1 \text { hour } \\
11 \frac{1}{2} \text { hours } \\
>1 \frac{1}{2} \text { hrs }\end{array}$ \\
\hline
\end{tabular}




\begin{tabular}{ll} 
Work Hours Off-duty & $<10$ \\
& $10-20$ \\
& $20-30$ \\
& $>30$ \\
& $<10$ \\
& $10-20$ \\
Court-time Hours & $20-30$ \\
& $>30$ \\
\hline
\end{tabular}

The initial exploration concerning the interrelationships among variables suggests some statistically significant correlations. However, the highest correlation is only moderate $(.556 ; p<.001)$ and does not exceed the conventional level of .7, where colinearity becomes an issue (Bachman and Paternoster, 2004). Because colinearity is not an issue, the variables are treated individually instead of reducing them to a composite index. A factor analysis reveals that certain items tend to group together, however, the KMO measure of sampling adequacy is weak (.464) and the determinant value (.200) is low indicating the data are not suitable for factor analysis.

\section{Site Description and Selection}

\section{City of Detroit}

Detroit is the largest city in Michigan. The U.S. Census Bureau ranks it as America’s eleventh largest city covering 143 square miles with a 2005 population estimated at $886,671{ }^{45}$ Detroit has steadily declined in size and ranking since the 1990 decennial census; between 1990 and 2000 the city lost an estimated 7.5\% of its population and slipped in rank from America's seventh largest city in 1990 to the tenth largest in 2000 to the eleventh largest in 2005. The single largest racial group in Detroit is African American, representing 82\% of the population, followed by $11 \%$ White and the remaining 7\% representing some other race or two or more races. Hispanic or Latino, of 
any race, represents $5.6 \%$ of the population. In 2000, Detroit was ranked the eighth largest metropolitan area (Detroit, Warren and Livonia, Michigan) in the United States. ${ }^{46}$

Detroit's urban ${ }^{47}$ designation connotes images of international commerce, diversity and a cosmopolitan atmosphere. It also brings images of blight, conflict and social problems typically associated with urban centers across the world. As population and economic bases began to shift in the 1960s, Detroit suffered the same fate as many U.S. urban centers and their international counterparts: Steady population loss, a concentration of poor minorities, dilapidated housing stock, racial stratification and suburban isolation (Warren, 1969-1970). The tumult and social unrest of urban America that began in 1967 accelerated the decline.

Economically, Detroit may be characterized as depressed with a median household income of $\$ 28,069$ (in 2005 inflation-adjusted dollars), which is only $61 \%$ of the median U.S. income (\$46,242). Per capita income (in 2005 inflation-adjusted dollars) is estimated at $\$ 15,042$, which is approximately $40 \%$ lower than the U.S. per capita income $(\$ 25,035)$. The percent of families who live below the poverty level is estimated at $27 \%$, nearly $164 \%$ higher than the U.S. poverty level (10.2\%). The percent of individuals below the poverty level is estimated at 31\%, nearly $136 \%$ higher than individuals across the U.S. (13.3\%). The housing stock is also under-valued compared to the national estimates; median home value in Detroit is $\$ 88,300,47 \%$ lower than the U.S. median of $\$ 167,500 .^{48}$

Detroit also suffers from a persistently high crime rate, particularly violent crime (Murder, rape, robbery and aggravated assault), compared to the national average and compared to other cities with a population of 500,000 or more. In 2007, Detroit recorded 
74,740 index offenses; ${ }^{49}$ the violent crime rate was 1,191 with an overall crime rate of 8,435. Violent crime, particularly homicide, has been part of Detroit's fabric for several decades and has been linked to firearms (Fisher, 1976:387).

\section{City of Paterson}

Paterson is New Jersey’s third largest city, behind Newark and Jersey City. The U.S. Census Bureau ranks it as America’s one hundred fiftieth largest city covering 8.7 square miles with a 2005 population estimated at 149,843, making it one of densest cities in the United States. ${ }^{50}$ Paterson's population base has remained relatively stable since the 1990 decennial census, fluctuating by just one or two thousand people. The single largest racial group in Paterson is White, representing 50\% of the population, followed by 33\% African American and the remaining 17\% representing some other race or two or more races. Hispanic or Latino, of any race, represents 50\% of the population. In 2000, Paterson was part of the largest metropolitan area in the United States (New York-Northern New Jersey--Long Island, NY--NJ--CT--PA Census metropolitan statistical areas $).^{51}$

Paterson's industrial might of the $19^{\text {th }}$ century gave way to similar economic conditions that beset Detroit when manufacturing slowed and service-based industries rose leaving unemployment and poverty in its wake. Today, nearly $20 \%$ of the families and $22 \%$ of the individuals live below the poverty level. Median household income of $\$ 31,723$ (In 2006 inflation-adjusted dollars) is just 54\% of the U.S. median income $(\$ 58,526)$. The housing stock is significantly above national estimates; median home value in Paterson is $\$ 351,500$, $89 \%$ higher than the U.S. median of $\$ 185,200 .^{52}$ 
Paterson's overall crime rate is above the national average. In 2006, the crime rate per 100,000 population was 4,034 (U.S. crime rate $=622.9$ ). Paterson's violent crime rate for the same period is 1,115 per 100,000 population compared to the U.S. rate of 473.5 (FBI UCR, 2006, Table 1 and Table 8). Among other contributing factors, this may be due in part to Paterson's high population density. Gun violence in Paterson, as in Detroit, may contribute to the problem, which led Paterson to adopt the successful CeaseFire initiative in October 2006 that originated in Boston (Kennedy et. al., 2001) and the Mayor is a member of the Mayor's Against Illegal Guns Coalition, whose purpose is to reduce the risks presented by illegal firearms. ${ }^{53}$

\section{Detroit and Paterson Police Departments}

Established in 1865, the Detroit police department (DPD) is a general service law enforcement agency with 3,327 sworn members ${ }^{54}$ who are responsible for Detroit proper (See appendix for table of organization); the metropolitan areas (i.e., suburbs) are serviced by their respective local police departments, not by DPD. DPD has recently been caught in the middle of the city's deteriorating fiscal posture. Facing receivership (bankruptcy) and a projected budget deficit of more than \$300 million for 2006, the Detroit municipal council adopted a lean budget, which was the impetus for a series of department reorganizations including layoffs, command staff reductions, slowed promotions, precinct consolidation and permanent precinct closures.

In September 2005, 150 of a projected 600 police officers were laid off. In the first quarter of 2006 the city’s fiscal posture began to improve slightly. In April the city rehired 30 officers to fill vacancies; in June the city promoted 72 officers after a two-year 
delay; and in September, 27 more laid-off police officers were rehired (Detroit Free Press, 2006).

The social conditions facing Detroit are correlated with crime; increasing crime means additional pressure on the police department (i.e., the chief executive and the command staff) to reduce it; the additional pressure is pushed downward to the individual officers who must contend with the conflict and the demands. When a city labors under the conditions that Detroit does, the bureaucracy that is created to deal with the social circumstance is often unwieldy and may influence what officers do and the way they behave (Brown, 1981; Klinger, 1997:284; Wilson, 1968). With a concentration of poor people living in a socially disorganized environment, there becomes great dependency on government service, particularly the police. This dependency saps the resources (i.e., strains organizational capacity) of the agency forcing the police to adjust their operating style due to volume (i.e., workload). The administrative complexity that grows to meet the challenges posed by such a needy populace means more rules, more regulations and more policy to bring the organization to a point of equilibrium. With more administrative controls to violate, there are more chances to second-guess officers' decisions, fewer options to handle the myriad situations that may arise, and more opportunities for supervisors to apply their idiosyncratic interpretation of the rules. The consequence may be lowered officer performance due to the organizational stressors.

Established in 1866, the Paterson police department (PPD) is also a general service law enforcement agency with 482 sworn members, who are responsible for Paterson proper; the metropolitan areas (i.e., suburbs) are serviced by their respective local police departments, not by PPD; the table of organization authorizes 519 officers 
(See appendix). Like Detroit, PPD services Paterson proper, while local police agencies service the surrounding suburbs. Paterson police department also operates with a lean budget, straining police operations and organizational capacity. In 2007, the police department apportioned more than $90 \%$ of their budget to salaries and wages, leaving little room support services such as training and equipment.

In 2002, the newly elected Mayor reorganized the police department and began reducing the command staff by demoting superior officers. The plan was to reduce the supervisory staff first through voluntary retirements, then through demotions. This brought an exodus of institutional knowledge and talent, which is slowly being replaced through promotions. By 2004, the Mayor's force reduction initiative left the agency with 397 sworn members. Although there are some similarities between the Paterson and Detroit police departments, Paterson does not face the extent or intensity of the conditions plaguing Detroit. The demotions were short-lived as was the reduction in force strength. Paterson has been on steady hiring campaign and is planning another basic police recruit class for the summer of 2008.

\section{Selection}

The DPD is a general service law enforcement agency with 3,327 sworn members. ${ }^{55}$ The primary determinant for selecting Detroit as the study site was the existing relationship between the Police Foundation, specifically the President, and the DPD. The considerations to approach DPD were: 1) the need for a "general purpose” 56 law enforcement agency; 2) preferably, a large urban department, where effects might be found, and 3) the need for mutual cooperation. 
Since the overwhelming majority of policing in the United States is carried out by local authorities, it is important to select a "general purpose” law enforcement agency responsible for primary response to crime and service demands. This means it is important to a find general-purpose local agency willing to participate with the research team. Based upon existing relationships, the DPD accepted the Police Foundation’s offer. Next, the problems associated with daily hassles and organizational stress are more likely to be found in large urban police departments because of the complexity and diversity of the bureaucracy that has been created and because of the politics that often pervade due to the crime, budgetary and social conditions. This is evidenced by Detroit's poor fiscal posture, downsizing the DPD through lay-offs, reorganizing DPD police precincts into district stations and permanently closing other precincts and halting promotions (Detroit Free Press, 2006).

Lastly, cooperation and commitment on behalf of the host agency is of the utmost importance. The DPD pledged their full support and cooperation including access to data, access to the police officers and access to police facilities to ensure the project meets its defined purpose. The local police union-Detroit Police Officers Association (DPOA) — acknowledged the research effort and helped secure voluntary participation of the officers.

Although the data obtained solely from Detroit would have been sufficient for this research and the statistical power suggests it is adequate to support multivariate analysis, my dissertation committee believed the sample size was too small, which could lead to unstable coefficients during analysis. The committee's recommendation was for me to raise the sample size to insure adequate power and improve external validity. The 
challenge was to find an agency of similar dimension as Detroit, who served a population with similar demographics. I selected the Paterson, New Jersey for a few reasons. First, the city bears demographic characteristics similar to those found in Detroit, although on a smaller scale. Paterson is an older urban city that shares many of the same social conditions as Detroit. Second, the Paterson police department is designated a general service police department and is considered a large agency by national standards. The city of Paterson is policed by Paterson's municipal police department; the outer suburbs are policed by their respective police departments. Third, in terms of cooperation, I had an existing relationship with Police Director Michael C. Walker and Police Chief James Wittig who granted me access to the required data. Although Paterson police officers are represented through a local union (Policeman’s Benevolent Association \#1), there were no objections or limitations to conducting the study. The organizational structure of the police department is also similar Detroit in that there are several career paths through various divisions of the department. Lastly, the police department underwent a reorganization effort similar to Detroit including personnel demotions and a plan to reinvigorate the agency through an aggressive hiring initiative. 


\section{CHAPTER IV. ANALYSIS AND RESULTS}

Pre-Analysis Data Screening (Diagnostics)

There are four purposes to pre-screening data prior to conducting multivariate

analyses: Data accuracy, incomplete data, extreme values (i.e., outliers) and adequacy of fit between the data and the assumptions of the statistical tests that are used (Mertler and Vannatta, 2005). If the data are not accurate, then interpretation of the statistical results will not be accurate, thus compromising valid conclusions. Various statistical tests are used to assess each of these conditions prior to multivariate analyses to ensure the data are adequate for this research. Additional data screening techniques are used prior to multivariate analysis to ensure the data are free from colinearity problems.

\section{Data Accuracy}

Proofreading the data to check for coding errors ensures the subsequent analyses are accurate (Jacob, 1984). For the quantitative explanatory variables in this research, five descriptive statistics were computed to ensure all of the data were properly coded: Mean, standard deviation, minimum, maximum and range. The means and standard deviations were examined to determine if the scores are plausible, that is, whether they fall within acceptable limits; this is an added measure of data accuracy that supports the range statistic. There are 65,001 individual survey questions (126 survey questions $\times 461$ participants). All values are within the specified numeric range meaning no items were miscoded and the means and standard deviations are plausible supporting the accuracy of the range of the data.

The data collected by each police department that reflects the criterion variable cannot be checked for accuracy in the same manner as the explanatory variables. These 
data may contain flaws due to the structural characteristics of the data collection process such as changing definitions, inconsistent rules or procedures for capturing the data, clerical errors, post-hoc corrections made by the agency, deliberate manipulation of the data and different classification of the data (Jacob, 1984). This is a limitation of this research and is acknowledged further under the “agency records” subsection of the “limitations" section.

\section{Incomplete (Missing) Data}

Missing data introduces bias into the inferences from the data, especially if the data are treated as though every case were a complete record. The problem with missing values is not so much a reduced sample size as it is the possibility that the remaining data set is biased. The statistical literature is mixed as to what procedure should be used to adjust for this deficiency; a compromise between the advantages and disadvantages of various techniques is the primary determinant (Allison, 2001; Little and Rubin, 1987; Pickles, 2005; Schafer and Olsen, 1998). Missing data was handled using listwise deletion, which, is the SPSS default standard. The analysis includes only complete cases and no effort was made to impute or otherwise substitute data for hypothetical values. Although listwise deletion often results in a decrease in the sample size available for the analysis and a concurrent decrease in power, the advantage is that it leads to unbiased parameter estimates (Little and Rubin, 1987). The proportion of missing data excluded from analysis via listwise deletion is stated and possible reasons are discussed under descriptive statistics. 


\section{Extreme Values (Outliers)}

Extreme values, known as outliers, can distort the results of analysis since many techniques are sensitive to such deviations (Tabachnick and Fidell, 2001). An outlier is any case with an extreme or unusual value on a single variable (Univariate) or on a combination of variables (Multivariate) (Meyers, Gamst and Guarino, 2006:65). The test for outliers includes converting the raw scores for the criterion and explanatory variables into $\mathrm{z}$-scores, then examining the minimum and maximum scores against the conventional standard based on the sample size. The conventional standard for a sample size greater than 100 is $z>+4.00$ and $z<-4.00$ (Stevens, 1992); the sample size in this research 461, so outliers are any scores whose minimum or maximum value fall outside this range.

None of the explanatory variables shows extreme values (Table 9). However, the upper bound of the criterion variable is slightly outside the suggested standard of $>+4.00$ (4.90, Table 9). To examine this finding further, Mahalanobis distance $\left(D^{2}\right)$ was calculated to identify the extent of the outliers. Mahalanobis distance values are evaluated using the chi-square $\left(\chi^{2}\right)$ distribution and a rigorous alpha level $(p=<.001)$, where the degrees of freedom are equal to the number of explanatory variables (12 in this research). The critical value for chi-square at $p<.001$ with twelve degrees of freedom is 32.910. Two cases, $65\left(D^{2}=42.079\right)$ and $80\left(D^{2}=44.758\right)$, exceed the critical value. As a guiding principle, Hair et al. (1998) suggest considering cases with a z-score greater than \pm 2.5 as outliers. The $z$-score for case 65 is .806 and for case 80 the $z$-score is -.838 , neither of which approach the \pm 2.5 outlier threshold. Cohen, Cohen, West and Aiken (2003:128) recommend that "if outliers are few (less than $1 \%$ or $2 \%$ of $N$ ), and not very 
extreme, they are probably best left alone.” Cases 65 and 80 represent less than $1 \%$ of the total cases and their values are not very extreme, therefore, both were retained as part of the criterion variable and included in the analysis.

\begin{tabular}{|c|c|c|}
\hline \multicolumn{3}{|c|}{$\begin{array}{l}\text { Table } 11 \\
\text { z-score Values on Criterion and Explanatory Variables' Test for Outliers }(N=461)\end{array}$} \\
\hline \multirow{2}{*}{ Variable } & \multicolumn{2}{|c|}{ z-scores } \\
\hline & Minimum & Maximum \\
\hline \multicolumn{3}{|l|}{ Criterion } \\
\hline Performance & -1.19 & 4.90 \\
\hline \multicolumn{3}{|l|}{ Explanatory } \\
\hline Supervision and Administration & -2.54 & 1.23 \\
\hline Professionalism & -2.03 & 1.56 \\
\hline Locus of Control & -1.29 & 2.61 \\
\hline Facilities and Equipment & -2.37 & 1.33 \\
\hline Favoritism & -1.12 & 2.53 \\
\hline Self-esteem & -1.29 & 2.55 \\
\hline Staffing & -1.98 & .998 \\
\hline Bureaucracy & -1.49 & 1.63 \\
\hline Promotions & -.890 & 2.66 \\
\hline Communications & -1.72 & 1.49 \\
\hline Internal Affairs & -1.23 & 1.78 \\
\hline Rating System & -1.05 & 1.77 \\
\hline
\end{tabular}

\section{Adequacy of Fit}

A test of data adequacy is to ensure the data meet the assumptions required for inferential analysis techniques. When assumptions about the data are violated, then biased conclusions may result from using multivariate techniques (Kennedy and Bush, 1985). The first assumption to be tested is normality, which is the extent to which the data are normally distributed. A normal probability plot was created for each explanatory variable and the criterion variable to examine the increasing order of magnitude for each variable, plotted against the expected value. To be defensible, normality should correspond to a straight line. The data points are reasonably close to the expected values, 
thus a normal distribution is assumed for each of the variables, which makes them suitable for analysis (Figures 2-14).

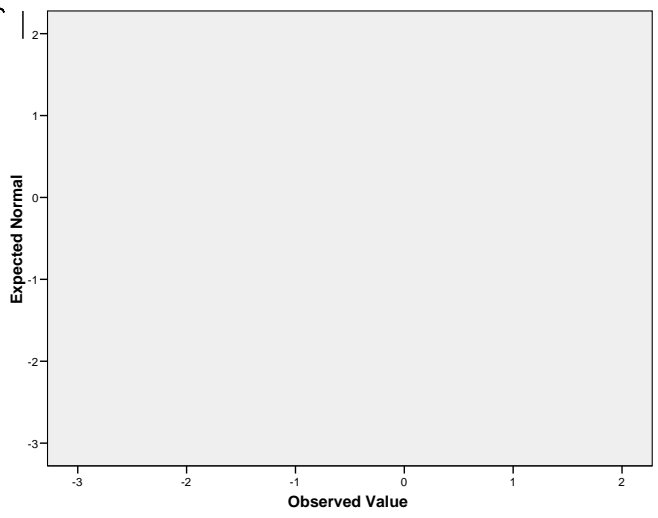

Figure 2

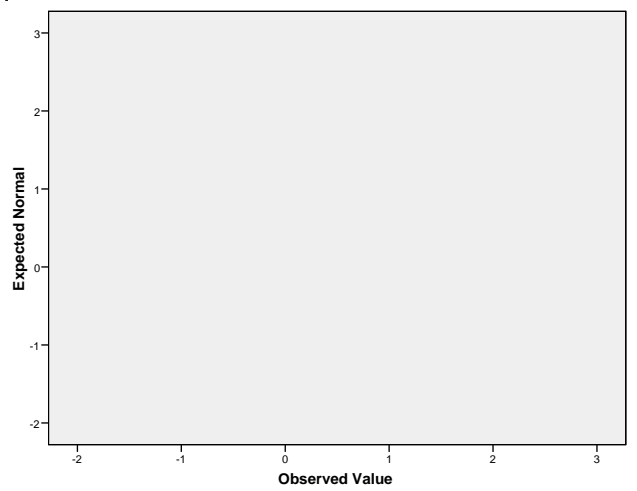

Figure 4

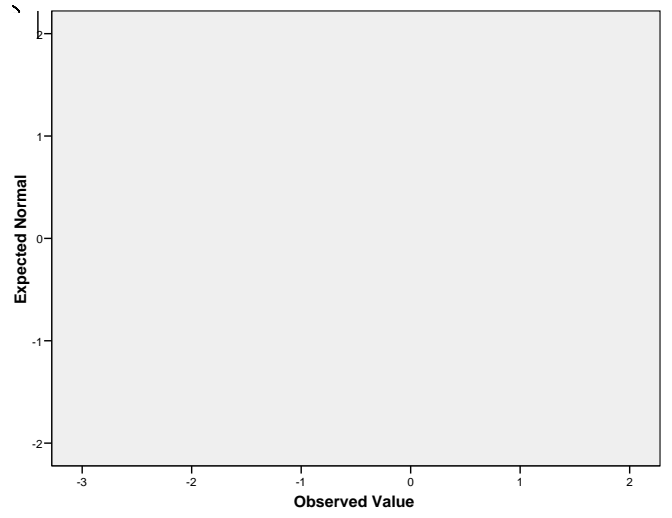

Figure 3

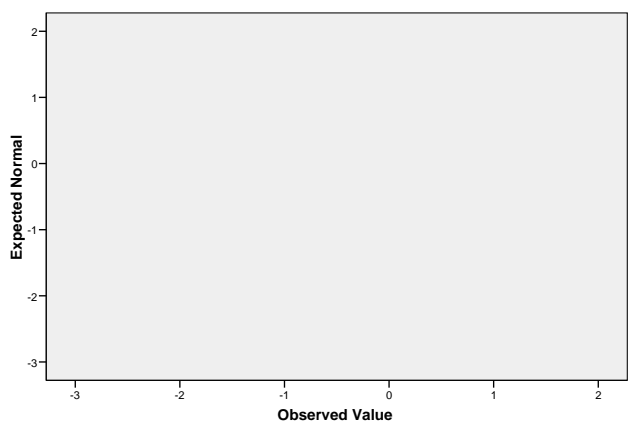

Figure 5 


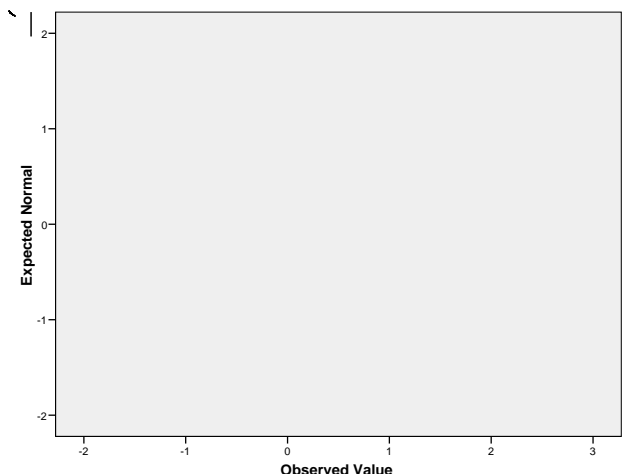

Figure 6

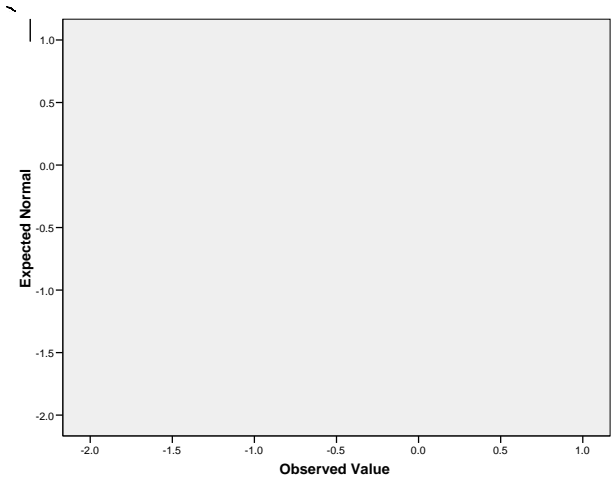

Figure 8

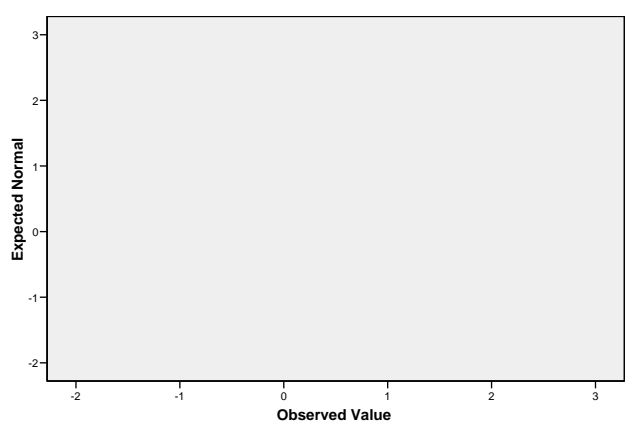

Figure 7

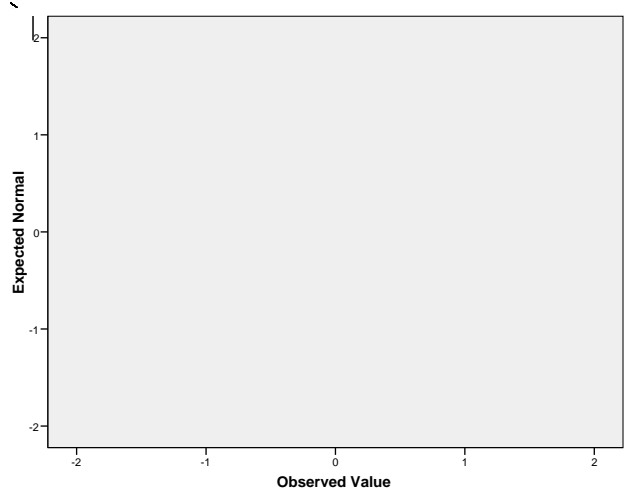

Figure 9 


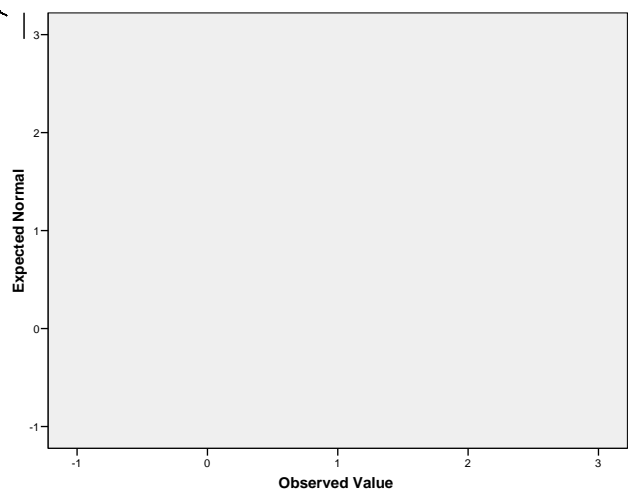

Figure 10

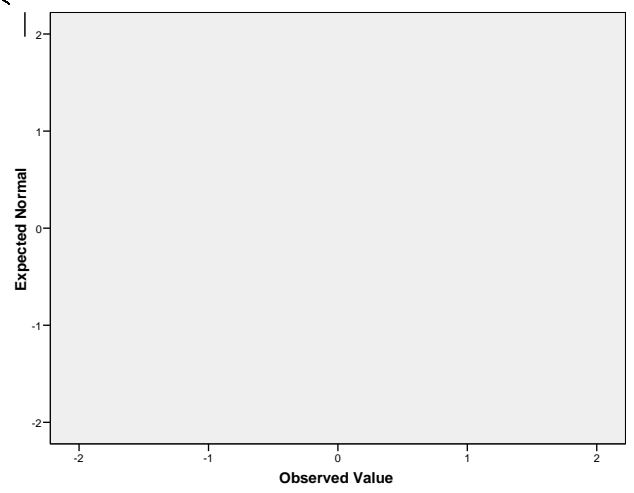

Figure 12

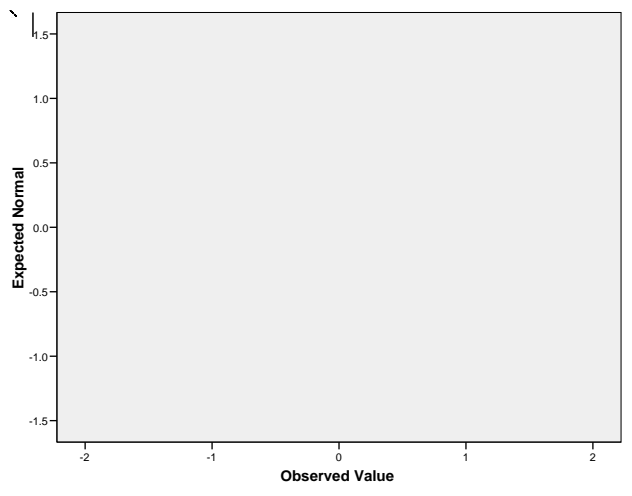

Figure 11

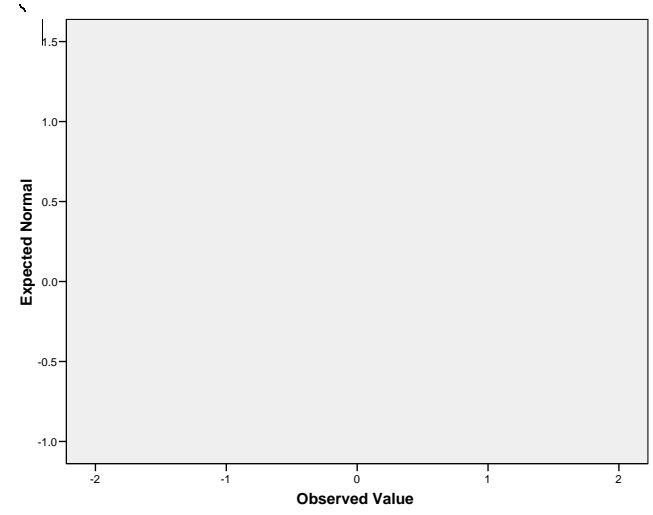

Figure 13 


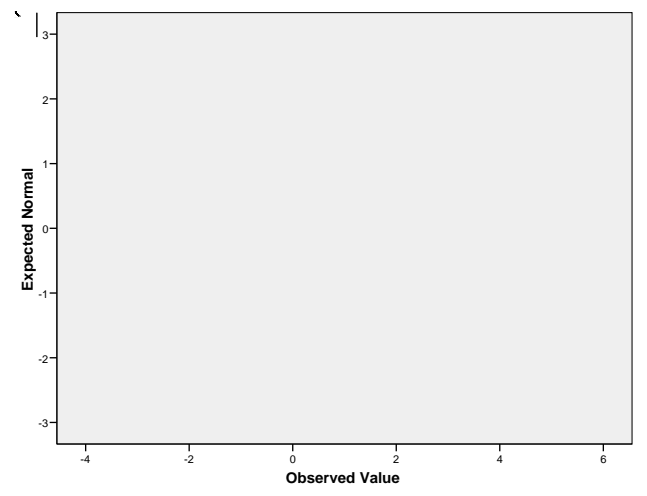

Figure 14

\section{Power Analysis}

Statistical power is the probability of detecting a meaningful difference, or effect, if one actually exists; "statistical power provides an estimate how often one would fail to identify a relationship that in fact existed” (Weisburd, Petrosino and Mason, 1993:340). It is the ability to make correct decisions (Accept or reject) about the hypothesis. When testing a hypothesis the idea is to correctly accept it or reject it based on empirical observation.

To test the hypotheses, the primary analytic techniques are correlation analysis and multiple regression analysis, since the criterion and explanatory variables are continuous (Quantitative). Using the standard significance level $(p<.05)$, with 12 explanatory variables, an anticipated effect size of .15, and a desired power level of .80, a sample size of 127 is required for an a priori multiple regression model; the sample size in this research is 461 . The power analysis suggests that this research is very likely to detect significant effects. Although power estimates vary a bit across statistical tests, this study’s design allows for very high statistical power if effects are moderate or even somewhat smaller (Table 12). 


\begin{tabular}{lr}
\hline Table 12 & \\
Power Analysis & .05 \\
\hline \hline Alpha Level & .15 \\
Anticipated Effect Size & .80 \\
Desired Statistical Power Level & 12 \\
Number of Predictors & 127 \\
Minimum Required Sample Size & \\
\hline
\end{tabular}

\section{Data Reduction (Factor Analysis)}

Before testing the hypotheses, a factor analysis of the two stress surveys was conducted to examine the utility of the samples. Factor analysis examines the underlying structure of multivariate data in a process that reduces the data and isolates the variables that measure the constructs in Kahn and Byosiere's (1992) model that are believed to be related to stress. This technique was selected to help explain the variability among observed variables, essentially to identify the extent to which there is measurement overlap (i.e., shared variance) (Williams, 1992), thus creating a more parsimonious model. The method by which factors are determined from the larger group of variables is extraction; principal components analysis (PCA) is perhaps the most common extraction method (Bryant and Yarnold, 1995; Meyers, Gamst and Guarino, 2006; Stevens, 1992) and is used in this research since Kahn and Byosiere's (1992) theoretical model suggests the factors should be correlated.

PCA with Varimax rotation and Kaiser Normalization was conducted to assess the underlying structure of the combined 65 items from the Police Stress Questionnaire and Daily Hassles and Uplifts Scale that measure organizational stress. Following the general recommendations of Comrey and Lee (1992) for sample size evaluation, the sample in this research $(N=461)$ is at the high end of "good" for factor analysis; they estimate a "good" sample size is 300 and a "very good" sample size is 500 participants, 
meaning the variables-to-cases ratio is adequate for factor analysis (In Meyers, Gamst and Guarino, 2006:467). The items indexed twelve factors that fit four constructs of Kahn and Byosiere’s (1992) model; the four constructs are: 1) Organizational antecedents, 2) stressors in organizational life, 3) properties of the person as stress mediators and 4) properties of the situation as stress mediators (Table 15). The data was tested for suitability using three standard measures: 1) Kaiser-Meyer Olkin (KMO), 2) Bartlett's Test of Sphericity and 3) the determinant value of the correlation matrix (Leech, Barrett and Morgan, 2008; Tabachnick and Fidell, 2001). All three measures indicate the data are suitable for factor analysis (Table 13). The KMO measure of sampling adequacy is .816, which exceeds the standard .70 indicating sufficient items for each factor. Similarly, Bartlett's test of sphericity is significant at the .05 level $(p<.001)$ indicating the correlation matrix is significantly different from an identity matrix, where correlations between variables are all zero. This means the variables are correlated highly enough to provide a reasonable basis for factor analysis. The determinant value of the correlation matrix is $9.52 \mathrm{E}-042$, which is greater than .0001 indicating there is no linear combination of the items.

\begin{tabular}{llr}
\hline Table 13 & & \\
KMO and Bartlett's Test of Assumptions with Determinant Value \\
\hline \hline \multicolumn{2}{l}{ Kaiser-Meyer-Olkin Measure of Sampling Adequacy } & .816 \\
Bartlett's test of sphericity & Approximate $\chi^{2}$ & 36695.852 \\
& $d f$ & 2080 \\
& $p$ & .000 \\
Determinant Value & & $9.52 \mathrm{E}-042$ \\
\hline
\end{tabular}

Using the Kaiser-Guttman retention criterion of Eigenvalues greater than 1.0, a twelve-factor solution provide the clearest extraction accounting for $74.8 \%$ of the total variance and none of the items cross loaded, which is a robust solution (Tabachnick and 
Fidell, 2001). A Scree plot supported this finding. Table 14 presents the rotated factor matrix, which includes the 36 items, their communality estimates, Eigenvalues and percentage of variance (See appendix 9 for the original scale items). Communalities were high for each of the 36 items, with a range of .706 to .894. The naming convention for the twelve factors was partly guided by Comrey and Lee (1992) and Rummel (1970), where only factor loadings greater than .60 are included to motivate the labeling and interpretation for each factor. The decision to retain factor loadings greater than .60 follows Comrey and Lee’s (1992) recommendation for magnitudes that are sufficiently related to the underlying factor to ensure the interpretation of the factor is relevant. Since a composite index for the predictor variables is used, factor loadings greater than .60 are more stringent, which improves reliability. Items are ordered in relation to size to facilitate interpretation and improve clarity.

After rotation, the first factor accounts for $37.4 \%$ of the variance; the second factor accounts for $8.6 \%$; the third factor accounts for $6.3 \%$; the fourth factor accounts for 4.4\%; the fifth factor accounts for 3.8\%; the sixth factor accounts for 3\%; the seventh factor accounts for $2.7 \%$; the eighth factor accounts for $2.6 \%$; the ninth factor accounts for $2.5 \%$; the tenth factor accounts for $2.3 \%$; the eleventh factor accounts for $2 \%$; and the twelfth factor accounts for $1.7 \%$. 
Table 14

Factor Loadings for the Varimax Rotated Factors

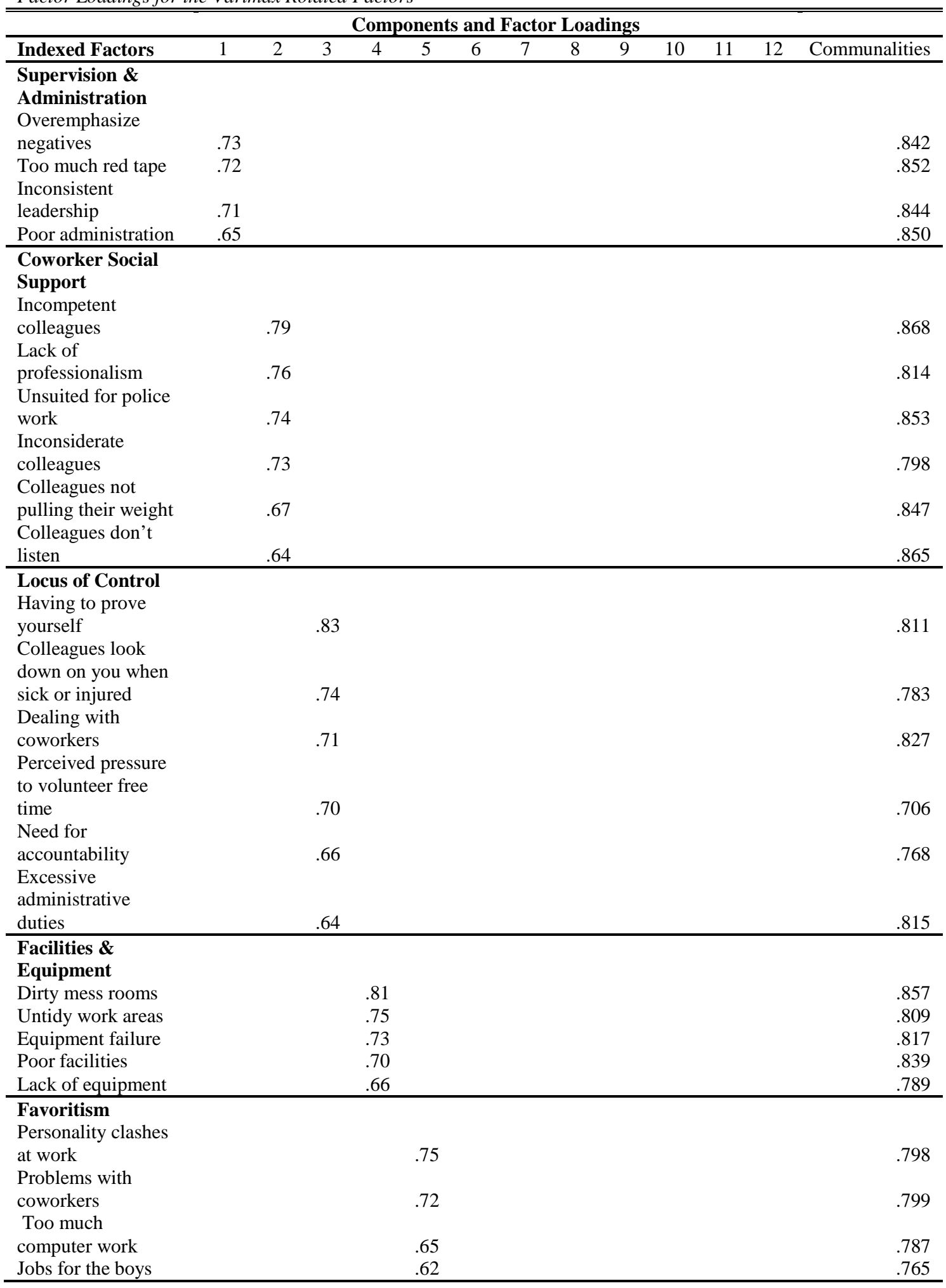


Self-esteem \&

Individuality

Not able to do anything

Staying objective

Feeling inadequate

.66

\section{Bureaucracy}

Excessive

paperwork

Unnecessary forms

\section{Promotional}

\section{Process}

Studying for work

Exams for work

Communication

Lack of honesty

from superiors

\section{Staffing}

Staff shortages

Internal Affairs

Internal

investigations

.62

.76
69

Rating System

Unfair promotions

Eigenvalues

\% of variance

$\begin{array}{lllll}24.3 & 5.6 & 4.0 & 2.8 & 2.5\end{array}$

2.5

\begin{tabular}{lll}
1.9 & 1.7 \\
\hline & 3.0 & 2.7
\end{tabular}

1.1

Note: Varimax rotation with Kaiser Normalization; Loadings $<.60$ are omitted

\begin{tabular}{|c|c|c|c|c|}
\hline \multicolumn{5}{|c|}{$\begin{array}{l}\text { Table } 15 \\
\text { Indexed Factors and Stress Constructs }\end{array}$} \\
\hline & \multicolumn{4}{|c|}{ Stress Constructs } \\
\hline \multirow{5}{*}{$\begin{array}{l}\text { Indexed } \\
\text { Factors }\end{array}$} & $\begin{array}{l}\text { Organizational } \\
\text { Antecedents }\end{array}$ & $\begin{array}{c}\text { Stressors in } \\
\text { Organizational } \\
\text { Life }\end{array}$ & $\begin{array}{c}\text { Properties of the } \\
\text { Person as Stress } \\
\text { Mediators }\end{array}$ & $\begin{array}{l}\text { Properties of the } \\
\text { Situation as } \\
\text { Stress Mediators }\end{array}$ \\
\hline & Bureaucracy & $\begin{array}{l}\text { Facilities and } \\
\text { equipment }\end{array}$ & Locus of control & $\begin{array}{l}\text { Supervision and } \\
\text { administration }\end{array}$ \\
\hline & $\begin{array}{l}\text { Communication } \\
\text { and feedback }\end{array}$ & $\begin{array}{l}\text { Promotional } \\
\text { process }\end{array}$ & $\begin{array}{l}\text { Self-esteem and } \\
\text { individuality }\end{array}$ & $\begin{array}{l}\text { Co-worker social } \\
\text { support }\end{array}$ \\
\hline & $\begin{array}{l}\text { Organizational } \\
\text { capacity/staffing }\end{array}$ & Internal affairs & & Favoritism \\
\hline & & Rating system & & \\
\hline
\end{tabular}

\section{Transforming the Variables (Computing the z-scale)}

Once the factors loaded on the components, the criterion and explanatory

variables were transformed into $z$-scores. The $z$-score standardizes the raw scores from 
the original data making them easier to compare and easier to grasp the magnitude of every score in the analysis without having to recall the details of the original measurement scale. Converting the raw scores to a common metric (i.e., the z-score) makes measurement and interpretation from different scales meaningful. The z-scores are then used to construct the composite measures of the criterion variable and the explanatory variables, which are then used for analysis. The metrics for the PSQ and DHUS are discrepant. Both instruments measure responses via different Likert-type scales with different metrics: The PSQ measures responses from 1 (No stress at all), to 4 (Moderate stress) to 7 (A lot of stress), and the DHUS measures responses from 1 (Definitely did not hassle or bother me) to 2-4 (Hassled or bothered me to some extent) to 5 (Strongly hassled or bothered me). This necessitates converting the data $z$-scores. Descriptive Statistics

The data in this study consists of survey responses that measure stress and agency records that measure performance; the data are summarized in Table 16. The performance data (Criterion variable) were collected from internal agency records and were reduced to a composite index, which includes: 1) arrests, 2) citations, 3) reports completed, 4) self-initiated investigations, 5) self-initiated stops, 6) sick hours, 7) citizen complaints, 8) administrative complaints, 9) on-duty injuries, 10) on-duty motor vehicle accidents and 11) ratio of failure to appear in court (\# of times failed to appear/\# of times scheduled to appear). Some of the individual measures for the criterion variable include missing data, however, the number of valid cases suitable for analysis does not decrease statistical power to a degree that would render the data useless or unreliable for multivariate analysis. For an explanation why these data are missing, see the "agency 
records" subsection under the "limitations" section. The mean performance score was 29.49 with a standard deviation of 24.7, which suggests a high degree of variability.

The explanatory variables were collected via the PSQ and DHUS. After factor analysis reduced the items to meaningful factors, composite scores were created from zscores for each of the following factors: 1) supervision and administration, 2) co-worker support, 3) locus of control, 4) facilities and equipment, 5) favoritism, 6) self-esteem, 7) bureaucracy, 8) promotions, 9) communications and feedback and 10) rating system. There is relative consistency across explanatory variables as reflected in the standard deviations, where the maximum value is 1.41 and the minimum value is 1.07 with a range of .34, which suggests relative agreement among officers about their perceptions of the police department as a source of stress.

The control variables were also collected via the PSQ and DHUS. All of the control variables are grouped; some assume interval-level properties such as age, education level and number of children, others assume ordinal-level properties such as education level and others assume nominal-level properties such as sex, race and marital status. The control variable "age” has a mean of 2.37 and a standard deviation of .716. Most officers are relatively young between 25-34 years old with the next largest group between 35-44 years of age. Cumulatively, these two groups account for $90 \%$ of study participants.

Most officers participating in the study self-identify their race as black (51.8\%). Overall, the sample has a mean 3.99 and a standard deviation of 1.07. This is consistent with the racial demographics of both cities, with Detroit having more Black residents and Paterson having more White residents. Similarly, most study participants are male 
(67.9\%); the sample mean is 1.71 with a standard deviation of .453 . This is consistent with the over representation of males in the policing profession in the United States. ${ }^{57}$

The general education requirement for most entry-level police officers is a high school diploma or general equivalency diploma. While some departments across the country require at least some college, that requirement is not standardized across the industry. Participants in this study have higher education with 51.2\% having some college. Overall, 376 participants (85\%) have a combination of college experience somewhere between less than an associate's degree and a graduate degree. The sample has a mean of 2.36 with a standard deviation of .955 .

The single largest group in this study identifies their marital status as married (41.9\%). However, overall marital status suggests that most police officers in the study are without a spouse $(M=2.87 ; S D=1.78)$ whether being single, separated or divorced. The number of children present in the officers' household is nearly evenly split between 0 (28.4\%), 1(29.1) and 2 (27.1\%); the group has a mean of 1.31 and a standard deviation of 1.13. Two factors that may mediate stress are the distance from work (Measured in miles) and the commuting time. The majority of officers (89.8\%) live within thirty miles from work; this group has a mean of 1.61 and a standard deviation of .673. Distance from work is correlated with commuting time $(.556 ; p<.001)$. Since nearly $90 \%$ of the participants live within thirty miles of work, their commuting time is relatively low. Overall, $98 \%$ of officers drive less than forty-five minutes to work with the majority of officers driving between 15-29 minutes. This group has a mean of 2.12 and a standard deviation of .733. This may be affected residency requirements, which I will briefly explain. 
Residency requirements for Detroit and Paterson differ slightly and necessitate some clarification. Detroit rescinded its residency requirement and does not mandate that officers live within city limits. Although given the opportunity to reside wherever they choose, most police officers live within thirty miles of Detroit, which keeps their commuting time relatively low. Paterson has a residency requirement established by city ordinance; however, the ordinance is limited by a combination of New Jersey statute and New Jersey Civil Service regulation. Civil service regulation grants municipalities the right to enact residency requirements for police officers via city ordinance at the time of application for the civil service exam. This means a person must establish residency in the municipality at the time they apply to take the entrance exam. However, state law prohibits any municipality from mandating continued residency after the person is hired as a police officer. This means after a person is hired by a police agency they are free to move anywhere in New Jersey. While police officers are free to reside throughout New Jersey, it appears that Paterson police officers live within a relatively short driving distance to work. Where an officer chooses to reside may reduce the officer's fatigue since commuting times are shorter.

Police officers are permitted to work secondary employment to supplement their income (i.e., moonlighting). Most officers (80.7\%) appear to keep off-duty employment to a minimum and did not work more than ten hours in the previous month $(M=1.27$; $S D=.661)$. Similarly, police officers do not appear to spend an inordinate amount of time in court during off duty hours. The majority (60.5\%) spent less than ten hours in court in the previous month; cumulatively, $94 \%$ spent no more than twenty hours $(M=$ 1.48; $S D=.761)$. 
Table 16

Descriptive Statistics for the Variables in the Analysis

\begin{tabular}{lrlrr}
\hline \multicolumn{1}{c}{ Variable } & \multicolumn{1}{c}{ N } & Metric & Mean & Std. Dev. \\
\hline Criterion Variable (Composite Index) & \multicolumn{1}{c}{--} & Continuous & 29.48 & 24.74 \\
Arrests & 448 & Continuous & 22.40 & 24.32 \\
Citations & 437 & Continuous & 42.96 & 62.34 \\
Reports Completed & 297 & Continuous & 175.01 & 127.26 \\
Self-initiated Stops & 266 & Continuous & 77.59 & 83.70 \\
Self-Initiated Investigations & 251 & Continuous & 73.31 & 82.52 \\
Sick Hours & 435 & Continuous & 42.63 & 57.82 \\
Citizen Complaints (External) & 461 & Continuous & .17 & .377 \\
Administrative Complaints (Internal) & 461 & Continuous & .14 & .348 \\
On-duty Injuries & 435 & Continuous & .03 & .164 \\
On-duty Auto Accidents & 422 & Continuous & .05 & .237 \\
Failure to Appear Ratio & 396 & Continuous & .04 & .123 \\
& & & & \\
Predictor Variables (Composite Index) & --- & Continuous & --- & -- \\
Supervision and Administration & 461 & Continuous & 4.36 & 1.32 \\
Co-worker Support & 461 & Continuous & 3.26 & 1.11 \\
Locus of Control & 461 & Continuous & 2.71 & 1.32 \\
Facilities and Equipment & 461 & Continuous & 3.56 & 1.07 \\
Favoritism & 461 & Continuous & 2.22 & 1.09 \\
Self-esteem & 461 & Continuous & 2.34 & 1.04 \\
Staffing & 461 & Continuous & 4.99 & 2.00 \\
Bureaucracy & 461 & Continuous & 2.90 & 1.27 \\
Promotions & 461 & Continuous & 2.00 & 1.12 \\
Communication and Feedback & 452 & Continuous & 3.18 & 1.26 \\
Rating System & 461 & Continuous & 2.49 & 1.41 \\
Internal Affairs & 460 & Continuous & 3.45 & 1.98
\end{tabular}

\section{Control Variables}

Age

18-24 (4.8\%)

25-34 (59\%)

35-44 (29.1\%)

45-54 (3\%)

$55+(2 \%)$

Race

Native (American, Alaskan)
Asian

Black (51.8\%)

Islander

White (41.\%)

Other (4.8\%)
$451 \quad 1$ to 5

2.37

.716

221

$272 \quad 2$

$134 \quad 3$

144

95

$450 \quad 1$ to 6

3.99

1.07
$0 \quad 1$

$0 \quad 2$

2393

$0 \quad 4$

1895

226 
Sex

Female (27.3\%)

Male (67.9\%)

Education Level

High School (14.1\%)

Some College (51.2\%)

Associates Degree (12.8\%)

Bachelors Degree (17.1\%)

Graduate Degree (.4\%)

$\mathrm{PhD}(0 \%)$

Marital Status

Married (41.9\%)

Separated (.7\%)

Divorced (19.3\%)

Widowed (0\%)

Single (36\%)

Number of Children

$$
\begin{aligned}
& 0 \text { (28.4\%) } \\
& 1(29.1 \%) \\
& 2(27.1 \%) \\
& 3(7.6 \%) \\
& 4(5.4 \%)
\end{aligned}
$$

Miles from Work

$$
\begin{aligned}
& <15(49.2 \%) \\
& 16-30(40.6 \%) \\
& 31-60(9.3 \%) \\
& 61-100(.4 \%) \\
& 101-150(0 \%) \\
& >150(0 \%)
\end{aligned}
$$

Commuting Time

$$
<15 \text { minutes (17.4\%) }
$$

$15-29$ (55.3\%)

30-44 (25.6\%)

45-60 (.7\%)

$1-1.5$ hours $(.7 \%)$

$>1.5$ hours $(.2 \%)$

Hours of Off-duty Employment

$<10(80.7 \%)$

$10-20(9.5 \%)$

21-30 (4.6\%)

$>30$ (2.4\%)

Hours in Court

$<10(60.5 \%)$

10-20 (28.4\%)

21-30 (1.3\%)
$439 \quad 1$ and 2

1.71

1261

3132

$441 \quad 1$ to 6

2.36

.955

651

$236 \quad 2$

$59 \quad 3$

$79 \quad 4$

25

06

$451 \quad 1$ to 5

2.87

1.78

1931

32

893

$0 \quad 4$

1665

450 Continuous

1.31

1.13

131 Continuous

134 Continuous

125 Continuous

35 Continuous

25 Continuous

$459 \quad 1$ to 6

1.61

.673

$227 \quad 1$

$187 \quad 2$

$43 \quad 3$

24

$0 \quad 5$

$0 \quad 6$

$459 \quad 1$ to 6

2.12

.733

$80 \quad 1$

$254 \quad 2$

1183

34

35

16

$448 \quad 1$ to 4

1.27

.661

3721

$44 \quad 2$

213

114

$438 \quad 1$ to 4

1.48

.761

2791

1312

63 


\section{Bivariate Correlation Analysis}

Pearson's correlation analysis provides a first look at the relationships between the dependent and explanatory variables and helps answer the first research question (To what extent do perceived organizational stressors correlate with police performance?). Table 15 presents the bivariate correlations, which suggests some support for Kahn and Byosiere's (1992) model that certain stress markers are associated with a decrease in performance. Eight of the twelve explanatory variables (Co-worker social support; locus of control; favoritism; self-esteem; promotions; communication and feedback; internal affairs and rating system) show a statistically significant relationship with the outcome variable (Police performance) at the bivariate level and are in the direction of causal theory. The strength of the relationships are moderate to weak ranging from -.344 to .079 .

This finding suggests, in substantive terms, that performance tends to decrease where each of these explanatory factors is more pronounced. Although supervision and administration has a negative relationship with police performance, which is in the direction of causal theory, the relationship is weak and is not statistically significant. Staffing shows an inverse relationship with performance and is also not statistically significant. Likewise, facilities and equipment and bureaucracy show a positive relationship with police performance, also in the direction of causal theory, however neither is statistically significant. The three strongest relationships with police performance are locus of control $(r=-.334)$, rating system $(r=-.226)$ and favoritism ( $r=$ -.211), all are statistically significant at the .01 alpha level. 
This suggests preliminary support for the theory that perceived organizational stressors decrease individual performance. Specifically for the three strongest explanatory variables, police officers who perceive a lack of autonomy and control over situations (Locus of control), the lower their performance. Similarly, the more police officers perceive the rating system as unfair and perceive a sense of inequitableness (Favoritism), the lower their performance. A cautionary note is that while correlation implies causation it does not prove causation. In correlational research, the direction and strength of the relationship are important but often cannot specify the time-order sequence necessary to infer causation. To infer causality, cause must precede the effect and when that cannot be determined, the research suffers from a limitation known as ambiguous temporal precedence (Shadish, Cook and Campbell, 2002:55).

Further examination of the variables reveals there is no threat of colinearity. The highest correlation is .655 (Facilities and equipment $\times$ supervision and administration) and does not exceed the conventional level of .70, where colinearity becomes a problem (Allison, 1999:64; Bachman and Paternoster, 2004:512; Meyers, Gamst and Guarino, 2006:181). Multicolinearity is examined further through tolerance and variance inflation factor (VIF) scores during multivariate analysis. 


\begin{tabular}{|c|c|c|c|c|c|c|c|c|c|c|c|c|c|c|}
\hline & & 1 & 2 & 3 & 4 & 5 & 6 & 7 & 8 & 9 & 10 & 11 & 12 & 13 \\
\hline 1 & $\begin{array}{l}\text { Performance } \\
\text { score (DV) }\end{array}$ & 1 & & & & & & & & & & & & \\
\hline 2 & $\begin{array}{l}\text { Supervision } \\
\text { administration }\end{array}$ & -.001 & 1 & & & & & & & & & & & \\
\hline 3 & $\begin{array}{l}\text { Co-worker } \\
\text { social support }\end{array}$ & $-.098^{*}$ & $.527^{* *}$ & 1 & & & & & & & & & & \\
\hline 4 & $\begin{array}{l}\text { Locus of } \\
\text { control }\end{array}$ & $-.334 * *$ & $.287 * *$ & $.449 * *$ & 1 & & & & & & & & & \\
\hline 5 & $\begin{array}{l}\text { Facilities and } \\
\text { equipment }\end{array}$ & .079 & $.655^{* *}$ & $.550 * *$ & $.239 * *$ & 1 & & & & & & & & \\
\hline 6 & Favoritism & $-.211 * *$ & $.365 * *$ & $.498 * *$ & $.584 * *$ & $.294 * *$ & 1 & & & & & & & \\
\hline 7 & Self-esteem & $.146 *$ & $.328 * *$ & $.515 * *$ & $.465 * *$ & $.369 * *$ & $.627 * *$ & 1 & & & & & & \\
\hline 8 & Staffing & -.086 & $.419 * *$ & .054 & $.155^{* *}$ & $.319 * *$ & .013 & -.041 & 1 & & & & & \\
\hline 9 & Bureaucracy & .044 & $.459 * *$ & $.483 * *$ & $.417 * *$ & $.349 * *$ & $.479 * *$ & $.624 * *$ & $.170^{* *}$ & 1 & & & & \\
\hline 10 & Promotions & $-.099 *$ & $.193 * *$ & $.318 * *$ & $.513 * *$ & $.231 * *$ & $.535^{* *}$ & $.532 * *$ & -.003 & $.381 * *$ & 1 & & & \\
\hline 11 & $\begin{array}{l}\text { Communication } \\
\text { and feedback }\end{array}$ & $-.133^{* *}$ & $.494 * *$ & $.475 * *$ & $.192 * *$ & $.342 * *$ & $.306 * *$ & $.318^{* *}$ & .063 & $.363 * *$ & $.267 * *$ & 1 & & \\
\hline 12 & Internal affairs & $-.175^{* *}$ & $.480^{* *}$ & $.436 * *$ & $.503 * *$ & $.276^{* *}$ & $.387 * *$ & $.304 * *$ & $.128 * *$ & $.288^{* *}$ & $.258^{* *}$ & $.237 * *$ & 1 & \\
\hline 13 & Rating system & $-.226 * *$ & $.388 * *$ & $.294 * *$ & $.285 * *$ & $.194 * *$ & $.290 * *$ & $.239 * *$ & .052 & $.218^{* *}$ & $.396 * *$ & $.387 * *$ & $.198 * *$ & 1 \\
\hline
\end{tabular}

\section{Difference of Means Analysis}

Organizational and Operational Stressors. To investigate whether

organizational stressors and operational stressors differ in a statistically significant way, a paired samples t-test was computed (Table 18). By comparing the difference in means between organizational stressors and operational stressors, we are able to test the second research question (Are perceived organizational stressors higher than perceived operational stressors?). Restated, this research aims to understand the relationship between perceived organizational stressors and police performance and to test the assumption suggested in the literature that scores for organizational stressors are higher than operational stressors.

Individual scores for each participant were transformed into an aggregate score for organizational stressors and operational stressors. As predicted, the paired sample $t$ 
test revealed that there is a statistically significant difference between organizational stressors and operational stressors at the .05 alpha level $(t(212)=p<.001)$. Therefore, we reject the null hypothesis that there is no difference between organizational and operational stressors. Mean scores on organizational stressors $(M=214.18 ; S D=49.83)$ are higher than mean scores on operational stressors $(M=173.86 ; S D=42.46)$. The confidence interval for the difference between the means is 35.93 to 44.70 indicating that the difference could be as small as thirty-six points or as large as large as forty-five points.

\begin{tabular}{|c|c|c|c|c|c|}
\hline \multicolumn{6}{|c|}{$\begin{array}{l}\text { Table } 18 \\
\text { Paired Samples } t \text { Test for Organizational and Operational Stressors Between Cities }\end{array}$} \\
\hline \multirow{3}{*}{ Variables } & \multicolumn{5}{|c|}{$t$ Test on Type of Stressors Between Cities } \\
\hline & \multicolumn{3}{|c|}{ Descriptive Statistics } & \multicolumn{2}{|c|}{ Correlation } \\
\hline & $\mathbf{N}$ & $\mathbf{M}$ & SD & $r$ & $p$ \\
\hline Organizational Stressors & 213 & 214.18 & 49.83 & 764 & 000 \\
\hline \multirow[t]{3}{*}{ Operational Stressors } & 213 & 173.86 & 42.46 & .164 & \\
\hline & \multicolumn{5}{|c|}{ Paired Samples } \\
\hline & $\mathbf{M}$ & SD & & df & $p$ \\
\hline $\begin{array}{l}\text { Organizational Stressors } \\
\text { Operational Stressors }\end{array}$ & 40.31 & 32.43 & 22 & 212 & .000 \\
\hline
\end{tabular}

Detroit Compared to Paterson. The next analysis is to determine whether perceived organizational and operational stressors differ between cities (Table 19). By comparing the difference in means between organizational stressors and operational stressors in Detroit and Paterson, we are able to test the third research question (To what extent do perceived organizational and operational stressors differ between Detroit and Paterson?). The theory suggests the scores should not be significantly different since both police departments are similar on the relevant aspects of their organizational and operational environments including size (They are both large diverse bureaucracies) and 
clientele (They both serve an urban, low socioeconomic, socially disorganized population) who depend more heavily on police than their suburban counterparts.

An independent sample $t$-test was computed to compare the mean scores for organizational stressors and operational stressors for both cities. Significance testing (Levene's $F$ for equality of variance) suggested that equal variances were not present between the samples across each of the independent variables. The results of this analysis did not reveal significant differences between these two groups. Therefore, we fail to reject the null hypothesis that there is no difference between organizational and operational stressors between each city. This finding is consistent with the literature on large urban police departments. Specifically, this result suggests that large urban police departments may be more similar than they are different, regardless of their geographic location (Detroit is in the mid-west region of United States and Paterson is in the midAtlantic region of the United States).

\begin{tabular}{llccc}
\hline Table 19 & & & & \\
Independent Sample t Test for Stressors by City & & & \\
\hline \hline & & $\mathbf{N}$ & $\mathbf{M}$ & SD \\
\cline { 2 - 5 } Descriptive Statistics & & & & \\
Operational Stressors & Detroit & 73 & 214.04 & 53.09 \\
& Paterson & 190 & 215.97 & 49.36 \\
Organizational Stressors & Detroit & 81 & 164.35 & 46.97 \\
& Paterson & 234 & 162.28 & 44.65 \\
\hline Independent Samples & & $\boldsymbol{t}$ & $\mathbf{d f}$ & $\boldsymbol{p}$ \\
Operational Stressors & Equal Variances & \multicolumn{3}{c}{} \\
& Assumed & -.278 & 261 & .781 \\
& Equal Variances & & & \\
& Not Assumed & -.269 & 122.62 & .788 \\
\hline Organizational Stressors & Equal Variances & \multicolumn{3}{|}{} \\
& Assumed & .355 & 313 & .723 \\
& Equal Variances & & & \\
& Not Assumed & .346 & 133.39 & .730 \\
\hline
\end{tabular}


Multivariate Analysis

The bivariate analysis suggests there is a statistically significant inverse relationship between nearly all of the organizational stressors and police performance. This means, the tendency is as perceived organizational stress increases, police performance decreases. The bivariate model is important to establish the strength and direction of the relationship between stress and police performance, but it does not account for the influence other predictors may have on the criterion variable (Police performance). Because there are typically many phenomena occurring at any given time, the bivariate model cannot control for these other influences. Therefore, bivariate correlations cannot answer the primary research question: What is the relationship between perceived organizational stressors and police performance? To answer this question, we use multiple regression analysis.

The stress and control variables were subjected to multiple regression analysis to reveal their unique contributions to predicting police performance. This analytic technique will also help answer the fourth and fifth research questions (Which of the regressed explanatory variables are influential in predicting police performance? and To what extent do various demographic factors significantly influence the relationship between perceived organizational stressors and police performance?) because other simultaneously occurring phenomena can be controlled. To investigate the incremental change in predicted police performance, a hierarchical linear multiple regression model was computed.

Multiple Regression Analysis. Before any multivariate statistics were conducted, tests for the presence of multicollinearity were performed. Multicolinearity 
diagnostics were performed to test whether the explanatory variables are related to each other instead of being related to the criterion variable. Multicollinearity was tested for using tolerance and variance inflation factor (VIF) statistics. Meyers, Gamst and Guarino (2006:212) suggest tolerance values at .01 or less indicate the presence of multicollinearity. Tolerance scores range from .252 to .649, which far exceed the .01 threshold for multicollinearity problems. The VIF statistic is a separate colinearity diagnostic technique. The VIF is the reciprocal of tolerance and Stevens (1992) suggests VIF scores that exceed 10 indicate multicollinearity. VIF scores range from 1.541 to 3.974, which do not approach the conventional level of 10 where multicollinearity becomes a problem. Therefore, the tolerance and VIF values are well within normal bounds, indicating multicollinearity is not present among the explanatory variables.

Table 20 shows the multivariate analysis results of police performance. In this table, the first set of items to be assessed for their influence on performance are organizational antecedents, the broad internal characteristics of the workplace that includes the functional interface between police officers and their operating environment. Communication and feedback is statistically significant $(\beta=-.290 ; p<.001)$. This is predicted by the previous research and suggests that police officers who perceive impaired communication have a tendency to perform lower. The results from bureaucracy and staffing (Organizational capacity) are unexpected and somewhat surprising given previous research. While both are in the direction of causal theory (They indicate a negative relationship), they did not make a statistically significant contribution to police performance, after controlling for various demographic factors. 
The second set of items to be assessed are stressors in organizational life, various job-related stimuli that generate negative consequences for those exposed to them and typically include physical (e.g., buildings, facilities and equipment) and psychosocial (e.g., role conflict, role ambiguity and role overload) aspects of the workplace. As expected, facilities and equipment and the internal affairs function are statistically significant. Facilities and equipment $(\beta=.157 ; p<.01)$ suggests that working in substandard facilities and using substandard equipment tends to lower police performance. Similarly, the more onerous officers perceive the internal affairs function ( $\beta=-.241 ; p<.001$ ), the lower their performance. Two unexpected findings are the rating system and promotions. Both are in the direction of causal theory, yet lost their statistical significance in the multivariate model and did not make a statistically significant contribution to police performance, after controlling for various demographic factors.

The third set of items to be assessed are the properties of the person as stress mediators, which focus on individual coping mechanisms such as personality and selfesteem, all of which may buffer the effects of stress. There are two items in this category, locus of control $(\beta=-.288 ; p<.001)$ and self-esteem $(\beta=.348 ; p<.001)$ that make a statistically significant contribution to performance. The results show that as police officers perceive less control, performance tends to decrease. Similarly, as self-esteem increases, performance also increases. This is an interesting theoretical finding inasmuch as the literature suggests communication and feedback are related to self-esteem. When supervisors praise their subordinate's work product and provide support in the form of feedback, the supervisor may concurrently raise the subordinate's level of self-esteem; 
higher self-esteem means high motivation; higher motivation means increased performance.

In the bivariate model, both locus of control and self-esteem are related to communication and feedback (.192 and .318, respectively; $p<.01)$. To further test the hypothesis_as communication and feedback increase, self-esteem increases-a separate regression model was computed. Using self-esteem as the criterion variable, communication and feedback as the predictor variable and controlling for the same demographic factors, the model is statistically significant, in a positive direction, with a moderate effect size $(R=.545$; adjusted $\mathrm{R}$-square $=.276 ; F(11,367)=14.087 ; p<.001)$. This model indicates that for every one-point increase in the officer's perceived level of positive feedback between them and their superiors, self-esteem is expected to increase by .319 points. Communication and feedback accounts for almost $28 \%$ of the variability in self-esteem.

The fourth set of items to be assessed for their influence on performance are properties of the situation, which includes relations with and support from co-workers and supervisors. There are three items in this category and one is statistically significant. The results show that as the level of perceived favoritism increases, performance decreases $(\beta=-.198 ; p<.001)$. Supervision and administration and co-worker social support did not make a statistically significant contribution to police performance, although they are in the direction of causal theory.

The demographic factors are the last set of items assessed. Specifically, race and education did not make a statistically significant contribution to police performance. Although race is not theoretically relevant, a finding that is not unexpected, education 
level is relevant. Previous research suggests that as education increases, motivation increases; increased motivation results in increased productivity (Performance). However, the finding here shows an inverse relationship—as education increases, performance decreases. Although speculative, this may owe to the fact that as education increases, police officers may become bored because they are not able to use their education since their autonomy is reduced; as boredom rises, disinterest for the job rises; as disinterest rises, performance decreases.

There are some interesting and surprising findings with the demographic variables that make a statistically significant contribution to police performance. The first two items_-driving distance to work and commuting time-are somewhat related. Driving distance is statistically significant at the .001 alpha level and shows a positive relationship with performance; as driving distance increase, police performance increases ( $\beta=.312 ; p<.001)$. This may be, although speculative, because police officers who are further away from their work environment—-deeper into the suburban or rural areas-are more relaxed by the longer drive to and from work and when they are home, they are surrounded by the quiet tranquil atmosphere beyond the urban enclave. Since they are more relaxed, they are more patient and more tolerant, thus less affected by organizational stressors.

However, if my speculation is correct, then it is logical to infer that longer commuting time should also increase police performance. Yet, the finding is opposite: Longer commuting time is associated with decreased performance $(\beta=-.135 ; p<.01)$. This finding is statistically significant and seems intuitive: The longer a police officer spends commuting and enduring the associated hassles of traffic and noise, the tendency 
is toward lower performance. While this seems to make sense, it does not reconcile with driving distance to work.

A similar finding that seems contradictory is the number of hours a police officer works off-duty. The data in this model show that as off duty work hours increase, a police officer's performance also increases $(\beta=.171 ; p<.001)$. This seems counter intuitive since more work is likely to create more physical and mental fatigue, which would concurrently lower performance, however, we find the opposite here. Again speculating, some police officers may enjoy occupying a portion of their free time with work and find solace in that work outside the police department, which helps them relax; when relaxed, they suffer fewer effects of organizational stress. The number of hours a police officer spends in court was also statistically significant in a positive direction $(\beta=.108 ; p<.05)$. As the number of hours spent in court increases, performance also increases. This may reflect a relationship between arrests and traffic citations (Performance indicators) and the overtime associated with going to court.

A police officer's age $(\beta=-.247 ; p<.001)$ and sex $(\beta=.155 ; p<.001)$ make a statistically significant contribution to police performance. The data show that as age increases, performance decreases. Age may be used as a proxy for length of years on the job. Previous research reveals curvilinear findings, that is, feelings of alienation gradually increase until around the fifteenth year of service, thereafter they began to decline (Jirak, 1975). This implies that junior officers may come to the police department with some preconceived ideals and expectations about the job. They may start out with great vigor and enthusiasm, endowed with visions for improving the community, but soon discover the "system" is not the well-oiled machine they once believed it to be. 
Then, around the fifteenth year, their alienation peaks and they stop trying, they become burned out (Maslach and Jackson, 1982). Consequently, their performance decreases.

Male police officers also tend toward higher performance than do female police officers $(\beta=.155 ; p<.001)$. This may be due to the natural aggressive tendencies in males who may assume a protective, almost paternalistic role over their female colleagues when encountering potentially dangerous situations. Male officers may charge headlong into such situations and ultimately come away arresting a suspect or issuing a traffic citation, which adds to their performance score, whereas female officers may tend to discuss circumstances and not resort to arrest as frequently as males.

The final set of items assessed for their influence on performance is marital status and number of children. Both factors make a statistically significant contribution to police performance. Police officers who are married tend to have higher performance $(\beta=-.204 ; p<.01)$. This may be due to the dynamics of the familial relationship, where a police officer uses his or her spouse as a sounding board to diffuse the stress and tension brought on by the agency. However, as the number of children increases, performance decreases. Police officers who reported having more children experienced lower performance scores $(\beta=-.118 ; p<.05)$.

The overall model answers the primary research question, What is the relationship between perceived organizational stressors and police performance? The model summary indicates there is a statistically significant relationship $(p<.001)$ between perceived organizational stressors and police performance, thus making it useful in predicting police performance with a large effect size of .762 and an adjusted R-square value of .554 (Cohen, 1988). The adjusted R-square value indicates that the prediction 
model accounts for a large amount of the variance in police performance; slightly more than $55 \%$ of the variance in police performance is attributable to organizational stressors. The coefficients also provide some insight into model's explanatory value. The beta weights suggest that self-esteem contributes the most to predicting police performance. And, self-esteem can be improved with more communication and feedback from supervisors, a variable that also contributes to predicting police performance.

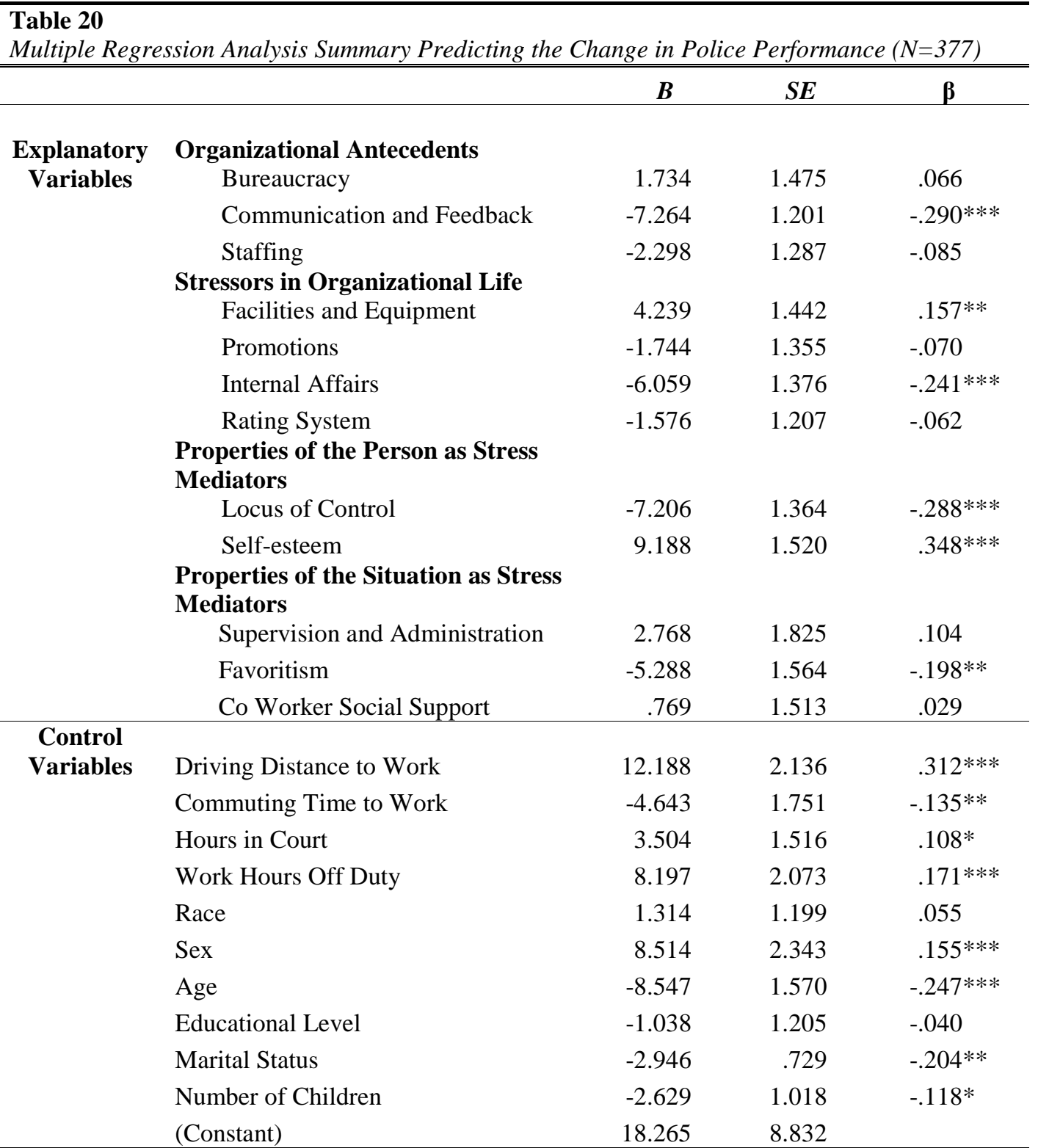

Note: $R=.762 ;$ Adjusted $R^{2}=.554 ; F(22,355)=22.316 ; p<.001$

${ }^{*} p<.05 ; * * p<.01 ; * * * p<.001$ 
Hierarchical Multiple Regression Analysis. Because this research is testing a theoretically driven model of organizational stress, there is a solid basis for selecting the variables in a specific order to determine which explanatory variables produce the most change in the criterion variable. As Kahn and Byosiere's (1992) theory suggests (Figure 1), police officers are exposed first to organizational antecedents, which combine with stressors in organizational life. Police officers then undergo an appraisal process to assess the magnitude and extent of the stress, which may be mediated by properties of the person and/or properties of the situation that ultimately increase or decrease performance. To investigate how well the explanatory variables in this research predict police performance, when adding the variables as a block described in Kahn and Byosiere's (1992) model, hierarchical regression analysis was computed.

Table 21 features five regression stages. The first block (Stage 1) reflects the organizational antecedents and is composed of three explanatory variables: Bureaucracy, communication and feedback, and organizational capacity. As reflected in the R-square value, only $3.6 \%$ of the variance in police performance is predicted by knowing the organizational antecedents. However, adding the other blocks significantly improves prediction. The second block (Stage 2) reflects stressors in organizational life and is composed of four explanatory variables: Facilities and equipment, the promotional process, internal affairs and the rating system. The change in $\mathrm{R}$-square $=.119, F(7,370)$ $=9.721, p<.001$. The third block (Stage 3 ) reflects properties of the person as stress mediators and is composed of two explanatory variables: Self-esteem and individuality, and locus of control. The change in R-square $=.160, F(9,368)=18.847, p<.001$. The 
fourth block (Stage 4) reflects properties of the situation as stress mediators and is composed of three explanatory variables: Supervision and administration, co-worker social support and favoritism. The change in R-square $=.069, F(12,365)=19.000$, $p<.001$. The fifth and final block (Stage 5) reflects the full model with control variables. The control variables are: Race, age, sex, education level, marital status, number of children, driving distance to work, commuting time to work, work hours off duty and hours in court. The change in R-square $=.196, F(22,355)=22.316, p<.001$. The entire group of variables significantly predicts police performance. The beta weights in Table 19 indicate that locus of control, followed by self-esteem, then followed by favoritism contribute the most to predicting police performance.

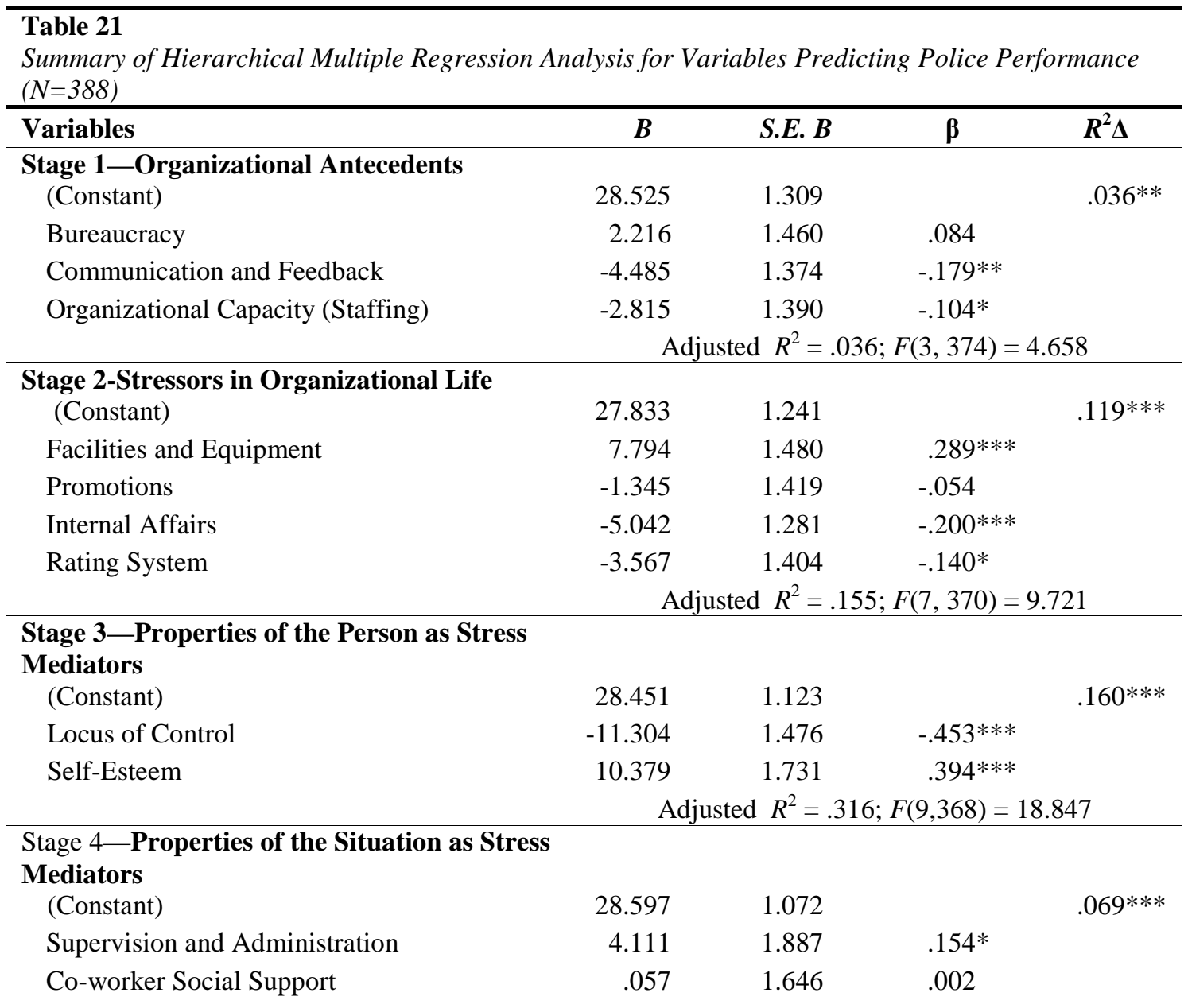




\begin{tabular}{|c|c|c|c|c|}
\hline Favoritism & -9.825 & 1.569 & $-.367 * * *$ & \\
\hline & Adjusted & $R^{2}=.3$ & $12,365)=$ & 00 \\
\hline Stage 5-Control Variables & & & & \\
\hline (Constant) & 18.265 & 8.832 & & $.196 * * *$ \\
\hline Race & 1.314 & 1.199 & .055 & \\
\hline Age & -8.547 & 1.570 & $-.247 * * *$ & \\
\hline Sex & 8.514 & 2.343 & $.155^{* * *}$ & \\
\hline Educational Level & -1.038 & 1.205 & -.040 & \\
\hline Marital Status & -2.946 & .729 & $-.204^{* * *}$ & \\
\hline Number of Children & -2.629 & 1.018 & $-.118 *$ & \\
\hline Driving Distance to Work & 12.188 & 2.136 & $.312^{* * *}$ & \\
\hline Commuting Time to Work & -4.643 & 1.751 & $-.135^{* *}$ & \\
\hline Work Hours Off Duty & 8.197 & 2.073 & $.171^{* * *}$ & \\
\hline Hours in Court & 3.504 & 1.516 & $.108^{*}$ & \\
\hline & Adjusted & $R^{2}=.5$ & $22,355)=$ & \\
\hline
\end{tabular}




\section{CHAPTER V. DISCUSSION AND CONCLUSION}

\section{Discussion}

\section{Summary of Findings}

Kahn and Byosiere's (1992) theory suggests the police organization is a source of stress greater than the nature of police work, which is supported by a wide body of research (e.g., Alexander, et al., 1991; Crank and Caldero, 1991; Davey et al., 2001; Kroes et al., 1974). Previous research points to several facets of the police organization, which are associated with officer stress and subsequently lead to lower performance. Organizational stressors are the niggling aspects of the work environment that pervade police organizations because of the structural arrangements (e.g., bureaucratic, quasimilitaristic environment, role conflict, role ambiguity). These aspects subject the lowest members of the organization to rigid, often conflicting and oppressive, rules and regulations that inhibit effective communications and fail to acknowledge autonomy and individual discretion. Because police officers cannot control or escape from these stressors, organizational theory suggests the consequence is decreased performance. These conditions may be mediated by personal or situational characteristics such as individual personality and relations with supervisors.

The findings of this research are consistent with some of the theoretical principles and inconsistent with others (Table 22). 


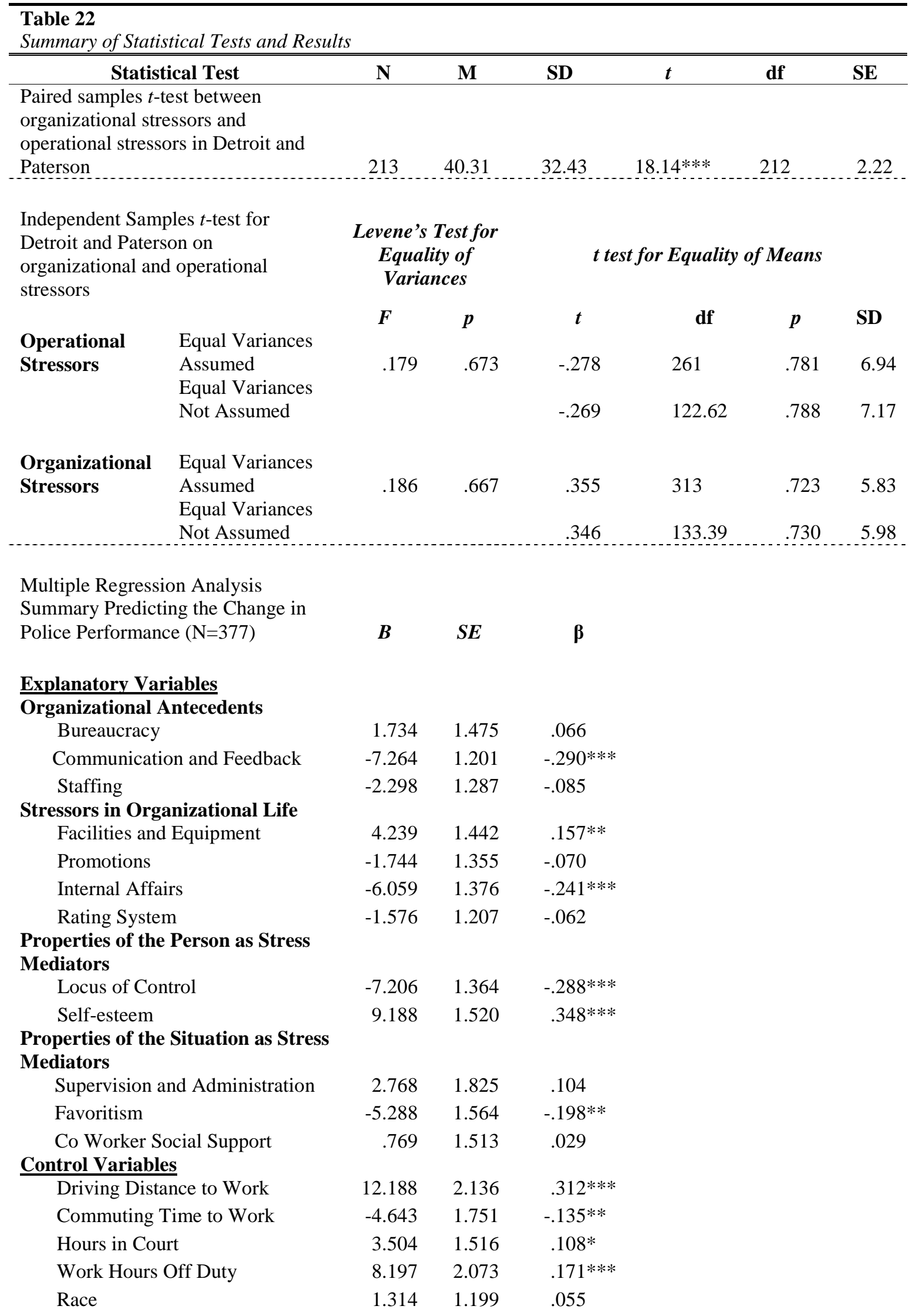




$\begin{array}{lrrl}\text { Sex } & 8.514 & 2.343 & .155^{* * *} \\ \text { Age } & -8.547 & 1.570 & -.247^{* * *} \\ \text { Educational Level } & -1.038 & 1.205 & -.040 \\ \text { Marital Status } & -2.946 & .729 & -.204^{* *} \\ \text { Number of Children } & -2.629 & 1.018 & -.118^{*} \\ \text { (Constant) } & 18.265 & 8.832 & \end{array}$

Note: $R=.762 ;$ Adjusted $R^{2}=.554 ; F(22,355)=22.316 ; p<.001$

${ }^{*} p<.05 ;{ }^{* *} p<.01 ; * * * p<.001$

The findings provide a platform for internal policy reform and managerial change about how police leaders organize their agencies and control their employees because they identify specific stress markers that are within the agency's control. Given the findings, it is easier to understand why police officers describe the working environment as onerous, objectionable and inhospitable. The findings also provide some limited insight into Kelling and Pate’s (1975) statement about how police officers feel about their role and how those feelings correlate with behavior. Using the explanatory variables as a proxy for police officers' feelings (i.e., officers' perceptions) and the criterion variable as a proxy for behavior (i.e., officers' performance), we get a better sense why officers do not consider their job a source of enrichment or personal fulfillment.

The primary research question this study sought to answer is What is the relationship between perceived organizational stressors and police performance? Some of the findings in this study support the hypothesis that the more police officers perceive the organization to be onerous (i.e., stress inducing), the lower their individual performance. As such, we are able to close part of an existing gap in the literature about the nature and extent of organizational stressors in policing and the affect they have on performance. Basic correlation analysis, followed by multivariate regression analysis confirmed that certain organizational stress markers make a unique significant prediction 
of police performance. After controlling for various demographic factors, we increase our confidence that the observed estimates are not spurious.

The phenomena Kahn and Byosiere (1992) suggest induces stress are situated in four categories of the work environment that exert pressure on officers, which is eventually reflected in the variability in performance. Some of the more pervasive and enduring features are bureaucracy, communication and feedback and organizational capacity (i.e., staffing). Bureaucracy and staffing did not make a statistically significant contribution to predicting police performance, although staffing is in the direction of causal theory. Bureaucracy, for example, is partly characterized by the department's hierarchical design. The design increases the social distance between ranks, which may impair effective internal communications. Communication and feedback are affected by the hierarchical design and the finding is consistent with previous research; police officers who reported sensing a lack of communication and feedback also showed lower performance.

Practitioners must not view striving to build solid relations between superiors and subordinates by altering the chain of command a fantasy. Rather, consistent, accurate and timely flow information about the organization and an officer's performance is a facet of leadership that should envelope the workforce. Also, changing the character of communications between subordinates and superior officers may improve communication and feedback. Asking for direction from top administrators or commandlevel employees should not translate into violating the chain of command (i.e., communicating with superiors outside the established network). Practitioners should consider creating simplified systems to remove barriers to communication. If officers are 
the object of rumor, or if administrators deliberately proffer filtered information, then the officers may begin to view the organization as purposely using them for some ulterior motive.

Stressors in organizational life are the physical and psychosocial aspects of organizational life, which include the complexity, simplicity, or monotony of the task at hand, as well as the social nature of the job including role ambiguity, role conflict, role overload and interpersonal relations between superior officers and subordinate personnel. The stressors in this category that did not make a statistically significant contribution to performance are promotions and the rating system. This finding is unexpected particularly because ratings may be linked to promotions and ratings are often seen as biased an unfair. Promotions and ratings were statistically significant in the bivariate model but lost their significance in the multivariate model. What did emerge as statistically significant in this category are facilities and equipment, and internal affairs.

My experience is that police departments tend to operate with lean budgets, owing the greatest proportion to salaries and benefits. As a practical matter, this means appropriations for capital improvements or the latest technology may not be sufficient. However, by not investing in technology or upgrading facilities, there may be a larger symbolic message sent to the officers. The unspoken message is "this is what we think of you and your efforts," suggesting beyond the paycheck — which is obligatory — the officers are not worthy of the city's investment. Few residents ever see the dilapidated and crowded interior of police departments. Yet, for the police officers working among the decay and clutter, the place they must call home is a living reminder of what city officials think of them and how seriously they view police service. Dilapidated buildings 
and items in need of repair such as police cars may jeopardize the officers' safety. Persistent requests for new equipment may go ignored by the administration, which creates strain and frustration. That frustration may turn into stress, which consequently lowers performance. Improving facilities and equipment may go a long way toward enhancing performance by raising morale, at the same time enhancing the public's perception of the agency.

Police officers also report the internal affairs function creates stress. This may be more of an expression of disdain for top management's oppressive policies and perceived inequities in the disciplinary process than for internal affairs itself. The disciplinary function may directly affect morale and esprit de corps, which lowers performance (Iannone, 1987:195). The subculture of policing may regard internal affairs as antithetical to police work since internal affairs investigators must breech the solidarity that binds the subculture. Breeching that solidarity means breaking the "blue wall of silence" and potentially revealing operating secrets and forcing police officers to testify against one another in a criminal trial or administrative hearing. As the literature suggests, providing officers who are under investigation with support in the form of copious feedback may be the best solution for reducing stress. Another solution is for policy makers to self-impose limits on the extent of allowable punishment and to rescind broad catchall rules that enable administrators to use internal affairs as an instrument of retaliation instead of the integrity-control mechanism it is intended to be.

Organizational antecedents and stressors in organizational life may be mediated by properties of the person and properties of the situation. Properties of the person include personality traits such as locus of control and self-esteem that help mediate stress. 
Both locus of control and self-esteem emerged as statistically significant in this research. Locus of control reflects a person's appraisal of a situation as within or outside their control. Because police officers are constrained by a vast body of rules and policies that infringe upon their actions, they sense they have little or no control over certain situations. The more they sense they have no control, the lower their performance. Selfesteem is also related performance insofar as people who feel their work is appreciated by their employer, will perform better. The findings suggest that as self-esteem increases, performance increases and this may be related to communication and feedback. This was supported a second statistical model that showed as an officer's perceived level of positive feedback between them and their superiors increased, self-esteem was expected to increase.

Properties of the situation that help mediate stress include relations and support from co-workers and supervisors. Previous research suggests historically the police are suspicious of the extent of administrative support given to them by upper-level management. The findings in this research lend some support to this notion. Supervision and administration, and co-worker social support were not statistically significant in this research, after controlling for other factors. However, both show a positive relationship with performance and are in the direct of causal theory. This suggests that as support from supervisors, administrators and co-workers increases, performance may also increase. The direction of the relationship is consistent with causal theory, however the findings are inconsistent with the previous literature since these variables did not significantly contribute the estimate on performance. 
Another property of the situation that is consistent with the literature is how favoritism affects performance. After controlling for a number of demographic factors, favoritism significantly contributes to lower officer performance. Police officers who perceive favoritism as an organizational stressor report lower performance. Favoritism surrounds various happenings in organizational life such as recommending certain employees for rare training opportunities, granting friends a coveted assignment or better work hours, or influencing the outcome of a disciplinary hearing.

It may not be so much that coveted assignments or rare training opportunities can only be granted to a few-by virtue of their status as coveted or rare suggests there are only a few to go around. Rather, it is how officers are selected for those opportunities that creates the impression of unfairness and favoritism. This may be related to the fact that police departments rarely articulate a formal application process for such assignments or training. Few, if any, police departments articulate a formal career path that leads from entry-level assignment to progressively more interesting or responsible positions (e.g., detective). The same is true for training opportunities. Training opportunities are not evenly distributed across the agency, they are rarely posted in a conspicuous place and may not contain any prerequisites. This suggests they are held in secret by top administrators and not subject to an application process.

Perhaps more troubling than coveted assignments and training opportunities is favoritism that arises during the disciplinary process. Friendships, associations, political affiliations and nepotism influence the disciplinary process so those without such affiliations are dealt with more harshly. It will take only a few such instances of disparate treatment for police officers to lose trust and confidence in management, a fact 
documented by the LAPD Rampart Commission and the NYPD Mollen Commission. One unanticipated outcome of this uneven treatment may be for more officers to search after a "hook," which ultimately perpetuates the problem instead of solving it. If officers recognize the only way to insulate themselves from discipline is to align themselves with someone prominent in the city, then discipline loses its meaning and effectiveness, emboldens the officer and creates a loss of respect for management and their policies. Thus begins the downward spiral of cynicism and department integrity.

The last set of findings describes the characteristics of the officer and their personal situation. Female police officers, who have longer commuting times and are head-of-household exhibit lower performance. This may be due to the additional familial responsibilities women incur as single head of household. The number of hours a police officer spends in court was also statistically significant in a positive direction $(p<.05)$; as the number of hours spent in court increases, performance also increases. This is counter to what was expected since more work may create fatigue, which lowers performance. However, this may reflect a relationship between arrests and traffic citations (Performance indicators) and the overtime associated with going to court. Court overtime is typically a contractually conferred benefit and can be quite lucrative. The time-honored practice of “collars for dollars” (A collar is police argot for an arrest) works in two ways that may serve as an incentive to increase performance, but is also a corruption hazard.

The first method is to make any arrest, perhaps based on frivolous allegations, near the end of the shift. The arrest leads to instant overtime since processing the arrest takes the officer beyond their scheduled work hours. That same arrest inevitably leads to 
paid overtime court appearances, often multiple court appearances, before the case is adjudicated by the court. The second method, known as "piggybacking,” occurs when the arresting officer falsifies official police reports by listing other officers who were at the scene (And sometimes officers who were not at the scene) of an incident on various reports (e.g., the evidence report; the arrest report), then attests the other officers are fact witnesses. This compels the prosecution and sometimes the defense to subpoena the other officers listed in the reports, which results in court overtime for another officer who may actually have little or nothing to do with the case and actually is not a fact witness. That same officer may be subpoenaed multiple times for a single case, making hundreds perhaps thousands of dollars in overtime before the matter is disposed. The same holds true of traffic citations, where two officers working together in the same car go to court to testify about their observations.

This is a negative implication of establishing arrests and traffic citations as performance indicators or predicating coveted assignments or unit performance solely on “numbers.” Since the action (i.e., issuing a citation or effecting an arrest) is indirectly linked to a monetary incentive, the officers may be motivated more by the money or prestige than the social utility the action is intended to serve. ${ }^{58}$ This is further evidence a multidimensional performance framework is key to managing police performance since other activities beyond arrests and citations—-which measure crime control—must also be counted. Work hours off duty was also statistically significant in a positive direction $(p<.001)$. This may stem from the fact that officers occupy their off-duty time with a second job, “moonlighting," which relaxes them; as they become more relaxed there may 
be a tendency for performance to increase since working a second job reduces the strain and frustration the police department produces.

There was no statistically significant difference between Detroit and Paterson. This may be due to the size of the police departments and the social environment with which they deal. Both agencies serve large, diverse, urban populations that suffer from a number of social ills including high rates of poverty, unemployment, single parent households and other indicators of social disorganization that tax the upper limits of local police departments. This suggests that large urban police departments may be alike than different regardless of their geographic location. Policy Implications

At its fundamental core, the purpose of reducing organizational stressors is to improve service delivery (Performance) and officer well being. Simply allocating additional funding for police systems in their current configuration probably will not achieve this result. Communities deserve a better class of policing and sustainable reforms that improve employee job satisfaction, motivation and productivity that results in better service delivery will, require a holistic approach that includes a multidimensional performance management framework, better management practices, and organizational restructuring. To do this effectively requires and interdisciplinary approach that includes industrial psychology, public administration and business management, as well as police systems.

The implications for policy and practice are aimed at top police administrators, elected officials from the police department's parent government and police scholars who seek answers to improving police performance. This research provides support for 
alternative designs that depart from the traditional quasi-military police model. The first implication is to create a multidimensional performance model that measures police activities beyond crime control. The second is to develop a discipline sentencing matrix that limits discretion, and the third is to flatten the organizational structure to improve communication and reduce the social distance between ranks.

Multidimensional Performance Framework. A multidimensional performance framework enables top police executives to balance the multitude of public interests that are often subject to debate and to define and enhance the police role. A framework similar to that proposed by police scholars (Table 2) may overcome some of the objections police officers voice about their role because it is employee-centric and valuedriven with an emphasis on outcomes, not necessarily on formal agency rules and compliance (Cordner, 1989). Such a framework requires police administrators to adopt a more systematic approach to performance management and resembles "The Corporate Strategy” method advocated by Kenneth R. Andrews (1980), which emphasizes setting goals, then designing an organizational structure and allocating resources to achieve those goals.

The bedrock of a police agency is its personnel. Personnel produce the value stream for the agency, that is, the tasks they are assigned are the "products" offered by the agency. Consequently, organizational effectiveness rests directly on personnel productivity. Improving productivity comes from establishing a commitment to and investment in personnel. This investment is a long-term process that must involve all personnel who have an interest in improving the agency, particularly the managers and supervisors (Whitaker et al., 1982). To do this, the chief executive must serve as the 
sponsor and internal champion, binding himself or herself both intellectually and emotionally to a stated course of action. Sponsorship provides legitimacy to the process, while championship provides the energy and dedication to follow through. Gradually, employees who feel affiliated and are involved in decisions that affect them, will believe the agency is sincere and will embrace its methods and goals.

A multidimensional performance framework that is embedded as part of a police agency’s management philosophy clarifies employee expectations and sets management parameters for the agency. Employees benefit in terms of career incentives that match enriching assignments to performance, knowledge, skills and abilities. There are also rewards from "performance targeting," a management practice where supervisors use performance data as a guidance, support and cooperation system instead of a punishment and rewards system (Halachmi and Holzer, 1987). In this model, supervisors can capitalize on individual strengths and remedy weaknesses to help employees embrace important activities before they become urgent.

The organization benefits from both hindsight and foresight. In an effort to become a "learning organization" ${ }^{\text {59 }}$ the agency develops the ability to look backwards and extract useful information from data as it forges ahead. Foresight is found in imagination and proactive management. Imagination is the organization's ability to forecast future states to anticipate vulnerabilities, improve resource allocation and service delivery through scenario-based planning. Imagination also helps top administrators envision where the agency will be if they do and do not do things differently. The organization also improves its capacity by linking performance indicators to priorities. This is all part of a proactive management effort that shifts the emphasis from compliance 
to managing for results through continuous feedback, by pooling information for joint operations and regularly reporting on streams of data and information.

Moreover, a multidimensional performance framework tends to promote organizational citizenship behavior (OCB). OCB are those "job-related behaviors which are discretionary, not formally recognized by the organizational reward system, and in the aggregate, promote the effective functioning of the organization” (Moorman, Neihoff and Organ, 1993). Essentially, these are the things employees do above and beyond their job description—going the extra yard — that make for a harmonious and efficient workplace, where attitudes of commitment, trust and altruism predominate. The organization cultivates this work ethic because employees perceive the organization’s decision-making systems as fair; therefore, they are more committed to organizational goals. The outgrowth of perceived fairness is workforce motivation. Kramer (1998:26) noted that "When employees feel their hard work counts for something, they strive to do their best," which is the premise of Herzberg's (1968) theory of productivity.

Disciplinary Sentencing Matrix. When imposing sanctions for policy violations, police administrators should remove the arbitrariness created by unfettered discretion by resorting to a disciplinary matrix that relies on proportionality where the penalties are progressive (Table 23). Relying on the principles of sentencing theory, ${ }^{60}$ an objective system of discipline would not account for length of service or an officer's rank as a mitigating or aggravating circumstance when dispensing sanctions. Rather, primary consideration would be given to the infraction for which the officer is charged and the officer's disciplinary history in a matrix anchored by cardinal and ordinal proportionality. In everyday management practice, the decisions on the absolute level of sanctions 
(Cardinal proportionality) must be linked with decisions on the relative level of sanctions for different infractions (Ordinal proportionality).

Cardinal proportionality concerns the upper and lower anchoring points for each level of the infraction on a seriousness scale. This sets limits on the severity or leniency of the sanctions appropriate to each infraction by examining the non-relative proportionality, where the overall level of punishment is addressed. Ordinal proportionality concerns how police officers are sanctioned relative to each other moving from the least serious to the most serious infraction. This orders (i.e., ranks) the amount of punishment proportionate to culpability in terms of parity between police officers committing infractions of similar gravity, such that the relative severity of punishment reflects the seriousness of the infraction. Parity requires that infractions of equal seriousness be ranked equally. A system of this sort would limit discretion and greatly reduce bias and favoritism.

A sentencing matrix that applies cardinal and ordinal proportionality would leave the Department with a predictable, uniform guide that accounts for the seriousness of the infraction, prior disciplinary history of the officer involved, and aggravating and mitigating circumstances. Other purposes of a disciplinary matrix include:

1. Promoting progressive discipline and correction through training for personnel;

2. Insuring community safety and department reputation by preventing infractions through the deterrent influence of proportionate sanctions;

3. Safeguarding personnel against excessive, disproportionate or arbitrary sanctions;

4. Providing personnel with fair warning of the nature of the sanctions that may be imposed upon a sustained finding;

5. Differentiating among infractions with a view toward just individualization in correction. ${ }^{61}$ 
In a reasoned system of internal discipline, the seriousness of infractions should be governed by the "principle of endangerment," which accounts for the harm that was done, for the anticipated harm that could have resulted (Risk), and the culpability of the officer. $^{62}$ Factors of intent, motive, and circumstance should determine the extent to which officers should be held accountable for their actions, not their length of service in the agency. Table 23 is an example of a progressive disciplinary sentencing matrix, where the levels represent cardinal proportionality and the infractions represent ordinal proportionality. $^{63}$

\begin{tabular}{|c|c|c|c|c|c|c|c|}
\hline \multicolumn{8}{|c|}{$\begin{array}{l}\text { Table } 23 \\
\text { Sample Progressive Discipline Sentencing Matrix }\end{array}$} \\
\hline \multirow[b]{2}{*}{ Level } & \multirow[b]{2}{*}{ Infractions } & \multicolumn{6}{|c|}{ Prior Record Grading } \\
\hline & & $\mathbf{0}$ & 1 & 2 & 3 & 4 & 5 \\
\hline \multirow{2}{*}{$\begin{array}{l}\text { Level } 6 \\
\text { DIS }\end{array}$} & $\begin{array}{ll}\text { 1. } & \text { State codified criminal conduct } \\
\text { 2. } & \text { Aiding or abetting a criminal (Conspiracy) } \\
\text { 3. } & \text { Perjury (Criminal or administrative hearing) }\end{array}$ & DIS & --- & --- & --- & --- & --- \\
\hline & $\begin{array}{ll}\text { 4. } & \text { Financial conflict of interest } \\
\text { 5. Unauthorized release of police intelligence } \\
\text { 6. }\end{array}$ & $\begin{array}{c}\text { SUS } \\
21-45\end{array}$ & DIS & --- & --- & --- & --- \\
\hline $\begin{array}{l}\text { Level } 5 \\
\text { RED }\end{array}$ & $\begin{array}{ll}\text { 1. Official inefficiency or incompetence } \\
\text { 2. Inefficiency or incompetence of superior officers }\end{array}$ & $\begin{array}{c}\text { SUS } \\
13-20\end{array}$ & $\begin{array}{l}\text { RED } \\
+5\end{array}$ & DIS & --- & --- & --- \\
\hline \multirow{4}{*}{$\begin{array}{l}\text { Level } 4 \\
\text { SUS }\end{array}$} & $\begin{array}{l}\text { 1. Using excessive force } \\
\text { 2. Unauthorized strip/cavity search } \\
\text { 3. State codified disorderly conduct (Non-criminal) }\end{array}$ & $\begin{array}{c}\text { SUS } \\
10-12\end{array}$ & $\begin{array}{c}\text { SUS } \\
13-15\end{array}$ & $\begin{array}{l}\text { RED } \\
+5\end{array}$ & DIS & --- & --- \\
\hline & $\begin{array}{l}\text { 4. Unlawful entry of home or business } \\
\text { 5. Unauthorized discharge of firearm } \\
\text { 6. Carrying unauthorized firearm or weapon }\end{array}$ & $\begin{array}{l}\text { SUS } \\
7-9\end{array}$ & $\begin{array}{c}\text { SUS } \\
10-12\end{array}$ & $\begin{array}{c}\text { SUS } \\
13-15\end{array}$ & $\begin{array}{l}\text { RED } \\
+5\end{array}$ & DIS & --- \\
\hline & $\begin{array}{ll}\text { 7. } & \text { Unfit for duty } \\
\text { 8. } & \text { Failing to answer subpoena } \\
\text { 9. } & \text { Unauthorized release of prisoner } \\
\end{array}$ & $\begin{array}{l}\text { SUS } \\
4-6\end{array}$ & $\begin{array}{l}\text { SUS } \\
7-9\end{array}$ & $\begin{array}{c}\text { SUS } \\
10-12\end{array}$ & $\begin{array}{c}\text { SUS } \\
13-15\end{array}$ & $\begin{array}{l}\text { RED } \\
+5\end{array}$ & DIS \\
\hline & $\begin{array}{l}\text { 10. Differential treatment } \\
\text { 11. Intoxicated while on duty } \\
\text { 12. Failing to preserve crime scene } \\
\text { 13. Unauthorized disposition of police equipment }\end{array}$ & $\begin{array}{l}\text { SUS } \\
1-3\end{array}$ & $\begin{array}{l}\text { SUS } \\
4-6\end{array}$ & $\begin{array}{l}\text { SUS } \\
7-9\end{array}$ & $\begin{array}{c}\text { SUS } \\
10-12\end{array}$ & $\begin{array}{c}\text { SUS } \\
13-15\end{array}$ & $\begin{array}{l}\text { RED } \\
+5\end{array}$ \\
\hline $\begin{array}{l}\text { Level } 3 \\
\text { REP }\end{array}$ & $\begin{array}{l}\text { 1. Proffering derogatory references/demeanor } \\
\text { 2. Insubordination }\end{array}$ & REP & $\begin{array}{c}\text { SUS } \\
1-3\end{array}$ & $\begin{array}{l}\text { SUS } \\
4-6\end{array}$ & $\begin{array}{l}\text { SUS } \\
7-9\end{array}$ & $\begin{array}{c}\text { SUS } \\
10-12\end{array}$ & $\begin{array}{c}\text { SUS } \\
13-15\end{array}$ \\
\hline $\begin{array}{l}\text { Level } 2 \\
\text { WAR }\end{array}$ & $\begin{array}{ll}\text { 1. } & \text { Loss of city issued equipment } \\
\text { 2. Feigning illness or injury/malingering } \\
\text { 3. Leaving assigned post }\end{array}$ & WAR & REP & $\begin{array}{l}\text { SUS } \\
1-3\end{array}$ & $\begin{array}{l}\text { SUS } \\
4-6\end{array}$ & $\begin{array}{l}\text { SUS } \\
7-9\end{array}$ & $\begin{array}{c}\text { SUS } \\
10-12\end{array}$ \\
\hline \multirow{2}{*}{$\begin{array}{l}\text { Level } 1 \\
\text { COU }\end{array}$} & $\begin{array}{l}\text { 1. Proffering insolent language } \\
\text { 2. Accepting gifts and gratuities }\end{array}$ & $\mathrm{COU}$ & WAR & REP & $\begin{array}{l}\text { SUS } \\
1-3\end{array}$ & $\begin{array}{l}\text { SUS } \\
4-6\end{array}$ & $\begin{array}{c}\text { SUS } \\
7-9\end{array}$ \\
\hline & $\begin{array}{l}\text { 3. Improper wearing of department uniform } \\
\text { 4. Punctuality/tardiness }\end{array}$ & $\mathrm{COU}$ & $\mathrm{COU}$ & WAR & REP & $\begin{array}{l}\text { SUS } \\
1-3\end{array}$ & $\begin{array}{c}\text { SUS } \\
4-6\end{array}$ \\
\hline \multicolumn{2}{|c|}{$\begin{array}{l}\text { Penalties } \\
\text { 1. COU = Counseling } \\
\text { 2. WAR = Warning notice } \\
\end{array}$} & \multicolumn{6}{|c|}{$\begin{array}{l}\text { Principle of Endangerment } \\
\text { 1. Level } 1 \text { and Level 2: Low risk of community harm } \\
\text { and to department integrity }\end{array}$} \\
\hline
\end{tabular}


3. REP $=$ Written reprimand

4. SUS $=$ Suspension from duty

5. RED = Reduction by a single rank for superior officers and detectives; +5 days from upper limit of previous grade for police officers

6. DIS $=$ Dismissal

7. Incremental infractions between 5-7 increase penalty by 1 level highest grade; $>7$ = dismissal

Sentencing Presumptions

Prior Record Penalty Guide

1. 0 = Presumption in favor of minimum penalty

2. 1-2 = Presumption in favor of median penalty

3. $>2$ = Presumption in favor of maximum penalty

Aggravating Circumstances

1 . Use of physical force during the act

2. Collusion or complicity

3. Intoxication

4. Aggravating circumstances increase penalty by 1 grade same level

Mitigating Circumstances

1. Following the advice from a superior officer

2. Ignorance or mistake of fact

3. Necessity

5. Mitigating circumstances reduce penalty by 1 grade same level
2. Level 3 and Level 4: Medium risk of community harm and to department integrity

3. Level 5 and Level 6: High risk of community harm, judicial and department integrity

Time Limitations

1. Department adjudication must commence no more than 45 days after the disposition of any criminal proceeding (i.e., trial or Grand Jury presentment)

2. Department adjudication must commence no more than 30 days after an infraction is discovered, except for criminal conduct

3. Only sustained findings shall be used to calculate penalties; unfounded, not sustained and exonerated dispositions are not calculated

4. Prior record of sustained findings shall not be considered if the finding is more than 1 year old

Management Practices. Police departments are rarely managed in a participatory manner. Chiefs rarely consider the employees' will or wishes when they make decisions affecting them and readily concede they are benevolent dictators, undemocratic and authoritarian leaders who exercise their power for the benefit of the community, not the individual. He or she may allow for some perfunctory democratic decision-making, such as when an officer can schedule their vacation, but operational decisions are retained at the highest levels of the agency. This is a maxim that is driven by the unfettered discretion bestowed upon top administrators and is reinforced by broad catchall rules from which police officers cannot escape.

To improve the work environment for police officers, top administrators must rescind the broad catchall rules and create representative bureaucracies of the type suggested by Rhoades (1991). The catchall polices and rules do not foster better performance and probably decrease performance overall. Their use by top administrators seems to suggest an air immaturity and laziness, for if a police officer's behavior does not 
squarely fit proscribed conduct, then they resort to this inescapable rule. It seems the intent of such rules is to govern judgment (i.e., discretion), specifically poor judgment. Poor judgment by itself is too subjective and debatable to be legislated and the penalties too severe to for individual interpretation; absent illegal or unethical conduct, the interpretation is laden with post hoc personal opinion. The implications for career advancement and the disciplinary sanctions levied in police departments are too great to permit such rules, moreover, virtually any discretionary decision that someone disagrees with can be classified as poor judgment.

By fostering organizational democracy, police officers can practice negotiation, compromise and diplomacy consistent with the values and obligations of a democratic police (Rhoades, 1991:13). When officers are consistently excluded from the decisionmaking process, cast aside and told by their boss “do as I say, not as I do," it seems inevitable they will reciprocate when dealing with the public. Several scholars across different disciplines and contextual settings (Brandes, Dharwadkar, and Wheatley, 2004; Eskew, 1993; Frost, 1994; Moorman, Neihoff, and Organ, 1993:209; Mosher, 1968:1718; Pateman, 1975:2; Rothwell and Baldwin, 2007) note the benefits of participatory management, democratic decision-making and social exchange:

- Better decision-making

- Improved ethical climate

- Increased efficiency and effectiveness

- Development of democratic ideals

- Improved accountability
- Improved morale

- Improved self-actualization

- Increased organizational commitment

- Employee-friendly/team-oriented

- Organizational citizenship

The impetus necessitating new management practices is, perhaps, the rise in egalitarianism. This is not to suggest police bureaucracy and agency rules be thrown out altogether, both are necessary and posses some positive attributes. Rather, I suggest as 
the potential workforce pool becomes better educated, the perceived need to control conduct in minute ways evanesces. This group of future police officers does not appreciate the rigid hierarchical structure of authority so willingly accepted by the less educated; they resent unquestioned obedience, particularly when management grants them little or no say in decisions that affect them. Consequently, they perceive their supervisors and top management as distant illegitimate authorities. The evolving social preference is recognition of the individual and respect for dignity over absolute authority and deference to rank. Tendering a salute and generally subordinating one's self while in the mere presence of superior officers implies the official rank (i.e., status) is more important than the person. Such hierarchical stratified systems may do more to undermine performance than build encouragement for it.

Because of the changing social attitudes, new police officers are less willing to immediately accept the broad body of rules and policies that govern their conduct. They are more willing to challenge the utility of the rules, not necessarily in an overt aggressive or insubordinate manner, but through other established means to express dissent—civil lawsuits and administrative processes (e.g., hearings before the merit system board or arbitrators that govern civil servants’ employment rights; union grievances).

Police administrators may find improved officer performance by appealing to officers’ personal sense of communal obligation-a deontological perspective-as well as giving them a voice in decisions that affect them and providing constructive feedback about their performance. Such constructive management practices may breed higher performance and achieve the overall discipline and deference the "old guard" so 
steadfastly cherishes by showing officers management respects them as valued organizational members first. This may raise police officers’ self-esteem and internal locus of control, which this research shows are associated with higher performance.

Organizational Restructuring. A recurring theme in the police organizational literature is to flatten the organizational structure to improve performance. The community policing movement is largely responsible for this paradigm shift. My recommendation is not new; rather, I concur with the previous recommendations and this research further validates the need for flattened organizational designs. To vest police officers with increased responsibility and decision-making authority, reduce communication and feedback problems and improve the overall relationship between management and labor, the rigid traditions and hierarchical structure of police departments must be changed (Sparrow, 1988). This means:

1. Reducing upper management positions and creating flattened, more horizontal (And less vertical) systems;

2. Setting goals and developing goal-directed strategies implemented by teams of well-trained and educated police officers;

3. Looking beyond small incremental improvements to larger gains over a shorter time period; and

4. Developing strategic partnerships with other government, corporate and non-profit groups that move toward achieving mutual goals.

Organizational designs such as this may give communities a better sense of the police mission and help shape their role in society, instead of placing the onus for quality of life squarely on their shoulders and castigating them for failing to do it alone. 
Strengths, Limitations and Threats to Validity of the Current Study

\section{Strengths of the Current Study}

The methodological strengths of this study include quantifying the level of organizational stress confronting police officers, relying on domain-specific instruments, sample size and a multidimensional concept of police performance. Although the results are from a non-probability sample of just two urban U.S. police departments, they are in the direction of causal theory. This finding, coupled with the instruments and the statistical power raise confidence in the results. The surveys used in this research are specifically designed to capture the stressors unique to policing. The Police Stress Questionnaire (McCreary and Thompson, 2006) and the Daily hassles and Uplifts Scale (Hart, Wearing and Heady, 1993) have been validated through police officers and do not include generic stressors that may be applicable to wide variety of occupational groups or individuals outside the police profession. The sample size provides sufficient power to detect moderate or even somewhat smaller effects. In practical terms, effect size helps when making decisions and interpreting the meaningfulness of the study. Police performance is operationalized by using more dimensions of police activity than previous studies. By operationalizing more activities, we account for more aspects of police performance that lend meaning to what the police do. Although these strengths represent improvements over previous research, there are a few limitations.

\section{Limitations of the Current Study}

It is important to acknowledge the limitations of this research, which include: 1) cross-sectional design, 2) self-report surveys, and 3) agency records. 
Cross-Sectional Design. Cross-sectional research design is favored for its ease and straightforward interpretation. This permits the research to be conducted more easily and the results disseminated to practitioners and scholars more quickly so replication may take place and policy decisions may be made. However, correlational research such as this cannot infer causality and the conclusions drawn from the data should be viewed as tentative. In correlational research, the direction and strength of the relationship are important but often cannot specify the time-order sequence necessary to infer causation. Cause must precede effect and when that cannot be established (e.g., which came first, higher stress levels or lower performance?), the research suffers from a limitation known as ambiguous temporal precedence (Shadish, Cook and Campbell, 2002:55).

Ambiguous temporal precedence is a threat to internal validity. Internal validity is whether the inferences about perceived organizational stressors and police performance reflect a causal relationship. To infer causality, three phenomena must be present: 1) The cause must precede effect in time; 2) the cause must covary with the effect; and 3) there must not be any other explanation for the relationship (Spuriousness) (Shadish, Cook and Campbell, 2002:37). In this research, it is inappropriate to suggest that the organization caused decrements in officer performance simply because a correlation between the focal measurements was found. Because of the short time span, the correlation could be confounded by a preexisting state of affairs within the officer, the agency, both the officer and the agency or something else such as the environment. This research does show that the data are consistent with and in the direction of causal theory and extends that body of literature. Nevertheless, it would be worthwhile to replicate the findings using a more 
advantageous longitudinal design, which would demonstrate stability and change among the predictors in this model (Maxwell, 1998; Shadish, Cook and Campbell, 2002).

Self-Report Surveys. Like many studies in stress research, this study uses subjective self-report surveys as the primary data source. A fundamental goal of survey research is to elicit accurate responses from participants so valid inferences may be drawn about a larger population of interest. Quantitative research that relies on selfreport data are subject to method variance to some extent, although the validity and reliability of self-report surveys has been used in previous research with success to measure other sensitive attributes such as criminal careers and offending (Farrington, 2004; Farrington, et al., 2003; Weiss, 1986) and to test theory (Funger-Tas and Marshall, 1999).

Lazarus and Folkman (1984:321) remarked that "Most researchers in the life sciences have long been aware of the limitations and disadvantages of self-report data...the problems of memory, the desire of the subjects to present themselves in a positive light, language ambiguity and the use of verbal reports as an ego defense.” The Police Stress Questionnaire and the Daily Hassles and Uplifts Scale used in this study depend on data obtained from active police officers who have the potential to positively influence work environment by fabricating their answers or because of recall error (Horney and Marshall, 1992). The survey was designed to measure various aspects of police officers’ organizational environment that are likely to affect performance.

The validity of self-report data are always questionable due to response bias, which occurs if participants respond to questions by altering their response to meet the real or perceived needs of the researcher. In the current survey, because participants are 
primarily reporting on the quality of their organizational experiences, it is possible that the validity of the data are compromised by response bias. Moreover, if this assumption is correct, then the results of any statistical tests conducted on these data may be biased because the findings and inferences are wholly dependent on how well the variables have been measured. However, self-report measures have been widely regarded as reasonable reflections of actual behavior, attesting to their validity and reliability (Blackmore, 1974; Clark and Tiff, 1966; Hindelang, Hirschi and Weis, 1981).

Agency Records. As discussed previously under the section on data accuracy, another limitation is reliance on data collected from agency records. When using data that is conceptualized and collected by another source, the current researcher has no control over the measurements. Data that may appear on its face to be reliable and trustworthy, are actually replete with inaccuracies and misrepresentations, such as: 1) an incomplete record of the data making analysis unreliable; 2) irreparable clerical errors that compromise analysis; 3) miscategorized data fields; 4) collection procedures or definitions that change over time resulting in two different data sets, and 5) manipulated data that reflects a more favorable position toward the agency (Jacob, 1984). The records for the criterion variable, police performance, were derived from log books, computeraided dispatch (CAD) records and personnel files within the Detroit and Paterson Police Departments, all of which are subject to the aforementioned errors.

Police performance is operationalized through recorded indicators of police activity (e.g., citizen and administrative complaints, arrests, citations). In general, the police have the ability to reduce this measure of performance by failing to record certain activity or recording activity different from that which was actually taken. In addition, 
the measure is sensitive to the willingness and initiative of police personnel to record the data in the first place. If personnel decide that it is not worth their effort to officially record the data after it occurs, then the instance will never become part of the permanent record as a measure of performance. Moreover, some police agencies simply do not record data that is damaging to the agency’s image or reputation, such as citizen complaints (Gordon and Heinz, 1979). Therefore, the actual number of police activities undertaken by Detroit and Paterson police officers may be higher than the recorded number. A few examples of how agency records may be incomplete or otherwise biased will illustrate the problem of relying on such data. In particular, self-initiated activity, citizen complaints, on-duty motor vehicle accidents and on-duty injuries-performance indicators used in this research-are highlighted.

Self-initiated Police Activity. Certain police activities (e.g., directed patrols, pedestrian stops, motor vehicle stops) may go unrecorded because, in many instances, the activity takes only a few minutes to complete and does not outweigh the effort required to make an official record (i.e., notifying the dispatcher who records the action in the CAD system). My experience is that police officers learn early in their careers to be efficient: Work as quickly as you can to resolve a condition and make yourself available to handle another priority assignment. To reconcile productivity and efficiency in an environment of competing demands, police officers frequently multi-task (e.g., stop more than one car at a time; issue more than one traffic citation at a time), which may skew official data since each individual activity is not accounted for separately.

Support for my experience is bolstered by observational research conducted by Maxfield and Andresen (2001) and Andresen (2005:182) with the New Jersey State 
Police. Specifically, Andresen found that while riding with New Jersey State Troopers he witnessed some troopers did not record self-initiated service contacts with the public. When he asked the trooper why he did not record the contact, the trooper replied it “saved time."

The three largest categories for missing data for the criterion variable are: 1 ) reports completed (36\%), 2) self-initiated stops (42\%) and 3) self-initiated investigations (46\%). As for the number of reports completed, under reporting may be explained through a combination of erroneous first-report information and time management. Official reports are not written by police officers in every circumstance, particularly where the first report is different from the actual situation. After police officers assess the on-scene situation and determine that no report is necessary, the need for a report is moot. Also, situations that do call for an official report may go unreported in the interest of time. When the situation is handled informally (i.e., curbside adjustment or advice) police officers may forego a written report because other priority calls are backing up in the queue that demand a response. Of course, a plausible explanation is also officer laziness at the scene as well as clerical errors in recording actual reports.

Citizen Complaints. Citizens who wish to complain about a police officer may be persuaded not to do so by another member of the department, often a supervisor. A citizen who disagrees with an officer’s actions may feel upset or frustrated until a supervisor assuages their anxiety by rationalizing the officer's actions. Although this practice is common, it may not be out of malevolence or deceit, it is simply a matter of ignorance. Citizens may not fully understand or are not completely familiar with the intricacies of the criminal law or agency practices that guide an officer's decisions. The 
citizen must be counseled on why certain actions were taken; after a full explanation, they decline to file a formal complaint.

An outgrowth of not filing an official record of a citizen complaint is preserving the individual officer's reputation. Police officers who have a documented complaint history face the stigma of being labeled by their superiors as unreliable, untrustworthy or pugnacious. Such a record severely limits an officer's career opportunities and upward mobility through promotion and preferred assignments because other superior officers may avoid the officer once their complaint history becomes known. If the complaint is never documented, then there is no official record. If there is no official record, then there is nothing to hold against the officer or otherwise limit the officer's career success. Consequently, if no official record exists, it cannot be measured.

On-duty Motor Vehicle Accidents and On-duty Injuries. On-duty accidents and on-duty injuries may go unrecorded, particularly when they are minor. If a police officer has a minor collision with a police vehicle, especially if the collision involves only the police vehicle and the police vehicle is older with preexisting scratches, dents or other damage, there is a tendency not to report the collision. Similarly, when an officer receives a minor on-duty injury there is a tendency not to report it. The reluctance may stem, in part, from the profession’s machismo (Jacobi, 1975; Reiser, 1974), but also from the amount of official paperwork involved for something perceived as trivial, regardless of the official policy.

Whether or not police activity is recorded is a balance officers strike between the cost of reporting (e.g., annoying their supervisors and commanders; losing precious time due to official paperwork; waiting in the CAD queue for a dispatcher to service their 
request) and the benefit of not doing so (e.g., efficiency and expediency). Reliability of the data are very much a function of the characteristics of the agency collecting the data and police departments, in particular, do not view organizational record-keeping as "real” police work or a primary responsibility (Chatterton, 1989; Manning 1977).

\section{Threats to External Validity (Generalizability)}

The generalizability of this research may be compromised, to a degree, by agency size and sample selection.

Agency Size. Generalizing to smaller and medium sized police departments, and suburban and rural police departments may be an issue (Crank and Caldero, 1991; Regoli et al., 1989). The approach to law enforcement in the United States is extremely fragmented with a concentration of smaller agencies (52\%). ${ }^{64}$ According to the Bureau of Justice Statistics (2002), there were 17,784 full-time law enforcement agencies in the United States as of June 2000. Of that approximately 12,666 (71\%) are "general purpose” or "general service” law enforcement agencies, which is the object of this research. As of the same time, only 5.8\% (1,032) of state and local police agencies employed 100 or more officers; this figure includes 77 agencies that employed 1,000 or more officers (See table 1). The Detroit police department employs over 3,000 sworn personnel and the Paterson police department employs nearly 500 sworn personnel, placing them in $99^{\text {th }}$ percentile of all U.S. police agencies.

There is some research to support differences in behavior and attitude of officers in large agencies compared to small agencies, which may affect generalizability (Brown, 1981; Mastrofski et al., 1987). While most police agencies operate along essentially the same lines with a rank structure, policies, rules and regulations, there are some notable 
differences. Large police departments are characterized by a more impersonal environment due to the size of the bureaucracy. This type of structure has a tendency to rely on negative discipline to elicit conformity and places a great deal of emphasis on efficiency and productivity (Bittner, 1970; Manning, 1977). There is also greater social distance between ranking officers and first-line officers due to the "tall" organizational structure compared to a "flattened" structure found in smaller agencies. This may negatively affect internal communications, accountability and interpersonal relations (Banton, 1964; Mastrofski et al., 1987; Violanti and Aron, 1995) making for more stress. Larger police departments also tend to adopt autocratic management styles that are inherently stressful in day-to-day operations (Reiser, 1974), whereas smaller agencies adopt more democratic or participative management styles. Autocratic management has been linked to various work-related problems including increases in stress where officers perceive themselves as having little or no voice over work activities (White and Marion, 1983) and psychological distress in British police officers when superior officers failed to consult them or involve them in decisions that directly affect them (Cooper, Davidson and Robinson, 1982). Conversely, research on participative management suggests police agencies using this style for daily operations produces greater job satisfaction and consequently less stress (Terry, 1981)

Other research has found that working in a large bureaucratic police department is stressful because the officers perceive the organization as self-serving and indifferent (Gaines et al., 1991). The self-serving nature of the organization manifests internally through things that are often left to management's discretion such as who is placed in a coveted position, a preferred assignment or granted a rare training opportunity, and 
whose rule infractions are overlooked while others are dealt with harshly for the same infraction. The self-serving nature also manifests externally through a process of institutionalization, where the organization ignores community sentiment and does not consult the community on policy development or policing priorities:

“...bases its approach to customers or clients on what best serves the comfort or preferences of the employees...With self-congratulation and hubris born of success and their comfort in the 'tried and true' processes and roles that made them dominant, organization members can increasingly see priority number one as maintaining their processes, their ways and each other” (O’Hara, 2005:20). ${ }^{65}$

The nature of managerial indifference manifests when officers voice their concerns over discretionary decisions or otherwise oppose the favoritism and are ignored or retaliated against by other Department members, especially when their voice is seen as threatening to the current administration.

Much research has focused on large bureaucratic agencies, driven by an agenda centered on community and legal issues and job aspects that may not be found in smaller agencies such as the risk of physical danger, impersonal relations and public apathy toward police. Smaller law enforcement agencies do not have the distance larger agencies have between the top and bottom of the organizational structure. There may also be more informal relationships among ranking officers and community members, which may contribute to a more supportive and hassle-free atmosphere.

Sample Selection. This research relies on a non-probability sample (i.e., convenience sample), not a random sample. Random sampling permits every element in the population to have an equal chance of being selected and often employs a table of random numbers or a random numbers generator program to produce the sample (Maxfield and Babbie, 2001:230), which reduces systematic bias. By contrast, a non- 
probability sample selects elements of the population based on their availability (e.g., soliciting volunteers) or due to some qualitative judgment that these elements are representative. The result is that an unknown segment of the population is excluded (e.g., those who did not volunteer).

Because some elements of the population have no chance of being sampled, the extent to which a convenience sample, regardless of its size, actually represents the entire population cannot be known. This introduces systematic bias and the inferences based on this type of data must be accepted with caution. Strictly speaking, inferences cannot be drawn from a non-probability sample about the proportion of the population exhibiting or not exhibiting a particular characteristic. However, the protections afforded human subjects (e.g., not forcing them to participate against their will), the practical limitations of police field research (e.g., union/contractual obligations, staffing requirements and public safety necessity) and other agency considerations of using active police officers in a major urban center (e.g., administrative subversion; see Bergstrom, 1985; Rice, 1985; Weiss and Boruch, 1996) limit the use of a probability sample in this research.

\section{Directions for Future Research}

The results of this study suggest a few directions for future research aimed at a better understanding of the relationship and causal processes between organizational stressors and police performance. Future research should examine the implications for performance in smaller and mid-size police agencies as well as suburban and rural agencies. Since some of the previous research suggests smaller agencies may not suffer the same effects as larger ones due to the flattened hierarchal structure, it would be interesting to see if the conclusions in this research hold over variations in agency size 
and geographic location. If so, then the notion the police organization is associated with higher stress levels than the nature of the job, may require policing as a whole to undergo a major paradigm shift away from the traditional model and toward a flattened organizational structure and a multidimensional performance framework.

Another interesting direction for future research is to examine organizational stressors over a longer time period and over the course of different police administrations via randomized experiment. This would provide better insight into how management styles correlate with stress and performance. The longer time period would smooth seasonal fluctuations or other anomalies that might adversely influence performance as well as improve low base rates for certain indicators (e.g., on-duty motor vehicle accidents; failure to appear in court ratios; complaints against personnel). A longitudinal design also allows for interrupted time-series analysis during the change in top police administrators. The expectation is, if the causal hypothesis about leadership is correctdemocratic leadership inspires higher levels of individual performance than autocratic leadership — then observations following the new leadership will have a different slope and a higher mean than before the change. A statistically significant positive relationship would be consistent with the police supervision literature that suggests democratic leaders inspire better performance in their employees than do autocratic leaders. Using stratified random sampling to first select police agencies based on size (See table 1), then randomly selecting officers to participate, we improve our confidence in the parameter estimates as well as get closer to inferring molar causation by answering the empirical question: Does the organization cause decrements in police officer performance? 
Another avenue for future research is to widen the participant pool to include superior officers and civilian personnel. Although a large body of literature relies on patrol officers as participants — the lowest level of service delivery in the agency-there is reason to believe others in the agency may suffer the same effects of stress as patrol officers. Because police organizations are stratified by rank and because ranking officers adhere to the bureaucratic tendencies of the quasi-military model, they may suffer from the same or similar issues facing patrol officers. It would be interesting to see whether the same or different stressors among ranking superior officers, particularly communication, favoritism and internal affairs, influence estimates of performance since superior officers are typically behind these stressors. This would also require researchers to conceptualize new performance measures for each rank under observation, since some of the performance indicators in this research are exclusive to patrol officers.

\section{CONCLUSION}

Despite the limitations, this study is the first to quantify the extent organizational stressors have on police performance. This study also extends the dimension of police performance by accounting for a broader base of police activities. A single study does not provide “definitive” evidence in support of its policy implications; however, it does add the knowledge base of similar previous studies that support causal theory. The results of this study, coupled with my personal experience lead me to believe the organization and all of its idiosyncrasies are more influential in affecting police performance than the nature of the job. Overall, a holistic approach to stress reduction must consider operational and organizational stressors; however, organizational stressors appear to be better predictors of performance. 
The implication is that improved methods for measuring performance, alternative organizational structures and better management practices may not only help remove barriers to performance, but top police administrators, policy makers and governing structures (e.g., Mayors, city managers, business administrators, city/county councils) may be more likely to embrace the suggested reforms because tangible results manifest in a shorter period of time and because the ability to alter organizational structures and processes is within their control.

Workforce reform is not only important for policing but also for addressing issues of public productivity. Therefore, in addition to contributing to a new, wider vision of police reform, this dissertation helps define a new systematic police management model. The multidimensional performance management framework envisioned in this essay could help generate a new compact between scholars, practitioners and non-profit groups, one that encourages collaboration and bridges the chasm that has existed between these groups for many decades. Another broad aim of this research is to better align the social and political priorities of the police to meet rising public expectations about the role of police in a democratic society. As public expectations rise, police role assignments will continue to blur absent an articulated structure that systematically accounts for what the public expect the police to produce, meaningful measures of those expectations and a feedback forum that can correct deficiencies and replicate the good.

It is also a reminder that there must be an institutional commitment to train and guide personnel toward measurable outcomes instead of relying on a rewards and punishments system (Control and compliance) that fails to foster cooperation, enthusiasm 
and initiative. Whether the reforms suggested here by themselves will explain all of the variance in police performance is debatable, but it is certainly better than not trying at all. 


\section{REFERENCES}

Adams, J.S. (1965). Inequality in social exchange. In L. Berkowitz (Ed.), Advances in Experimental Social Psychology, Vol. 2, pp. 267-299. New York: Academic Press.

Adams, T. (1990). Police field operations. Englewood Cliffs, NJ: Prentice-Hall.

Alberts, D.S. and Hayes, R.E. (2006). Understanding command and control. Center for Advanced Concepts and Technology, Department of Defense. Retrieved on May 6, 2008 from http://www.dodccrp.org/files/Alberts_UC2.pdf.

Albrecht, K. (1979). Stress and the manager. Englewood Cliffs, NJ: Prentice-Hall.

Alex, N. (1976). New York cops talk back. New York, Wiley.

Alexander, D.A., Walker, L.G., Innes, G. and Irving, B.L. (1993). Police stress at work. London: The Police Foundation.

---(1991). Innes, G, Irving, B.L., Sinclair, S. and Walker, L.G. Health, stress and policing: A study in Grampian police. London: The Police Foundation.

Allison, P. D. (1999). Multiple regression: A primer. Thousand Oaks, Ca: Pine Forge Press.

---(2001). Missing data. Thousand Oaks, CA: Sage Publications.

Alpert, G.P. and Moore, M.H. (1994). Measuring police performance in the new paradigm of policing. In Geoffrey P. Alpert and Roger G. Dunham, 2001, Critical Issues in Policing: Contemporary Readings. $4^{\text {th }}$ ed. Prospect Heights, Il: Waveland Press. Original publication: U.S. Department of Justice, Bureau of Justice Statistics-Princeton University Study Group on Criminal Justice Performance Measures. Performance Measures for the Criminal Justice System 1994:108-141. Accessible at http://www.ojp.usdoj.gov/bjs/pub/pdf/pmcjs.pdf.

---Flynn, D. and A. Piquero (2001). Effective community policing performance measures. Justice Research and Policy, Vol. 3, No. 2:79-94.

Amaranto, E., Steinberg, J., Castellano, C. and Mitchell, R. (2003). Police stress interventions. Brief Treatment and Crisis Interventions, Vol.3, No. 1:47-53.

American Bar Association. (1973). The urban police function. Chicago: American Bar Association.

American Heritage Dictionary. (1996). American heritage dictionary of the English language. $3^{\text {rd }}$ ed. New York: Houghton Mifflin. 
American Psychological Association. (1994). Diagnostic and statistical manual. Washington, D.C: American Psychological Association.

Amick, B.C., Kawachi, I., Coakley, E.H., Lerner, D., Levine, S. and Colditz, G.A. (1998). Relationship of job strain and iso-strain to health status in a cohort of women in the United States. Scandinavian Journal of Work Environment Health, Vol. 24: 54-61.

Andresen, W.C. (2005). State police: Discretion and traffic enforcement. Unpublished dissertation, Rutgers The State University of New Jersey-Newark.

Andrews, K. (1980). The Concept of Corporate Strategy. Chicago, IL: Irwin.

Angell, J.E. (1971). Toward an alternative to the classic police organizational arrangements: A democratic model. Criminology, Vol. 9:185-206.

---and Endell, R.V. (1981). Police executive career mobility: A study of Alaska chief. Criminal Justice Review, Vol. 16:16-22.

Anson, R.H. and Bloom, M.S. (1988). Police stress in an occupational context. Journal of Police Science and Administration, Vol. 16:337-356.

Archbold, C.A. and Maguire, E.R. (2002). Studying civil suits against the police: A serendipitous finding of sample selection bias. Police Quarterly, Vol. 5, No. 2:222-249.

Arcuri, A.F., Gunn, M.M. and Lester, D. (1987). Moonlighting by police officers: A way of life. Psychological Reports, Vol. 60:210.

Armacost, B.E. (2004). Organizational culture and police misconduct. The George Washington Law Review, Vol. 72:453-546.

Argyris, C. (1957). The individual and the organization: Some problems of mutual adjustment. Administrative Science Quarterly, June:1-24.

Aschoff, J. (1978). Features of circadian rhythms relevant op the design of shift schedules. Ergonomics, Vol. 21:739-754.

Auten, J.H. (1988). Preparing written guidelines. Washington, D.C: FBI Law Enforcement Bulletin, Vol. 57:1-7.

Bachman, R. and Patersonster, R. (2004). Statistics for criminology and criminal justice. $2^{\text {nd }}$ ed. New York: McGraw Hill. 
Band, S.R. and Manuelle, C.A. (1987). Stress and police officer performance: An examination of effective coping behavior. Police Studies, Vol. 10:122-131.

Banton, M. (1964). The policeman in the community. New York: Basic Books.

Baratta, C.R. (1988). The relationship between education and police performance. Unpublished master's thesis, University of Baltimore.

Barrineau, H.E. (1987). Civil liability in criminal justice. Cincinnati, OH: Anderson.

Barton, J. (1994). Choosing to work at night: A moderating influence on individual tolerance to shiftwork. Journal of Applied Psychology, Vol. 79:449-454.

Basnight, T.A. and Wolkinson, B.W. (1977). Evaluating managerial performance: Is your appraisal system legal? Employee Relations Law Journal, Vol. 3, No. 2:240-254.

Baxter, D. (1978). Coping with police stress. Trooper 3, Vol. 4, no. No. 68, 69, 71 and 73.

Bayley, D.H. (2002). Law enforcement and the rule of law: Is there a tradeoff? Criminology and Public Policy, Vol. 2, No. 1:133-154.

---(1996). Getting serious about police brutality. In Phillip C. Stenning (ed.), Accountability for Criminal Justice. Toronto, Canada: University of Toronto Press.

---(1994). Police for the future. New York: Oxford.

Beehr, T.A. (1995). Psychological stress in the workplace. London: Routledge

---and Newman, J.E. (1978). Job stress, employee health and organizational effectiveness: A fact analysis model and literature review. Personnel Psychology, Vol. 31:665-699.

Bem, D.J. (1967). Self-perception: An alternative interpretation of the cognitive dissonance phenomena. Psychology Review, Vol. 74:183-200.

Bennis, W. (1966). Changing organizations. New York: McGraw-Hill.

---and Slater, P. (1964). Democracy is inevitable. Harvard Business Review (March-April):51-59.

Bergstrom, K. (1985). Police experimentation with civilian subjects: Formalizing the informal. In Police leadership in America: Crisis and opportunity. W. Geller (ed.). New York: Praeger. 
Berkley, G. (1969). In Western Europe and the United States-how the police work. New Republic, October.

Best, W.H. (1957). Some new directions in personnel appraisal. Personnel, Vol. 37:46.

Bittel, L.R. (1974). What every supervisor should know, New York: McGraw-Hill.

Bittner, E. (1970). The functions of police in modern society. Rockville, Md: National Institute of Mental Health.

---(1980). The functions of the police in modern society. Cambridge Ma:

Olgeschlager, Gunn and Hain.

---(1990). Aspects of police work. Boston: Northeastern University Press. pp. 136-147.

Blackmore, J. (1974). The relationship between self-reported delinquency and official convictions amongst adolescent boys. British Journal of Criminology, Vol. 14:172-176.

---(1978). Are police allowed to have problems of their own? Police Magazine, Vol. 1, No. 3:47-55.

Blau, P. (1974). On the nature of organizations. New York: John Wiley.

Bonnet, M.H. (1985). The effect of sleep disruption on performance, sleep and mood. Sleep, Vol. 8:11-19.

Boorstin, R.O. (November 5, 1986). Port agency police overtime up 24\%. New York Times, p. B3L.

Bopp, W.J. (1974). Police personnel administration: The management of human resources. Boston, Ma: Holbrook.

Bordua, D.J. and Reiss, Jr., A.J. 91966). Command, control and charisma: Reflections on police bureaucracy. The American Journal of Sociology, Vol. 72, No. 1:68-76.

Bosma, H., Marmot, M.G., Hemingway, H., Nicholson, A.G., Brunner, E. and Stansfield, A. (1997). Low job control and risk of coronary heart disease in Whitehall II (prospective cohort) study. British Medical Journal, Vol. 314:558-565.

Bostrom, M.D. (2003). The impact of higher education on police officer work habits. Unpublished doctoral dissertation, Hamline University. 
Bousfield, G. (December, 1999). Dutch study to explore workplace stress. Safety and Health-The International Safety, Health and Environment Magazine. In M. Dollard, A.H. Winfield and H.R. Winfield (eds.). Occupational Stress and the Service Professions, New York: Taylor and Francis.

Brandes, P.A. , Dharwadkar, R. and Wheatley, K. (2004). Social exchanges within organizations and work outcome: The importance of local and global relations. Group \& Organization Management, Vol. 29, No. 3:276-301.

Brantingham, P and Brantingham, P. (1995). Criminality of place: Crime generators and crime attractors. European Journal of Criminal Policy and Research, Vol. 3, No. 3:1-26.

Breslow, L. and Buell, P. (1960). Mortality from coronary heart disease and physical activity of work in California. Journal of Chronic Disease, Vol. 11:615-626.

Bratton, W.J. with Peter Knobler. (1998). Turnaround: How America’s top cop reversed the crime epidemic. New York: Random House.

Brooks, L. and Piquero, N. (1998). Police stress: Does department size matter? Policing: An International Journal of Police Strategies and Management, Vol. 21, No. 4:600-617.

Broughton, R.J. and Ogilvie, R.D. (eds.). (1992). Sleep, arousal and Performance. Boston, Ma: Birkhauser.

Brown, J.M and Campbell, E.A. (1994). Stress and Policing: Sources and Strategies. Chichester: Wiley and Sons.

---(1990). Sources of occupational stress in police. Work and Stress, Vol. 4:305318.

Brown, J., Cooper, C. and Kirkcaldy, B. (1999). Stressor exposure and methods of coping among senior police mangers at a time of organizational and management change. International Journal of Police Science and Management, Vol. 2, no. 3:217-228.

Brown, M. (1981). Working the street: Police discretion and dilemmas of reform. New York: Russell Sage Foundation.

Brown, W.J. (1996). Organization assessment: Determining the state of a police organization. Journal of Police Science and Administration, Vol. 14, No. 4:267284. 
Bryant, F.B. and Yarnold, P.R. (1995). Principal components analysis and exploratory and confirmatory factor analysis. In L.G. Grimm and P.R. Yarnold (Eds.) Reading and Understanding Multivariate Statistics, (pp. 99-136). Washington, D.C: American Psychological Association.

Buerger, M.E. (2000). Reenvisioning police, reenvisioning policing: A response to Thomas Cowper. Police Quarterly, Vol. 3, No. 4:451-464.

Burbeck, E. and Furman, A. (1985). Police officer selection: A critical review of the literature. Journal of Police Science and Administration, Vol. 6:58-69.

Bureau of Justice Statistics. (2006). Sourcebook of criminal justice statistics online. Table 3.154, Law enforcement officers killed 1972-2004. Retrieved on February 1, 2006 from http://www.albany.edu/sourcebook/pdf/t31542004.pdf.

---(2002). Census of state and local law enforcement agencies, 2000. NCJ\# 194066. Retrieved from http://www.ojp.usdoj.gov/bjs/pub/pdf/csllea00.pdf on March 7, 2007.

Burke, P.J. and Tulley, J.C. (1977). The measurement of role identity. Social Forces, Vol. 55:880-897.

Burke, R.J. (1994). Stressful events, work-family conflict, coping, psychological burnout and well being among officers. Psychological Reports, Vol. 75:787-800.

Cacciope, R.L and Mock, P. (1985). The relationship of self-actualization, stress and quality of work experience in senior Australian police officers. Police Studies, Vol. 8:173-186.

Callahan, M. (1989). Municipal liability for inadequate training and supervision: Divergent views. FBI Law Enforcement Bulletin, Vol. 58, No. 3:24-30.

Cannon, L. (1997). Official negligence: How Rodney King and the riots changed Los Angeles and the LAPD. New York: Random House.

Cannon, W.B. (1915; reprinted 1970). Bodily changes in pain, hunger, fear, and rage: An account of recent researches into the function of emotional excitement. McGrath: London.

Caplan, R.D., Cobbs, S., French, J.R.P., Harrison, R.V. and Pinneau, S.R. Jr. (1975). Job demands and worker health. Washington, D.C: HEW Publications No. NIOSH 75-160.

---and Jones, K.W. (1975). Effects of workload, role ambiguity and Type A personality on anxiety, depression and heart rate. Journal of Applied Psychology, Vol. 60, No. 6:713-719. 
Carter, D. (1994). Police disciplinary procedures: A review of selected police departments. In T. Barker and D. Carter, (Eds.), Police Deviance, $3^{\text {rd }}$. ed. Cincinnati, OH: Anderson. pp. 355-375.

Cartwright, S. and Cooper, C.L. (2002). ASSET: Management guide. Manchester, England: Robertson Cooper.

Carver, C.S., Scheier, M.F. and Weintraub, J.K. (1989). Assessing coping strategies: A theoretically based approach. Journal of Personality and Social Psychology, Vol. 56:267-283.

Cascio, W.F. (1977). Formal education and police officer performance. Journal of Police Science and Administration, Vol. 5, No. 1:89-96.

Cast, A.D. and Burke, P.J. (2002). A theory of self-esteem. Social Forces, Vol. 80, No. 3:1041-1068.

Cattell, R.E. (1967). Factor description of composite policeman's profile. Champaign, Il: Institution for Personality and Ability Testing.

Chan, K.B. (1977). Individual differences in reactions to stress and their personality and situational determinants: Some implications for community mental health. Social Science and Medicine, Vo. 11: 89-103.

Chatterton, M.R. (1989). Managing paperwork. In Police Research, M. Weatheritt (Ed.), Aldershot, England: Avebury. pp.107-136

Chemerinsky, E. (2000-2001). An independent analysis of the Los Angeles police department's board of inquiry report on the Rampart scandal. Loyola of Los Angeles Law Review, Vol. 34:545-655

Cherniss, C. (1980). Staff burnout: Job stress in the human services. Beverly Hills: Sage.

Christopher Commission (Independent Commission) on the Los Angeles Police Department. (1991). Report, California Public Management Institute, Los Angeles, Ca.

Claiborne, W. (April 15, 1994). Houston lengthens long arm of the law. The Washington Post, p.A3.

Clark, J. and Tiff, L. (1966). Polygraph and interview validation of self-reported deviant behavior, American Sociological Review, Vol. 31:516-523.

Clarke,R.V. (1997). Situational crime prevention : Successful case studies.. $2^{\text {nd }}$ ed. New York: Harrow and Heston. 
Cohen, J. (1988). Statistical power and analysis for the behavioral sciences. $2^{\text {nd }}$ ed. Hillsdale, NJ: Lawrence Earlbaum Associates.

--and Cohen, P., West, S.G. and Aiken, L. (2003). Applied multiple regression/correlation analysis for the behavioral sciences. $3^{\text {rd }}$ ed. Hillside, NJ: Erlbaum.

Collier, P.M. (2001). Police performance measurement and human rights. Public Money and Management, Vol. 21:35-39.

---(2006). In search of purpose and priorities: Police performance indicators in England and Wales. Public Money and Management, Vol. 26:165-172.

Coman, G. and Evans, B. (1991). Stressors facing Australian police in the 1990s. Police Studies, Vol. 14:153-164.

Cooper, C., Davidson, M. and Robinson, P. (1982). Stress in police service. Journal of Occupational Medicine, Vol. 24:30-36.

Cooper, C.L. (ed). (1998). Theories of organizational stress. New York: Oxford. ---and Marshall, J.J. (1977). Understanding executive stress. New York: PBI Books.

Cooper, S., Sloan, S. and Williamson, G. (1988). Perceived stress in a probability sample of the Unites States. In S. Spacapam and S. Oskamp (eds.), The Social Psychology of Health: Claremont Symposium on Applied Social Psychology. Newbury Park, Ca: Sage.

Coman, G. and Evans, B. (1991). Stressors facing Australian police in the 1990s. Police Studies, Vol. 14:153-164.

Comrey, A.L. and Lee, H.B. (1992). A first course in factor analysis. $2^{\text {nd }}$ ed. Hillsdale NJ: Earlbaum.

Corbett, M. (1979). Conflict, consensus and perceptions among the police. Journal of Police Science and Administration, Vol. 7, No. 4:449-458.

Cordner, G. (1989). Written rules and regulations: Are they necessary? FBI Law Enforcement Bulletin, July:17-21.

Cottam, M. and Marenin, O. (1981). Problems of cognition and judgment in policing. In James J. Fyfe (ed.) Contemporary Issues in Law Enforcement, Beverly Hills, Ca: Sage. pp.104- 135. 
Cotton, P. (1995). Psychological health in the workplace: Understanding and managing occupational stress. Carlton, Australia: The Australian Psychological Society.

Cotton, S.J., Dollard, M.J., deJonge, J. and Whetman, P. (2003). Clergy in crisis. In M. Dollard, A.H. Winfield and H.R. Winfield (eds.). Occupational Stress and the Service Professions, New York: Taylor and Francis.

Cowper, T. (2000). The myth of the military model of leadership in law enforcement. Police Quarterly, Vol. 3, No. 3:228-246.

Cox, T. (1978). Stress. London: McMillan.

--- Griffiths, A., and Rial-Gonzalez, E. (2000). Research on work-related stress. Belgium: European Agency for Safety and Health at Work.

Crank, J., Culberton, R., Hewitt, J. and Regoli, B. (1993). An assessment of work stress among police executives. Journal of Criminal Justice, Vol. 21:313-324.

---and Caldero, M. (1991). The production of occupational stress in medium-sized police agencies: A survey of line officers in eight municipal departments. Journal of Criminal Justice, Vol. 9:339-349.

---Regoli, R., Hewitt, J.D. and Culbertson, R.G. (1995). Institutional and organizational antecedents of role stress, work alienation, and anomie among police executives. Criminal Justice and Behavior, Vol. 22, No. 2:152-171.

Cromwell, P.F. and Keefer, G. (1973). Police-community relations. St. Paul, Mn: West Publishing.

Crowley, L. (1997). Introduction to health and human disease. Sudbury, Ma: Jones and Bartlett.

Cullen, F.T., Lemming, T., Link, B and Wozniak, J.F. (1985). The impact of social supports on police stress. Criminology, Vol. 23, No. 3:503-522.

Cummings, L.L. and Schwab, D. (1973). Performance in organizations: Determinants and appraisal. Glenview: Scott, Foresman.

Czeisler, C.A., Weitzman, E.D. and Coleman, R.M. (1982). Rotating shift work schedules that disrupt sleep may be improved by applying circadian principles. Science, Vol. 217:460-463.

Daley, R.E. (1978). The relationship of personality variables to suitability for police work. Unpublished doctoral dissertation, Florida Institute of Technology. 
Dallas Police Department. (1972). Five year plan. Dallas, TX: Dallas Police Department.

Davey, J.D., Obst, P.L. and Sheehan, M.C. (2001). Demographic and workplace characteristics which add to the prediction of stress and job satisfaction within the police workplace. Journal of Police and Criminal Psychology, Vol. 16, No. 1:2939.

Davis, R. (1983). Stress: Deadlier than a bullet. Police Marksman, March:10-12.

Dean, D. (1980). Citizen ratings of the police: The difference contact makes. Law and Policy Quarterly, Vol. 2, No. 4:445-471.

DeGeneste, H.I. and Sullivan, J.P. (1997). Policing a multicultural community. Washington, D.C.: Police Executive Research Forum.

DeLone, G.J. (2007). Law enforcement mission statements post September $11^{\text {th }}$. Police Quarterly, Vol. 10, No. 2:218-235.

Denhardt, R.B. (1999). Public administration: An action orientation. $3^{\text {rd }}$ ed. Ft. Worth, Tx: Harcourt Brace.

Department of Defense. (2001). Dictionary of military and associated terms. Joint Publication 1- 02. As amended through March 22, 2007. Retrieved on May 29, 2007 from http://www.dtic.mil/doctrine/jel/new_pubs/jp1_02.pdf

Detroit Free Press. (April 12, 2006). 30 Detroit cops to return.

---(June 15, 2006). Detroit cops' wait is over: 72 promoted after almost 2 years.

---(September 8, 2006). 27 laid-off Detroit cops recalled.

Retrieved from www.freepress.com/archives on January 25, 2007.

Doctor, R.S., Curtis, D., and Isaacs, G. (1994). Psychiatric morbidity in policemen and the effect of brief psychotherapeutic intervention: A pilot study. Stress Medicine, Vol. 10:151-157.

Dollard, J., Doob, L.W., Miller, N.E., Mowrer, O.H. and Sears. R.R. (1939). Frustration and aggression. New Haven: Yale University.

Dollard, M., Winefield, A.H. and Winefield, H.R. (2003). Occupational stress in the service professions. London: Taylor-Francis.

---(2001). Occupational stress and efficacy in human service workers. Dordrecht: Kluwer Academic Publishers. 
Donohue, M.E. (1992). Crisis in police ethics: Is professionalization the answer? American Journal of Police, Vol. XI, No 4:47:70.

Droppleman, L. and McNair, D.M. (1971). An experimental analog of public speaking. Journal of Consulting and Clinical Psychology. Vol. 36, No. 1:91-96.

Duckworth, D. (1987). Post-traumatic stress disorder. Stress Medicine, Vol. 3:175-183.

Duggan, P. (April 5, 1993). D.C. losing in overtime: Officers wait to testify-at $\$ 30$ an hour. Washington Post, p.A1.

Dutton, J. and Dukerich, J. (1991). Keeping an eye on the mirror: mage and identity in organizational adaptation. Academy of Management Journal, Vol. 34: 517-554.

Dwyer, T. (1991). Life and death at work: Industrial accidents as a case of socially produced error. New York: Plenum.

Eck, J.E., and Spellman, W. (1987). Problem solving: Problem-oriented policing in Newport News. Washington, DC: Police Executive Research Forum.

Edelman, M. (1964). The symbolic uses of politics. Champaign, Il: University of Illinois Press.

Edelwich, J. (1980). Burnout: Stages of disillusionment in the helping professions. New York: Human Science Press.

Eisenberg, T. (1975). Labor management relations and psychological stress: View from the bottom. The Police Chief, Vol. 42:54-58.

Eisenberger, R., Huntington, R. Hutchinson, S. and Sowa, D. (1986). Perceived organizational support. Journal of Applied Psychology, Vol. 71:500-507.

Ellison, K. and Genz, J. (1983). Stress and the police officer. Springfield, Il: Charles Thomas.

Enter, J.E. (1986). The rise to the top: An analysis of police chief career patterns. Journal of Police Science and Administration, Vol. 14:334-346.

Eskew, D.E. (1993). The role of organizational justice in organizational citizenship behavior. Employee Responsibilities and Rights Journal, Vol. 6, No. 3:185-194.

Farrington, D.P. (2004). What has been learned from self-reports about criminal careers. London: Home Office. 
---Jolliffe, D., Hawkins, J.D., Catalano, R.F., Hill, K.G. and Kosterman, R. (2003). Comparing delinquency careers in court records and self-reports.

Criminology, Vol. 41, No. 3:933-958.

FBI Uniform Crime Report. (2006). Crime in the United States. Washington, D.C: FBI.

Fell, R.D., Richard, W.D. and Wallace, W.L. (1980). Psychological job stress and the police officer. Journal of Police Science and Administration, Vol. 8:139-144

Feuille, P. and Juris, H.A. (1976). Police professionalization and police unions. Sociology of Work and Occupations, Vol. 3:88-113.

Field, H.S. and Holly, W.H. (1982). The relationship of performance appraisal system characteristics to verdicts in selected employment discrimination cases. Academy of Managerial Journal, Vol. 25:392-406.

Fink, J. (1974). Community and the police: Conflict or cooperation. New York: John Wiley.

Fisher, J. (July 15, 2004). Shootings call for change in police unit. New York Times.

Fogelson, R.M. (1977). Big-city police. Cambridge: Harvard University Press.

Folkman, S., Lazarus, R., Gruen, R.J., and DeLongis, A. (1986). Appraisal, coping, health status, and psychological symptoms. Journal of Personality and Social Psychology, Vol. 50, No. 3:571-579.

---and Lazarus, R. (1985). If it changes it must be a process: A study or emotion and coping during three stages of college examination. Journal of Personality and Social Psychology, Vol. 48:150-170.

---and Lazarus, R. (1980). An analysis of coping in a middle-aged community sample. Journal of Personality and Social Psychology, Vol. 21:219-239.

Franz, V. and Jones, D.M. (1987). Perceptions of organizational performance in suburban police departments: A critique of the military model. Journal of Police Science and Administration, Vol. 15, No. 2:153-161.

French, J.R.P, Jr. (1975). A comparative look at stress and strain in policemen. In William H. Kroes and Joseph J. Hurrell (ed.) Job stress and the police officer: Identifying stress reduction techniques. pp. 60-72. Proceedings of symposium, Cincinnati, Oh, May 8-9, 1975, Washington, D.C.: U.S. Government Printing Office.

---and Caplan, R.D. (1970). Psychosocial factors in coronary heart disease. Industrial Medicine and Surgery, Vol. 39, No. 9:232-238. 
---and Caplan, R.D. (1973). Organizational stress and individual strain. In A.J. Morrow (ed.), The failure of success. New York: AMACON, pp.31-66.

---Caplan, R.D. and Harrison, R.V. (1982). The mechanisms of job stress and strain. London: John Wiley.

Friedman, H.S., and Silver, R.C. (Eds.) (2006). Foundations of health psychology. New York: Oxford University Press.

Frost, T.F. (1994). Creating a teamwork-based culture within a manufacturing setting. Industrial Management, Vol. 25:125-140.

Funger-Tas, J. and Marshall, I.H. (1999). The self-report methodology in crime research. Crime and Justice, Vol. 25:291-367.

Gaines, L., Sutherland, M. and Angell, J. (1991). Police administration. New York: McGraw-Hill.

Galliher, J.F. (1971). Explanations of police behavior: A critical review and analysis. The Sociological Quarterly, Vol. 12:308-318.

Gandevia, S.C. (1992). Some central and peripheral factors affecting human motoneuronal output in neuromuscular fatigue. Sports Medicine, Vol. 13, No. 2: 93-8.

Ganster, D.C. and Schaubroeck, J. (1991). Work stress and employee health. Journal of Management, Vol. 17:235-271.

Gastorf, J.W., Suls, J. and Sanders, G.S. (1980). Type A coronary-prone behavior patter and social facilitation. Journal of Personality and Social Psychology, Vol. 38:773-780.

Gecas, V. (1982). The self-concept. Annual Review of Sociology, Vol. 8:1-33.

Germann, A.C. (1962). Police executive development. Springfield, Il: Charles C. Thomas.

Gershon, R. (2000). Project shields. National Institute of Justice Final Report. Washington D.C: NIJ, NCJ\#185892.

Gerth, H. and Mills, C.W. (1946). (eds.). From Max Weber. Essays in sociology. New York: Oxford University Press.

Glass, C.G. and Singer, J.E. (1972). Behavioral after effects of unpredictable and uncontrollable aversive events. American Scientist, Vol. 60:457-465. 
Glasser, M. (1999). On violence: A preliminary communication. International Journal of Psycho-Analysis, Vol. 79:887-902.

Glowinkowski, S.P. and Cooper, C.L. (1985). Current issues in organizational stress research. Bulleting of the British Psychological Society, Vol. 38:212-216.

Goldberger, L. and Breznitz, S. (1982). Stress research at a crossroads: In L. Goldberger and S. Breznitz. (eds). Handbook of stress: Theoretical and Clinical Aspects. New York: Free Press.

Goldsmith, A. (2001-2002). The pursuit of police integrity: Leadership and governance dimensions. Current Issues in Criminal Justice, Vol. 13, No. 2:185-202.

Goldstein, H. (1966). Policy formulation: A proposal for improving police performance. Michigan Law Review, Vol. 65:1123-1146).

---(1977). Controlling and reviewing police-citizen contacts. In Policing a Free Society, Cambridge, Ma: Ballinger Publishing.

---(1979). Improving policing: A problem-oriented approach. Crime and Delinquency, Vol. 25

---(1990). Problem-oriented policing. New York: McGraw Hill.

Goldstein, J. (1960). Police discretion not to invoke the criminal process: Low visibility decisions in the administration of justice. Yale Law Journal, Vol.66:543.

Goode, W.J. (1969). The theoretical limits of professionalization. In Amitai Etzioni (Ed.), The Semi-Professions and their Organization. New York: Free Press. pp. 266-313.

Gordon, A.C. and Heinz, J.P. (1979). Public access to information. New Brunswick, NJ: Transaction Books.

Gould, J.B. and Mastrofski, S.D. (2004). Suspect searches: Assessing police behavior under the U.S. constitution. Criminology and Public Policy, Vol. 3, No. 3:315362.

Greenglass, E.R. and Burke, R.J. (2003). Teacher stress. In M. Dollard, A.H. Winfield and H.R. Winfield (eds.). Occupational Stress and the Service Professions, New York: Taylor and Francis.

Griffiths, A., Randall, R., Santos, A and Cox, T. (2003). Senior nurses: Interventions to reduce work stress. In M. Dollard, A.H. Winfield and H.R. Winfield (eds.). Occupational Stress and the Service Professions, New York: Taylor and Francis. 
Gross, E. (1973). Work, organization and stress. In S. Levine and N.A. Scotch (eds.) Social Stress, Chicago: Aldine Publishing.

Gross, E. and Grambusch, P.W. (1974). Changes in university organization, 1964-1971. New York: McGraw Hill.

Gudjonsson, G. and Adlam, K. (1985). Occupational stressors among British police officers. Police Journal, Vol. 58:73-85.

Gulle, G., Tredoux, C. and Foster, D. (1998). Inherent and organizational stress in the SAPS: An empirical survey in the Western Cape. South African Journal of Psychology, Vol. 28:129-134.

Haar, R. (1997). They're making a bad name for the department: Exploring the link between organizational commitment and police occupational deviance in a police patrol bureau. Policing: An International Journal of Police Strategy and Management, Vol. 20, No. 4:786-812.

Hagberg, M. (1981). Muscular endurance and surface electromyogram in isometric and dynamic exercise. Journal of Applied Physiology: Respiratory, Environmental and Exercise Physiology, Vol. 51, No. 1: 1-7.

Hageman, M.J.C. (1978). Occupational stress of law enforcement officers and marital and familial relationships. Journal of Police Science and Administration, Vol. 6:402-412.

Hahn, H. (1974). Profile of urban police. J. Goldsmith and S.S. Goldsmith (eds.), Police community: Dimensions of and occupational subculture. Pacific Palisades, Ca: Palisades Publisher.

Hair, J.F., Anderson, R.E., Tatham, R.L., and Black, W.C. (1998). Multivariate data analysis. $5^{\text {th }}$ ed. Upper Saddle River, NJ: Prentice Hall.

Halachmi, A. and Holzer, M. (1987). Merit pay, performance targeting, and productivity. Review of Public Personnel Administration, Vol. 7, No. 2:80-91.

Half, R. (1985) On hiring. New York: Crown Publishers.

Hall, R. (1991). Organizations: Structures, Processes and Outcomes. Englewood Cliffs, NJ: Prentice Hall.

Harrington, J.M. (1978). Shift work and health. London: Her Majesty’s Stationery Office. Harris, R.N. (1973). The police academy: An inside view. New York, NY: Wiley. 
Harrison, F.E. (1975). Bureaucratization: Perceptions of role performance and organizational effectiveness. Journal of Police Science and Administration, Vol. 3, No. 3:319-326.

Harrison, F.E. and Pelletier, M.A. (1987). Perceptions of bureaucratization, role performance and organizational effectiveness in a metropolitan police department. Journal of Police Science and Administration, Vol. 15, No. 4:262-270.

Harriston, K.A. (March 2, 1993). Kelly calls for clampdown on police: Those who abuse overtime should expect harsher penalty, she says. Washington Post, p.B3.

Hart, P.M. and Cooper, C.L. (2001). Occupational stress: Toward a more integrated framework. In N. Anderson, D.S. Ones, H.K. Sinangil and C. Viswesvaran, (eds.), 2001, Handbook of Industrial and Organizational Psychology. Vol. 2: Personnel Psychology. London: Sage.

---and Cotton, P. (2002). Conventional wisdom is often misleading: Police stress within an organizational health framework. In M. Dollard, A.H. Winfield and H.R. Winfield (eds.). Occupational Stress and the Service Professions, New York: Taylor and Francis.

---Wearing, A.J. and Heady, B. (1993). Assessing police work experiences: Development of the police daily hassles and uplift scales. Journal of Criminal Justice, Vol. 21, No. 6:553-572

---Wearing, A.J. and Heady, B. (1994b). Perceived quality of life, personality and work experiences: Construct validation of the police daily hassles and uplifts scale. Journal of Criminal Justice and Behavior, Vol. 21: 283-311.

--- Wearing, A.J. and Heady, B. (1995). Police stress and well-being: Integrating personality, coping and daily work experiences. Journal of Occupational and Organizational Psychology, Vol. 68:133-156.

Hatry, H.P., Blair, L.H., Fisk, D.M., Greiner, J.M., Hall, Jr. J.R., and Schaenman, P.S. (1992). How Effective are your Community Services? Procedures for Measuring their Quality. $2^{\text {nd }}$ ed. Washington, D.C: Urban Institute and International City/County Management Association. In Edward R. Maguire, Measuring the Performance of Law Enforcement Agencies, Fairfax, Va: Commission on Accreditation for Law Enforcement Agencies, CALEA, pp.11-12.

Hawley, J.A. and Reilly, T. (1997). Fatigue revisited. Journal of Sports Sciences, Vol. 15, No. 3: 245-6.

Hays, K.L. Regoli, R. and Hewitt, J.D. (2007). Police chiefs, anomia, and leadership. Police Quarterly, Vol. 10, No. 1:3-22. 
Heiler, K. (1998). The 12-hour working day: Emerging issues. Working Paper no .51. Australian Center for Industrial Relations Research and training.

Heinrich, D.L. and Speilberger, C.D. (1982). Anxiety and complex learning. In Heinz W. Krohne and Lothar Laux, Achievement, Stress and Anxiety. Washington, D.C: Hemisphere Publishing.

Herzberg, F. (1968). One more time: How do you motivate employees? Harvard Business Review, Vol. 46:53-62.

Herzog, S. (2000). Deviant organizational messages among suspect police officers in Israel. Policing: An International Journal of Police Strategies and Management, Vol. 23, No. 4:416-438.

Heyer, T. (1998). A follow-up study of the prediction of police officer performance on psychological evaluation variables. Unpublished doctoral dissertation, Minnesota School of Professional Psychology.

Hickman, M.J., Piquero, A.R. and Greene, J.R. (2000). Discretion and gender disproportionality in police disciplinary systems. Policing: An International Journal of Police Strategy and Management, Vol. 23, No.:105-116.

Hillgren, J.S., and Bond, R.B. (1975). Stress in law enforcement: Psycho-physiological correlates and legal implication. Journal of Forensic Psychology:25-34.

Hindelang, M., Hirschi, T. and Weis, J. (1981). Measuring delinquency. Beverly Hills, Ca: Sage.

Holbrook, M.I., M.H. White, and M.J. Hutt. (1994). Increasing awareness of sleep hygiene in rotating shift workers: arming law enforcement officers against impaired performance. Perceptual and Motor Skills, Vol. 79: 520-522.

Holden, R.N. (1986). Modern police management. Englewood Cliffs, NJ: Prentice Hall.

Holmes, T.H. and Rahe, R.H. (1967). Social readjustment rating scale. Journal of Psychosomatic Research, Vol.11:606-611.

Holroyd, K.A. and Lazarus, R.S. (1982). Stress, coping and somatic adaptation. In L. Goldberger and S. Brenitz (eds.), Handbook of Stress: Theoretical and Clinical Aspects, New York: The Free Press.

Hoover, L.T. (1995). Quantifying quality in policing. Washington D.C: Police Executive Research Forum.

Horne, D.G. (1992). Public opinion surveys: Implications for police organizations. Canadian Police College Journal, Vol. 16, No.4: 263-281. 
Horney, J. and Marshall, I.H. (1992). An experimental comparison of two self-report methods for measuring lambda. Journal of Research in Crime and Delinquency, Vol. 29, No. 1:102-21.

House, S. (1974). Occupational stress and coronary heart disease: A review and theoretical integration. Journal of Health and Social Behavior, Vol. 15:12-27.

Houston, B. (2000). Let's put more esprit in de corporation. Harvard Business Review, November-December 1972:55-61.

Hughes, E. (1945). Men and their work. Glenco, Il: The Free Press.

Hummel, R.P. (1994). The bureaucratic experience: A critique of life in the modern organization. New York: Bedford Books of St. Martens Press.

Hunt, R.G. (1976). Role and role conflict. In E.P. Hollander and R.G. Hunt (Eds.), Current Perspective in Social Psychology, New York: Oxford University Press pp. 175-184.

Hurrel, J. (1977). Job stress among police officers: A preliminary analysis. U.S. Department of Health Education and Welfare (NIOSH) Washington, D.C: U.S. Government Printing Office.

Hutchinson, S. and Garstka, M.L. (1996). Sources of perceived organizational support: Goal setting and feedback. Journal of Applied Social Psychology, Vol. 60:112131.

Iannone, N.E. (1987). Supervision of police personnel. $4^{\text {th }}$ ed. Englewood Cliffs, NJ: Prentice Hall.

---(1994). Supervision of police personnel. $5^{\text {th }}$ ed. Englewood Cliffs, NJ: Prentice Hall.

Jacob, H. (1984). Using published data: Errors and remedies. Sage University Paper 42. London: Sage Publications.

---(1975). Reducing police stress: A psychiatrist's point of view. In W.H. Kroes and J.J. Hurrell (eds.), Job Stress and the Police Officer, Washington, D.C: H.E.W.-NIOSH, pp.85-116.

Jacobi, J.H. (1975). Reducing police stress: A psychiatrist's point of view. In W. Kroes and J. Hurrel (Eds.), Job Stress and the Police Officer (HEW Publication No 76187, pp. 85-116). Washington, DC: US Government Printing Office. 
Jamal, M. (1985). Type A behavior and job performance: Some suggestive findings. Journal of Human Stress, Vol. 11:60-68.

Jirak, M. (1975). Alienation among members of the New York City police department on Staten Island. Journal of Police Science and Administration, Vol. 3:149-161.

Johnson, L.C., D.I. Tapas, W.P. Colquhoun, M.J. Colligan. (1981). Biological rhythms, sleep and shift work. New York: Spectrum.

Jones, J.B., Flyn, D.M. and Kelloway, E.K. (1995). Perception of support from the organization in relation to work stress, satisfaction and commitment. In S.L. Sauter and L.R. Murphy (Eds.), Organizational Risk Factors for Job Stress, 4152. Washington, D.C: American Psychological Association.

Jones, T.L. (1998). Developing performance standards. Law and Order Magazine. July:109 - 112. Herndon Publishing.

Juris, H. and Feuille, P. (1973). Police unionism. Lexington, Ma: Lexington Books.

Kahn, R.L. and Byosiere, P.B. (1992). Stress in organizations. In M.D. Dunnette and L.M Hugh (eds.). Handbook of Industrial and Organizational Psychology. Vol. 3, pp.571-650. Palo Alto, Ca: Consulting Psychologists Press.

Kahn, R.S., Wolfe, D.M., Quinn, R.P. and Snoek, J.D. (1964). Organizational stress: Studies in role conflict and ambiguity. New York: John Wiley.

Kanter R.M. (1977). Men and women of the corporation. Basic Books: New York. ---and Brinkerhoff, D. (1981). Organizational performance: Recent developments in measurement. Annual Review of Sociology, Vol. 7:321-349.

Kaplan, R. and Norton, D. (1996). The balanced scorecard. Boston: Harvard University Press.

Karasek, R.A. (1979). Job demands, job decision latitude and mental strain: Implications for job redesign. Administrative Science Quarterly, Vol. 24:285-308.

Katsampes, P. (1974). Participation in Policing. The Police Chief, Vol. XLI, No. 12. December. pp.60-65.

Kaufman, C.N. (February, 1973). The danger within: Organization stagnation. FBI Law Enforcement Bulletin, pp.3-28.

Keller, P.a. (1978). A psychological view of the police officer paradox. The Police Chief, (April):24:25. 
Kelling, G.L. (1999) Broken windows and police discretion. Washington, D.C. National Institute of Justice. NCJ\# 178259.

---and Moore, M.H. (1988). The evolving strategy of policing. Perspectives on Policing. Washington, D.C: National Institute of Justice. NCJ\# 114213.

---and Pate, M.A. (1975). The Person-role fit in policing: The current knowledge and future research. In Job stress and the Police Officer: Identifying Stress Reduction Techniques. Proceedings from Symposium, Cincinnati, Oh, May 8-9, 1975. Washington, D.C: U.S. Department of Health, Education and Welfare

Kellog, M. (1975). What to do about performance appraisal. New York: AMACOM.

Kelly, M.J. (1975). Police chief selection New York: Police Foundation.

Kendall, E., Murphy, P., O’Neill, V. and Burnsnall, S. (2000). Occupational stress: Factors that contribute to its occurrence and effective management. Centre for Human Services, Griffith University.

Kennedy, D., Braga, A., Piehl, A,M. (2001). Reducing gun violence: The Boston gun project's operation cease fire. Washington, D.C: National Institute of Justice, NCJ\# 188741.

Kennedy, J.J. and Bush, A.J. (1985). An introduction to the design and analysis of experiments in behavioral research. Lanham, MD: University Press of America.

Kinnane, A. (1979). Policing. Chicago: Nelson-Hall.

Kirkcaldy, B., Cooper, C.L. and Ruffalo, P. (1995). Work stress and health in a sample of U.S. police. Psychological Reports, Vol. 76:700-702.

Kirkham, G. and Wollman, L. (1980). Introduction to law enforcement. New York: Harper and Row.

Kirschman, E. (1998). Organizational stress: Looking for love in all the wrong places. The Police Chief. Washington, D.C: The IACP.

---(1983). Wounded heroes: A case study and system analysis of job-related stress and emotional dysfunction in three police officer. Unpublished doctoral dissertation, University Microfilms International: Ann Arbor, MI.

Klinger, D.A. (1997). Negotiating order in patrol work: An ecological theory of police Response to deviance. Criminology, Vol. 35, No. 2:277-306.

Klockars, C.B., Ivkovic, S.K. and Haberfeld, M.R. (2006). Enhancing police integrity. Dordrecht, The Netherlands: Springer. 
Kohlan, R.G. (1973). Police promotional procedures in fifteen jurisdictions. Public Personnel Management, May/June:167-170.

Kolts, J.G. (1992). The Los Angeles County Sheriff's Department: A report by special counsel James G. Kolts and staff, Los Angeles, Ca: Los Angeles County.

Koortzen, P. (1996). Die dimensionaliteit van polisie stressore [The dimensionality of police stressors]. Acta Criminologia, Vol. 9, No. 2:55-63.

Kramer, M. (March 1998). Designing an individualized performance evaluation system: A value-based process. FBI Law Enforcement Bulletin, Vol. 67, No. 3:20-26.

Kraus, K. (July 19, 2007). Sheriff's discipline policy aims to eliminate favoritism. Dallas Morning News.

Kroes, W.H. (1985). Society's victims-The police: An analysis of job stress in policing. 2nd ed. Springfield, Il: Charles Thomas.

---(1976). Society's victim, the policeman: An analysis of job stress in policing. New York: Charles C. Thomas.

---and Gould, S. (1979). Stress in policeman. Journal of Police Science and Administration. Vol. 1:484-490.

---(1986). Society’s victim: The police officer. Springfield, Il: Charles C. Thomas.

---Margolis, B., and Hurrell, J.J. Jr. (1974). Job stress in policeman. Journal of Police Science and Administration, Vol. 2:145-155.

Kuykendall, J. and Roberg, R.R. (1982). Mapping police organizational change. Criminology, Vol. 20, No. 2:241-256.

Landy, F.J. (1977). Performance appraisal in police departments. Washington, D.C: Police Foundation.

Lane, R. (1977) Policing the city: Boston, 1822-1885. New York: Atheneum.

Langworthy, R.H. (1999). Measuring what matters: Proceedings from the policing research institute meetings. Washington, D.C: U.S. Department of Justice, COPS Office. NCJ\# 170610. Retrieved on June 12, 2006 from http://www.ncjrs.gov/pdffiles1/nij/170610.pdf.

---(1985). Administrative overhead in municipal police departments. American Journal of Police, Vol. IV, No. I:20-36 
Laub, J. and Kayten, P. (1988). Sleepiness, circadian dysrhythmia, and fatigue in transportation system accidents. Sleep, Vol. 11:503-512.

Laux, L. and Vossel, G. (1982). Paradigms in stress research: Laboratory versus field and traits versus processes. In L. Goldberger and S. Brenitz (eds.), Handbook of Stress: Theoretical and Clinical Aspects, New York: The Free Press.

Lawrence, R.A. (1984). Police stress and personality factors: A conceptual model. Journal of Criminal Justice, Vol. 12:247-263.

Lazarus, R.S. (1990). Puzzles in the study of daily hassles. Journal of Behavioral Medicine, Vol. 7:375-389.

---and Folkman, S. (1984). Stress appraisal and coping. New York, NY: Springer.

LeBlanc, P.M. and Schaufeli, W.B. (2003). Burnout among oncology care providers: Radiation assistants, physicians and nurses). In M. Dollard, A.H. Winfield and H.R. Winfield (eds.). Occupational Stress and the Service Professions, New York: Taylor and Francis.

Lee, C. and Gillen, D.J. (1986). Relationship of Type A behavior pattern to self efficacy perceptions and performance: A field study of sales persons. In C. Lee, P.C. Earley and L. A. Hanson. (1988). Are Type A's better performers? Journal of Organizational Behavior, Vol. 29:263-269.

Leech, N.R., Barrett, K.C. and Morgan, G.A. (2008). SPSS for intermediate statistics: Use and interpretation. $3^{\text {rd }}$ ed. New York: Lawrence Erlbaum Associates.

Lester, D., Butler, A.J.P., Dalley, A.F., Lewis, T. and Swanton, B. (1983). Job satisfaction, cynicism, and belief in an external locus of control: A study or police in four nations. Police Studies: An International Review of Police Development, Vol. 6:6-9.

---(1982). Subjective stress and sources of stress for police officers. Psychological Reports, Vol. 50:1094-1099.

Lipsky, M. (1971). Street-level bureaucracy and the analysis of urban reform. Urban Affairs Quarterly, June:391-409.

Little, R. J. A. and Rubin, D. B. (1987). Statistical analysis with missing data. New York: John Wiley and Sons.

Livingston, D. (1994). Police reform and the department of justice: An essay on accountability. Buffalo Criminal Law Review., Vol. 2:814-8157. 
Lorinskas, R., Kalinch, D. and Bana, D. (1985). Symbolism and rhetoric: The guardians of status quo in the criminal justice system. Criminal Justice Review, Vol. 10:4146.

Los Angeles Police Department. (2002). Los Angeles department manual. Los Angeles Police Department.

Lunden, W.A. (1958). The mobility of chiefs of police. The Journal of Criminal Law, Criminology, and Police Science, Vol. 49, No. 2:178-183.

Maas, J. B., Wherry, M. L., Axelrod, D. J., Hogan, B. R., and Bloomin, J. (1998). Power sleep New York: Random House. p. 110.

Maguire, E.R. (2003). Measuring the performance of law enforcement agencies. CALEA Updates, Number 83 and 84. Fairfax, Va: Commission on Accreditation for Law Enforcement Agencies (CALEA). Retrieved on June 25, 2008 from http://www.calea.org/newweb/newsletter/Newletters.htm.

---(2004). Police departments as learning laboratories. Ideas in American Policing, No. 6. Washington, D.C: Police Foundation. Available at www.policefoundation.org.

---and Uchida, C.D. (2000). Measurement and explanation in the comparative study of police organizations. In D. Duffee (Ed.), Measurement and analysis of crime and justice (pp. 491-557). Washington, DC: National Institute of Justice.

Mahtesian, C. (January 1997). Mission impossible. Governing, Vol. 10, No.4:19-23.

Malloy, T.E. and Mays, G.L. (1984). The police stress hypothesis. Criminal Justice Bulletin, Vol. 11:197-224.

Manderscheid, R.W., Silbergeld, S. and Dager, E.Z. (1975). Alienation: A response to stress. Journal of Cybernetics, Vol. 5:91-105.

Manning, P.K. (1971). The police: Mandate, strategies and appearances. In J.D. Douglas (Ed.) Crime and Justice in American Society. Indianapolis, In: Bobbs-Merrill. pp.149-193.

---(1977). Police work: The social organization of policing. Cambridge, Ma.: The MIT Press.

Manolias, M. (1983). A preliminary study of stress in the police service. London: Home Office, SRDB, Human Factors Group.

Margolis, B., Kroes, W. and Quinn, R. (1974). Job stress and unlisted occupational hazard. Journal of Occupational Medicine, Vol. 1:659-661. 
Marion, N.E. (1997). Symbolic policies in Clinton's crime control agenda. Buffalo Criminal Law Review. Vol. 1, No. 67:67-108.

Marsh, R.M. (1961). Formal organization and promotion in a pre-industrial society. American Sociological Review, Vol. 26:547-556.

Maslach, C. (1976). Burned-out. Human Behavior, Vol. 5:16-22.

---(1982). Burnout: The cost of caring. Englewood Cliffs, NJ: Prentice Hall.

Maslach, C. and Jackson, S. (1982). Burnout in health professionals: A social psychological analysis. In G. Sanders and J. Suls (eds.), Social Psychology of Health and Illness. Hillsdale, NJ: Earlbaum, pp.227-251.

Maslow, A. H. (1943). A theory of human motivation. Psychological Review, Vol. 50:370-396.

Mastrofski, S.D. (1981). Reforming police: The impact of patrol assignment patterns on officer behavior in urban residential neighborhoods. Ph.D. dissertation, University of North Carolina, Chapel Hill. In National Research Council, 2004, Fairness and Effectiveness in Policing: The Evidence, Washington, D.C: National Academies Press. p.171

---(1981). Policing the beat: The impact of organizational scale on patrol officer behavior in urban residential neighborhoods. Journal of Criminal Justice, Vol. 9:387- 402.

---Ritti, R. and Hoffmaster, D. (1987). Organizational determinants of police discretion: The case of drinking-driving. Journal of Criminal Justice, Vol. 15:387-402.

---and Wadman, R. (1991). Personnel and agency performance measurement. In W. Geller (ed.). Local government police management. Washington, D.C: International City Managers Association.

---(1999). Policing for people. Ideas in American Policing. Washington, D.C: U.S. Department of Justice, Police Foundation, March. In Edward R. Maguire, Measuring the Performance of Law Enforcement Agencies, Fairfax, Va: Commission on Accreditation for Law Enforcement Agencies, CALEA, pp.11-12. Available at www.policefoundation.org.

Matteson, M.T., Ivancevich, J.M and Smith, S.V. (1984). Relation of Type A behavior to performance and satisfaction among sales personnel. Journal of Vocational Behavior, Vol. 25:203-214. 
Maureen, D. (2004). In Ford, S. (October 2004). Workplace stress: Environmental and individual factors. InPsych Highlights. Australian Psychological Society.

Maxfield, M. G. and Babbie, E. (2001). Research methods for criminal justice and criminology. $3^{\text {rd }}$ ed. Belmont, Ca: Wadsworth.

---and Andresen, W.C. (2001). Evaluation of New Jersey State Police In-car Mobile Video Recording System. Draft Final Report. New Jersey Department of Law and Public Safety, February 1.

Maxwell, S.E. (1998). Longitudinal designs in randomized group comparisons: When will intermediate observations increase statistical power? Psychological Methods, Vol. 3:275-290.

McAlary, M. (1996). Good cop, bad cop. New York: Doubleday.

McCaffrey, B.R. (Autumn 1995). Human rights and the commander. Defense Technical Information Center. Accessible at http://www.dtic.mil/doctrine/jel/jfq_pubs/0709.pdf.

McCreary, D.R., and Thompson, M.M. (2006). Development of two reliable and valid measures of stressors in policing: The operational and organizational police stress questionnaires. International Journal of Stress Management, Vol. 13:494-518.

---and Sadava, S.W. (1998). Stress, drinking, and the adverse consequences of drinking in two samples of young adults. Psychology of Addictive Behaviors, Vol. $12: 247-261$.

McNair, D.M., Frankenthaler, L.M., Czerlinsky,T., White, T.W., Sasson, S and Fisher, S. (1982). Simulated public speaking as a model of clinical anxiety.

Psychopharmacology, Vol. 77, No. 1:7-10.

Meagher, M.A. (1986). Assessing the importance of patrol officer task performance. American Journal of Police, Vol. 5:67-89.

Melnicoe, W. and Mening, J. (1978). Elements of police supervision. $2^{\text {nd }}$ ed. Glencoe, Ca.

Mertler, C.A. and Vannatta, R.A. (2005). Advanced and multivariate statistical methods: Practical application and interpretation. $3^{\text {rd }}$ ed. Glendale, Ca: Pyrczak Publishing.

Meyers, L.S., Gamst, G. and Guarino, A.J. (2006). Applied multivariate research: Design and interpretation. Thousand Oaks, Ca: Sage.

Milligan, S.O. and Fridell, L. (April 2006). Implementing an Agency-Level Performance Measurement System: A Guide for Law Enforcement Executives. Final Report to the National Institute of Justice. Washington, D.C: U.S. Department of Justice. 
Mitler, M.M., Dinges, D.F. and Dement, W.C. (1994). Sleep medicine, public policy and public health. In Kryger, M.H., Roth, T and Dement, W.C. (eds.) Principles and practices of sleep medicine. $2^{\text {nd }}$ ed. Philadelphia, Pa: W.B. Saunders.

Mollen Commission. (1994). Commission to investigate allegations of police corruption and the ant-corruption procedures of the police department. Commission Report, City of New York.

Monk, T.H. (1988). Coping with the stress of shift work. Work and Stress, Vol. 2:169172.

Monk, T.H. and S. Folkard. (1985). Individual differences in shiftwork adjustment. In S. Folkard and T.H. Monk (eds.), Hours of work-temporal factors in work scheduling. New York: Wiley.

Monkkonen, E.H. (1192). History of urban police. Crime and Justice, Vol. 15:547-580.

Moore, M. (1995). Creating public value. Cambridge, Ma: Harvard University Press.

Moore, M. Thatcher, D., Dodge, A. and Moore, T. (2002). Recognizing Value in Policing: The Challenge of Measuring Police Performance. Washington, D.C: Police Executive Research Forum.

---and Braga, A. (2003). The "bottom line” of policing: What citizens should value (and measure!) in police performance. Police Executive Research Forum. Retrieved on June 24, 2008 from http://www.leoprd.org/reading/BottomLineofPolicing.pdf.

---and Braga, A. (2004). Police performance measurement: A normative framework. Criminal Justice Ethics, Vol. 3:3-19.3

---Thatcher, D., Hartmann, F.X., Coles, C. and Sheingold, P. (1999). Case studies of the transformation of police departments: A cross-site analysis. Program in Criminal Justice Policy and Management, John F. Kennedy School of Government, Harvard University. Working Paper 99-05-16.

Moore, R.Y. (1990). Circadian rhythm and sleep-wake behavior. In J. Montpalaisir and R. Goodbout (eds.), Sleep and biological rhythms: Basic mechanisms and application to psychiatry. New York: Oxford University Press.

More, H.W. (1976). The American police. St. Paul, MN: West Publishing.

Moorman, R.H., Neihoff, B.P. and Organ, D.P. (1993). Treating employees fairly and organizational citizenship behavior: Sorting the effects of job satisfaction, organizational commitment and procedural justice. Employee Responsibilities and Rights Journal, Vol. 6, No.3:209-225. 
Mosher, F.C. (1968). Democracy and the public service. New York: Oxford University Press.

Muchinsky, P.M. (1997). Psychology applied to work: An introduction to industrial and organizational psychology. New York: Brooks Cole.

Narvaez, A.A. (February 3, 1984). Lawsuit by U.S. charges Newark violates jail inmates; civil rights. New York Times, p.A1.

National Research Council. (2004). Fairness and effectiveness in policing: The evidence. Washington, D.C: National Academies Press.

Neiderhoffer, A. (1967). Behind the shield. New York: Doubleday.

Nichols, L.T. (1991). Whistleblower or renegade: Definitional contests in an official inquiry. Symbolic Interaction, Vol. 14:395-414.

O’Hara, P. (2005). Why law enforcement organizations fail: Mapping the organizational fault lines in policing. Durham, NC: Carolina Academic Press.

O’Leary-Kelly, A.M., Riffin, R.W., and Glew, D.J. (1996). Organization-motivated aggression: A research framework. Academy of Management Review, Vol. 21:225-253.

O’Malley, T.J. (1997). Managing for ethics: A mandate for administrators. Washington, D.C: FBI Law Enforcement Bulletin, Vol. 66:20-27.

O’Neil, M.W., Needle, J.A. and Galvin, R.T. (1980). Appraising the Performance of Police Agencies: The PPPM (Police Program Performance Measures) System. Journal of Police Science and Administration, Vol. 8, No. 3:253-264. In Edward R. Maguire, Measuring the Performance of Law Enforcement Agencies, Fairfax, Va: Commission on Accreditation for Law Enforcement Agencies, CALEA, pp.11-12

O’Neill, J.L. and Cushing, M.A. (1991). The impact of shift work on police officers. Washington, D.C: Police Executive Research Forum.

Osterburgh, J.W. (1962). Selection of criminal investigators in law enforcement agencies. Journal of Criminal Law, Criminology and Police Science, Vol. 53:264-268.

Ostrom, E., Parks, R., Whitaker, G. (1977). The police services study, Bloomington. Workshop in Political Theory and Policy Analysis, Indiana University.

Oettmeier, T.N. and Wycoff, M.A. (1994). Police performance in the nineties: Practitioner perspectives. American Journal of Police, Vol. 13, No. 2:21-48. 
Packer, H. L. (1968). The limits of the criminal sanction. Stanford University Press.

Paoline, III, E.A. (2004). Shedding light on police culture: An examination of officers' occupational attitudes. Police Quarterly, Vol. 7, No. 2: 205-236.

Park, K. (1987). Human reliability: Analysis, prediction and prevention of human errors. Amsterdam, The Netherlands: Elsevier.

Pateman, C. (1975). A contribution to the political theory of organizational democracy. Administration and Society, Vol. 7, No. 1:5-26.

Patten, T.H., Jr. (1977). Pay: Employee compensation and incentive plan. New York: Free Press.

Peacock, B., Glube, R., Miller, M., and Clune, P. (1983). Police officers' responses to 8 and 12 hour shift schedules. Physiology and Behavior, Vol. 26:479-493.

Pearlin, L.I. (1989). The sociological study of stress. Journal of Health and Social Behavior, Vol. 30:241:256.

Perrewe, P.L., and Anthony, W.P. (1990). Stress in a steel pipe mill: The impact of job demands, personal control and employee age on somatic complaints. Journal of Social Behavior and Personality, Vol. 5:77-90.

Perrow, C. (1986). Complex organizations: A critical essay. New York: Random House.

Pfiffner, J.M. (1951). Supervision of personnel: Human relations in the management of men. New York: Prentice Hall.

Philadelphia Police Department. (1987). Philadelphia police study task force, Philadelphia and its police: Toward a new partnership. Philadelphia, PA: PPD.

Pickles, A. (2005). Missing data, problems and solutions. In Kimberly Kempf-Leonard, ed., Encyclopedia of social measurement. Amsterdam: Elsevier. pp. 689-694.

Pierce, J.L. and Dunham, R.B. (1992). The 12-hour work day: A 48-hour, eight-day week. Academy of Management Journal, Vol. 35:1086-1098.

Pilcher, J. J. and Huffcutt, A. I. (1996). Effects of sleep deprivation on performance: A meta-analysis. Sleep, Vol. 19, no. 4:318-326.

Pollock-Byrne, J.M. (1989). Ethics in crime and justice: Dilemmas and decisions. Pacific Grove, Ca: Brooks/Cole Publishing. 
Potter, J. (1978). Liberation of the police wife. Police Magazine, Vol. 5:39-45.

---and Blackmore, J. (1980). Rising to the top: The new chief and how they got there. The Police Chief, Vol. 3, No. 3:40-46.

Potts, L.W. (1980). Integrating the chief of police into the municipal administrative process. Criminal Justice Review, Vol. 13: 12-21.

---(1982). Police leadership: Challenges for the eighties. Journal of Police Science and Administration, Vol. 10, No. 2:181-188.

President's Commission on Law Enforcement and Administration of Justice, Task Force Report: The Police. (1967). Washington, D.C.: U.S. Government Printing Office.

Price, B.R. (1972). Police corruption: An analysis. Criminology, Vol. 10:161-176.

---(1976). Police administrators’ ambivalence toward professionalism. Criminal Justice Review, Vol. 1:13-20.

Punch, M. (1985). Conduct unbecoming: The social construction of police deviance and control. London: Tavistock.

Pursley, R.D. (1974). Leadership and community identification attitudes among two categories of police chiefs: An exploratory inquiry. Journal of Police Science and Administration, Vol. 2:414.

Quarles, C.L. (1985). A validation study of a police managerial assessment center. American Journal of Police, Vol. IV, No I:71:92.

Quick, J.C., Murphy, L.R. and Hurrell, J.J. Jr. (1992). Stress and well-being at work: Assessments and interventions for occupational mental health. Washington, D.C: American Psychological Association.

Quinn, R.P, Seashore, S. and Mangione, I. (1971). Survey of working conditions. Washington, D.C. U.S. Government Printing Office.

Rainguet, F.W. and Dodge, M. (2001). The problems of police chiefs: An examination of the issues in tenure and turnover. Police Quarterly, Vol. 4, No. 3:268-288

Rampart Independent Review Panel. (2000). Report of the rampart independent review panel: A report to the Los Angeles board of police commissioners concerning the operations, policies, and procedures of the Los Angeles police department in the wake of the Rampart scandal. Retrieved from http://www.lacity.org/oig/rirprpt.pdf on January 30, 2006. 
Rand, S.R. and Manuele, C.A. (1987). Stress and police officer performance: An examination of effective coping behavior. Police Studies: International Review of Police Deviance, Vol. 10:122-131.

Regestein, Q.R. and T.H. Monk. (1991). Is the poor sleep of shift workers a disorder? American Journal of Psychiatry, Vol. 148:1487-1493.

Regoli, R., Crank, J. and Culbertson, R. (1989). Police cynicism, job satisfaction and Work relations of police chiefs: An assessment of the influence of department size. Sociological Focus, Vol. 22, No. 3:161-171.

Reiser, M. (1973). Practical psychology for police officers. Springfield, Il: Charles C. Thomas.

---(1974). Some organizational stresses on policemen. Journal of Police Science And Administration, Vol. 2, No. 2:156-159.

Reiss, A.J. Jr. (1971). The police and the public. New Haven, Ct: Yale. ---(1988). Private employment of public police. Issues and Practices. Washington, D.C: National Institute of Justice. NCJ\# 105192.

---(1992). Police organization in the twentieth century. Crime and Justice, Vol. 54:51-97.

Reuss-Ianni, E. (1984). Two cultures of policing: Street cops and management cops. Contemporary Sociology, Vol. 13, No. 4:448-449.

Rhoades, L. and Eisenberger, R. (2002). Perceived organizational support: A review of the literature. Journal of Applied Psychology, Vol. 87:698-714.

Rhoades, P. (1991). Political obligation: Connecting police ethics and democratic values. American Journal of Police, Vol. 10, No. 2:1-22.

Rice, F. (1985). The quest for certainty: Ethical concerns in police experiments. In Police leadership in America: Crisis and opportunity. W. Geller (ed.). New York: Praeger.

Robin, G. and Anson, R.H. (1990). Introduction the criminal justice system. New York: Harper and Row.

Robinson, P. (1981). Stress in the police service. Police Review, November, 2254-2259, 2308- 2312; December, 2364-2367, 2412-2414.

Rodgers, D.T. (1974). The work ethic in industrial America. Chicago: University of Chicago Press. 
Roosendaal, P. (2002). SAPS officials_-victims of crime: The end result...suicide. Servamus, Vol. 98, No. 8:20-24.

Rosa, R.R., Colligan, M.J. and Lewis, P. (1989). Extended workdays: Effects of 8 and 12 hour rotating shift schedules on performance, subject alertness, sleep patterns and psychosocial variables. Work and Stress, Vol.3:21-32.

Roseman, I.J. (1984). Cognitive determinants of emotion: a structural theory. In P. Shaver (ed.) Review of Personality and Social Psychology, Vol. 5: Emotions, Relationships, and Health. (pp. 11-36). Beverly Hills, CA: Sage.

Rosekind, M.R., Gander, P.H., Miller, D.L., Gregory, K.B., Smith, R.M., Weldon, K.J., Co, E.l., McNally, K.L. and Lebacqz, J.V. (1994). Fatigue in operational settings: Examples from the aviation environment. Human Factors, Vol. 36:327-338.

Rosenbaum, D.P., Schuck, A.M., Costello, S.K., Hawkins, D.F. and Ring, M.K. (2005). Attitudes toward the police: The effects of direct and vicarious experience. Police Quarterly, Vol. 8, No. 3:343-365.

Rosenberg, M. (1976). Beyond self-esteem: The neglected issues in self-concept research. Paper presented at the annual meetings of the ASA. In A.D. Cast and P.J. Burke. (2002). A theory of self-esteem. Social Forces, Vol. 80, No. 3:10411068.

---(1979). Conceiving the self. New York: Basic Books.

---(1990). The self-concept: Social product and social force. pp. 593-624. In M. Rosenberg and R.H Turner (eds.) Social psychology: Sociological perspectives. New York: Basic Books.

Roskies, E. and Lazarus, R.S. (1980). Coping theory and the teaching of coping skills. In Behavioral Medicine: Changing health lifestyles. P. Davison (ed)., New York: Brunner/Mazel, pp.36-69.

Rothman, S., Meiring, D. Van der Walt, H.S. and Barrick, M. (2002, April). Predicting job performance using personality measures in South Africa. Paper presented at the $17^{\text {th }}$ Annual Conference of the Society for Industrial and Organizational Psychology, Toronto, Ontario, Canada.

Rothwell, G.R. and Baldwin, J.N. (2007). Ethical climate theory, whistle-blowing and the code of silence in police agencies in the state of Georgia. Journal of Business Ethics, Vol. 70:341-361. 
Rubenstein, J. (1973). City police. New York: Farrar, Staus and Girous.

Rummel, R.J. (1970). Applied factor analysis. Evanston, Il: Northwestern University Press.

Sandy, J.P. and Devine, D.A. (1978) Four stress factors unique to rural patrol. The Police Chief, Vol. 45, No.9:42-44.

Sauter, S.l., Murphy, L.R. and Hurrell Jr., J.J. (1990). Prevention of work-related psychological disorders. American Psychologist. Vol. 45:1146-1158.

Savery, L., Soutar, G. and Weaver, J. (1993). Stress and the police officer: Some Western Australian evidence. The Police Journal, July:227-290.

Schafer, J.L. and M. K. Olsen (1998). Multiple imputation for multivariate missing-data problems: A data analyst's perspective. Multivariate Behavioral Research. Vol. 33: 545-571.

Schaufeli, W.B. and Enzmann, D. (1998). The burnout companion to study and practice: A critical analysis. Washington, D.C: Taylor and Francis.

Scheff, T. and Retzinger, S. (1991). Emotions and violence. Lexington: Lexington Books

Scheier, M.F., Carver, C.S and Bridges, M.W. (1994). Distinguishing optimism from neuroticism (and trait anxiety, self-mastery and self-esteem): A reevaluation of the Life Orientation Test. Journal of Personality and Social Psychology, Vol. 67:1063-1078.

Schnall, P.L., Landsbergis, P.A., and Baker, D. (1994). Job strain and cardiovascular disease. Annual Review of Public Health, Vol. 15:381-411.

Scholl, R.W. (1977). Career lines and employment stability. Academy of Management Journal, Vol. 26:86-103.

Schroeder, D.L., Lombardo, F. and Strollo, J. (1995). Management and supervision of law enforcement personnel. Binghampton, NY: Gould Publications.

Scott, A.J. (ed.) (1990). Occupational medicine: Shiftwork. Vol. 5, No. 2. Philadelphia: Hanley and Belfus.

Scott, W.R. (1975). Organizational structure. In A. Inkeles, J. Coleman and N. Smelser (eds.) Annual Review of Sociology Vol. 1: Palo Alto, Ca: Annual Review Inc.

Seigler, R.T. and Wilson, C.N. (1988). Stress in the workplace: Comparing police stress with teacher stress. Journal of Police Science and Administration. Vol. 16:151162. 
Selye, H. (1956). The stress of life. New York: McGraw-Hill.

---1974. Stress without distress. New York: New American Library.

Senge, P.M. (1994). The Fifth Discipline: The Art and Practice of the Learning Organization. rev. ed., New York: Currency Doubleday. In William A. Geller, 1997, Suppose We Were Really Serious About Police Departments Becoming "Learning Organizations"? National Institute of Justice Journal, December 1997:2-8.

Senger, J. (1971). Managers' perceptions of subordinates: Competence as a function of personal value orientations. The Academy of Management Journal, Vol. 14, No. 4:415-423.

Serrano, R.A. (May 30, 1994). Hiring more police in Houston pays off as overall crime rate in city plummets. Los Angeles Times, p.A15.

Shadish, W.R., Cook, T.D. and Campbell, D.T. (2002). Experimental and quasiexperimental designs for generalized causal inference. New York: HoughtonMifflin.

Sherman, L.W. (1974). Police corruption: A sociological perspective. Garden City, NY: Anchor.

---(1975). Middle management and police democratization: A reply to John E. Angell. Criminology, Vol. 12:363-377.

---(1993). Defiance, deterrence, and irrelevance: A theory of the criminal justice sanction. Journal of Research in Crime and Delinquency, Vol. 30.

Sigler, R.T. and Wilson, C.N. (1988). Stress in the workplace: Comparing police stress with teacher stress. Journal of Police Science and Administration. Vol. 16, No. 3:151-162.

Silbert, M.H. (1982, June). Job stress and burnout of new police officers. The Police Chief, 46-48.

Skogan, W.G. and Hartnett, S.M. (1997). Community policing: Chicago style. New York: Oxford University Press.

Skolnick, J.H. (1966). Justice without trial: Law enforcement in a Democratic society. New York: John Wiley.

---.(1994). Justice without trial: Law enforcement in a democratic society. $3^{\text {rd }}$ ed. New York: Macmillan. 
---(1968). Justice Without Trial. New York: John Wiley and Sons.

---and Fyfe, J. (1993). Above the law: Police and the excessive use of force. New York: The Free Press.

---(1996). A sketch of the police officer's 'working personality'." In Criminal Justice in America: Theory, Practice, and Policy. Upper Saddle River, NJ: Prentice-Hall, pp. 89-113.

---(1999). On democratic policing. Ideas in American Policing. Washington, D.C: Police Foundation. Retrieved on June 25, 2008 at www.policefoundation.org.

Smith, B. (1940). Police systems in the United States. New York: Harper and Brothers.

Smith, C.A. and Lazarus, R.S. (1990). Emotion and adaptation. In L.A. Pervin (ed.). Handbook of Personality: Theory and Research. Chapter 23, pp. 609-637. New York: Guilford.

Smith, B.L and Ward, R.M. (1983). Stress and military policing: A comparative analysis. American Journal of Policing, Vol. 3:111-117.

Snyder, R.A. (1995). One man's time warp is another (wo)man's treasure: The importance of individual and situational differences in shift work tolerance and satisfaction. Human Resource Development Quarterly, Vol. 6, No. 4:397-407.

Souryal, S.S. and McKay, B.W. (1996). Personal loyalty to superiors in public service. Criminal Justice Ethics, Vol. 15: 44-62.

Sparrow, M.K. (November 1988). Implementing community policing. Perspective in Policing 9. Washington, D.C: National Institute of Justice.

Speilberger, C.D. and Reheiser, E.C. (1995). Measuring occupational stress: The job stress survey. In R. Crandall and P.L. Perrewe (eds.), Occupational stress: A handbook, pp. 51-69. Philadelphia: Taylor Francis.

Standsfell, S.A., Fuhrer, R., Shipley, M.J., and Marmot, M.G. (1999). Work characteristics predict psychiatric disorder: Prospective results from the Whitehall II study. Occupational and Environmental Medicine, Vol. 56:302-307.

State Comptroller. (1 986). State comptroller report number 36. Office of the State Comptroller. Jerusalem: 544-62. In S. Herzog, (2000). Deviant organizational messages among suspect police officers in Israel. Policing: An International Journal of Police Strategies and Management, Vol. 23, No. 4:416-438. 
Stephens, J. (1994). Out of the closet: Confessions of a Type B personality. July/August. Trends in Library Management and Technology.

Stets, J.E. and Burke, P.J. (2000). Identity theory and social identity theory. Social Psychology Quarterly, Vol. 63:224-237.

Stevens, J. (1992). Applied multivariate statistics for the social sciences. $2^{\text {nd }} \mathrm{ed}$. New York: Harper Collins.

Stevenson, D.B. (1996). Tanker crew fatigue: Some new solutions to an old problem. Journal of Maritime Law and Commerce, Vol. 27, No. 3:453-468.

Stinchcombe, J.B. (2004). Searching for stress in all the wrong places: Combating chronic organizational stressors in policing. Police Practice and Research, Vol. 5, No.3:259-277.

---(1980). Beyond bureaucracy: A reconsideration of the "professional” model. Police Studies: An International Review of Police Development, Vol. 49:49-61.

Stoddard, E. (1968). The informal "code” of police deviancy. Journal of Criminal Law, Criminology and Police Science, Vol. 59 201-213.

Stratton, J.G. (May 1978). Police stress: An overview. The Police Chief. Alexandria, Va: IACP. pp. 73-77.

Suro, R. (November 1, 1991). Crime rate could claim Houston mayor. New York Times, p.A19.

Swanke, J.A., Jr. (1989). Public officials liability losses-1989. Baseline Data Report, Vol. 21, No. 4. Washington, D.C: ICMA.

Sykes, D. and Matza, G.M. (1957). Techniques of neutralization: A theory of delinquency. American Sociological Review, Vol. 22.

Tabachnick, B., and Fidell, L. (2001). Using multivariate analysis. $4^{\text {th }}$ ed. California State University Northridge: Harper Collins College Publishers.

Tafoya, W. (April 1974). Lateral entry. Police Chief. pp. 60-62.

Talarico, S.M. and Swanson, C.R. (1983). An analysis of police perceptions of supervisory and administrative support. Police Studies: An International Review of Police Development, Vol. 5:47-54.

Tang, T.L-P, and Hammontree, M.L. (1992). The effects of hardiness, police stress and life stress on police officers. Illness and Absenteeism, Public Personnel Management, Vol. 21:493-510. 
Terrill, W. (1997). Police coercion: Application of the force continuum. New York: LFB Publishing. In National Research Council. (2004). Fairness and effectiveness in policing: The evidence. Washington, D.C: National Academies Press. p.283.

Territo, L. and Vetter, H.J. (eds.). (1981). Stress and police personnel. Boston: Allyn and Bacon.

Terry, W.C. III. (1981). Police stress: The empirical evidence. Journal of Police Science and Administration. Vol. 9:61-75.

Thayer, R.E. (1989). The biopsychology of mood and arousal. New York: Oxford University Press.

Theorell, T. (1998). Job characteristics in a theoretical and practical health context. In C. Cooper (ed.), Theories of organizational stress. Oxford, England: Oxford University Press. pp. 205-219.

Thibault, E.A., Lynch, L.M. and McBride, R.B. (1985). Proactive police management. Englewood Cliffs, NJ: Prentice Hall.

Thorndyke, E.L. (1920). A constant error is psychological rating. Journal of Applied Psychology, Vol. 4:25-29.

Thorne, D. R., Johnson, D. E., Redmond, D. P., Sing, H. C., and Belenky, G. (2005). The Walter Reed Palm-held Psychomotor Vigilance Test [Abstract]. Behavioral Research Methods, Vol. 37, No. 1:111-118.

Tift, L.L. (1974). Cop personality reconsidered. Journal of Police Science and Administration, Vol. 2:266.

Torsvall, L., T. Akerstedt, T. K. Gillander, and A. Knutsson. (1989). Sleep on the night shift: 24-hour EEG monitoring of spontaneous sleep/walk behavior. Psychophysiology, Vol. 26, No. 3:352-358.

Townley, G. (2000). Long hours culture causing economy to suffer. Management Accounting, Vol. 78:3-5.

Treichel, J.A. (1982). Type A personality: The physical response. Science News, Vol. 122, No. 18:279.

Trojanowicz, R.C. (1980). The environment of the first-line police supervisor. Englewood, Cliffs, NJ: Prentice-Hall.

Turnage, J.J. and Speilberger, C.D. (1991). Job stress in mangers, professionals and clerical workers. Work and Stress, Vol. 5:165-176. 
Tyler, T. (1990). Why people obey the law. New Haven, Ct: Yale University Press.

United States Conference of Mayors. (1933). Merit ratings in police departments. Chicago: American Municipal Association.

Van Maanen, J. (1972). Pledging the police: A study of selected aspects of recruit socialization in a large urban police department. Unpublished dissertation, Graduate School of Administration, University of California, Irvine.

---(1978). Observations in making a policeman. In P. Manning and J. Van Maanen (Eds.), Policing: A View from the Street, New York: Random House.

Vaughn, D. (1993). Theory elaboration: From whistleblowing to organizational dissent. Paper presented at the American Society of Criminology, Phoenix, Az.

Velez, M. (2006). Leading to scandal: A case study. Unpublished dissertation. Ann Arbor, MI: UMI Dissertation Services.

Veninga, R.L and Spradley, J.P. (1981). The work/stress connection. Boston: Little Brown.

Vila, B. (1996). Tired cops: Probable connections between fatigue and the performance, health and safety of patrol officers. American Journal of Police, Vol. XV, No.2:51-92.

---(2000). Tired Cops: The Importance of Managing Police Fatigue. Washington DC: Police Executive Research Forum.

Vila, B. J., and Kenney, D. J. (2002). Tired cops: The prevalence and potential consequences of police fatigue. National Institute of Justice Journal, 248:16-21. NCJ\# 190634.

Vila, B., and Morris. C. (eds.) (1999). The role of police in American society: A documentary history. Westport, Conn.: Greenwood Press.

Violanti, J.M. and Aron, F. (1993). Sources of police stressors, job attitudes and psychological distress. Psychological Reports, Vol. 72:899-904.

---(1995). Police stressors: Variations in perceptions among police personnel. Journal of Police Science Administration, Vol. 11, No. 1:61-75.

Violanti, J.M, Vena, J.E. and Marshall, J.R. (1986). Disease risk and mortality among police officers: New evidence and contributing factors. Journal of Police Science and Administration, Vol. 14:17-23. 
---and Aron, F., (1995). Ranking police stressors. Psychological Reports, Vol. 75:824-826.

---(1996a). Police suicide: An overview. Police Studies, Vol. 19, No. 2:77-89.

---(1996b). Violence turned inward: Police suicide in the workplace. In G.R. VandenBos and E.Q. Bulatao (eds.) Violence on the job: Identifying the risks and developing solutions (pp.229-249). Washington, D.C: American Psychological Association.

Vollrath, M., Torgersen, S. and Alnaes, R. (1995). Personality as a long-term predictor of coping. Personality and Individual Differences, Vol. 18:117-125.

Wadman, R.C. and DeLadurantey, J.C. (1984). Overcoming limitations to police productivity measurement: The Omaha experience. Public Productivity Review, Vol. 8, No. 3:225-235.

Waite, J.B. (1931). Report on police: Comment. Michigan Law Review, Vol. 63, No. 1:63-69.

Walker, S. (1998). Popular justice: A history of American criminal justice. $2^{\text {nd }}$ ed. New York: Oxford University Press. pp.165-167.

---(1993). Taming the system: The control of discretion in criminal justice, 19501990. New York: Oxford University Press.

---(1977). A critical history of police reform. Lexington, Ky: Lexington Books.

---(2008). The police in America: An introduction. $6^{\text {th }}$ ed. New York: McGrawHill.

Wall, D.S. (1994). Ideology of internal recruitment: The selection of chief constables and changes within the tripartite arrangement. British Journal of Criminology, Vol. 34, No. 3:322-338.

Walsh, W.F. (1990). Performance evaluations in small and medium police departments: A supervisory perspective/ American Journal of Police, Vol. 9:93-109.

Ward, G.E. (1979). Physiological, psychological and social issues specifically related to the police profession. Law and Order, Vol. 27, No. 1:12.

Warren, D.I. (1969-1970). Suburban isolation and race tension: The Baltimore experience. Social Problems, Vol. 17:324-339.

Watts, E. (1982). Patterns of promotion: The St. Louis police department, 1899-1975. Social Science History, Vol. 6, No. 2: 233-258. 
Wayne, S.J., Shore, L.M., and Linden, R.C. (1997). Perceived organizational support and leader-member exchange: A social exchange perspective. Academy of Management Journal, Vol. 40:82-111.

Webb, S.D. and Smith, D.L. (1980). Stress prevention and alleviation strategies for police. Criminal Justice Review, Vol. 5:1-15.

Weber, M. (1946). From Max Weber: Essays in Sociology, translated and edited by Hans H. Gerth and C. Wright Mills. New York: Oxford University Press.

--(1971). Three types of legitimate rule. In M. Truzzi (Ed.), Sociology: The Classic Statements, (pp. 169-179). New York: Random House.

Webster, W. H. and Williams, H. (1992). The city in crisis: A report by the special advisor to the board of police commissioners on the civil disorder in Los Angeles. Washington, D.C: Police Foundation.

Wechter, J. (2004). Investigating citizen complaints is different: Special challenges of investigating citizen complaints against police officers. A Report by the Police Professionalism Initiative of the University of Nebraska. Retrieved on June 24, 2008 from http://www.nacole.org/jaysonspaper.pdf.

Weinblatt, R.B. (October 1999). Shifting landscape of chief's jobs. Law and Order, Vol. 47, No.10:49-51.

Weisburd, D., Petrosino, A. and Mason, G. (1993). Design sensitivity in criminal justice experiments. Crime and Justice, Vol. 17:337-379.

Weiss, A. and Boruch, R.F. (1996). On the use of police officers in randomized field experiments: Some lessons from the Milwaukee domestic violence experiment. Police Studies, Vol. 19, No. 1:45-52.

Weiss, J.A. (1996). Public management and psychology. In D. Kettl and B. Milward (Eds.), The state of public management (pp.118-143). Baltimore, MD: Johns Hopkins University Press.

---and Piderit, S.K. (1999). The value of mission statements in public agencies. Journal of Public Administration Research and Theory, Vol. 9, No. 2:193-223.

Weiss, J.G. (1986). Issues in the measurement of criminal careers. Chapter 1. In A. Blumstein, J. Cohen, J.A. Roth and C.A. Visher (eds), Criminal Careers and Career Criminals, Vol. 2. pp.1-51. Washington, D.C: National Academy Press.

Weiss, M. (1983). Effects of work stress and social support on information systems managers. MIS Quarterly, Vol. 7, No. 1:29-43. 
Weitzer, R. and Tuch, S.A. (2005). Determinants of public satisfaction with the police. Police Quarterly, Vol. 8, No. 3:279-297.

Wexler, J.G. and Logan, D.D. (1983). Sources of stress among women police officers. Journal of Police Science and Administration, Vol. 11:264-74.

Whisler, T.L. (1955). A realistic role for merit rating. Journal of Business, Vol. 28:39.

Whitaker, G., Mastrofski, S., Ostrom, E., Parks, R.B. and Percy, S.L. (July 1982). Basic issues in police performance. Washington, D.C: National Institute of Justice. p.xi.

White, S. and Marion, K. (1983). Job attitudes and police stress: An exploratory study of causation. Journal of Police Science and Administration, Vol. 11, No. 3: 264-274.

White-Sydney, W. (1981). The effects of shift rotation on police job stress. Unpublished Dissertation, Michigan State University. Ann Arbor, MI: University Microfilms International.

Williams, F. (1992). Reasoning with Statistics: How to read quantitative research. $4^{\text {th }}$ ed. Fort Worth, Tx: Harcourt Brace Jovanovich.

Williams, P.G., Wiebe, D.J., and Smith, T.W. (1992). Coping processes as mediators of the relationship between hardiness and health. Journal of Behavioral Medicine, Vol. 15:237-255.

Wilson, J.Q. (1968). Varieties of police behavior. Cambridge, Ma: Harvard University Press.

---(1989). Bureaucracy: What government agencies do and why they do it. New York: Basic Books.

Wilson, O.W. (1963). Police administration. New York: McGraw-Hill.

Winefield, A.H., Montgomery, B., Gault, U., Muller, J., O’Goman, J., Reser, J., and Roland, D. (2002). The psychology of work and unemployment in Australia today: An Australian psychological society discussion paper. Australian Psychologist, Vol. 37:1-9.

Winefield, H.R. (2003). Work stress and its effects in general practitioners. In M. Dollard, A.H. Winfield and H.R. Winfield (eds.). Occupational Stress and the Service Professions, New York: Taylor and Francis.

Witte, J.H., Travis III, L.F. and Langworthy, R.H. (1990). Participatory management in law enforcement: Police officer, supervisor and administrator perspectives. American Journal of Police, Vol. 9:1-23. 
Wolfskill, J.R. (1989). Higher education and police performance. Unpublished doctoral dissertation, University of Kansas.

Wren, T.E. (1985). Whistle-blowing and loyalty to one’s friends. In W.C. Heffernan and T. Stroup (eds.) Police Ethics: Hard Choices in Law Enforcement. New York: John Jay Press.

Wright, L. (1988). Type A behavior pattern and coronary artery disease: Quest for the active ingredients and the elusive mechanism. American Psychologist, Vol. 43:214.

Wright, T.A. and Cropanzano, R. (2000). Psychological well-being and job satisfaction as predictors of job performance. Journal of Occupational Health Psychology, Vol. 5:84-94.

Yarmey, A.D. (1990). Understanding police and police work: Psychological issues. New York, NY: New York University Press.

Zhao, J., Thurman, C. and He, N. (1999). Sources of job satisfaction among police officers: A test of demographic and work environment models. Justice Quarterly, Vol. 16,No. 1:153-173.

\section{Cases Cited}

City of Canton, Ohio v. Harris, 489, U.S. 378 (1989)

Davis v. Mason County, 927 F.2d 1473 (9 $9^{\text {th }}$. Cir. 1991)

Garrity v. New Jersey, 385 U.S. 493 (1967)

Monell v. New York City Department of Social Services, 436 U.S. 658 (1978)

Spell v. McDaniel, 864 F.2d 1380 (1981)

United States v. Koon, 833 F. Supp. 769, 774 (C.D. Cal. 1993) 


\section{Appendices}

Appendix 1

\section{Police Performance Data Collection Protocol}

\section{Participant ID\#:}

1. Total sick hours:

2. Total on-duty injuries:

3. Total on-duty accidents:

\section{Citizen and administrative complaints}

Number of administrative (internal) complaints:

Number of citizen (external) complaints:

5. Failure to appear in court

Number of scheduled appearances:

Number of times failed to appear:

6. Total arrests:

7. Total citations:

8. Total reports completed:

9. Total stops:

10. Total self-initiated investigations: 


\title{
Appendix 2
}

\section{INFORMED CONSENT}

\author{
Organizational Stressors and Police Performance Officer Survey \\ Conducted by: \\ Jon M. Shane \\ Rutgers School of Criminal Justice
}

The Paterson Police Department has agreed to participate in a research study conducted by Jon M. Shane on the relationship between organizational stressors and police performance. This study is entitled "Organizational Stressors and Police Performance."

I understand that if I volunteer to participate, the researchers will ask me to prepare a confidential survey regarding my perception of various organizational stressors. I certify that I am currently an active duty officer assigned to respond to calls for service. I am not on restricted duty and expect to stay on patrol.

\section{Overview of the Study}

The research study involves a survey of perceptions. The survey component will be completed and returned to Jon M. Shane for analysis. The next section outlines the specific steps required of me (on a volunteer basis), if I agree to participate.

\section{Steps Involved if I Participate}

1) Complete some self-report measures - this survey asks about work attitudes, job satisfaction, and job stress, as well as some related questions and demographics. It is expected that this will take between 30-45 minutes to complete.

2) Authorize review of relevant departmental performance data. I understand that the City (Paterson Police Department) may provide basic information to Jon M. Shane regarding sick/injury leave, complaints, on-duty accidents, arrests, stops and self-initiated investigations, citations, and court appearances for comparison purposes. This will permit analysis of various factors that affect performance.

I understand that there are some conditions to participating in this survey. The study does require a commitment of time and a willingness to provide honest and complete information whenever possible. I am aware that some of the questions may be of a personal nature and the researchers promise to protect my confidentiality by not connecting any of my responses to my name or personal identity. I am assured that my responses to any personal questions or survey responses are directly related to the study's purposes and will not be revealed to any other member of the department.

I understand that the researchers will only present aggregate data or a summary of results based on groups large enough so that no person can be individually identified. The collection of my information will only be attached to an ID number that I will be assigned for the study. Only Jon M. Shane (and not any member of the police department) will be able to associate my name with my ID number in order to connect my survey data to performance data. I understand that when the study is complete, the researchers will destroy the list that links participant names with identification numbers. All information I provide to Jon M. Shane will be kept in strict confidence according to the policy on human subjects research at Rutgers University. I understand that my responses will never be revealed in a way that can personally identify me, nor will any information about me personally be provided to the police department, EXCEPT if I make a direct threat or express an intention to harm myself or someone else. 
If I agree to participate in the survey, then I understand that I may withdraw at any time and may refuse to answer any question. If I choose to withdraw, I understand that I will not be required to complete any more surveys. I realize that there will be no penalties or negative consequences to me if I decide to skip any questions or stop participating altogether.

If I have any questions, concerns, or complaints, I am free to contact Jon M. Shane. Below is my signature indicating my consent to begin participating in this study.

Jon M. Shane

Principal Investigator

Rutgers University

123 Washington Street

Newark, NJ 07102

973-699-6880

I have read and understand the information in the Organizational Stressors and Police Performance Informed Consent document, and I have had all questions answered to my satisfaction. I voluntarily agree to participate in this research.

Print Name

Today's Date:

Contact Number:
Signature

Researcher Initials:

Email: 


\title{
Appendix 3
}

\author{
Recruitment Letter for Shift Work Project
}

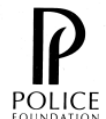

November 13, 2006

Dear Officer:

Are you interested in working either 4/10-hour shifts or 3/12-hour shifts? The Police Foundation in Washington, DC has been awarded a federal grant to conduct a study of shift work that will assess the feasibility of these compressed work schedules. As such, the Detroit Police Department and the Detroit Police Officers' Association have collaborated with the foundation and agreed to be a key site for this research project which will have national impact. The study will examine how 5/8s, 4/10s, and 3/12s affect fatigue and officers' health, safety, performance, and quality of life. As a volunteer, you would be contributing greatly to this effort. If you volunteer you agree that you are willing to be randomly assigned to $3 / 12 \mathrm{~s}^{*}, 4 / 10 \mathrm{~s}$, or $5 / 8 \mathrm{~s}$ for the 6 months of the study. You cannot choose your shift, but your platoon will remain the same.

\section{WHO'S ELIGIBLE?}

All active-duty officers from Platoons I, II, and III who are assigned to respond to calls for service.

\section{BENEFITS}

- If you are selected to participate you will receive a stipend of $\$ 100$ (\$50 in the first and last months of the study). The payment is to compensate you for the time you spend off-duty completing the survey and to thank you for participating.

- You will also have two chances to win one of two $\$ 1,000$ prizes. Participants who complete all exercises in each phase of the study will be entered in the prize drawings (one the first month and one the last month).

- Your participation will aid in the development of policing practices designed to improve the health, safety, performance, and quality of life of police officers nationwide, and help the Detroit PD assess the advantages and disadvantages of each shift schedule.

\section{WHAT'S REQUIRED?}

Participation in the study involves 2 basic activities over two periods of time (before the start of the assigned shift and 6 months later):

- A practical/tactical session completed during the last 3 hours of a work shift that will include a shooting simulator, a driving simulator, a video simulation, and other practical/tactical exercises.

- Surveys completed off-duty.

\section{HOW TO GET INVOLVED}

There are a limited number of spaces available in this study. Researchers will be on-site from November $15^{\text {th }}$ through November $20^{\text {th }}$ conducting information sessions and sign ups during roll-call briefings. If you are interested please volunteer as soon as possible, but no later than November $27^{\text {th }}$. Your participation in this study will be strictly voluntary, but volunteering does not guarantee that you will be selected to participate as there are only 270 spaces available. If more than 270 officers volunteer, selections will be made based on district and seniority. All simulations and surveys will be completed in mid-December and early January and new shift assignments will take effect on January 15, 2007 and continue through July 14, 2007.

\section{To volunteer:}

$>$ Complete the attached informed consent

Bring your completed form to roll call on one of the days we will be on site (we will have extra forms there as well), OR 
$>\quad$ Fax the forms to (202) 296-2012, OR

$>$ Send an email with the same information as on the attached form to Kzinsser@policefoundation.org, OR

$>$ Call the Research Coordinator Kate Zinsser toll free at 1-866-697-7290 to get any questions answered before signing up.

All information collected during this study will be kept confidential. If you have any questions, concerns, feel free to contact either of the people listed below during regular business hours

Dr. Karen L. Amendola, Principal Investigator

1201 Connecticut Ave., NW, Suite 200

Washington, D.C. 20036

Commander John Autrey

(202) 833-1460

Detroit Police Department

(313) 218-3374

*3/12s will be operationally defined as working 3 consecutive, 12-hour shifts in week \#1, and in week \#2, 3 consecutive 12-hour shifts plus a fourth day of 8 hours (total of 80 hours every two weeks, or an average of 40 hours per week). 


\section{Appendix 4}

\section{Recruitment Script for the Shift Work Project}

Good morning/Afternoon. My Name is ____ (add in name here) and I am part of a research team from the Police Foundation in Washington, DC. We are a non-profit organization that has been performing cutting edge research in policing for over 30 years.

I am here to talk to you about taking part in an exciting research project being funded by the U.S. Department of Justice. We are thrilled to be working with the Detroit Police Department and DPOA on this ground breaking study that will examine the implication of 8, 10, and 12 hour shift lengths on officer health, safety, performance, and quality of life.

Recently, law enforcement agencies and officers nationwide have shown interest in compressed work schedules, such as the $4 / 10$ schedule. Yet very little is known about how various shift schedules affect an officer's quality of life and their performance if at all. We are conducting this study for the National Institute of Justice in order to assess potential advantages and disadvantages of various shift schedules to officers and police agencies. With your assistance we should be able to address these questions and assist agencies throughout the country in determining which shifts to employ in different circumstances, the implications of those shifts, and additional resources or support necessary.

We would like to ask you to volunteer for this research study. By volunteering you will be agreeing to be RANDOMLY ASSIGNED to one of three shifts for the period of January $15^{\text {th }}, 2007$ through July $14^{\text {th }}$, 2007. The shifts will include an 8 hour shift five days a week, a 12 hour shift three collective days a week with a fourth 8 hour work day every other week, or 10 hour shifts four days a week. We will then ask you to complete a few activities before you start your new shift and again five to six months from now when the study is ending. Once you volunteer, we expect that you will stick with the study for the 6 month period, unless there is an extenuating circumstance (such as promotion or reassignment) or other emergent condition. All active-duty officers from Platoons I, II, and III who are assigned to respond to calls for service are eligible.

The first activity is to complete a survey that asks you about various aspects of your on and off-duty life. Since you will work on the survey at home, we will give you $\$ 50$ each time you complete it to compensate you for you time. Secondly, participants will be asked to complete a sleep diary and alertness log for two weeks and return them to us. Participants that complete those will be entered into a drawing for $\$ 1000$ at two points in the study. Finally participants will come to the training academy during the last three hours of their shift and perform a number of practical and tactical simulations.

We will be conducting these exercises starting in early December prior to the state of the new shifts will begin January $15^{\text {th }}$ of 2007 . The measures will be repeated starting in June once participants have been on their new shift assignment for about 5 months and the study will end on July $14^{\text {th }}, 2007$.

Participation in this study is completely voluntary and confidential. If you volunteer, your name will never be linked with your responses or performance.

We are very excited about this study and we really hope you will consider participating. However, we have limited space in the study as there are only 270 spaces available, so volunteering does not guarantee that you will be included in the study. If more than 270 officers volunteer, priority will be given based on district and seniority. This is to ensure relatively equal numbers of officers participating across all districts.

If you meet these qualifications I would like to ask you to volunteer to work with us not only to examine the feasibility of more compressed schedules in Detroit, but to help other agencies nationwide make similar determinations. 
Do you have any questions?

We are handing out informed consent forms that include the information I provided today and more details. If you are interested in participating please take a few minutes to read the consent form carefully. Please feel free to ask me any questions. If you would like to participate you may return the volunteer form and informed consent to me now or by fax to the number provided no later than November $27^{\text {th }}$. If you complete the form while we are here on site, we will give you a small token of our appreciation.

THANK YOU SO MUCH FOR YOUR TIME! 
Appendix 6

\section{Law Enforcement Officer Survey}




\section{INSTRUCTIONS}

In this packet are a number of questions that address general and specific issues and/or factors that have been identified within the law enforcement community as having an impact on performance and job satisfaction. Read each statement carefully and select the appropriate choice that corresponds with your answer; simply circle your answer, preferably in ink. Please answer every item and be open and honest with your responses so that we can get a true picture of your feelings about the various issues addressed throughout this packet.

Your responses to all questions will be kept confidential and restricted to Jon M. Shane for analysis and review. These responses will help us to identify how these different issues and factors relate to one another and help us to determine how they impact police work. The results will be provided to your agency and published only in aggregate form, so no individuals can be identified in this process. When completed, please seal the survey inside the envelope and call Jon M. Shane at 973-699-6880 to arrange for pick up.

Please do not pay attention to the question-numbering scheme next to each item, this is for internal tracking purposes; the numbering convention does not begin with question 1 and may not be sequential.

\section{Permission}

Police Stress Questionnaire (PSQ, Items 1 - 40). The PSQ is in the public domain and is free for academic research. It is the intellectual property of authors McCreary and Thompson. See McCreary, D.R., and Thompson, M.M. (2006). Development of two reliable and valid measures of stressors in policing: The operational and organizational police stress questionnaires. International Journal of Stress Management, Vol. 13:494518.

Police Daily Hassles and Uplifts Scale (DHUS, Items 41 - 126). The DHUS is copyright protected. It is reprinted here with permission from Dr. Peter Hart for its limited purpose. It is the intellectual property of authors Hart, Wearing and Heady. See Hart, P.M. and Cooper, C.L. (2001). Occupational stress: Toward a more integrated framework. In N. Anderson, D.S. Ones, H.K. Sinangil and C. Viswesvaran, (eds.), 2001, Handbook of Industrial and Organizational Psychology. Vol. 2: Personnel Psychology. London: Sage. 


\section{Section I: Work Attitudes}

The purpose of this section is to give you a chance to tell how you feel about your present job, what things you are satisfied with and what things you are not satisfied with.

\section{Items 1 - 40}

Below is a list of potentially stressful items that describe different aspects of being a police officer. For each item, please indicate how much stress it has caused you over the past 6 months, using a 7-point scale that ranges from "No Stress at All” to "A Lot of Stress:"

\begin{tabular}{|c|c|c|c|c|c|c|}
\hline $\begin{array}{c}\text { No Stress } \\
\text { At All }\end{array}$ & 2 & $\begin{array}{c}\text { Moderate } \\
\text { Stress }\end{array}$ & & & $\begin{array}{c}\text { A Lot Of } \\
\text { Stress }\end{array}$ \\
\hline 1 & 2 & 3 & 4 & 5 & 6 & 7 \\
\hline
\end{tabular}

1. Shift work

2. Working alone at night

3. Over-time demands

4. Risk of being injured on the job

5. Work related activities on days off (e.g., court, community events, etc.)

$\begin{array}{lllllll}1 & 2 & 3 & 4 & 5 & 6 & 7 \\ 1 & 2 & 3 & 4 & 5 & 6 & 7 \\ 1 & 2 & 3 & 4 & 5 & 6 & 7 \\ 1 & 2 & 3 & 4 & 5 & 6 & 7\end{array}$

6. Traumatic events (e.g., motor vehicle accidents, domestics, death)

7. Managing your social life outside of work

8. Not enough time available to spend with friends and family

9. Paperwork

10. Eating healthy at work

11. Finding time to stay in good physical condition

12. Fatigue (e.g., shift work, over-time)

13. Occupation-related health issues (e.g., back pain)

14. Lack of understanding from family and friends about your work

15. Making friends outside the job

16. Upholding a "higher image" in public

17. Negative comments from the public

18. Limitations to your social life (e.g., where you socialize)

19. Feeling like you are always on the job

20. Friends/family feel the effects of the stigma associated with your job

21. Dealing with co-workers

22. The feeling that different rules apply to different people (e.g., favoritism)

$\begin{array}{lllllll}1 & 2 & 3 & 4 & 5 & 6 & 7\end{array}$

$\begin{array}{lllllll}1 & 2 & 3 & 4 & 5 & 6 & 7\end{array}$

$\begin{array}{lllllll}1 & 2 & 3 & 4 & 5 & 6 & 7\end{array}$

$\begin{array}{lllllll}1 & 2 & 3 & 4 & 5 & 6 & 7\end{array}$

$\begin{array}{lllllll}1 & 2 & 3 & 4 & 5 & 6 & 7\end{array}$

$\begin{array}{lllllll}1 & 2 & 3 & 4 & 5 & 6 & 7\end{array}$

$\begin{array}{lllllll}1 & 2 & 3 & 4 & 5 & 6 & 7\end{array}$

$\begin{array}{lllllll}1 & 2 & 3 & 4 & 5 & 6 & 7\end{array}$

$\begin{array}{lllllll}1 & 2 & 3 & 4 & 5 & 6 & 7\end{array}$

$\begin{array}{lllllll}1 & 2 & 3 & 4 & 5 & 6 & 7\end{array}$

$\begin{array}{lllllll}1 & 2 & 3 & 4 & 5 & 6 & 7\end{array}$

$\begin{array}{lllllll}1 & 2 & 3 & 4 & 5 & 6 & 7\end{array}$

$\begin{array}{lllllll}1 & 2 & 3 & 4 & 5 & 6 & 7\end{array}$

$\begin{array}{lllllll}1 & 2 & 3 & 4 & 5 & 6 & 7\end{array}$

23. Feeling like you always have to prove yourself to the organization

$\begin{array}{lllllll}1 & 2 & 3 & 4 & 5 & 6 & 7\end{array}$

$\begin{array}{lllllll}1 & 2 & 3 & 4 & 5 & 6 & 7\end{array}$

24. Excessive administrative duties

25. Constant changes in policy/legislation

26. Staff shortages

27. Bureaucratic red tape

28. Too much computer work

29. Lack of training on new equipment

30. Perceived pressure to volunteer free time

$\begin{array}{lllllll}1 & 2 & 3 & 4 & 5 & 6 & 7\end{array}$

$\begin{array}{lllllll}1 & 2 & 3 & 4 & 5 & 6 & 7\end{array}$

$\begin{array}{lllllll}1 & 2 & 3 & 4 & 5 & 6 & 7\end{array}$

$\begin{array}{lllllll}1 & 2 & 3 & 4 & 5 & 6 & 7\end{array}$

$\begin{array}{lllllll}1 & 2 & 3 & 4 & 5 & 6 & 7\end{array}$

$\begin{array}{lllllll}1 & 2 & 3 & 4 & 5 & 6 & 7\end{array}$

$\begin{array}{lllllll}1 & 2 & 3 & 4 & 5 & 6 & 7\end{array}$

$\begin{array}{lllllll}1 & 2 & 3 & 4 & 5 & 6 & 7\end{array}$

$\begin{array}{lllllll}1 & 2 & 3 & 4 & 5 & 6 & 7\end{array}$ 


\begin{tabular}{|c|c|c|c|c|c|c|}
\hline $\begin{array}{c}\text { No } \\
\text { Stress } \\
\text { At All }\end{array}$ & & & $\begin{array}{c}\text { Moderate } \\
\text { Stress }\end{array}$ & & & $\begin{array}{c}\text { A Lot Of } \\
\text { Stress }\end{array}$ \\
\hline 1 & 2 & 3 & 4 & 5 & 6 & 7 \\
\hline
\end{tabular}

31. Dealing with supervisors

32. Inconsistent leadership style

33. Lack of resources

34. Unequal sharing of work responsibilities

35. If you are sick or injured your co-workers seem to look down on you

36. Leaders over-emphasis the negatives (e.g. supervisor evaluations)

37. Internal investigations

38. Dealing with court system

39. The need to be accountable for doing your job

40. Inadequate equipment $\begin{array}{lllllll}1 & 2 & 3 & 4 & 5 & 6 & 7\end{array}$

$\begin{array}{lllllll}1 & 2 & 3 & 4 & 5 & 6 & 7\end{array}$

$\begin{array}{llllllll}1 & 2 & 3 & 4 & 5 & 6 & 7\end{array}$

$\begin{array}{lllllll}1 & 2 & 3 & 4 & 5 & 6 & 7\end{array}$

$\begin{array}{lllllll}1 & 2 & 3 & 4 & 5 & 6 & 7\end{array}$

$\begin{array}{lllllll}1 & 2 & 3 & 4 & 5 & 6 & 7\end{array}$

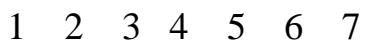

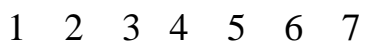

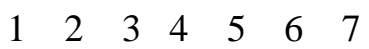

$\begin{array}{lllllll}1 & 2 & 3 & 4 & 5 & 6 & 7\end{array}$

\section{Items 41 - 126}

Indicate the degree to which each experience/item hassled or bothered you as a result of police work DURING THE PAST MONTH, where 1 = definitely did not hassle/bother me and 5 = strongly hassled/bothered me. If the item hassled or bothered you to some extent circle 2, 3, or 4 as appropriate.

\begin{tabular}{|c|c|c|c|c|}
\hline $\begin{array}{c}\text { Definitely } \\
\text { did NOT } \\
\text { hassle or } \\
\text { bother me }\end{array}$ & \multicolumn{2}{|c|}{ Hassled or bothered me to some extent } & $\begin{array}{c}\text { Strongly } \\
\text { hassled or } \\
\text { bothered } \\
\text { me }\end{array}$ \\
\hline 1 & 2 & 3 & 4 & 5 \\
\hline
\end{tabular}

41. Going on a raid

42. Going to dangerous calls

43. Having to make a forcible arrest

44. Delivering a death message

45. Giving bad news

46. Dealing with domestics

47. Dealing with road victims

48. Dealing with abused children

49. Dealing with assault victims

50. Seeing other people in misery

51. Taking an (road) accident report

52. Hoax calls

53. Not being able to charge someone who is guilty

54. Doing work I don't like

55. Doing things I don't agree with

56. Not being able to get an admission from someone who is guilty

$\begin{array}{lllll}1 & 2 & 3 & 4 & 5 \\ 1 & 2 & 3 & 4 & 5 \\ 1 & 2 & 3 & 4 & 5 \\ 1 & 2 & 3 & 4 & 5 \\ 1 & 2 & 3 & 4 & 5 \\ 1 & 2 & 3 & 4 & 5 \\ 1 & 2 & 3 & 4 & 5 \\ 1 & 2 & 3 & 4 & 5 \\ 1 & 2 & 3 & 4 & 5 \\ 1 & 2 & 3 & 4 & 5 \\ 1 & 2 & 3 & 4 & 5 \\ 1 & 2 & 3 & 4 & 5 \\ 1 & 2 & 3 & 4 & 5 \\ 1 & 2 & 3 & 4 & 5 \\ 1 & 2 & 3 & 4 & 5 \\ & & & & \\ 1 & 2 & 3 & 4 & 5\end{array}$




\begin{tabular}{|c|c|c|c|c|}
\hline $\begin{array}{c}\text { Definitely } \\
\text { did NOT } \\
\text { hassle or } \\
\text { bother me }\end{array}$ & \multicolumn{2}{|c|}{ Hassled or bothered me to some extent } & $\begin{array}{c}\text { Strongly } \\
\text { hassled or } \\
\text { bothered } \\
\text { me }\end{array}$ \\
\hline 1 & 2 & 3 & 4 & 5 \\
\hline
\end{tabular}

57. Dealing with people who abuse the police

58. Unreasonable expectations from others outside the department (e.g., lawyers, judges, the public)

59. Court decisions being too lenient

1

$\begin{array}{lllll}1 & 2 & 3 & 4 & 5 \\ 1 & 2 & 3 & 4 & 5 \\ 1 & 2 & 3 & 4 & 5\end{array}$

60. Outside interference with police work (e.g., government, public, concerned citizens)

61. Wasting time at court

62. Lack of police powers

63. Poor media coverage

64. Courts setting inconvenient dates

65. Irregular meal times

66. Missing meals

67. Rushed eating

68. Shift work interfering with other activities

69. Quick changeovers

70. Sitting around then suddenly active

71. Departmental handling of complaints

72. Complaints by the public

73. Being responsible for others

74. Dealing with other people's problems

75. Trying to show interest in people

76. Too much work to do

77. Too much expected of me

78. Insufficient time to complete a job

79. Meeting deadlines

80. Heavy traffic

81. Poor drivers on the road

82. Not being able to speak my mind

83. Having no say in decisions that affect me

84. Lack of honesty about my work by superiors

85. Interference in my decisions by others

86. Responsibility without authority to make decisions

87. Not receiving recognition for a job well done

88. Station instability

89. Personality clashes at work

90. Low morale

$\begin{array}{lllll}1 & 2 & 3 & 4 & 5\end{array}$

$\begin{array}{lllll}1 & 2 & 3 & 4 & 5\end{array}$

$\begin{array}{lllll}1 & 2 & 3 & 4 & 5\end{array}$

$\begin{array}{lllll}1 & 2 & 3 & 4 & 5\end{array}$

$\begin{array}{lllll}1 & 2 & 3 & 4 & 5\end{array}$

$\begin{array}{lllll}1 & 2 & 3 & 4 & 5\end{array}$

$\begin{array}{lllll}1 & 2 & 3 & 4 & 5\end{array}$

$\begin{array}{lllll}1 & 2 & 3 & 4 & 5\end{array}$

$\begin{array}{lllll}1 & 2 & 3 & 4 & 5\end{array}$

$\begin{array}{lllll}1 & 2 & 3 & 4 & 5\end{array}$

$\begin{array}{lllll}1 & 2 & 3 & 4 & 5\end{array}$

$\begin{array}{lllll}1 & 2 & 3 & 4 & 5\end{array}$

$\begin{array}{lllll}1 & 2 & 3 & 4 & 5\end{array}$

$\begin{array}{lllll}1 & 2 & 3 & 4 & 5\end{array}$

$\begin{array}{lllll}1 & 2 & 3 & 4 & 5\end{array}$

$\begin{array}{lllll}1 & 2 & 3 & 4 & 5\end{array}$

$\begin{array}{lllll}1 & 2 & 3 & 4 & 5\end{array}$

$\begin{array}{lllll}1 & 2 & 3 & 4 & 5\end{array}$

$\begin{array}{lllll}1 & 2 & 3 & 4 & 5\end{array}$

$\begin{array}{lllll}1 & 2 & 3 & 4 & 5\end{array}$

$\begin{array}{lllll}1 & 2 & 3 & 4 & 5\end{array}$

$\begin{array}{lllll}1 & 2 & 3 & 4 & 5\end{array}$

$\begin{array}{lllll}1 & 2 & 3 & 4 & 5\end{array}$

$\begin{array}{lllll}1 & 2 & 3 & 4 & 5\end{array}$

$\begin{array}{lllll}1 & 2 & 3 & 4 & 5 \\ 1 & 2 & 3 & 4 & 5\end{array}$

$\begin{array}{lllll}1 & 2 & 3 & 4 & 5\end{array}$

$\begin{array}{lllll}1 & 2 & 3 & 4 & 5\end{array}$

$\begin{array}{lllll}1 & 2 & 3 & 4 & 5\end{array}$

91. Feelings of having to conform to "pressure" from peers

92. Working with people who lack professionalism

93. Other members not pulling their weight

94. Working with people who are incompetent

95. Working with people who are not suited for police work

$\begin{array}{lllll}1 & 2 & 3 & 4 & 5 \\ 1 & 2 & 3 & 4 & 5 \\ 1 & 2 & 3 & 4 & 5 \\ 1 & 2 & 3 & 4 & 5 \\ 1 & 2 & 3 & 4 & 5 \\ 1 & 2 & 3 & 4 & 5 \\ 1 & 2 & 3 & 4 & 5 \\ 1 & 2 & 3 & 4 & 5\end{array}$




\begin{tabular}{|c|c|c|c|c|}
\hline $\begin{array}{c}\text { Definitely } \\
\text { did NOT } \\
\text { hassle or } \\
\text { bother me }\end{array}$ & \multicolumn{2}{|c|}{ Hassled or bothered me to some extent } & $\begin{array}{c}\text { Strongly } \\
\text { hassled or } \\
\text { bothered } \\
\text { me }\end{array}$ \\
\hline 1 & 2 & 3 & 4 & 5 \\
\hline
\end{tabular}

96. Working with people who are inconsiderate

97. Working with people who do not listen

98. Problems with coworkers

99. Jobs for the boys

100. Unfair rating system

101. Disagreement about how to do something

102. Being told what to do by others

103. Too much supervision

104. Unnecessary forms

105. Poor administration

106. Inconsistent application of rules and policy

107. Lack of forward planning

108. Too much red tape to get something done

109. Inappropriate rules and regulations

110. Excessive paperwork

111. Lack of clarity in operational guidelines

112. Inability to change the system

113. Feeling generally inadequate

114. 'Bottling' up my feelings

115. Difficulty staying objective (not expressing my emotions)

116. Feelings of not being able to do anything

117. Concerns about the status of police

118. Feelings of just being a number

119. Untidy work areas

120. Dirty mess rooms

121. Poor facilities

122. Lack of equipment

123. Equipment failure

124. Studying (for work purposes)

125. Exams (for work purposes)

126. Unfair promotional policy

$\begin{array}{lllll}1 & 2 & 3 & 4 & 5\end{array}$

$\begin{array}{lllll}1 & 2 & 3 & 4 & 5\end{array}$

$\begin{array}{lllll}1 & 2 & 3 & 4 & 5\end{array}$

$\begin{array}{lllll}1 & 2 & 3 & 4 & 5\end{array}$

$\begin{array}{lllll}1 & 2 & 3 & 4 & 5\end{array}$

$\begin{array}{lllll}1 & 2 & 3 & 4 & 5\end{array}$

$\begin{array}{lllll}1 & 2 & 3 & 4 & 5\end{array}$

$\begin{array}{lllll}1 & 2 & 3 & 4 & 5\end{array}$

$\begin{array}{lllll}1 & 2 & 3 & 4 & 5\end{array}$

$\begin{array}{lllll}1 & 2 & 3 & 4 & 5\end{array}$

$\begin{array}{lllll}1 & 2 & 3 & 4 & 5\end{array}$

$\begin{array}{lllll}1 & 2 & 3 & 4 & 5\end{array}$

$\begin{array}{lllll}1 & 2 & 3 & 4 & 5\end{array}$

$\begin{array}{lllll}1 & 2 & 3 & 4 & 5\end{array}$

$\begin{array}{lllll}1 & 2 & 3 & 4 & 5\end{array}$

$\begin{array}{lllll}1 & 2 & 3 & 4 & 5\end{array}$

$\begin{array}{lllll}1 & 2 & 3 & 4 & 5\end{array}$

$\begin{array}{lllll}1 & 2 & 3 & 4 & 5\end{array}$

$\begin{array}{lllll}1 & 2 & 3 & 4 & 5\end{array}$

$\begin{array}{lllll}1 & 2 & 3 & 4 & 5\end{array}$

$\begin{array}{lllll}1 & 2 & 3 & 4 & 5\end{array}$

$\begin{array}{lllll}1 & 2 & 3 & 4 & 5\end{array}$

$\begin{array}{lllll}1 & 2 & 3 & 4 & 5\end{array}$

$\begin{array}{lllll}1 & 2 & 3 & 4 & 5\end{array}$

$\begin{array}{lllll}1 & 2 & 3 & 4 & 5\end{array}$

$\begin{array}{lllll}1 & 2 & 3 & 4 & 5\end{array}$

$\begin{array}{lllll}1 & 2 & 3 & 4 & 5\end{array}$

$\begin{array}{lllll}1 & 2 & 3 & 4 & 5\end{array}$

$\begin{array}{lllll}1 & 2 & 3 & 4 & 5\end{array}$

$\begin{array}{lllll}1 & 2 & 3 & 4 & 5\end{array}$

$\begin{array}{lllll}1 & 2 & 3 & 4 & 5\end{array}$

\section{Section II: Work Schedule and Commuting}

\section{Items 127 - 133}

The following items deal with your work schedule and commuting. Please answer according to the response scale provided. 
127. How many miles do you live from where you work?

15 miles or less $\quad 16-30 \quad 31-60 \quad 61-100 \quad 101-150$ $>150$

128. How long does your commute to work teach each day, EACH WAY?

$\begin{array}{llllll}<15 \text { min. } & 15-29 & 30-44 & 45-60 & 1 \text { hour } & 1\end{array}$ hours $>1 \frac{1 / 2 \mathrm{hrs}}{}$

129. What is your main means of commuting to and from work?
a. Driving a motor vehicle
b. $\quad$ Public transportation
c. Car Pool
d. Motorcycle
e. Walking/biking
f. Friend or family member drives you

130. In the past MONTH, how many hours did you spend in court?

$<10 \quad 10-20 \quad 20-30 \quad>30$

131. In the past MONTH, what is the average amount of hours a week that you work off-duty employment?

$<10 \quad 10-20 \quad 20-30 \quad>30$

132. How many times have you pulled a double shift in PAST SIX MONTHS?

$\begin{array}{llllll}0 & 1-2 & 3-4 & 5-6 & 7-8 & 9-10\end{array}$

133. How long have you been working the current schedule?
a. Less than 2 months
b. 2-4 months
c. $\quad$ 4-6 months

\section{Section III: Demographics}

The purpose of this section is for us to examine the impact of various demographic characteristics on any of the research questions in the study. These will be kept in strict confidence and none of this data will be used to identify you personally.

\section{Items 134 - 141}

Please indicate the appropriate response to each of the following. 
134. What is your ethnicity?

Hispanic or Latino Not Hispanic or Latino

135. What is your race? (choose one):

a. American Indian or Alaskan Native

b. Asian

c. Black or African American

d. Native Hawaiian or other Pacific Islander

e. White

f. Other

136 Sex

Female Male

$137 \quad$ Age

$18-24 \quad 25-34 \quad 35-44 \quad 45-54 \quad 55$ or more

138 Education: HS/GED Some college Associate's Degree Bachelors Degree Graduate Degree Doctoral Degree Prof. Degree

$139 \quad$ What is your current marital status?
a. $\quad$ Married
b. Separated
c. Divorced
d. Widowed
e. $\quad$ Never Married

$140 \quad$ How many children do you have?
a. 0
b. 1
c. 2
d. 3
e. 4 or more

141

Are you the primary caregiver for the children?
a. Yes
b. No
c. Not applicable

THIS COMPLETES THE SURVEY. THANK YOU VERY MUCH FOR PARTICIPATING! 


\section{Appendix 6}

2007 Paterson Police Department Table of Organization

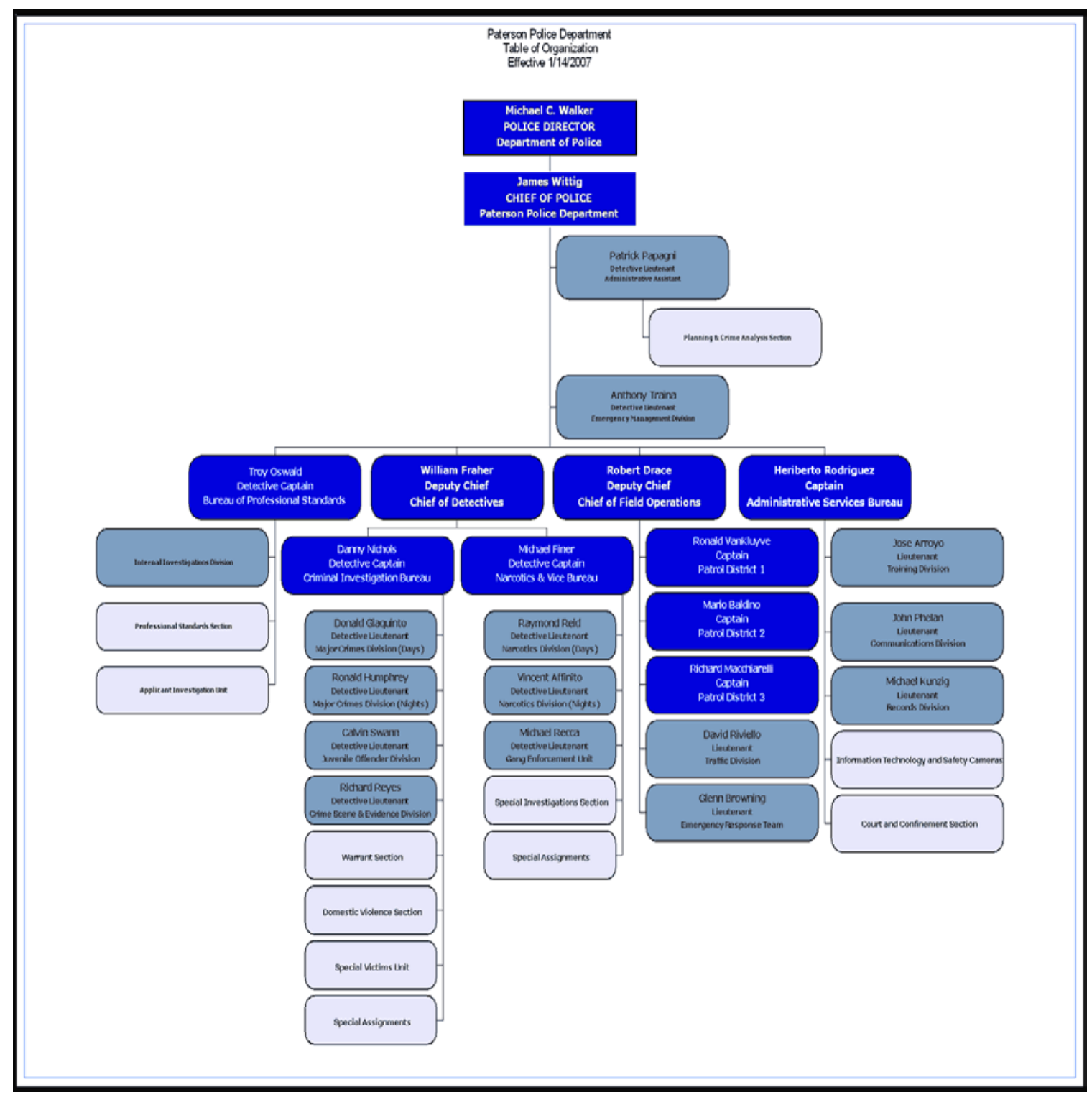




\section{Appendix 7}

\section{Detroit Police Department Table of Organization}

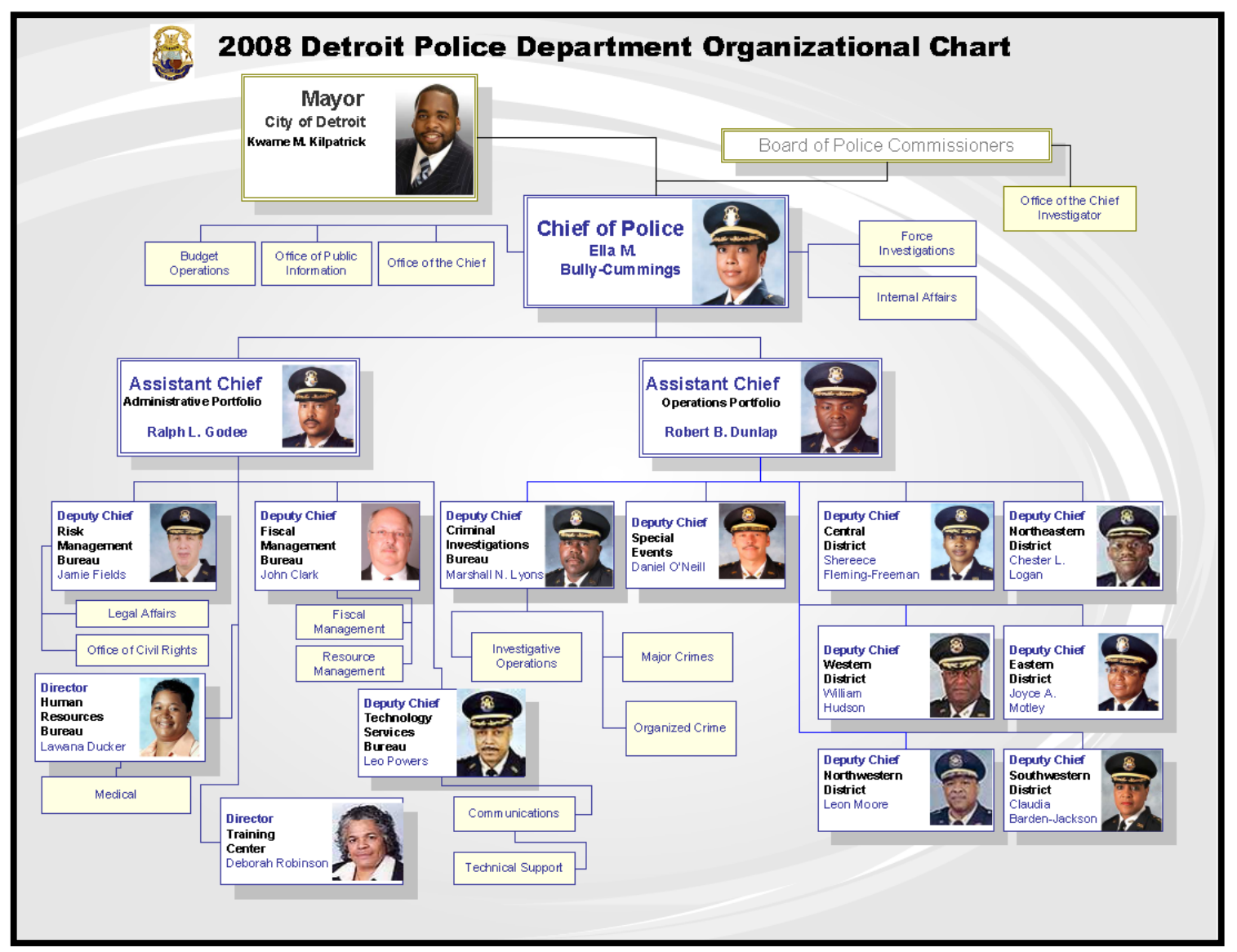




\section{Appendix 8}

\section{Paterson (NJ) Police Department, Letter of Participation}

\section{CITY OF PATERSON POLICE DEPARTMENT}

Michael C. Walker Police DiRector

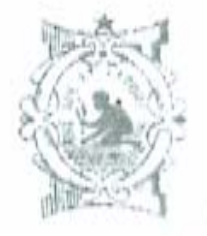

\section{J)osé "joę" Torres ftlapor}

\author{
MUNICIPAL COMPLEX \\ 111 BROADWAY \\ Paterson, NJ 07505-1124 \\ Phone (973) 321-1270 \\ Facsimile (973) $321-1271$
}

March 21, 2008

Jon M. Shane, Principal Investigator

Rutgers School of Criminal Justice

123 Washington Street

Newark. NJ 07102

RE: Dissertation research

Dear Mr. Shane:

This letter will serve to confirm the Paterson Police Department's (Department) participation in your dissertation reseurch entitled Organizational Siressors and Police Performance. The Paterson Police Department hereby grants you aceess to department records and police officers assigned to the patrol division for this limited purpose. You are granted aceess to the aforementioned in a supervised capacity. If, at any time, any member of the department wishes not to participate, then they may withdraw at any tume and shall not incur any pressure to continue: participation is eompletely voluntary, as indicated in your Informed Consent document provided to each willing participant.

The Department further understands any member of the agency will not have aceess to any other member's individual data and that you will keep all data collected about police officers confidential during and after the research is completed; when the research is completed, the original documents will be destroyed and you will not keep any copies, whether paper or electronic. The only data that you will retain is an aggregate electronic file for analysis purposes. which will not link any individuals to specific answers on the surveys. Furthermore, the Department will not ineur any expenses: any costs associated with the researeh will be bome by you. Lastly, the Department understands the results will eventually be published; the publication outlet will be determined by you in the future. The city of Paterson and/or the Paterson Police Department may be identified by name as a participating agency in the publieation. but individual police officers will not be linked to any specific survey responses or other data elements and will not be named. This agreement terminates when the research is completed.

Please contact me if you need additional information at 973-321-1270

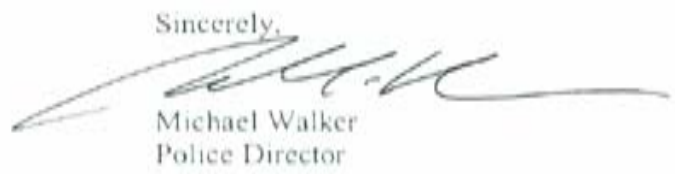

ce: James Wittig, Chief of Poliee 


\section{Appendix 9}

\section{Summary of Indexed Factors, Original Scale, Item Number and Item Name for Principal Components Analysis}

\begin{tabular}{|c|c|c|c|}
\hline Factor & $\begin{array}{l}\text { Scale } \\
\text { Origin }\end{array}$ & $\begin{array}{c}\text { Original } \\
\text { Item } \\
\text { Number }\end{array}$ & $\begin{array}{l}\text { Original Item } \\
\text { Name }\end{array}$ \\
\hline \multirow{4}{*}{$\begin{array}{l}\text { Supervision \& } \\
\text { Administration }\end{array}$} & PSQ & 36 & Leaders overemphasize the negatives \\
\hline & DHUS & 108 & Too much red tape to get something done \\
\hline & PSQ & 32 & Inconsistent leadership style \\
\hline & DHUS & 105 & Poor administration \\
\hline \multirow{6}{*}{$\begin{array}{l}\text { Coworker Social } \\
\text { Support }\end{array}$} & DHUS & 94 & Working with people who are incompetent \\
\hline & DHUS & 92 & Working with people who lack professionalism \\
\hline & DHUS & 95 & $\begin{array}{l}\text { Working with people who are not suited for police } \\
\text { work }\end{array}$ \\
\hline & DHUS & 96 & Working with people who are inconsiderate \\
\hline & DHUS & 93 & Other members not pulling their weight \\
\hline & DHUS & 97 & Working with people who do not listen \\
\hline \multirow{6}{*}{ Locus of Control } & PSQ & 23 & $\begin{array}{l}\text { Feeling like you have to prove yourself to the } \\
\text { organization }\end{array}$ \\
\hline & PSQ & 35 & $\begin{array}{l}\text { If you are sick or injured your co-workers seem to look } \\
\text { down on you }\end{array}$ \\
\hline & PSQ & 21 & Dealing with coworkers \\
\hline & PSQ & 30 & Perceived pressure to volunteer free time \\
\hline & PSQ & 39 & The need to be accountable for doing your job \\
\hline & PSQ & 24 & Excessive administrative duties \\
\hline \multirow{5}{*}{$\begin{array}{l}\text { Facilities \& } \\
\text { Equipment }\end{array}$} & DHUS & 120 & Dirty mess rooms \\
\hline & DHUS & 119 & Untidy work areas \\
\hline & DHUS & 123 & Equipment failure \\
\hline & DHUS & 121 & Poor facilities \\
\hline & DHUS & 122 & Lack of equipment \\
\hline \multirow{4}{*}{ Favoritism } & DHUS & 89 & Personality clashes at work \\
\hline & DHUS & 98 & Problems with coworkers \\
\hline & PSQ & 28 & Too much computer work \\
\hline & DHUS & 99 & Jobs for the boys \\
\hline \multirow{3}{*}{$\begin{array}{l}\text { Self-esteem \& } \\
\text { Individuality }\end{array}$} & DHUS & 116 & Feelings of not being able to do anything \\
\hline & DHUS & 115 & $\begin{array}{l}\text { Difficulty staying objective (Not expressing my } \\
\text { emotions) }\end{array}$ \\
\hline & DHUS & 113 & Feeling generally inadequate \\
\hline \multirow{2}{*}{ Bureaucracy } & DHUS & 110 & Excessive paperwork \\
\hline & DHUS & 104 & Unnecessary forms \\
\hline \multirow{2}{*}{$\begin{array}{l}\text { Promotional } \\
\text { Process }\end{array}$} & DHUS & 124 & Studying for work purposes \\
\hline & DHUS & 125 & Exams for work purposes \\
\hline Communication & DHUS & 84 & Lack of honesty about my work by superiors \\
\hline Staffing & PSQ & 26 & Staff shortages \\
\hline Internal Affairs & PSQ & 37 & Internal Investigations \\
\hline Rating System & DHUS & 126 & Unfair promotional policy \\
\hline
\end{tabular}




\section{NOTES}

${ }^{1}$ Operational overtime is work beyond the prescribed shift or beyond the scheduled work week. Mandatory operational overtime occurs when there is a personnel shortage (e.g., regularly scheduled officers call out sick; vacations; unfilled vacancies due to a slow hiring process), or when a special initiative is planned and a sufficient number of volunteers cannot be obtained. Voluntary operational overtime occurs when a police officer willingly submits to work beyond their prescribed shift or work week.

${ }^{2}$ Outside employment is defined as working another job in addition to the officer's regular full-time police employment (i.e., moonlighting).

${ }^{3}$ That some stressors are inescapable suggests they are chronic. "A chronic stressor, stress or strain refers to an ongoing exposure, condition or reaction respectively" (Dollard, Winefield and Winefield, 2003:6). An example of a chronic stressor is poor supervision, which is presumably linked with a chronic or long lasting reaction, as exposure to it cannot be avoided.

${ }^{4}$ The job-related violence in Amaranto et al.'s (2003) research was the 1999 murder/suicide of two Newark (NJ) police officers and a 2001 murder/hostage incident in Newark.

${ }^{5}$ Critical or traumatic incidents are defined as "those events a person experiences, witnesses or is confronted with...that involves actual or threatened death or serious injury or a threat to the physical integrity of self or others" (DSM-IV criterion for PTSD, American Psychiatric Association, 1994, in Liberman et al., 2002:422)

${ }^{6}$ One practical example is the structure of the Los Angeles Police Department (LAPD). The 2002 LAPD operating manual is 636 pages that consists of six volumes (Vol's 0, I, II, II, IV and V) and an appendix, which describes the structure, operating polices, rules and procedures of the entire agency.

${ }^{7}$ For example, the three largest U.S. police departments have very tall rank structures: The New York City Police Department's rank structure is: 1) police officer; 2) sergeant; 3) lieutenant; 4) captain; 5) deputy inspector; 6) inspector; 7) deputy chief; 8) assistant chief; 9) bureau chief; 10) chief of department; and 11) police commissioner (personal communication, Inspector Michael J. Harrington, August 27, 2007). The Los Angeles Police Department's rank structure is: 1) police officer; 2) sergeant and detective; 3) lieutenant; 4) captain; 4) commander; 5) deputy chief; and 6) chief of police (2002, Manual of the Los Angeles Police Department, p.32). The Chicago Police Department's rank structure is: 1) police officer; 2) sergeant; 3)lieutenant; 4) captain; 5) commander; 6) deputy chief; 7) assistant deputy superintendent; 8) chief; 9) deputy superintendent; 10) first deputy superintendent and; 11) superintendent of police (Personal communication, Commander Michael Chasen, August 27, 2007).

${ }^{8}$ The doctrine of command and control borrows from the military and is defined by the U.S. Department of Defense as: "The exercise of authority and direction by a properly designated commander over assigned and attached forces in the accomplishment of the mission. Command and control functions are performed through an arrangement of personnel, equipment, communications, facilities, and procedures employed by a commander in planning, directing, coordinating, and controlling forces and operations in the accomplishment of the mission. Also called C2" (Department of Defense, 2001:75). In its simplest form, "command" means the determination of something desired and "control" means to translate that desire, through various decisions, into a set of rules that govern what actions will be taken (Alberts and Hayes, 2006:20-21). Command and control is a process that works by formulating a plan, executing the plan, monitoring the results and making adjustments where necessary to achieve the plan's outcomes. The attributes of command and control that may create or perpetuate stress and low performance include: 1) quality of management and supervision (Autocratic management style and little delegated decision making authority); 2) quality of control (Oppressive or unnecessarily restrictive policies, rules or other internal constraints that are applied inappropriately); 3) mission mandates (Undefined or ambiguous goals and 
performance measures leading to inconsistent accountability or preferential treatment); 4) situation information (Poor communication resulting in filtered information, unsubstantiated rumor or a general lack of analysis); 5) limited resources (Too few personnel, inadequate facilities or poorly functioning equipment); and 6) lack of training and education.

${ }^{9}$ Personal communication with Dr. Wayne Fisher, Executive Director, Police Institute, Rutgers School of Criminal Justice, Newark, NJ, July 25, 2008.

${ }^{10}$ In general, authoritarianism describes a form of organizational control characterized by strict obedience to the authority of the agency's leader who maintains and enforces control through the use of oppressive measures, typically the internal affairs and disciplinary processes and the process of assignment and personnel transfer. Authoritarian organizations are strongly hierarchical.

${ }^{11}$ For example, the Los Angeles Police Department defines "chain of command" in the following manner: "The Chief of Police must necessarily limit the number of persons who report to him/her. Therefore, to ensure unity of command, clearly defined lines of authority must be drawn so that there exists a structural relationship between each employee and the Chief of Police. Employees must be aware of their relative position in the organization, to whom they are immediately responsible, and those persons who are accountable to them. Employees should strive at all times to operate within the chain of command and to keep their supervisors informed as to their activities. The Chief of Police is available by appointment to any member of the Department” (Manual of the Los Angeles Police Department, 2002:27, section 1/650).

${ }^{12}$ For a classic example of a well-organized police department, see the Task Force Report on the Police, President's Commission of Law Enforcement and Administration of Justice, 1967, p.47; for a contemporary organizational structure, see the Los Angeles Police Department at http://www.lapdonline.org/inside the_lapd/content_basic_view/1063, retrieved on March 31, 2008.

13 Basically, "unity of command" means that each police officer reports to a single supervisor. The goal is to eliminate the potential for conflicting orders from different supervisors, which supposedly increases accountability.

${ }^{14}$ The investigation of the Space Shuttle Challenger disaster of January 28, 1986 concluded that due to poor vertical and horizontal communication (emphasis added) within the NASA bureaucracy, NASA managers failed in their safety responsibilities. Preoccupied with mission launch and a general eagerness to get the project underway, "The Commission concluded that there was a serious flaw in the decision making process leading up to the launch of flight 51-L... [NASA management waived] launch constraints at the expense of flight safety...[Morton] Thiokol management reversed its position and recommended the launch of 51-L, at the urging of [NASA/Marshall Space Flight Center] and contrary to the views of its engineers in order to accommodate a major customer" Report of the Presidential Commission on the Space Shuttle Challenger Accident - in compliance with Executive Order 12546 of February 3, 1986, p.17-18; See also Allan J. McDonald, Lessons Learned but Forgotten from the Space Shuttle Challenger Accident, paper presented at the Space 2004 Conference and Exhibit, September 28, 2004, San Diego, Ca. According to McDonald "The Columbia accident suffered from a similar breakdown in communications along with failure to consider the seriousness of engineers’ concerns much like the Challenger” (p.1).

${ }^{15}$ Circadian rhythms are the 24-hour biological cycles found in humans that regulate periods of sleep wakefulness (Moore, 1990).

${ }^{16}$ The Newark (NJ) Police Department limits outside employment to no more than 20 hours per week for individual officers (Newark Police Department, Rule and Regulations Manual 3:2.9; Police Director's memorandum 03-1382, issued December 2003; General Order 67-5). 
17 See Moore, Thatcher, Hartmann, Coles and Sheingold (1999:70-71) for a nice description of the intangible benefits physical infrastructure improvements had on officer morale in the Lowell, Ma police department and organizational trust in the Spokane, Wa police department.

${ }^{18}$ Michael Lipsky (1971:393-395) characterizes the working environment of "street-level bureaucrats," a term often applied to police officers, as one of: 1) "limited resources that necessitates quick decisions based on inadequate information, 2) a lack of control over physical and psychological threats, and 3) contradictory or ambiguous job expectations.”

${ }^{19}$ The foundation for unreasonable governmental intrusion is embedded in the Fourth Amendment to the United States Constitution: "The right of the people to be secure in their persons, houses, papers, and effects, against unreasonable searches and seizures, shall not be violated, and no Warrants shall issue, but upon probable cause, supported by Oath or affirmation, and particularly describing the place to be searched, and the persons or things to be seized."

${ }^{20}$ Personal communication, May 1, 2007, with Tom Frazier, Executive Director, Major Cities Chiefs Association (www.majorcitieschiefs.org). According to Frazier, the national average for a "major city chief" is about three years. This is consistent with research by Lunden (1958) fifty years earlier, where the length of service for chiefs in Iowa between 1899 and 1956 was five years or less; the average was 4.3 years. Similarly, Bruce Smith (1940), who studied police systems in the United States found considerable turnover in the chief's position in several major U.S cities including El Paso, Tx, Detroit, Mi, St. Paul, Mn, and New York, NY.

${ }^{21}$ A "hook" is a derogatory term in police vernacular for someone who looks after a member of the police department and has the ability to advance the member's career. A hook can equally get someone out of trouble, into a preferred assignment or set along a particular career path by influencing decision makers. Hooks are typically established through informal associations that are often cultivated by money, nepotism or "partisan balance” (i.e., "political patronage," meaning they are usually intimately tied to political influence and motivated by partisan or self-serving objectives) and are looked upon with disdain because the influence they exert is rarely ever merit based. Hooks often connote that the member receiving preferential treatment is not necessarily experienced or qualified for the position; the member is absolved from accountability for their share of the work while in the position; and the member is insulated from disciplinary action. Someone who has a hook is termed to be "hooked up." Similar police vernacular includes being "connected," as in he/she is politically connected (See Berkley, 1969:17); having a "Rabbi," as in who is his/her Rabbi? and "political Godfather," as in he/she has a political Godfather. Neiderhoffer (1967:77) discussed how officers in the New York City Police Department sought to “....arrange contracts with Rabbis" to get out of uniform and into a "...good detail to escape from foot patrol duty. The lower ranks tend to believe that special assignments depend on 'whom you know,' and not on merit." A "detail" in the police department is a preferred or special assignment, typically a desirable one that may also bring a promotion, and a "Rabbi" is someone with influence in the department that can make that happen (See Price, 1972:166). A corporate analogy may be a "well placed contact" who "touts" an employee to the boss in an effort to "jumpstart" the employee’s career so they can "get a leg up" in the firm.

${ }^{22}$ See for example, John Dombrink The Touchables: Vice and Police Corruption in the 1980's, (p.211), which describes the politicized and corrupt promotional practices of the Philadelphia Police Department; O.W. Wilson, Problems in Police Personnel Administration, (p.844) for the historical problems of civil service in selecting qualified personnel. In one early study of selecting criminal investigators, survey respondents revealed that the most common basis for selection was "consistently good police work" without defining what constituted "consistently good police work" (Osterburg, 1962:266). Osterburg's study noted that selection was often accomplished without an objective basis by the head of the agency and there was great reliance on “opinion” from the individual's immediate supervisor. 
${ }^{23}$ The state of California, for example, has been experimenting with lateral entry at various ranks since around 1974 (See Tafoya, 1974). Organizations representing police officers or conducting employment searches frequently list vacancies for lateral supervisory and management positions in law enforcement on the Internet. Some of the progressive cities in California include Visalia, Brawley, and Bell Gardens (See http://www.porac.org/employment.html; http://www.averyassoc.net/jobs.htm).

${ }^{24}$ See, for example, Mike McAlary (1996) Good Cop, Bad Cop, for an account of former New York City police sergeant Joseph Trimboli, whose career ended after he investigated and helped prosecute corrupt police officer Michael Dowd, who was the primary target of the Mollen Commission (1994); Report of the Independent Commission of the Los Angeles Police Department, (1991:171) for an account of various police officers whose careers ended after they witnessed and reported corrupt police activities; L.A.P.D. Blues, PBS FrontLine investigation, for an account of L.A.P.D. detective Russell Poole who resigned from and later sued the LAPD after he alleged Chief Bernard Parks and others, conspired to prevent a thorough investigation of corruption within the department, which he uncovered (http://www.pbs.org/wgbh/pages/frontline/shows/lapd/bare.html); Los Angeles Times, July 2, 1991, for the comments of former Los Angeles police officer Linda Grinston who described police whistleblowing: "When an officer finally gets fed up and comes forward to speak the truth, that will mark the end of his or her career. The police profession will not tolerate it, and civilian authorities will close their eyes when the retaliatory machinery comes down hard on the officer.”

${ }^{25}$ See CALEA standard 52, Internal Affairs, $4^{\text {th }}$ edition Standards for Law Enforcement Agencies (January 1999, p.52-1) (www.calea.org).

${ }^{26}$ Overall discipline means the degree of orderliness present in the organization and is demonstrated by voluntary compliance with agency rules and policies.

${ }^{27}$ Politics, in this sense, is used broadly to define the various combinations of interpersonal relationships, intrigue and maneuvering among government employees and citizens in order for one to gain control or power, or to appease a vocal opponent of police action.

${ }^{28}$ For example, it is common for a mayor or other elected official along with the chief of police to visit a police officer in the hospital after a traumatic event where the officer may have been injured to comfort and reassure them and provide moral support; this is very common after officer-involved shootings. It is also common for elected official and top police administrators to pay special attention to family members of police officers who are injured in the line of duty. This paternalistic role represents an extension of the police "family" that so often characterizes the police service.

${ }^{29}$ See Henry Hart, (1958), The aims of the criminal law, Law and Contemporary Problems, Vol. 23 for a discussion about the philosophy of strict liability offenses. p.422.

${ }^{30}$ For example, the Newark (NJ) police department expressly prohibits officers from claiming ignorance as a defense: "In the event neglect of duty is charged against a member for failure to observe the Rule and Regulations, Departmental procedures or Orders, ignorance of any provision of this Manual or of any Departmental procedures, or Order, will not be accepted as an excuse” (Newark Police Department Rules and Regulations Manual, revised January 1, 2006; Rule 1:1.7, p.1-2).

${ }^{31}$ See Los Angeles Police Department-Department Manual, 2002, p. 9, Rule 210.05 for Conduct Unbecoming an Officer; See Newark Police Department Rules and Regulations, January 1, 2006 (rev.): 1) Neglect of Duty, p. 2-6 Rule 2:3.17; Conduct in Public and Private, p.3-1, Rule 3:1.1.; Conduct, p.5-1, Rule 5:1.1; Bound by Duty, p. 5-3, Rule 5:3.5. 
32 In psychological research, hardiness, also known as resilience, is a person’s positive capacity to cope with stress and catastrophe. The characteristics of resilience include positive outcomes regardless of highrisk status, constant competence under stress and shorter recovery time from trauma (Masten, Best and Garmezy, 1990). Protective factors thought to be related to resilience include: 1) personal attributes, such as gregariousness, positive self-image and self-esteem; 2) strong family bonds; and 3) community, such as support from peers (Cicchetti, Rogosch, Lynch, and Holt, 1993; Werner, 1995).

${ }^{33}$ Politics in this sense means to deal with people in an opportunistic, manipulative, or devious way for career advancement.

${ }^{34}$ There are two classifications of internal complaints in the LAPD each with different disposition. Internal investigations classified as "Misconduct Allegations" may receive one of the following dispositions: 1) Unfounded: the act complained of did not occur; 2) Exonerated: the act occurred but the act was justified, lawful and proper, 3) Not resolved: insufficient evidence to prove or disprove the allegations made; 4) Sustained: the act complained of did occur and constitutes misconduct; 5) Sustained-no penalty: the act complained is sustained, however "No Penalty" is the appropriate disposition. Allegations classified as "No Misconduct Allegations” may receive: 1) Unfounded; 2) Exonerated; or 3) Policy/Procedure: the compliant deals exclusively with a Department policy or procedure, as opposed to the conduct of a specific employee. Alternate dispositions include: 1) Insufficient evidence to adjudicate: the investigation could not be thoroughly investigated. This may be due to lack of cooperation on behalf of the complainant and/or witnesses, the absence of a critical interview necessary for the matter to proceed, the physical evidence and witness statements are insufficient to adjudicate the complaint; 2) Non-department employee: no employee of the LAPD was involved; 3) Withdrawn by the Chief of Police: the Chief may withdraw the complaint based on: a) advice form the City Attorney; b) in the interest of justice or fairness; c) the evidence used to sustain a complaint is lost, stolen or destroyed; d) other articulable reasons; 4) Duplicate: when a preliminary investigation reveals the complaint is already under investigation (Los Angeles Police Department, 2002:233-234).

${ }^{35}$ For an emerging alternative to current police disciplinary sentencing schemes, see Samuel Walker, The Discipline Matrix: An Effective Police Accountability Tool? Conference Report, January 2003. Retrieved from http://www.unomaha.edu/criminaljustice/PDF/matrixreport.pdf on July 20, 2008.

${ }^{36}$ Political patronage may be defined as the support, encouragement, or financial aid given by a person to aid a political figure holding elected or appointed office. In the modern sense, "political patronage" is often used to describe corrupt and unethical practices of elected officials to advance the interests of individuals, groups, families, ethnicities or races in exchange for electoral support (See Fogelson, 1977; Walker, 1977).

${ }^{37}$ Passive-aggressive is an aspect of personality “...in which individuals resist demands for adequate performance in work and social situations. The resistance is indirectly expressed, for example, by misplacing work assignments, or being late to appointments, or forgetting things. Persons with this type of personality often have difficulties both socially and in the work place" (University of Michigan Depression Center, retrieved on March 9, 2006 from http://www2.med.umich.edu/psychiatry/umdc/defquery.cfm). Passive-aggressive behavior is often rationally used to avoid doing an unpleasant task, tending to an unpleasant situation (i.e., attending a meeting), or confronting someone face-to-face (i.e., a performance evaluation discussion). From an occupational perspective, people afflicted with passive-aggressive personality disorder (PAPD) tend to display an attitude mixed with passive resistance and grumbling compliance toward their work or their colleagues especially authority figures (i.e., their immediate boss or management in general). The condition often manifests through obstinance or willful disobedience without overt insubordination or aggression. The Diagnostic and Statistical Manual III (DSM-III-R, 1987) states that someone who displays five or more of the following behaviors may suffer from PAPD: 1) procrastinates, 2) sulks or argues when asked to do something he doesn't want to do, 3) works inefficiently on unwanted tasks, 4) complains without justification of unreasonable demands, 5) "forgets" obligations, 6) believes he is doing a much better job than others think, 7) resents useful suggestions, 8) fails to do his 
share, or 9) unreasonably criticizes authority figures. However, the DSM-IV (1994:733-734) dropped PAPD as an official mental disorder and relegated it to an appendix (Appendix B, Criteria Sets and Axes Provided for Further Study) because disentangling unconscious (Irrational) behavior from conscious (Rational) behavior requires further research. Other characteristics of passive-aggressive personality include resentment, stubbornness, intentional inefficiency and features of Parkinson's Law, which states that "work will expand to fill the time available for its completion." This becomes a human resource management problem where employees work at a pace that takes them to the end of the work day to a complete a task that is worth, at best, only a few hours (Originally conceptualized by Cyril Northcote Parkinson, 1955, and published in the London Economist).

${ }^{38}$ The original NIJ solicitation is entitled The Effects of Shift Work Schedules on Police Officer Health, Safety, Performance and Quality of Life (Posted May 5, 2005, award \# 2005- FS-BX-0057). For more information about the Police Foundation, visit www.policefoundation.org; for information about the National Institute of Justice, visit www.ojp.usdoj.gov/nij.

${ }^{39}$ See www.ies-usa.com for a complete description.

${ }^{40}$ See www.stisimdrive.com for a complete description.

${ }^{41}$ See www.bpad.com for a complete description.

${ }^{42}$ See www.pmifit.com for a complete description.

${ }^{43}$ The original Law Enforcement Officer Survey (LEOS) is on file with the Police Foundation Washington, D.C. Appendix 6 of this research study is the subscales of the Police Stress Questionnaire (McCreary and Thompson, 2006) and the Daily Hassles and Uplifts Scale (Hart, Wearing and Heady, 1993) used to measure organizational stressors.

${ }^{44}$ The complete validation procedure was can be reviewed at http://spartan.ac.brocku.ca/ dmccrear/PSQ_Development.html (Accessed July 4, 2007).

${ }^{45}$ See http://www.census.gov/popest/cities/tables/SUB-EST2005-01.xls, retrieved on January 19, 2007.

${ }^{46}$ http://www.census.gov/population/www/cen2000/phc-t3.html . See table 3. Retrieved on January 19, 2007.

${ }^{47}$ Urban areas are defined by the U.S. Census Bureau as "as contiguous census block groups with a population density of at least 1,000 people per square mile. Urban areas are delineated without regard to political boundaries. Urban areas with a population of at least 50,000 serve as the core of a metropolitan statistical area" (retrieved from www.census.gov on January 19, 2007).

${ }^{48}$ All demographic characteristics derived from the 2005 U.S. Census Bureau, American Community Survey (retrieved on January 19, 2007 from www.census.gov).

49 There are eight FBI UCR index offenses, classified as violent and property crimes: the violent index offenses are 1) murder and non-negligent manslaughter, 2) forcible rape, 3) robbery, 4) aggravated assault; the property index offenses are: 5) burglary, 6) larceny-theft, 7) motor vehicle theft and 8) arson.

50 See http://www.census.gov/popest/cities/tables/SUB-EST2005-01.xls, retrieved on January 19, 2007.

51 http://www.census.gov/population/www/cen2000/phc-t3.html . See table 3. Retrieved on January 19, 2007. 
52 All demographic characteristics derived from the 2005 U.S. Census Bureau, American Community Survey (retrieved on March 24, 2008 from www.census.gov).

${ }^{53}$ See http://www.mayorsagainstillegalguns.org/html/home/home.shtml

${ }^{54}$ Data for the Detroit police department is from Bureau of Justice Statistics, 2003, Local Police Departments, NCJ\# 210118.

${ }^{55}$ Data for the Detroit police department is from Bureau of Justice Statistics, 2003, Local Police Departments, NCJ\# 210118.

${ }^{56}$ A "general purpose" or "general service” law enforcement agency is a police department operated by a municipal or county government that has primary police jurisdiction and is responsible for responding to service demands. Police departments with special jurisdiction such as public parks, transit systems, bridge and tunnel authorities, airports and school systems are defined as "special police" and do not meet the requirements of general purpose law enforcement agencies.

${ }^{57}$ The 2006 FBI Uniform Crime Report, Table 74, indicates that 88.2\% of sworn law enforcement personnel in the United States are males and 11.2\% are female. Retrieved on April 25, 2008 from http://www.fbi.gov/ucr/cius2006/data/table 74.html.

${ }^{58}$ See, for example, Joseph P. Fried, 3 Officers Accused of Making 'Collars for Dollars' Go on Trial, New York Times, March 16, 1995; Jeff Leen, Gail Epstein and Lisa Getter, Dade Cops Like to Play 'Collars for Dollars' Police Officers Pile on as Witnesses to Cases that Go To Court in a Bid to Make Extra Overtime Pay, Miami Herald, July 20, 1997; Lou Michel and Susan Schulman, Officers' Court Time Drains Scarce Resource, Buffalo News, December 14, 2003; Milton Mollen, Mollen Commission Report, July 7, 1994, p.39; Joe Mahoney, Ex-Albany Cop Says Department Needs Civilian Oversight, The Time Union, June 22, 1995; Peter Sampson, Fort Lee's Supercop Relegated to Desk Duty, The Record, August 5, 1986.

${ }^{59}$ A "learning organization" is an organization that is continually expanding its capacity to create its future (See Senge, 1994, p.vx, 14). An organization that actively monitors change in the environment, then adapts to and learns from that change typically by acquiring new KSA's (Knowledge, skills, or abilities) and applying them to improve service quality.

${ }^{60}$ See, for example, Bureau of Justice Assistance, National Assessment of Structured Sentencing Washington, DC: U.S. Government Printing Office, 1996; Robin Lubitz and Thomas W. Ross, Sentencing Guidelines: Reflections on the Future, Washington, DC: U.S. Justice Department, 2001. Accessible at www.ncjrs.org, NCJ \#186480.

${ }^{61}$ See, for example, Cassia C. Spohn, How Do Judges Decide: The Search for Fairness and Justice in Punishment, Thousand Oaks, CA: Sage Publications, 2002_Chapter 1, The Goals of Sentencing.

${ }^{62}$ See an example of the principle of endangerment by Inkeri Anttilla, Plans For a New Penal Code in Finland - Some Observations (From Papers on Crime Control, 1977-1978, Research Institute of Legal Policy, Finland. NCJ \#058113.

${ }^{63}$ This is a fictitious example and resemblance to any actual sentencing matrix is merely coincidental. This example may not account for all of the nuances or exceptions that might arise in an actual sentencing matrix.

64 “Smaller" is defined as fewer than 10 full-time officers (Bureau of Justice Statistics, 2002:3). 
${ }^{65}$ See also Mollen Commission (1994:71), where the Commission concluded the NYPD’s integrity controls collapsed due to “.... deep-seated institutional reluctance to uncover serious corruption with no independent external pressure...This attitude infected the entire Department, manifesting itself in different ways throughout the ranks. It encouraged the Department's top managers to allow corruption controls to wither through neglect and denial of resources, and to allow the principles of command accountability to collapse through lack of enforcement.” 


\section{VITA}

\section{Jon M. Shane}

1966 Born January 4 in Newark, New Jersey.

1984 Graduated from Nutley High School, Nutley, New Jersey.

1985 - Entered career in policing in Clifton, New Jersey as a civilian (1985-1989) and Newark,

2005 New Jersey as a sworn officer (1989 - 2005). Retired at the rank of captain.

1996 Police Foundation Washington, D.C. Visiting fellow, Police Fellowship Program.

1998 Attended Federal Bureau of Investigation, FBI National Academy-193rd Session Quantico, Virginia.

2001 Attended Harvard University, John F. Kennedy School of Government and Police Executive Research Forum (PERF)—Senior Management Institute for Police, Session 25, Boston, Massachusetts.

2002 B.S. in criminal justice, Rutgers University, Newark, New Jersey.

2004 Article: Reducing Drug Dealing in Private Apartment Complexes: Final Report to the U.S. Department of Justice Office of Community Oriented Police Services on a Project Undertaken in Newark, NJ to Test the Utility of the Problem-Oriented Guides for Police Project. Washington, D.C.: U.S. Department of Justice, COPS Office.

2004 Certificate in non-profit management-Graduate Department of Public Administration, Rutgers University, Newark, New Jersey.

2004 present

2005

2005

2005

2005

2008

2008

2009
Senior research associate, Police Foundation Washington, D.C.

Article: Responding to Persons with Mental Illnesses: Police Perspectives on Specialized and Traditional Practices. Behavioral Sciences and the Law. Vol. 23:647-657.

M.A. in criminal justice, Rutgers University-School of Criminal Justice, Newark, New Jersey.

Staff member, New Jersey Attorney General's Office-Camden Commission for Public Safety through Rutgers Police Institute.

Lecturer and adjunct professor of criminal justice at Rutgers University, Newark, Fairleigh Dickinson University, Teaneck (NJ) and John Jay College of Criminal Justice, New York City.

Ph.D. in criminal justice, Rutgers University_-School of Criminal Justice, Newark, New Jersey.

Tenure-track assistant professor in the Department of Law, Police Science and Criminal Justice Administration, John Jay College of Criminal Justice, New York City. 